\title{
WAVES OF
}

SAND AND SNOW

VAUGHAN CORNISH 
Q P $m$ m $\$ 3^{\text {sino }}$ 





\section{WAVES OF SAND AND SNOW}

AND THE EDDIES WHICH MAKE THEM

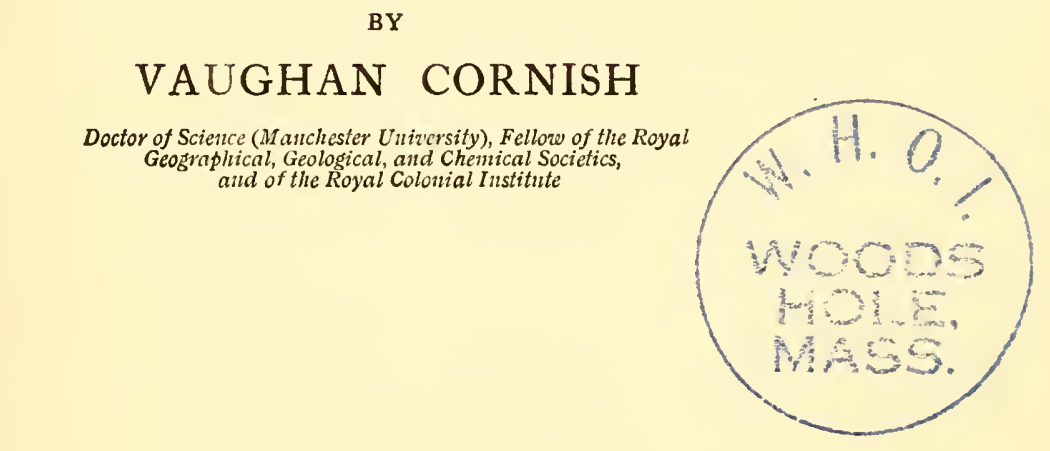

WITH 88 PHOTOGRAPHS TAKEN BY THE AUTHOR

$3 O$ DIAGRAMS AND 2 MAPS

THE OPEN COURT PUBLISHING COMPANY

$378-388$ WABASH AVENUE

CHICAGO 
(All rights reservcd) 
THE MEMORY OF MY MOTHER,

ANNE CHARLOTTE CORNISH,

WHO TAUGHT ME AS A BOY

TO OBSERVE AND REVERENCE

THE CREATION,

I DEDICATE THIS BOOK

V. C. 



\section{PRE F A C E}

IN I 895 I went to live on the South Coast, and every day the waves of the sea-beautiful, mysterious, and insistent-drew me more and more to the path on the cliff whence I could watch them curl and break, and listen to their splash upon the sandy shore. I stood there on the afternoon of a calm day in early autumn at the time of low. water of a spring tide. The little waves, gliding slowly in over the flat sands, bent round the ends of a shoal, as waves of light are refracted, and, meeting, passed through each other, each to continue its own course. Elsewhere a long, low wave, impinging obliquely on a small bank of sand, was thrown backwards at an angle of reflection equal to that at which it had struck the obstacle. And as I watched I thought what a fine thing it would be if the study of all kinds of waves could be coordinated. I had just finished another piece of work, so I embarked at once on a course of reading on waves of all kinds, which was, moreover, not altogether new ground to me. I found that the ideas which Newton and his successors have so 
marvellously developed in the theory of waves originated in the common knowledge of the "undulating inequalities," as Dr. Johnson calls them, which wind makes upon the sea. Periodicity, and the transmission of an impulse by the material, are the aspects of sea waves which are repeated in the transit of light and sound, and owing to these analogies we speak of "waves" of light and sound, although a corrugated surface of progressive inequalities is no part of their character.

I found, however, that while the physicists had applied with great success the ideas got from the aspect of the heaving sea to the study of sound, light, electricity, and other matters, geographers and geologists had not sufficiently availed themselves of these ideas in the study of certain natural inequalities which, from their form and movement, are as nearly related to sea waves in one way as the pulsations of sound are in another. I also found that the mathematical study of the waves of the sea had been pushed nearly as far as the available data allowed, so that further progress in their study could best be secured by observations accompanied by measurement, which I was capable of undertaking.

Thus having surveyed the whole subject of waves, I decided to confine myself for the pur- 
pose of original research to the study of the surface waves of the atmosphere, hydrosphere, and lithosphere, or air, water, and earth', calling the subject "kumatology," and classing it as a department of physical geography. This is the practical form of the idea which has led me by an untrodden path to the Land of the Unknown. In this country there are no sign-posts to direct the traveller, no roads for him to follow, no maps to show him how to shape his course. Here watchfulness, patience, and docility to experience are the only passports. But it is a delightful land, and its call is like "the call of the wild."

At first my home on the South Coast was a favourable position for observations both of waves of water and of sand, but presently travel became necessary in order to develop the subject. The home was given up, and I wandered abroad among sandhills and snowdrifts, explored amphibiously the sandbanks of estuaries, measured waves in storms at sea, timed the throbbing surge of torrents, the heaving of whirlpools, and the drumming thunder of waterfalls. I was by good fortune in Kingston, Jamaica, when the earthquake of January, I9.07, wrecked the city, and I mapped the seismic waves which traversed the island. Later, I studied on the spot those curious gravitation waves in vol- 
canic rock which so greatly hamper work on the Panama Canal by bulging up the bottom of the Culebra Cut, and I am now pursuing the study of this kind of wave.

My observations have been communicated from time to time to the Royal Geographical Society, the British Association, and the Royal Society of Arts, and will be found in their Journals and Proceedings from 1896 to I9I3.I My observations of water waves, up to I 909 , have also been published in book form, 2 and the present volume contains those on waves of sand and snow.

That waves, progressive transverse inequalities, should be produced by wind in sand and snow is a strange thing, which ought to excite our surprise, for the familiar action of wind upon loose bodies is of the opposite kind. First, it blows them from salient to sheltered positions, thus tending to obliterate transverse inequalities; secondly, it finds out weak places in materials which it is capable of eroding, gouging out grooves, which it lengthens until it has driven through a longitudinal furrow. Thus the more familiar action of wind is to

I See Appendix, catalogue of original papers by the author.

2 "Waves of the Sea and other Water Waves." By Vaughan Cornish. Published by Fisher Unwin, Igro. 
obliterate the transverse, and create longitudinal, inequalities.

Yet the smooth surface of the dry sand of the desert and of the dry snow of the prairie is ruffled transversely by the wind, and the transverse inequalities grow in size and become more nearly regular in length and height, travelling, moreover, in orderly procession before the wind, as passive waves. Currents of water produce similar progressive waves on the surface of sandbanks. The means by which these waves of sand and snow originate, grow, and move are peculiar and interesting. What I have been able to add to previous knowledge of waves in sand and snow and the eddies which make them is told in the following chapters, where I have also recorded certain incidental investigations on rippled clouds, on "snowmushrooms," on the undulations produced by sledges, on quicksands, miniature deltas, and other matters.

I have to thank Dr. J. Scott Keltie, Secretary of the Royal Geographical Society, for permission to reproduce some of the plates and figures from my papers in the Geographical Journal.

Woodville, Camberley.

September, 1913. 



\title{
CONTENTS
}

\author{
PART I \\ AEOLIAN SAND.WAVES
}

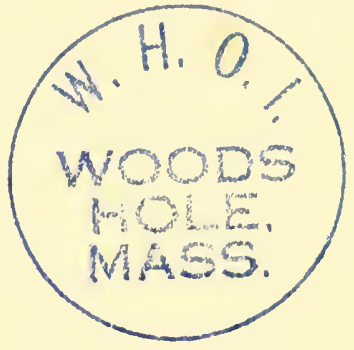

\section{CHAPTER I}

Sand-waves near Helwan, their height and lengthFormation of peaks on the ridges-Course of the wind as it blows over a series of the ridges, direct current and eddy-Note on the wind-screen of motor vehicles and the return current-Height of wave limited by velocity of wind-Significance of constant ratio of length to height-The eddy-curve ichthyomorphic, with blunt head and fine tail-Longitudinal bank to leeward of a peak-On the formation of the pits called fuljesTravelling mounds of sand of crescentic shape, called barchans-Rate of advance of the sand-waves-Mode by which the undulations originate in a level deposit of sand-On a limit to the size of level ridges due to fineness of the sand-Large dunes east of the Suez Canal-Illusion of mountainous size-Formation of dew upon the sands-Dunes west of Suez Canal; influence of moist ground on their formation-Effect of electrification upon the mobility of sand-On the sizes of the sand-grains. 


\section{CHAPTER II}

AEOLIAN SAND-RIPPLES

All aeolian sand-waves have a rippled surface - 75

Description of the formation of aeolian sand-ripples in level deposits of loose sand blown from the beachMeasurements of height and length-The ripples grow without change of shape-Ratio of length to height the same as in the larger sand-waves-Rate of advance -Winnowing of fine from coarse sand-grains observed during growth of aeolian ripples-" Erosion ripples" formed where the level of the sand is being loweredThe formation of a protecting cover of "lag gravel" on the crests-Experiments by means of an artificial blast-No rippling of assorted sand-grains of uniform large size, although travelling freely - Immediate rippling when small sand-grains mixed with themExplanation offered, that eddy in lee of larger grains tosses away the smaller, hence the existence of ripples upon the larger waves-Ripples in shell-sand showing lines of notches in the wave-fronts where the troughs are deeper.

\section{PART II}

SNOW-WAVES AND SNOWDRIFTS

CHAPTER III

SNOW-WAVES AND SNOW-RIPPLES

Ripples in Moist Snow.

Damp snow and dry snow-Ripples in moist snow during snowfall observed in Hyde Park-They face up- 


\section{CONTEN'TS}

wind-Recede by erosion of wind-facing cliff-During lulls travel up-wind-Mode of erosion of partially consolidated snow : first, transverse ; finally, longitudinal ridges, with a transition stage between-Stratification shown by erosion.

Waves in Dry Drifting Snow.

Formed near Montreal at minus $8^{\circ}$ Fahrenheit-Length and height - Flatter than sand-waves - Movement visible and more rapid than that of sand-Surface unrippled-Measurements of snow-waves in Manitoba, formed during removal of snow-Waves formed during snowfall-Their formation upon a plane surface free from obstructions.

Crescentic Snow-Waves or Snow-Barchans.

Formed in patches of loose snow travelling on a hard surface-Finer lines than sand-barchans both in profile and plan-Formation of crust on surface of snow and its effect in arresting growth and movement of snowwaves-Explained as due to sublimation-Increase in density of snow which has been drifted by windCompared with increase of density due to pressure.

Ripples in Snow-Sand.

Mode of formation of granular snow or "snow-sand" -Rate of movement-Growth and movement more rapid than those of sand-ripples-Measurements of length and height-Obliteration in lee of larger ridge.

Forms produced by Wind-erosion in Compact Snow (Studies in Canada.)

Measurements of transverse ridges, facing up-windShape of pits-Longitudinal structures-Note on the longitudinal sand-dunes of the great Indian Desert. 
The Eddy-form of Snow-Waves and Snowdrifts.

Complex forms of drifts produced by fixed obstaclesAll contained by a boundary curve having blunt head and fine tail-This is the boundary of the eddy caused by the obstruction-Complex forms are stages of filling in of eddy-space, and due to insufficient supply of snow-The eddy-curve and its relation to the forms of fish and cetaceans-of the wings of birds-of the submerged part of ships-of torpedoes and non-rigid airships-Forms of holes scoured out in snow round the trunks of trees-Relation of snow-barchans to the eddy-curve-The relation of form and movement between the travelling crescentic snowdrifts and the swirl made in water by an oar-Shape of the eddy in snow-waves-Inference as to the distance to which hedges and belts of trees extend shelter from wind.

On the Three Modes of Deposition of Drifted Material depending upon Rate of Subsidence.

Behaviour of gravel, sand, and dust before the windOf shingle, sand, and mud under the action of waves and currents-Single tail of sand behind a narrow obstacle-Double tail of snow-powder-Single train of black smoke, but double track of steam, from chimneys-How fallen leaves drift before the windOn "banner clouds" and on sandbanks to leeward of promontories-On the action of an obliquely crossing wind upon the swell of the sea. 


\section{CHAPTER IV}

SNOW-MUSHROOMS AND CAHOTS

Snore-Mushrooms.

Weather and snowfall in the Selkirk mountains, B.C. -Snowcaps on high stumps of felled tree sat Glacier House resemble large mushrooms-Diameter, 9 feet -Weight about I ton-Shape due to bending under its own weight-Mode of growth-Reason of their permanence.

On the Sparseness of the Falling Snoruflakes.

Cahots, French name for undulations made by sledges in snow-Formed on the ice of the St. Lawrence-In the streets of Montreal-None in Manitoba during midwinter-Similar undulations on an ordinary rough road at Coniston, Lancashire, produced by a sledge. Experiments with a small model sledge-The undulations are produced without an initial inequality-And during slow and steady motion-They are due to a loose but adhesive condition of the road-Other examples of transverse inequalities of roads.

\section{PART III}

\section{SUB-AQUEOUS SAND-WAVES}

\section{CHAPTER V}

Ripple-mark.

Sir G. H. Darwin's experimental reproduction of ripplemarks-My measurements of natural ripple-markOsborne Reynolds' experiments. 
Current-mark.

In very slow streams with a smooth surface-Effect of making the course of the stream straight-Action of current upon a body projecting above the bed of the stream-Current-mark in shallow streams with a waved surface and a velocity of $I^{\prime} 5$ feet per second-Moving down-stream-The same in a stream with a velocity of 2.2 feet per second move up-stream-Dr. Owens' experiments on the diminished rate of settlement of sand in sandy water-Explanation of the up-stream movement of the current-mark or sand-ripples in a shallow stream with a rapid motion-Effect of progressive water-waves upon the current-mark of streams -Ratio of length to height of current-mark compared with that of ripple-mark.

\section{CHAPTER VI}

The Mawdach Estuary, Barmouth, N. Wales, its drying sandbanks and their waved surface-Measurements of length and height-D shape of estuaries-Influence on course of tidal currents and effect in producing unsymmetrical sand-waves upon the drying sandbanksMeasurements showing how far these sand-waves depart from uniformity-Ratio of length to height-Sandwaves in the estuaries of the Findhorn and South Esk -The estuary of the Severn: smooth sandbanks at Severn Bridge, waved sandbank near Severn Tunnel, explanation of the difference-Sand-waves in estuary of the Dovey, North Wales-Stakes fixed in sandbank and measurements of size and movement of sand-waves during seventeen days-Effect of velocity of current 
and depth of water upon the sand-waves-Sand-waves upon the North Goodwin Sand-Pools left after partial obliteration of sand-waves, similarity of their form to that of the pits called fuljes which occur in sandy deserts.

Sand-reefs in the Mississippi.

Their size and movement-Not true transverse waves - Their formation in freshly deposited sediment-How the size of the sand-grains limits the size of the sandwave-Suggested effect of greater heterogeneity of material to increase the limiting size of the sand-wave -On the relation of velocity of current to size of sandwave in water of sufficient depth.

\section{CHAPTER VII}

ON THE SMALLEST DELTA, ON THE COMPOSITION OF QUICKSAND, AND ON "MACKEREL SKY"

On the Transverse and Longitudinal Ridges formed in the Flow of Watery Sand, and on the Smallest Delta.

Settlement of sand through water and subsidence of water through sand-Transverse and longitudinal ridges formed during the latter process-Rapid deposition of the small longitudinal ridges in radiating branchesTheir diameter equal to that of a fully-grown drop of water.

On the Composition of Quicksand.

Observations of Mr. C. Carus-Wilson on presence of marsh gas-Experiments of Mr. C. E. S. Phillips on effect of included gas-Author's observations on effect 
of imprisoned air-On the effect of some finer earthy particles to prevent the escape of air from sand-The three kinds of fluid, gaseous, liquid, and granular, and suggestion that an emulsion of all three produces a quicksand.

On the Rippled Clouds called "Mackerel Sky."

Ruskin's remark - Mathematical investigations by Helmholtz and others-Sir G. H. Darwin's description - The author's observations-Shape of the cloudsTheir wave-length-Description of author's photographs-The positive and negative compared-The former shows the white clouds, the latter the blue sky - It is the latter which has the form of ripple-mark in sand-The clouds correspond, not to ripple-mark but to the eddies of water which make the ripple-mark. 


\section{ILLUS'TRATIONS}

Plate

PLATES.

No.

I. Tidal sand-waves in the estuary of the River Dovey . Frontispiece

2. Aeolian sand-waves near Helwan . . . . 33

3. Aeolian sand-waves with undulating crests (top) . $\quad$. 43 Transverse ridges with longitudinal projections (bottom) • 43

4. The pits termed fuljes $($ top $)$ • . . . . . 47

The hillocks termed barchans (bottom) . $\quad$ • . . 47

5. Accumulation of blown sand caused by a fence of reeds near Helwan $(t o p)$. $\quad$. $\quad$. $\quad$. $\quad 55$

Accumulation of blown sand caused by marram grass at Aberdovey (bottom) . . . . . 55

6. Sand-dune with crest reversed by wind (top) . 59

On the slope of a sand-dune having water at its foot (bottom) 59

7. Pyramidal summit of sand-dune at Ismailia (sand on lee side in act of slipping) . $\quad . \quad$. $\quad . \quad . \quad 63$

8. Sand-dune encroaching on a plantation at Ismailia (top) . 67 On the top of an encroaching sand-dune at Ismailia (bottom) 67

9. Sand grains from the cliff of a sand-dune at Ismailia

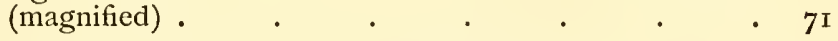

Io. Aeolian sand-ripples at Southbourne $(t o p) \quad \cdot \quad$ • . $\quad 77$

Aeolian sand-ripples at Southbourne, in which the sorting of

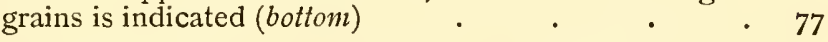

II. Aeolian sand-ripples at Southbourne, in which the sand grains have been much sorted (top) • • . 85

Aeolian sand-ripples at Ismailia, to leeward of a sand-dune where there is an upward current of air (bottom) $\quad 8_{5}$

12. Drifting waves of dry snow near Montreal (temperature minus $8^{\circ}$ Fahrenheit) 
I3. Drifting waves of dry snow near Winnipeg

I4. Drifting waves of dry snow at Winnipeg . . . III

I5. Ripples in granular snow $\quad . \quad$. . . . II5

I6. Ripples in coarse granular snow . . . . . . II9

I7. Granular snow rippled, and a drift of fresh snow unrippled . 123

I8. Ripple-like ledges formed by drifting snow-particles falling on the lee face of a drift . $\quad . \quad$. 127

I9. Erosion-ripples in the surface layers of snow . . . I3I

20. Erosion-ripples in compact snow, showing its stratification . I 35

2I. Erosion structures intermediate between the transverse and longitudinal, showing the stratification of the snow $\quad$ I39

22. Longitudinal structures formed by erosion of snow . . I43

23. Longitudinal ridges of snow to leeward of obstructions . 146

24. Beginnings of a snowdrift on the lee side of railings, near Montreal .

25. Snowdrift near Grantown-on-Spey, showing curve of the upward current of the wind-eddy on the lee side ${ }^{2} 5^{2}$

26. Snowdrift near Winnipeg, showing overhanging cornice on lee side

27. Snowdrift near Winnipeg, with small longitudinal ridge on lee side formed between the currents which converge from right and left, taken looking up-wind .

28. The snowdrift with small longitudinal ridge on lee side, transverse view . $. \quad . \quad . \quad . \quad$ I62

29. Snowdrift near Winnipeg, with large longitudinal structure on the lee side $\quad$ - . . . . 165

30. Bank of snow collected between currents converging on lee side of house (whilst the snow was drifting it ascended like smoke from the pointed summit)

3I. Snowdrift round a house on the prairie, enclosing a space swept bare by the wind .

32. Hollow kept clear of snow by the wind round an outhouse . $\quad$ I77

33. Bank of drifted snow against the lee side of a house at Winnipeg.

34. Space near a tree kept free from snow by the wind . $\quad$ I85 


\section{ILLUS'TRA'TIONS}

35. Bosses of snow, Glacier House, B.C. · 189

36. Bosses of snow in a valley of the Sellirk Range, B.C. $\quad 193$

37. Bosses of snow formed on stumps of trees, Glacier House, B.C. 197

38. "Snow-mushrooms," or caps of snow formed on tree stumps, Glacier House, B.C. . . . . . 201

39. A "button-mushroom" in snow . . . . 205

40. The "prize-mushroom" of Glacier House, a symmetrical snow-cap nine feet in diameter . . . . 209

4I. A nine-foot snow-mushroom seen from below . . 213

42. Twelve-foot snow-cap on a broken tree at Glacier House . 217

43. Twelve-foot snow-cap seen from below . . . 220

44. Snow-cap formed upon the cross-piece of a telegraph pole and upon the wires $\quad . \quad$. $\quad . \quad 223$

45. Snow-cap upon a telegraph pole and wires . . . . 226

46. "Cahots" (i.e., " jolts"), the undulations made by sledges in snow, Montreal . . . . .

47. "Cahots," the undulations made in a road by the sledges which descend from the Saddlestone Quarry, Coniston, Lancs . . . . . .

48. The sledge, used as a drag, which makes the "cahots" at Coniston . . . . . .

49. Cart and sledge descending steep track, and wheeled truck used to transport the sledge over flatter portions of the road .

50. Undulations made by a model sledge drawn slowly and steadily through slightly moist sand . .

5I. Transverse furrows produced by the tread of cattle on their way to and from a pond. . . . . 247

52. Transverse furrows produced by the tread of cattle . . $25 \mathrm{I}$

53. Symmetrical ripple-mark produced by waves of the sea at Montrose $(t o p)$. Unsymmetrical ripple-mark produced by waves of the sea

54. Ripple-mark at Grange, Lancs, in sand of a somewhat tenacious kind

55. Ripple-mark in quaking sand at Grange, Lancs 
56. Sand rippled by two sets of waves, which were probably simultaneous; at Grange, Lancs .

57. Sub-aqueous sand-waves moving up-stream and carrying with them their superposed water waves; at Cannes .

58. Current-mark made during rain by a temporary stream on a sandy road, photographed after the road had dried

59. Current-mark on the sands of the Dovey estuary, with larger sand-waves which have been flattened as the tidal water ran off

6o. Tidal sand-waves, winding channels of ebbing tide, and shining mud patches in places, where horizontal eddying probably occurs. Mawdach estuary

6r. Tidal sand-waves in the estuary of the South Esk, Montrose

62. The river Severn between Beachley Point and Severn Tunnel, showing the Dun Sands . . . . .

63. Two sets of tidal sand-waves caused by successive currents in different directions, on the Dun Sands, river Severn.

64. Tidal sand-waves and current-mark; Dun Sands, river Severn

65. Map of the estuary of the river Dovey

66. Tidal sand-waves of which the daily movement was measured ; Dovey estuary $(t o p)$

Tidal sand-waves with current-mark in troughs; Dovey estuary (bottom)

67. Tidal sand-waves and low-water channels; Dovey estuary . 3I7

68. Winding channels of the ebbing tide ; Dovey estuary $\quad 320$

69. Tidal sand-waves, at right angles to the sea shore, in a "low," or depression ; at Mundesley $(t o p)$. . .

Tidal sand-waves partially obliterated on the sea shore; at Mundesley (bottom)

70. Tidal sand-waves on the North Goodwin

71. Pools formed in the trough of a tidal sand-wave by the washing-off of crests during ebb-tide; at Montrose .

72. A fan-shaped deposit of sand, showing a stream of water which soaks into the porous material; at the foot of the East cliff, Bournemouth

73. Tongues of sand, each of which is instantaneously formed by the sudden subsidence of the water by which the sand grains were carried; at Bournemouth 


\section{ILLUSTRATIONS}

74. Deposit of cliff-sand, containing an admixture of fine particles, left after subsidence of water, showing transverse ridges; at Bournemouth . . . . .

75. Deposit of cliff-sand, containing an admixture of fine particles, showing transverse ridges formed by subsidence of water; at Bournemouth

76. Deposit of muddy sand carried down the cliff by water, showing no transverse ridges; at Bournemouth

77. Rippled cirrus cloud, seen from Branksome Chine, near Bournemouth

78. A " mackerel sky," seen from Branksome Chine, near Bournemouth, August 5, Igoo, looking west . . . 361

79. Wave-clouds, or "mackerel sky," seen from Branksome Chine, near Bournemouth, August 5, I900, looking south

8o. Negative of the photograph of wave-clouds, in which the blue sky appears light and the clouds dark, showing that it is the blue sky and not the cloud which more closely resembles the ripple-mark of sand

No.

I. Sir G. H. Darwin's diagram of currents flowing over ripplemark

2. Profile of sand-dune with crest reversed by contrary wind .

3. Sand-dune with undulating crest, showing development of peaks and saddles .

4. Profies

4. Profile of twenty-nine snow-waves near Winnipeg

5. Profile of twenty-four aeolian sand-waves, near Helwan, Egypt

6. Barchans of snow and sand, from photographs . . II4

7. A patch of rippled snow, plan . . . . . . 129

8. Conversion of above to a barchan, early stage $\quad$. $\quad$ I29

9. The same at a later stage . . . . . r . ro

ro. Erosion waves in compact snow, with grooves showing stratification, wind from the right hand 
Fig.

No.

II. Erosion form analogous to a barchan, wind from the left, from a photograph

I2. Fence and completed snowdrift

13. Stages of growth of snowdrift formed by a fence

I4. Snowdrift on both sides of a fence, on the right completed, on the left incomplete, from a photograph

The fundamental curve of snowdrifts . I 48

16. Plan of snowdrift caused by clump of bushes, wind from the

I7. Profile (dotted) and central longitudinal section of the same

17. Profle drift.

18. Section across the dotted line of Fig. I6 . . . . I63

19. Plan of the principal snowdrift around a house on the prairie, near Winnipeg, wind from the left . . . I64

20. Profile and central longitudinal section of same snowdrift . ${ }^{2} 67$

2I. Transverse section of snowdrift on lee side of an outhouse on the prairie $\quad . \quad$. . . $\quad$ I67

22. Plan of hollow round a tree, wind from the left . . I68

23. Longitudinal section of the same . . . . I7I

24. Cross section of the same, lee side . . . . I7I

25. Hollow, etc., cut by wind, from left, around a stone, from a photograph taken in Scotland, February, I900 . . 172

26. Hollow cut by wind, from left, around a heap of manure on a field, from a photograph . $\quad$. $\quad . \quad$ I75

27. Longitudinal growth on lee side of a travelling snowdrift . I76

28. Snow mushroom with hollow beneath, from a photograph . 215

29. Current-mark on road after a thunderstorm . . . 285

30. Plan of five ridges showing positions on four succeeding days, Dovey estuary, scale $I^{\prime \prime}=16^{\prime}$. 


\section{PART I}

\section{AEOLIAN SAND-WAVES}





\section{CHAPTER I}

\section{DESERT SAND-DUNES}

Sand-waves near Helwan, their height and length-Formation of peaks on the ridges-Course of the wind as it blows over a series of the ridges, direct current and eddyNote on the wind-screen of motor vehicles and the return current-Height of wave limited by velocity of windSignificance of constant ratio of length to height-The eddy-curve ichthyomorphic, with blunt head and fine tailLongitudinal bank to leeward of a peak-On the formation of the pits called fuljes-Travelling mounds of sand of crescentic shape, called barchans-Rate of advance of the sand-waves-Mode by which the undulations originate in a level deposit of sand-On a limit to the size of level ridges due to fineness of the sand-Large dunes east of the Suez Canal-Illusion of mountainous size-Formation of dew upon the sands-Dunes west of Suez Canal; influence of moist ground on their formation-Effect of electrification upon the mobility of sand-On the sizes of the sand-grains.

ON May 7, I 899, when staying at Helwan, near Cairo, I crossed the Nile one morning in order to see the desert on the west bank near the 31 
pyramids of Sakhara. I had to land upon an extensive stretch of loose sand uncovered by the subsidence of the river, which was then at a low stage. The river-borne sand is very different from the somewhat coarse, rounded, quartz sand of the desert, being composed of minute particles of many different minerals, including flakes of light-coloured mica and splinters of dark-coloured minerals derived from eruptive rocks. Many of the splinters stuck in a wire sieve with a mesh of $\frac{1}{192}$-inch diameter, but many slipped through a mesh of $\frac{1}{384}$ of an inch. The sand that lay even a little above the present level of the river was thoroughly dried by the action of the sun and of the desiccating desert wind. A brisk wind was blowing of about the force, which sailors describe as a "moderate breeze," which has a velocity of I 5 miles an hour. The light sand drifted freely before it, not only close to the surface but also in considerable quantity for a height of several feet above. The appearance of the sand-bank was very remarkable, for the surface was in regular ridges and furrows, or waves, transverse to the wind. They were on an average $I$ foot 8 inches in height with a wavelength from crest to crest of 30 feet 9 inches. They were desk-shaped, having a long slope on 


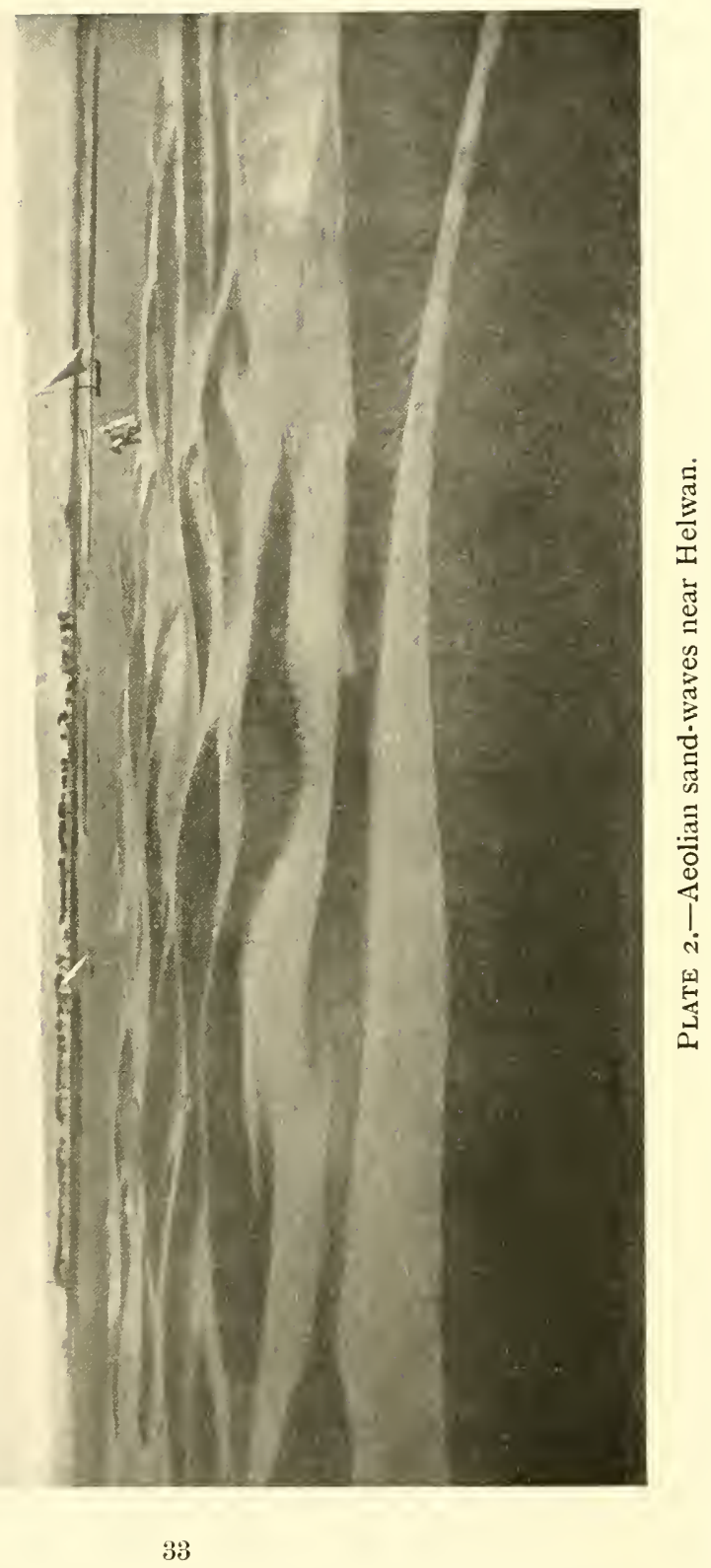



the weather side, whilst the lee side consisted of a straight cliff standing at the maximum angle allowed by the looseness of the material-that is to say, about $33 \frac{1}{2}^{\circ}$ The rise is I vertically in I $\frac{1}{2}$ horizontally. The angle of the weather slope is $3 \frac{1}{2}^{\circ}$, the rise being I vertically in $16 \frac{1}{2}$ horizontally, the length of the mound being thus eighteen times as great as the height. The weather side was covered with minute waves or ripples of a few inches from crest to crest, with which I shall deal in the next chapter. The slipping lee face was unrippled. A photograph taken looking towards the Nile (Plate II) shows a remarkably regular series of aeolian sand-waves. When looking up wind the series of waves stands out boldly owing to the marked difference in the light reflected from the steep lee slopes and from the adjacent upper part of the weather slopes, which is nearly horizontal. Looking down wind the steep lee slope is out of sight, and there is so little contrast between the weather slopes of succeeding waves that it is not easy to realize how much the surface undulates. I paid a second visit to the sandbank in the afternoon, when the wind had increased in force to about the strength of a "fresh breeze," which has a velocity of 21 miles an hour. The ridges or waves were higher than in the morning-that 
is to say, their "amplitude" or height from trough to crest was greater. The actual level of the troughs had been lowered, as was evident from the fact that a relatively hard floor of a compact material was exposed, whereas in the morning there was some depth of loose sand even in the troughs. Whether the absolute level of the crests had been raised or whether the increased amplitude was accompanied by a lowering of the crests less than the lowering of the troughs I did not ascertain. The average level of the surface was certainly lower, for the sandbank was obviously being depleted by the wind. The quantity of sand now flying in permanent suspension was great, and it formed a thick haze 20 or 30 feet high. It was necessary to protect the eyes, nose, and ears from the penetrating particles, and even then prolonged observations were attended by considerable discomfort. Wandering over the sandbank, I found that in some parts the crest of each ridge varied considerably in height, presenting a series of peaks and saddles. In order to determine the relation of height to length in the waves I measured next day, May 8th, a continuous series of 24 . The first ridge was 40 yards from the Nile, and the measurements were taken proceeding down wind and away from the Nile to the end of the 
tract of loose sand, the twenty-fourth wave being succeeded by hard ground. The size of the waves was as follows:-

\begin{tabular}{|c|c|}
\hline $\begin{array}{l}\text { Length of Wave. } \\
33 \mathrm{ft} \text {. }\end{array}$ & $\begin{array}{l}\text { Height of Wave. } \\
2 \mathrm{ft} \text {. I I } \frac{1}{2} \text { in. }\end{array}$ \\
\hline $5^{2} \mathrm{ft}$. & $2 \mathrm{ft} .8$ in. \\
\hline $36 \mathrm{ft}$. & $2 \mathrm{ft} .8$ in. \\
\hline $54 \mathrm{ft}$. & I ft. $6 \frac{1}{2}$ in. \\
\hline $30 \mathrm{ft}$. & I ft. 2 in. \\
\hline $25 \mathrm{ft}$. & $2 \mathrm{ft.} 2 \frac{1}{2}$ in. \\
\hline $22 \mathrm{ft}$. & - 6 in. \\
\hline $2 \mathrm{I} \mathrm{ft}$ & $2 \mathrm{ft} .3 \mathrm{in.}$ \\
\hline 35 ft. 6 in. & $2 \mathrm{ft} . \quad 8 \frac{1}{2}$ in. \\
\hline 27 ft. 6 in. & $3 \mathrm{ft} . \quad I$ in. \\
\hline $40 \mathrm{ft} .6 \mathrm{in}$. & $2 \mathrm{ft} .9$ in. \\
\hline $29 \mathrm{ft}$ & I ft. o in. \\
\hline I9 ft. 6 in. & I ft. 5 in. \\
\hline $35 \mathrm{ft}$. & - 7 \\
\hline $30 \mathrm{ft}$. & - 9 \\
\hline I8 ft. & I ft. 5 \\
\hline $30 \mathrm{ft}$. & I ft. 4 in. \\
\hline $29 \mathrm{ft}$. & - II \\
\hline $30 \mathrm{ft}$. & - $7 \mathrm{in.}$ \\
\hline I5 ft. & - $6 \frac{1}{2} \mathrm{in}$. \\
\hline I6 ft. & I ft. $9 \frac{1}{2}$ in. \\
\hline $34 \frac{1}{2} \mathrm{ft}$. & $2 \mathrm{ft}$. I I in. \\
\hline $37 \frac{1}{2} \mathrm{ft}$ & I ft. 2 in. \\
\hline $3 \mathrm{I} \frac{1}{2} \mathrm{ft}$ & - II \\
\hline
\end{tabular}

Thus the average length of the waves was 30 feet 6 inches and the average height I foot 8 inches. The ratio of length to height obtained by 3 
dividing the sum of all the lengths by the sum of all the heights is 18.4 .

It was a matter of great interest to ascertain if this were a constant ratio-i.e., if the average steepness of the waves were always the same, or if it were, on the other hand, dependent upon circumstances. Passing over for the present other observations made on 7 th and 8 th, I therefore record here the measurement of a series of waves made on the I oth (near the series measured on the 8th), proceeding down wind as before. The total length of the series of twenty-three waves was 656 feet, the average wave-length being therefore 28 feet 6 inches. The individual wave-lengths were not measured, but the height of each wave was taken, the average being I foot 8.5 inches. The ratio of length to height was therefore 16.7 , which only differs by about io per cent. from the ratio obtained two days before. The significance of this result was much increased by the circumstance that I already found the profile of the little ripples made by wind in the surface layers of loose sand upon the Dorsetshire coasts to have this shape, the ratio of length to height being I 8. 55. I In any group of these ripples the indi-

I "On the Formation of Sand Dunes," by Vaughan Cornish, Geographical fournal, March, 1897 . 
viduals are very uniform in size and the crests are quite level. It is very remarkable that in the Helwan waves there should be the same average steepness, although the ratio of height to length in individuals varied from 8.9 to 60 .

The course of the wind as it blows over a series of sand-waves in regular ridges, such as those in one of the photographs, can be made out fairly well by ordinary observation. It is, however, much more difficult to observe in the case of the

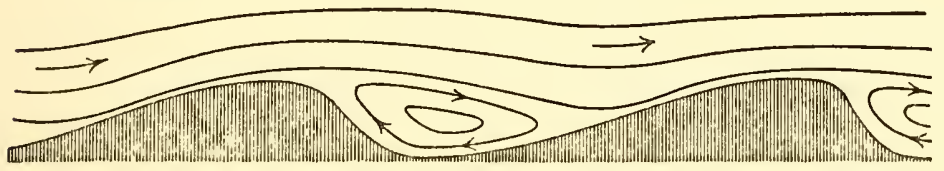

FIG. I.

aeolian sand-ripples, which had been my first study, and I had obtained my first clear notion of the process from the accompanying figure, by which the late Sir G. H. Darwin illustrated the motion in a current of water made to flow over a series of very small sand-ridges. ${ }^{\prime}$ These lines of current and eddy he had actually seen by means of a special ink introduced into the water which rendered its flow visible (Fig. I). I give the

I "On Ripple Mark," by G. H. Darwin, Proc. Roy Soc., I883-4. 
figure, but amplify the information it contains from my own observations of the action of wind on waves in sand and snow. On the lee side of each cliff an eddy or vortex is active, a body of air which whirls vertically round a horizontal axis. At the crest the surface currents converge. Both currents are loaded with sand, which deposits on the lee side of the crest. At a position on the long, gently sloping weather side of the next wave the surface currents are, on the contrary, divergent, that at the tail end of the elongated vortex drawing sand back I from the nodal position, whilst the

r Since I began the study of sand-waves and the eddies which make them the use of motor vehicles has made familiar to most of us the upward deflection of wind by an obstacle, and the consequent return draught on a lower level. On the front seat of the motor omnibuses now running in London one can look over the top of the wind-screen without feeling the wind in the eyes, the direct current of air being thrown slightly upwards, as can be proved by raising the hand a few inches above the head, where the wind is felt. If the hand be held close to the floor a return draught can be felt, and this brings the dust and dirt which accumulates at the foot of the wind-screen. This effect is the same as that which occurs when the wind blows outwards from the area of sand-dunes over the neighbouring stony plain. Those sand-grains which drop near the dunes are swept back by the return draught which blows along the ground, and are deposited against the cliff of the dune, the neighbouring part of the stony plain being thus kept clear of sand. When a taxi-cab is opened by letting 
direct wind, descending just above the node, drives the sand of all the upper part of the ridges forwards. Thus the upper part of each ridge is continually being scoured away and the eddy space to leeward is continually being filled up. By this process the position of each ridge continually advances to leeward, the core of eddying air being thus pushed forward, the progression of each successive core of eddying air permitting likewise the motion of the passive sand-waves.

A sand-grain of any given size and weight has its own rate of subsidence through air. To raise it needs an upward current of slightly greater velocity. The scouring out of the troughs and the increase in amplitude of the waves depends upon the eddy being sufficiently strong. When the wind is strong and the ridges small their growth proceeds, the eddy gaining in strength as the ridge grows. But if, after the ridge has reached its maximum, the wind abates, the troughs begin to silt up again, as I observed one day on the Helwan sandbank.

down the back part an inconvenience is caused by the fact that the front of the cab has not been designed as a windscreen and is too high for the purpose, so that the return current of air, instead of striking the back of the vehicle, cuts in over it, blowing on the back of the passenger's head and neck. 
The constant ratio of length to height in the sand-waves shows that the air-eddy maintains the same shape whether the ridges be large or small and whether the wind be light or strong. The characteristic shape of an eddy is ichthyomorphici.e., fish-shaped, with blunt head and fine tail. Numerous examples of this will appear in the course of this record. The sand ridges have fine lines aft and a blunt fore part-i.e.., have a desk shape, and advance as if the desk were being pushed forward. But they are passive waves. They are moulded upon, and move by virtue of, the eddies of air, and each of these has a blunt head and a fine tail. The eddies, however, are annulled when the wind ceases, whereas the sandridges remain, passive but permanent.

So much of explanation for the present of the growth and movement of aeolian sand-waves already formed in transverse ridges. The explanation of the process by which these waves originate from a level surface of loose sand must be reserved until later.

On some parts of the Helwan sandbank the waves, although in ridges of great lateral extension, had unlevel crests, each ridge consisting of a series of peaks separated by saddles. The wind sweeps through these depressions with increased 



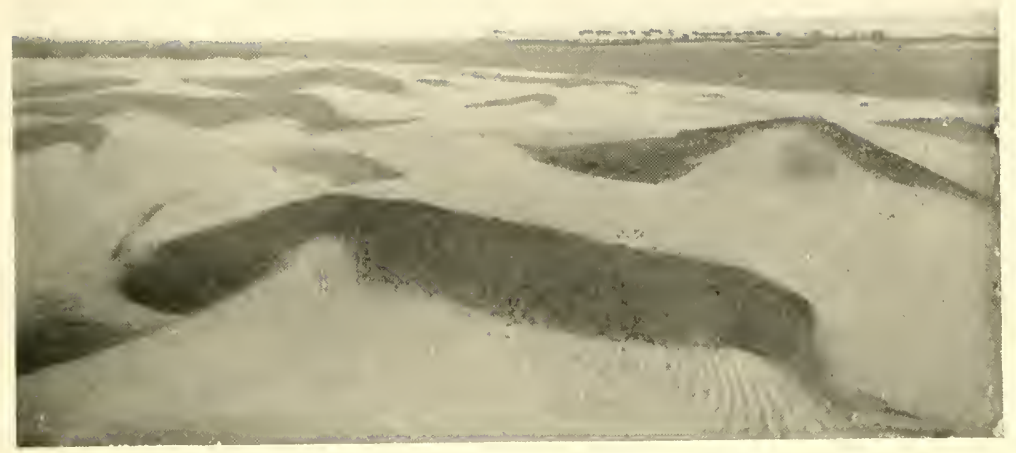

PLATE 3.-Acolian sand-waves with undulating crests.

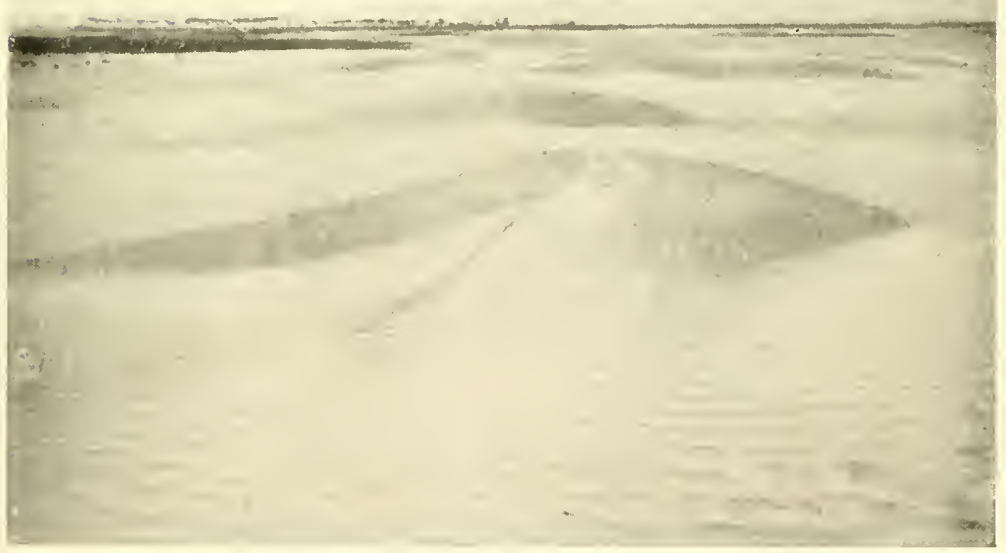

Plate 3.-Transverse ridges with longitudinal projections. 

pushing force and, swinging round from either side in a right-handed and left-handed spiral, curls upwards on the lee of the central peak. Thus in addition to the eddy with horizontal axis formed on the lee of a long ridge there is here an eddy, or a pair of eddies, with inclined or vertical axis on the lee of a peak. Sometimes the effect of these eddies is to build up against the lee side of the peak a mound or bank tapering to leeward, with its axis parallel to the wind. This is deposited where the spiral whirls, coming in from either side and each heavily loaded with sand, meet and ascend.

In other places on the sandbanks I found a series of waves of no great lateral extension, each ridge being a single broad mound tapering from the centre until it merged at either end in the general level of a plain of loose sand. From the highest and central part of each ridge there projected at right angles a tongue of sand tapering to leeward until it merged in the general level of the plain. This tongue of sand had an absolutely sharp ridge, and was concave on either side, being apparently modelled by whirls of air.

There was, however, yet a third variety of the action of secondary eddies on the lee side of peaks, for there were places where depletion instead of 
accumulation had occurred. This case is illustrated in Plate IV. On the lee side of the peak the loose sand had been entirely removed, the converging spirals of air having cut down to the solid substratum, whereas the saddles of succeeding ridges were still connected by a bed of loose sand. I did not ascertain at the time the precise variation of condition which produced this changed function of the eddies on the side of peaks. I can, however, give an explanation which is based upon subsequent observations. Wind blowing over loose sand is sometimes overcharged, and drops more than it picks up. It then silts. Sometimes the amount which it is picking up is equal to that which it is dropping, and it then neither silts nor scours. Thirdly, it is sometimes picking up more than it drops, and then it scours. In the first condition, and perhaps in the second, a mound of sand would be deposited where the two whirls of air coming from the right and left meet under the peak. In the last case erosion occurs. The result is, as is partly shown in the photograph, to sweep bare a more or less oval space between two succeeding peaks, whilst the space on either side between the succeeding saddles remains covered with loose sand. On one part of the sandbank the general appearance was that 


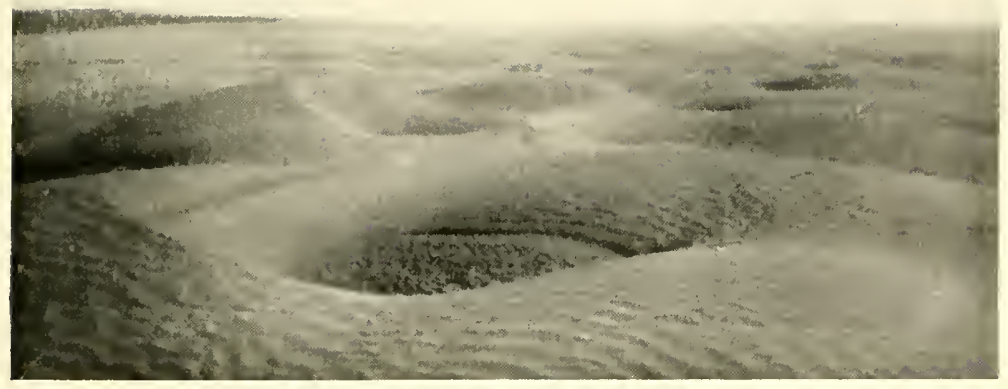

PLATE +-The pits termed fuljes.

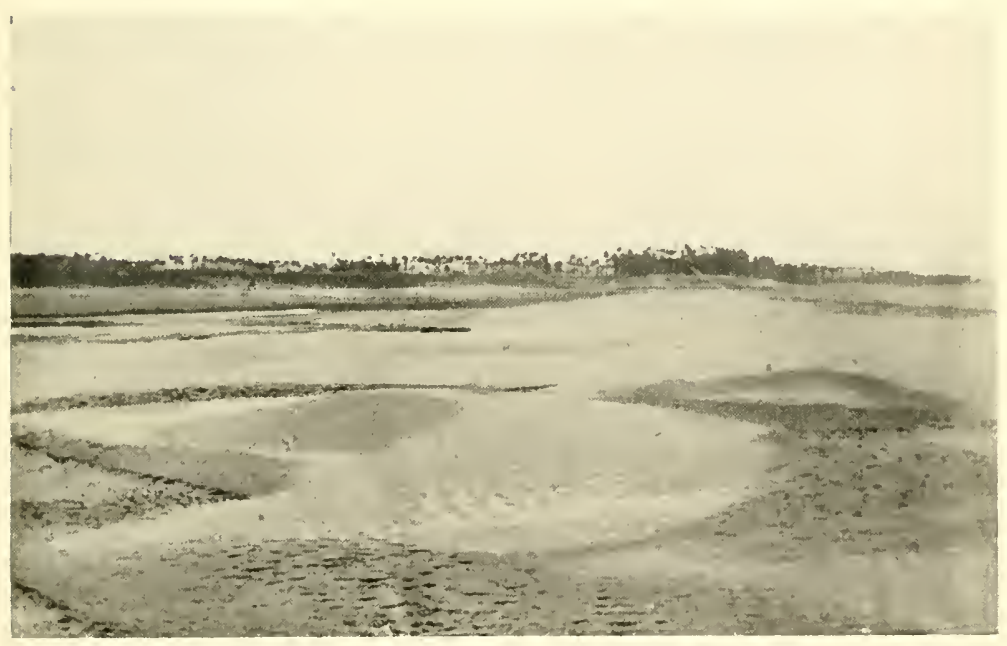

PLATE 4.-The hillocks termed barchans. 

of an elevated, undulating plain pitted with hollows. The profile of each pit in the direction of the wind was the same as that of the regular waves, except that some of the lower parts of the sand-wave were wanting, all the sand being removed, leaving a floor of hard material. The floor of the pit was in some cases oval in shape; in others loose sand lay within the oval on the lee side, making the floor crescentic in form, recalling the shape of a horse's footprint. There remained, however, the characteristic steep slope on one side and gentle slope on the other. Pits of this shape and of great depth were observed by Mr. W. S. Blunt I in the Arabian Nefud, where they are called fuljes. It has taxed the ingenuity of more than one writer to imagine a mode of action by which the wind could scour out holes of such a great depth and of this peculiar and constant form. I have not seen the large structures described by $\mathrm{Mr}$. W. S. Blunt, but wherever they are formed in loose sand I believe that they are what I saw on the Helwan sandbanks. The weather and lee sides of the pit are not parts of one structure, but the lee and weather slopes respectively of two succeeding sandwaves. In a later part of this work I shall describe how I observed pits of similar shape left at low r Appendix to "A Pilgrimage to Nejed." 
tide on sandbanks, in which the characteristic steep and gentle slopes were also the lee and weather side of succeeding waves of sand.

The higher part of the sandbank near to the permanent bank of the river was of course the first to be uncovered during the subsidence of the Nile, and had therefore been longer exposed to the action of wind. This part of the sandbank was dotted over with mounds of loose sand separated from each other by bare earth. Most of them were of a definite and remarkable crescentic shape. The profile-that is to say, the section taken in the direction of the wind, which I call the longitudinal section-is very nearly the same as that of the sand-waves which are in regular ridges. It consists of a gently sloping weather face and a cliff on the lee standing at the steepest angle allowed by the looseness of the material. The cliff is highest in the centre, and from that position extends forwards on either side, the mound having two arms or horns similar in shape to the cusps of a fourdays-old moon. This crescentic form of aeolian sandhill, with a height of 20 or $30 \mathrm{feet}$, is well known in many deserts. In those of Central Asia it is called a barchan, in Peru a medaño. The height of those on the sandbank sometimes attained 3 feet. From the situation where I found them 
it was evident that the specimens on the sandbank were residual structures. Had I visited Helwan earlier in the season whilst this part of the sandbank was still covered with loose sand, I should no doubt have found it in regular transverse ridges and furrows similar to those now occupying the tract to windward and nearer the present margin of the river. The ridges with crests consisting of peaks separated by saddles are an intermediate condition. I have described two cases : first, that in which there was an accumulation of sand on the lee side of each peak, and second that in which the loose sand was swept away under the lee of the peak, leaving an oval patch of bare ground. In this latter case the tract presented the appearance of a somewhat undulating plain pitted with holes. The dark-coloured ground in the hollows was the most conspicuous feature in the miniature landscape, but the peaks and steep cliff on the weather side were also noticeable. To the right and left of the peak there was a low saddle, the walls of the pit being lower at the sides than across the central longitudinal section. Let us suppose the action of the wind in gouging out the saddles to have continued until the bare ground was reached. The sandbank would then be covered by a number of crescentic mounds of 
the barchan or medaño form in close proximity to each other. Structurally there is little difference between the elevated plain of loose sand closely pitted by fuljes and the low plain of bare ground closely studded by barchan-shaped sandhills, but in the one case the eye takes note of the shape of the depressions, in the other of the form of the hillocks.

In both cases the profiles are essentially wave profiles, differing but little from those of the regular ridges formed in the earlier stages of wind action on a deep deposit of loose sand. In the regular ridges the crests of the waves extend indefinitely in breadth, so that there are only two dimensions to be studied, just as is the case in waves of the sea. When, however, the loose sand no longer completely covers the ground, we have to study the plan as well as the profile of the moving mounds of sand. Are we to regard the mound of moving sand, called a barchan, as a wave? When barchans occur in regular series one behind the other, each dependent in form, position, and movement upon the shelter afforded by that to windward, I think they should certainly be regarded as a group of sand-waves. The fact that they have a definite lateral boundary imparts a completeness to their study which is novel in the subject 
of surface waves. The idea of a lateral boundary, or third dimension, is not, however, revolutionary in wave theory. For instance, in examining crystals by means of a convergent beam of polarized light we have a cone-shaped wave-front.

I have pointed out that crescentic dunes or barchans were left as scattered mounds where there had once been continuous sand in consecutive ridges. This part of the sandbank, now partly bare, was, however, receiving a shower of sand from the cloud which formed a haze 20 or 30 feet high over the sandbank. The freshly deposited sand collected in patches, and I saw that they were beginning to shape themselves so as to produce barchans. The profile was at first symmetrical, with a gentle slope fore and aft, but after a time the lee slope began to steepen. In plan the patches had the same convex end to windward as the barchan, and to leeward a nearly straight transverse front corresponding to a line drawn from horn to horn of the barchan. I thought that a cliff would soon form, and cusps be produced, and this conclusion I subsequently confirmed by observations of the production of similar forms in snow. Thus, if loose sand lies in patches the wind produces crescentic dunes. On the day of my first visit to the sandbank I 
drove a reed into the sand at the crest of a wave. In the course of forty-eight hours it advanced $29 \frac{1}{2}$ inches, which is at the rate of $0.6 \mathrm{I}$ inches per hour or 150 yards per annum.

I will now describe the process which I believe originated the aeolian sand-waves upon the Helwan sandbank. My views developed gradually in the course of several years' observations of phenomena of this class, and their full justification will become more evident to the reader later on when more of the phenomena have been described. Meanwhile it will be convenient to have the explanation now, even though much of the evidence on which it is based be delayed.

In the first place it must be stated that the mere rolling of sand-grains along the surface does not produce waves. On the contrary, when there is only this mode of motion the tendency is for wind to obliterate transverse inequalities, the miniature rolling stones accumulating in the hollows where the forward velocity of the wind parallel to the surface is least and where the resistance to forward rolling is greatest.

The formation of waves in drifting sand is, on the contrary, dependent upon another mode of action of the wind, viz., that by which the sandgrains are picked up, carried for some distance 


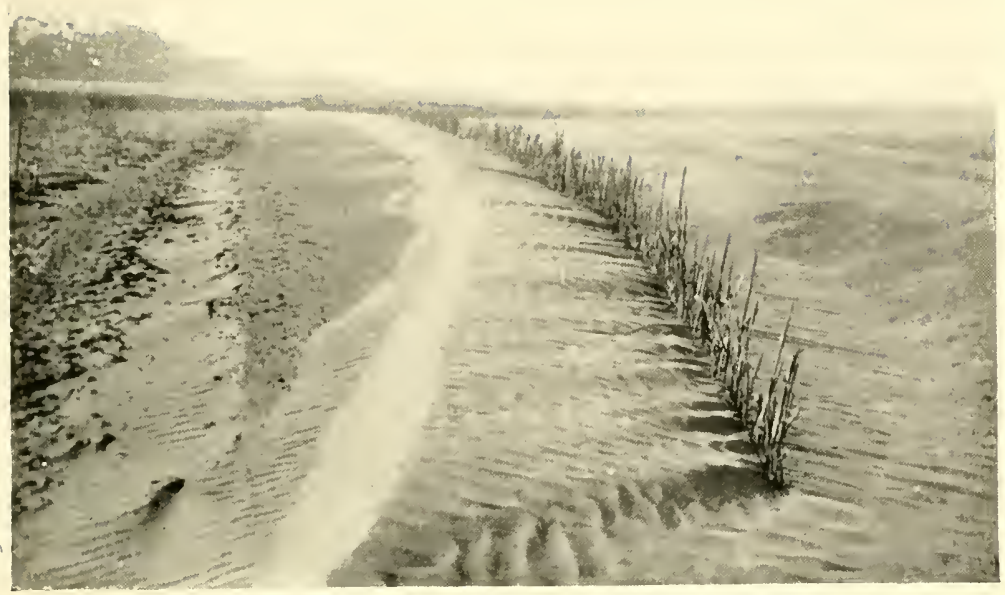

Plate 5.-Accumulation of blown sand caused by a fence of reeds (near Helwan).

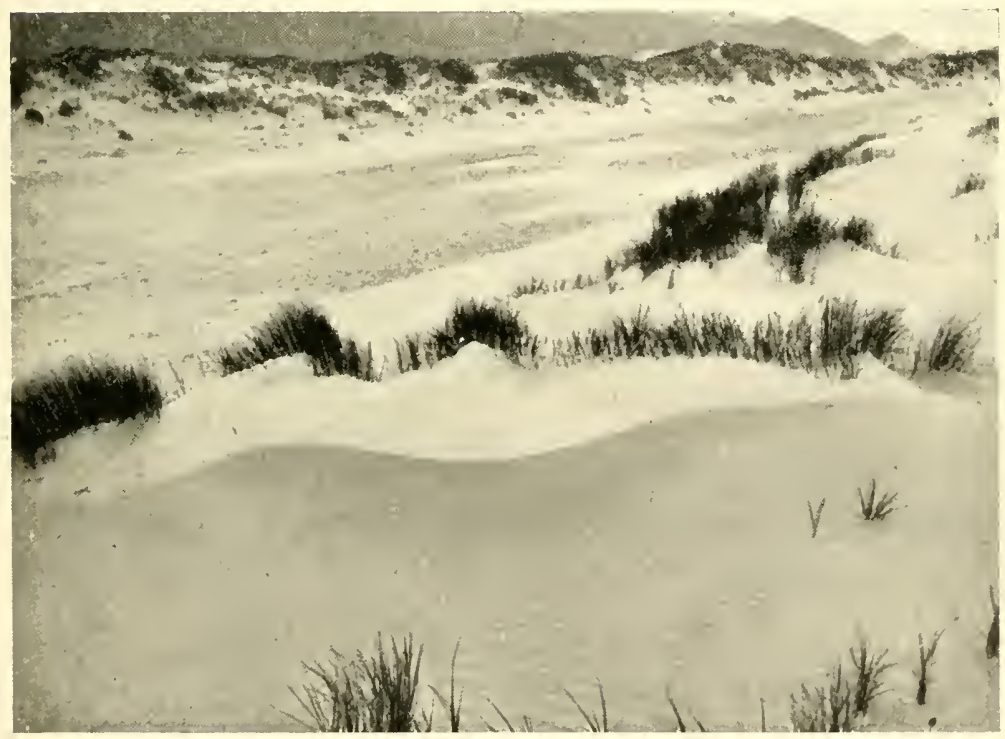

Plate 5.-Accumulation of blown sand caused by marram grass (at Aberdovey). 

in suspension, and again dropped. As rolling, however, goes on at the same time, account has to be taken of this concurrent circumstance.

The condition for uniform drift of sand in suspension is that the amount picked up should be equal to the amount dropped. Then there occurs neither scouring nor silting. If at any place the air had less than its full charge of suspended sand, it would scour the next section. If at any place it became overcharged, it would silt-up the next section. It is evident, therefore, that the continuance of uniform sand-drift would require the maintenance of great steadiness in the velocity of the air. But wind of sufficient strength to pick up. sand and carry it in suspension is not even approximately a steady current. On the contrary, its speed always varies to the amount of about 50 per cent. every few minutes, even in open places, and where there are obstructions the variation is about I 00 per cent. Thus, on December I6, I9I2, I found that the self-registering anemometer of the Meteorological Office in London showed a variation every few minutes of from 6 to 12 miles an hour, on the 17 th of 6 to 14 miles an hour, on the 2 oth 5 to 8 miles an hour, on the 29 th 9 to 2 I miles an hour, and on January 4, I 913,5 to 10 miles an hour. Let us suppose wind to be blowing over 
the Helwan sandbank as it blew in London on December 17, I912. It would be described as a wind of ro miles an hour, but as a matter of fact it is a jerky current of 6 to 14 miles an hour. Further, this particular range of speeds is not itself steadily persistent. If we consider the velocity at successive minutes above any fixed place on the ground, it is not constant; and if we follow in imagination any particular particle or parcel of air in its onward course, its velocity will likewise vary greatly. It is evident, therefore, that in one place the air will become suddenly surcharged with sand owing to loss of speed, and will drop the excess, forming a mound, and at the same moment in another place it will scour out a hollow. Thus vertical inequalities inevitably originate. I have already explained how, when once formed, they are increased, owing to a confluence of currents at the crest and a separation of currents at an intermediate position, and to the effect of this arrangement upon sand carried in suspension. Transverse ridges are thus soon formed. They increase in wave length, and maintain level crests until, apparently, a particular height is reached, when peaks and saddles are developed.

When the ridges are small an incipient depression is quickly mended, but when they are large 


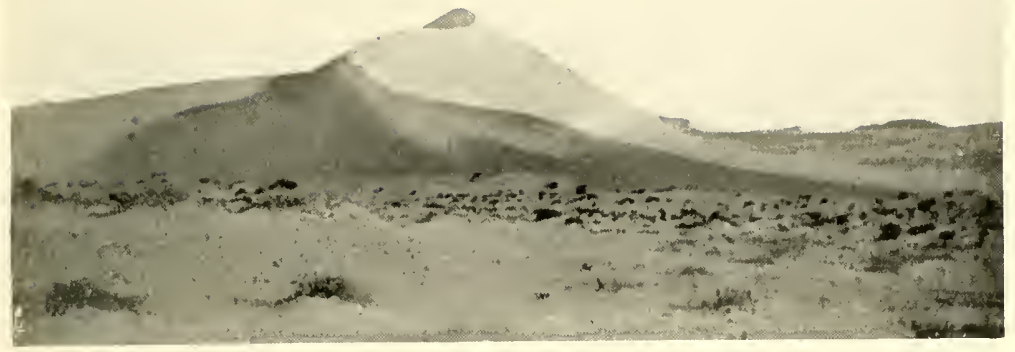

Plate 6.-Sand dune with crest reversed by wind.

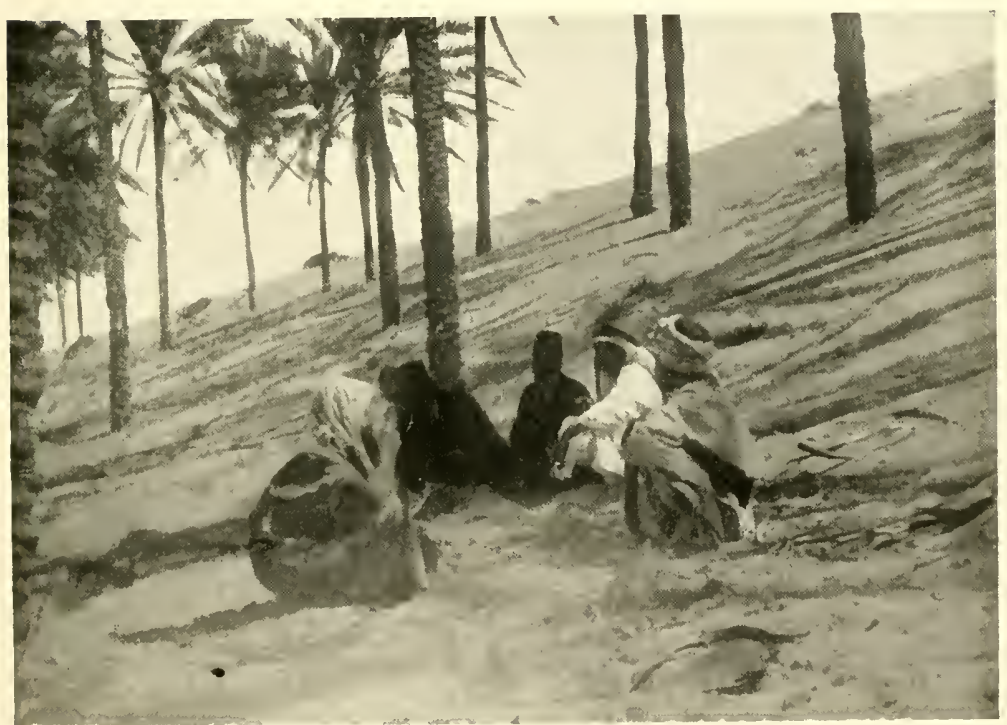

Plate 6.-On the slope of a sand-dune having water at its foot. 

it is increased. The latter effect appears to be owing to the upper layers of loose sand being unable to withstand the thrust to which they are subjected owing to the sudden change in the horizontal velocity of the air between the forward current and the eddy, the strength of which increases with the height of the ridge.

The sand driven through the saddles is drawn in by the eddies towards the peaks, and the fact that the average ratio of length to height is the same when the crests are level as when they are unlevel suggests that the lateral action of the eddies catches and retains all the extra sand driven through the saddles.

My next observations were of dunes about one hundred times as high as those on the Helwan sandbank, and composed of the coarser quartz sand of the desert. They are situated east of the Suez Canal on the route to El Arish. Leaving Kantara on the canal one morning on camel-back, I camped that night at Bir Nisf. Next day, starting at six in the morning, I rode east as far as Abu Ramle, and, turning back, camped for the second night at El Ookha, and returned to Kantara on the morning of the third day.

For some miles east of Kantara we traversed 
a sandy plain of a dirty brown colour. West of the canal, on the contrary, the sand was of a bright yellow colour, like that of ripe wheat. The prevailing drift of the sand is from the west. The canal intercepts much of it, so that the level of the sand near by on the east is now being lowered. The roots of bushes have consequently been exposed, and the general tone of the groundcolour is darkened by admixture of decayed vegetable matter.

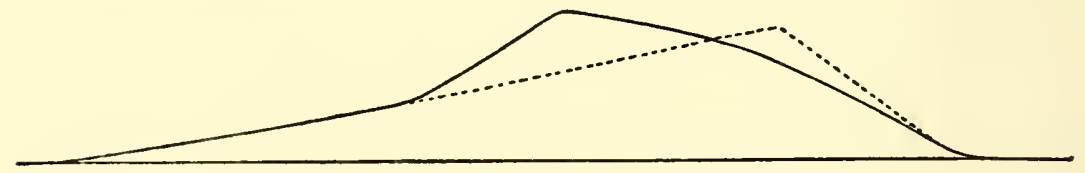

FIG. 2.

Farther east we began to ascend a sand-buried tract, the individual sandhills being at first roundtopped and of indefinite shape. Later I saw on the north of our route large sand-dunes in consecutive parallel ridges. A group of four had quite the appearance of a train of waves. The long, gentle slope was on the west, and there was a steeper slope on the east, but the wind now daily prevalent was opposite to that which must have produced this form. The present moderate breeze was blowing up the steep east face, eddying on the west of its summit, where 


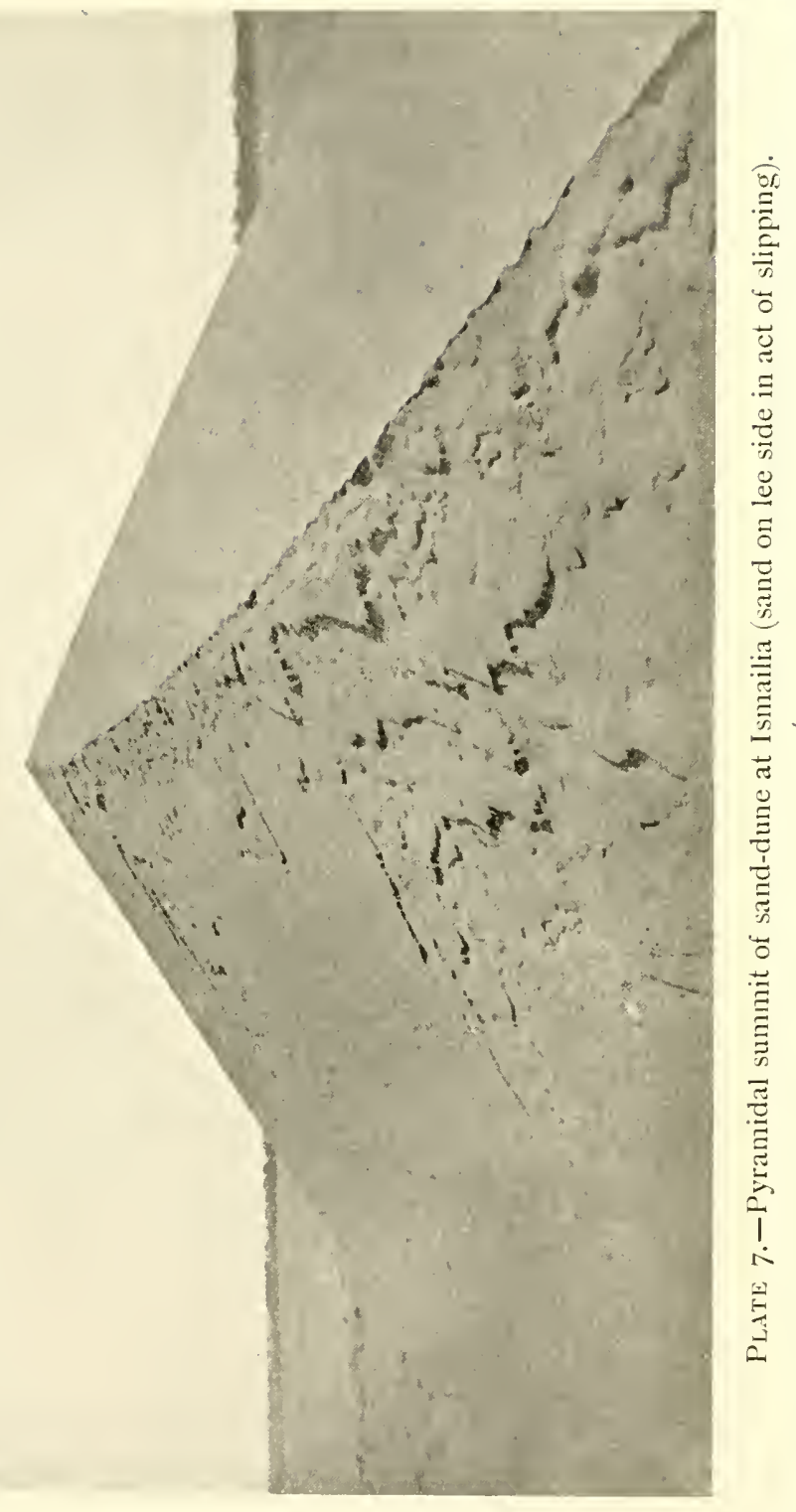





\section{DESERT SAND-DUNES}

a ridge was growing with a steep lee cliff to the west and the original east cliff for its weather side. Thus each of the four large sand-dunes presented the appearance of a wave with its crest curled back (Fig. 2). It was evident that if the present wind persisted long enough these sand-dunes would be completely reversed, for the eastern faces were, no doubt, being flattened.

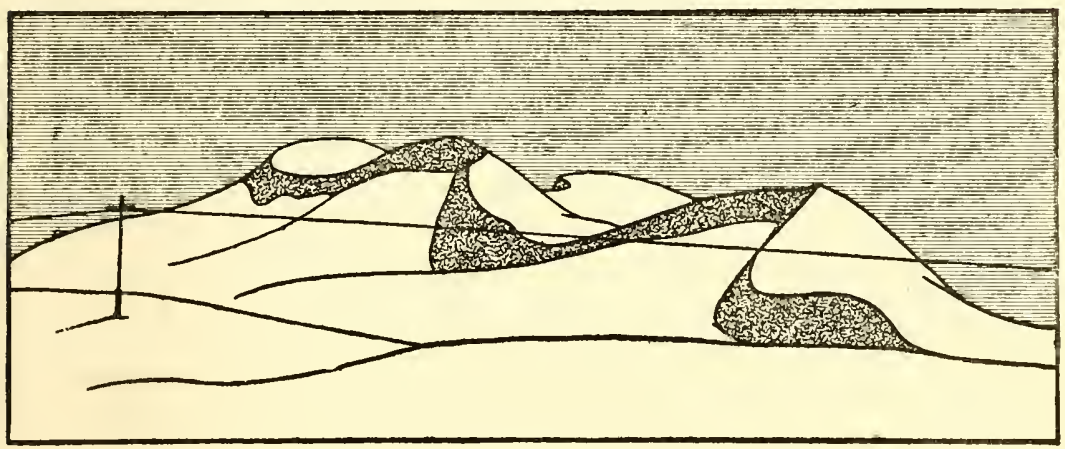

FIG. 3.

I saw the ridge of one great sand-dune with four peaks and three intermediate saddles (Fig. 3 ). The sand being so much coarser than that of the Helwan sandbank, the ridges can, however, grow to a large size before the sand in a saddle is ploughed off, making vertical sinuosities inevitable. In some cases there were very prominent peaks with a great mound of sand piled against their 
lee side. They appeared almost as independent hills. But everywhere the loose sand lay deep, and the wind was unable, therefore, to isolate any mound of sand so as to shape it into a barchan or crescentic dune.

On the afternoon of the first day there was a slight haze in the air due to suspended sand. I was struck next morning by the changed appearance of the scene. There was no haze in the light of early day, but, on the contrary, an atmosphere of singular clearness. The steep slopes, the sharp arêtes, and the pyramidal peaks of the sand-dunes stood out with an intensity of light and shadow which, combined with uniformity of tint, was more like lunar scenery as viewed with a telescope than any terrestrial landscape which I had hitherto seen. The slopes of the dunes were smooth and unspotted, and in the absence of detail or of objects of known size there was nothing to provide a scale of magnitude. With a low sun, which threw long, dark shadows, the dunes, with their bold, mountainous forms, loomed immense, and an unbiased observer might easily have supposed their height to be thousands of feet instead of one or two hundred.

On the second day I camped on a plateau of pure sand some 40 feet above a depression, where 


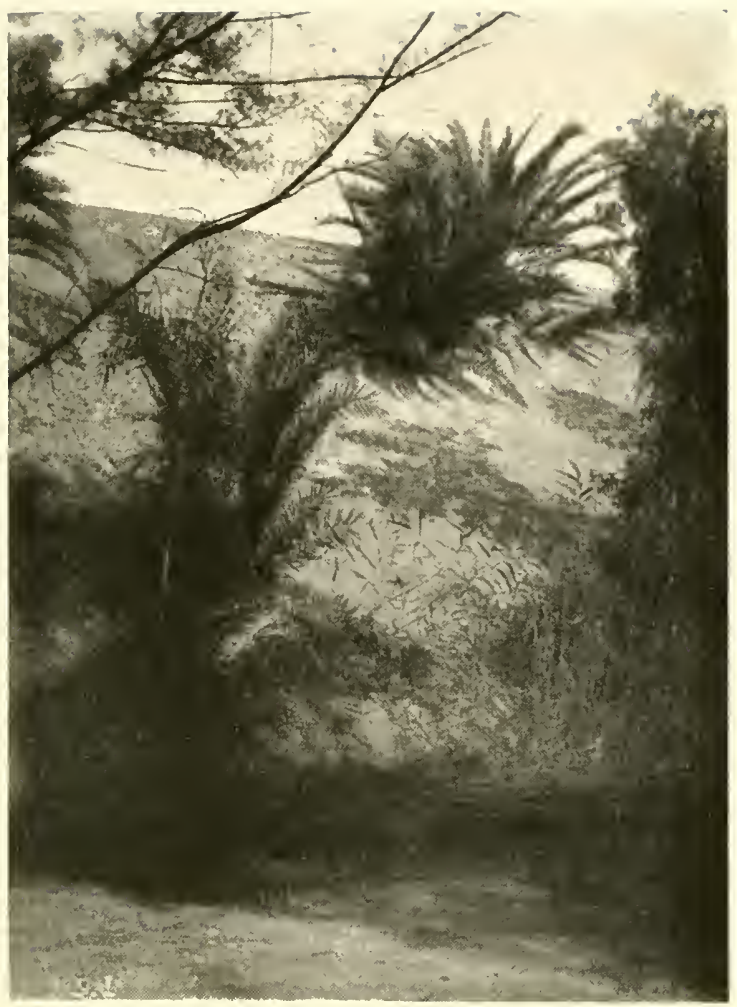

PLATE 8.-Sand-dune encroaching on a plantation at Ismailia.

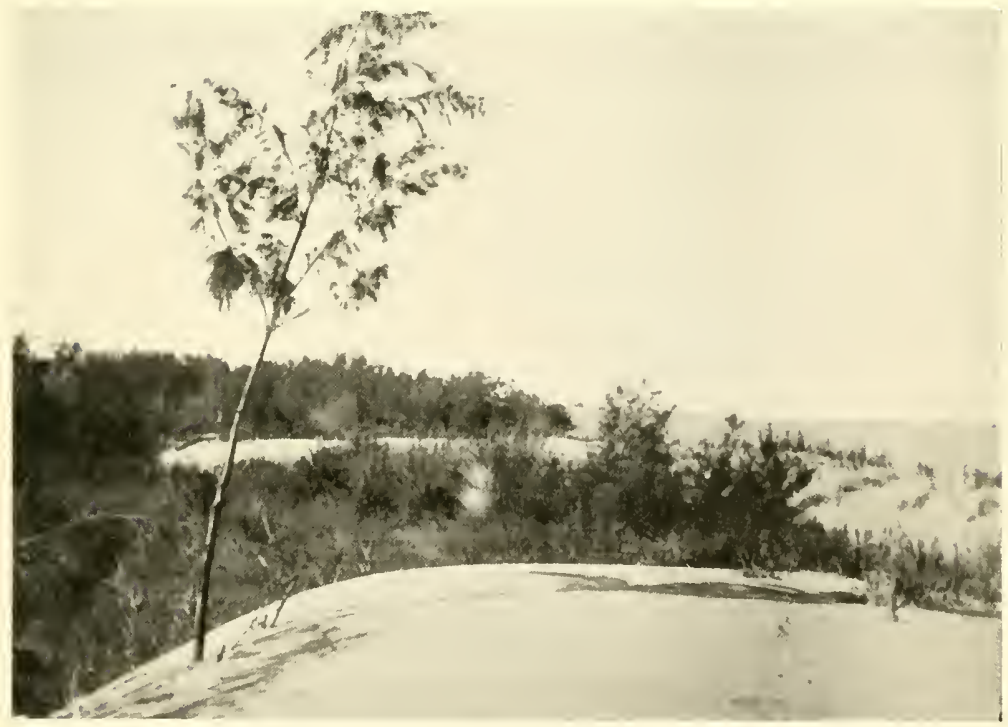

Plate 8.-On the top of an encroaching sand-dune at Ismailia. 



\section{DESERT SAND-DUNES}

date-palms grew and where water could be obtained by digging. The day had been very hot, there was no evidence of recent rain, neither could I hear of rain having fallen recently in the neighbourhood. The air was so dry that when I tried to wash my hands the soap was left as a solid film upon the skin owing to evaporation of the water. Yet the sand 3 inches below the surface was sufficiently damp to stick to the sides of the glass sample-bottle. I slept that night in a tent which had been pitched on the same spot before sunset. The interior remained dry and very hot all night, but on going out before sunrise I found that the camp equipage outside was wringing wet with dew. The heat of the sun evidently does not penetrate far into the sand, but the size of the interstices between the sand-grains permits of interior distillation. Rain falling on the porous surface cannot collect in superficial channels, but sinks through the sand. Thus moisture lies at the foot of the sand-dune and provides dew.

At Bir Abu Ballah, south-west of Ismailia, I saw a large mass of sand on the west of a cultivated tract, which had formerly been occupied by a salt marsh. The sand was piled in a steep bank, which had a very sinuous frontage, following apparently the margin of the former salt marsh, and 
not conforming at all to the direction of the wind. The surface of the tract of sand showed, however, two sets of undulations, one of which seemed to be transverse waves due to westerly winds, and one to be waves similarly produced by the northerly winds now prevalent.

Apparently the accumulation of a mass of blown sand in this place was due to diminution of mobility by moisture. Between Ismailia and Abu Hammad I saw other sand-dunes produced apparently by the same cause. South of the Wady Toumilat is a plain dotted with scrub and free from sanddunes, but a line of them fringes the south border of the moist Wady which bounds the plain. Sandgrains can drift freely and swiftly over the dry plain, but are checked at the margin of the moist valley, and grow into dunes. Moist ground is apparently the origin of the dunes near Ismailia, on the west of Lake Timsah, and in the other flat districts which I visited in the neighbourhood of the Nile delta moist ground seemed to have determined the position of the dunes. In deserts where there are great variations of wind-exposure the positions of dune-tracts are no doubt often determined by shelter, but I have not visited these localities.

The influence of moist ground appeared to 


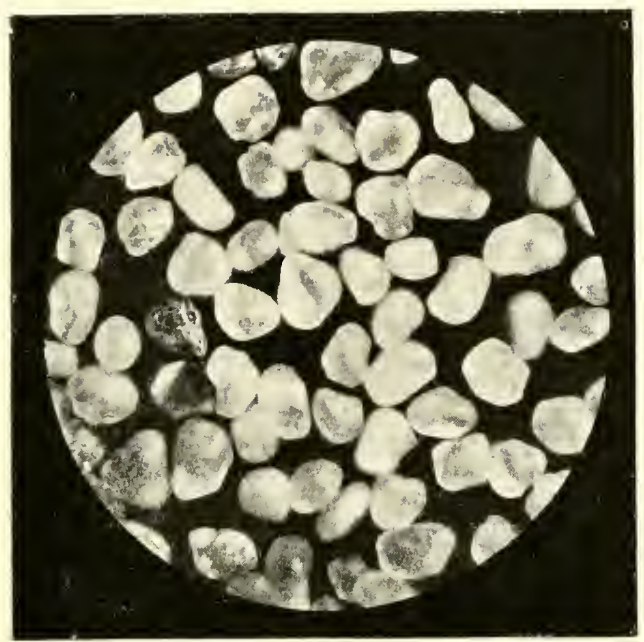

PLATE 9.--Sand grains from the cliff of a sand-dune at Ismailia (magnified). 



\section{DESER'T SAND-DUNES}

be so great wherever I went that I wondered if it could be altogether a mechanical effect. There is a current opinion that when the atmosphere is electrified, wind moves sand much more freely than at other times, the material going into suspension and remaining suspended to an unusual degree. I therefore tried in the laboratory the effect of electtrifying sand, and was much struck with the great mobility which it acquired. It has occurred to me that sand-dunes where the underlying ground is moist, being well "earthed," would be less susceptible to the effects of electrified wind. My cousin the late Mr. E. A. Floyer, Inspector of Egyptian Telegraphs, informed me that in the dry desert, on the other hand, the insulation is so good that it is often difficult to get an "earth" when it is required for sending a telegraphic message.

From the slipping lee cliff of a sand-dune at Abu Racan, near Ismailia, I collected a sample of sand by pushing in a wide-mouthed glass bottle. The position was about the centre, under the peak, of a rather long transverse dune about 40 feet high. Here the air eddies vertically round and round, winnowing the sand. The uniformity of the material which remains is remarkable. Plate IX. reproduced from a micro-photograph, illustrates this, but the fact is more strikingly shown by 


\section{WAVES OF SAND AND SNOW}

the mechanical analysis which I made of the sample. In order to make the analysis I had six sieves of copper-gauze made with square meshes from $\frac{1}{12}$ to $\frac{1}{384}$ of an inch in diameter. I passed the sand through one sieve after the other, with prolonged tappings, and weighed the separated portions. Twenty grams weight of the material were taken and I9.98I grams were recovered, the difference of O.0I9 gram remaining attached to the sieves or being otherwise lost. The result was as follows :-

Sand-grains more than $\frac{1}{12}$ inch diameter

Weight. Percentage $\begin{array}{lllll}\text { Less than } \frac{1}{12} \text { inch but greater than } 2_{2}^{\frac{1}{4}} \text { inch } & \ldots & 0.003 & 0.015\end{array}$

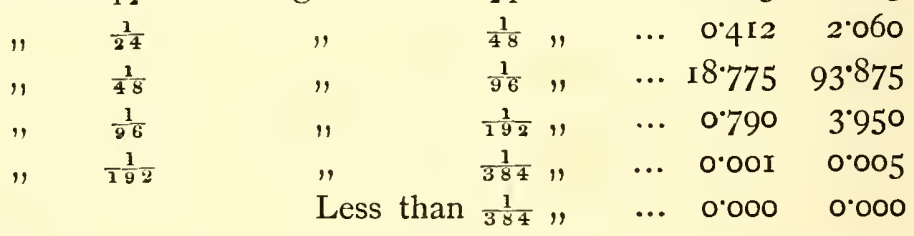

Thus, in round numbers, 2 per cent. by weight of the sand-grains had a diameter more than $\frac{1}{48}$ of an inch and 4 per cent. diameter less than $\frac{1}{96}$. Of the remaining 94 per cent., the largest grain was not more than twice the diameter of the smallest. 


\section{CHAPTER II}

\section{AEOLIAN SAND-RIPPLES}

All aeolian sand-waves have a rippled surface-Description of the formation of aeolian sand-ripples in level deposits of loose sand blown from the beach-Measurements of height and length-The ripples grow without change of shapeRatio of length to height the same as in the larger sandwaves-Rate of advance-Winnowing of fine from coarse sand-grains observed during growth of aeolian ripples"Erosion-ripples" formed where the level of the sand is being lowered-The formation of a protecting cover of "lag gravel" on the crests-Experiments by means of an artificial blast-No rippling of assorted sand-grains of uniform large size, although travelling freely-Immediate rippling when small sand-grains mixed with them-Explanation offered, that eddy in lee of larger grains tosses away the smaller, hence the existence of ripples upon the larger waves-Ripples in shell-sand showing lines of notches in the wave-fronts where the troughs are deeper.

THE little sand-dunes at Helwan were covered with small ripples of a form very much like that of the dunes themselves-i.e., with a gentle slope to windward and a steep lee face. The great desert dunes 
of quartz sand, which I have described, were likewise covered with ripples. In fact, all aeolian sand-waves, whether they be the small dunes élémentaires of French writers such as those at Helwan, or the great dunes of the desert, have their otherwise smooth surface corded with a delicate and regular pattern of ripples. These ripples have a length of some inches from crest to crest, relatively great lateral extension or breadth, and level crests. They face everywhere the direction in which the air flows over the surface of the dune, and show precisely how the shape of the dune deflects the wind. They are formed on all parts of the dune where the air flows parallel to a surface of non-coherent sand. The slipping cliff, which forms sometimes the whole, sometimes only a part, of the lee side, is unrippled. There are also on the greater dunes positions where the wind, cutting down to lower layers of sand which have become somewhat coherent owing to superincumbent pressure, makes another variety of minor wave or ripple, of greater wave length but less breadth. These, which I call erosion ripples, I shall deal with presently, confining myself now to ripples in loose sand, which are the most regular and the prettiest of the patterns modelled in sand by the wind. 


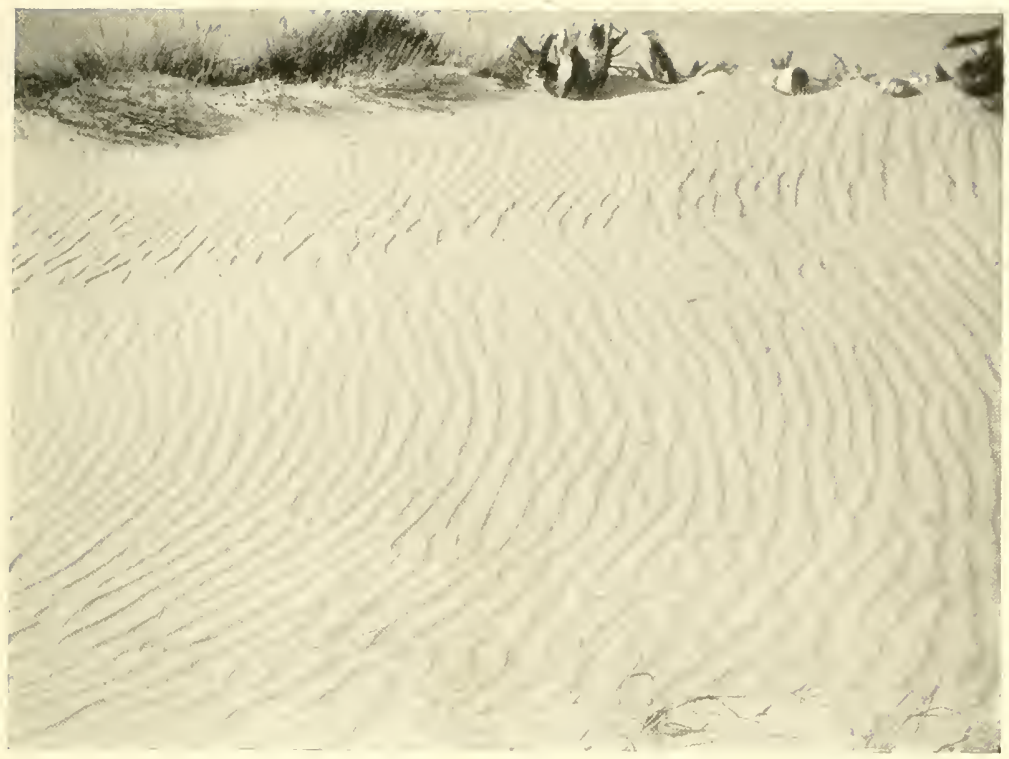

Plate Io.-Aeolian sand-ripples at Southbourne.

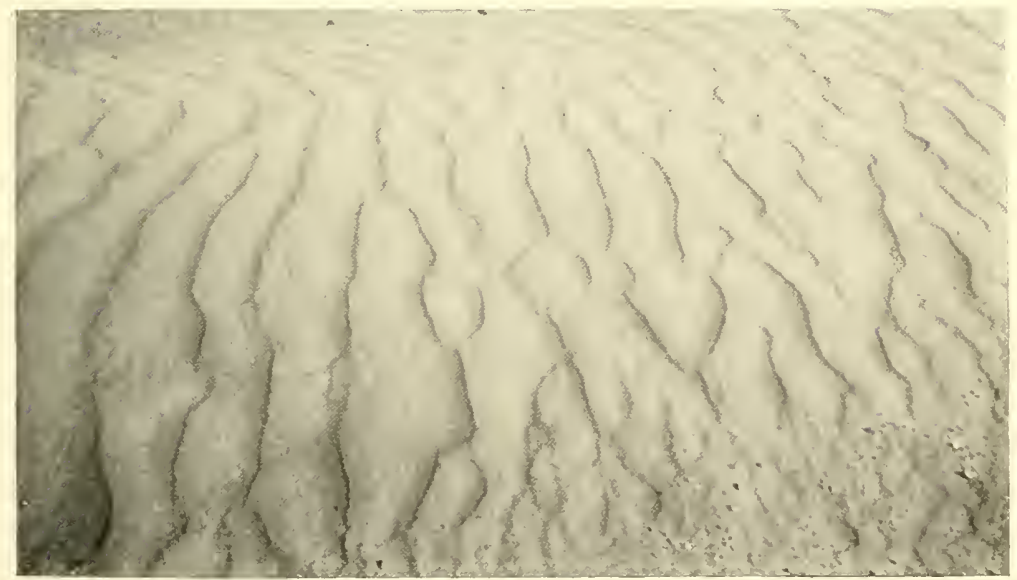

Plate IO.-Aeolian sand-ripples at Southbourne, in which the sorting of grains is indicated. 

Although an aeolian sand-wave cannot be formed without the production of ripples, the converse does not hold, for wind blowing over a horizontal surface of loose sand can produce the ripples without the formation of the larger kind of wave. During the winter of I 895-6 I made numerous observations of this action upon the loose, dry sand of the sea-shore between Branksome Chine and Poole Haven, on the Dorset coast, upon the beach between Poole Haven and Studland, and among the small sand-dunes on either side of the entrance to Poole Harbour. ${ }^{\mathrm{I}}$ The conditions varied so little that what was learnt on different days may safely be combined in the following general description.

A moderate off-shore breeze after rain dried the surface of the neighbouring sand-dunes and a sheet of freshly blown sand began to accumulate on the firm, smooth, and slightly damp surface of the sandy beach. At first the loose surface of accumulating sand was smooth, but it soon became mottled, and the mottled appearance very quickly changed to that of transverse ridges. These had at first a length from crest to crest of $I$ inch, which increased as time went on. But the ridges

₹ "On the Formation of Sand-dunes," Geographical Fournal, March, I897, by Vaughan Cornish. 
developed in breadth much more rapidly than in length, for when the wave-length had attained $2 \frac{1}{2}$ inches the breadth, or lateral extension, of the ridges was no less than 3 feet I I inches.

The newly deposited accumulation of loose sand began to ripple when its depth was certainly not more than $\frac{1}{8}$ of an inch. The size of the sandgrains was such that, on an average, I was able to arrange fifty-four of them, touching each other, in the space of I inch. The best method of measuring the height of the little ridges is to stretch a thread over a group of them and measure down to the surface at the crest and trough respectively. In the earlier observations which I am now describing, however, I used to make a longitudinal section of the ridge with the blade of a knife, and, lying flat on the sand, measure the height of the ridge above the trough directly. I used also to count the number of sand-grains which were piled one upon another between the uppermost continuous layer of sand, which is that at the level of the trough, and the summit of the ridge. By counting the number of sand-grains which could be placed side by side in the space of I inch I obtained an indirect measure of the height in one or two cases when I was not provided with a measure suitable for taking the height of very 
small ridges in quite loose sand. The following measurements were made :-

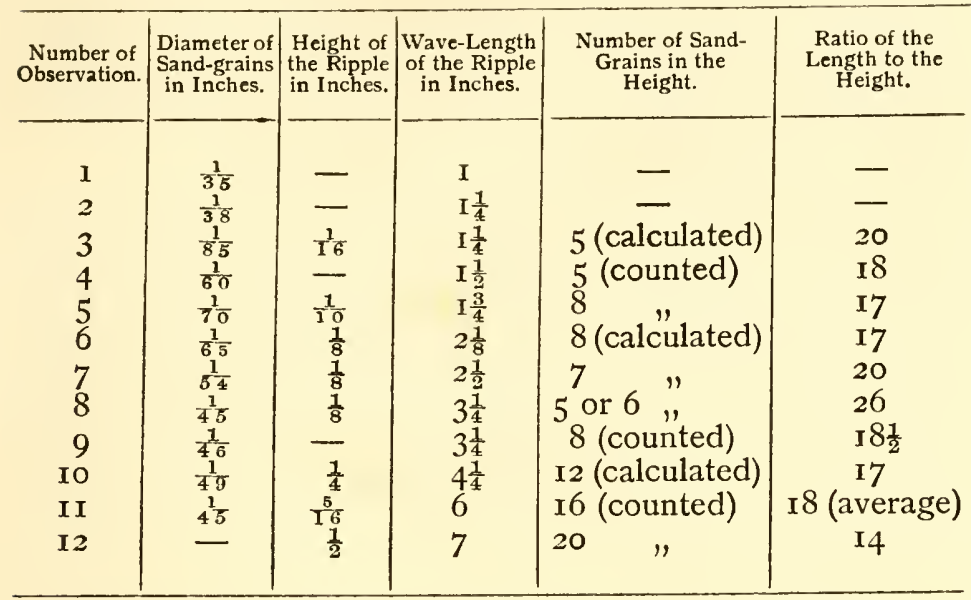

(In the case of number 12 there were smaller ripples upon the weather slope.)

The indication afforded by this table is that the ratio of length to height remains constant during the growth of the ripples, or, in other words, that the shape of the wind-eddy which moulds them is not affected by their growth. The average ratio of length to height is I 8.55 , which, as has already been pointed out, is the same as that of the sandwaves with a wave-length of 30 feet-that is to say, with linear dimensions $\mathrm{I} 20$ times as great. I have appealed to travellers in desert regions to make similar measurements of a series of great dunes, but have not yet received any results. 
If the ratio of length to height in the last ten ripple measurements hold for the first two, of which only the length and the diameter of the sand-grains were measured, the sand is already regularly rippled when the trough is one grain lower and the crest one grain higher than the mean surface.

The movement of the ripples was measured on several occasions. When the wind was blowing as a strong breeze-i.e., about 27 miles an hourthe following measurements were taken in different positions not far from each other, but in which ripples varied in size on account of the difference in their exposure :-

Rate of Advance of Ripples of Nine Inches Wave-Length.

\begin{tabular}{|c|c|c|c|c|c|}
\hline$x^{\circ} 50$ & $"$ & $3^{\circ} 0$ & " & $=0.50$ & " \\
\hline •25 & " & $5^{\circ} \mathrm{O}$ & $"$ & $=0.45$ & $"$ \\
\hline & $"$ & 7.5 & $"$ & $=0.43$ & $"$ \\
\hline$\div 25$ & $"$ & 9.5 & $"$ & $=0^{\circ} 447$ & $"$ \\
\hline
\end{tabular}

the average of the five determinations being 0.50 inch per minute.

Rate of Advance of Ripples of Four Inches Wave-Length.

$I^{\circ} \circ$ inch in $2^{\circ} 0$ minutes $=0.50$ inch per minute

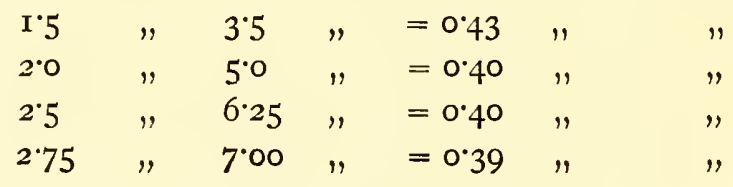


the average of the five determinations being 0.424 inch per minute.

Rate of Advance of Ripples of Three Inches Wave-Length (in a Sheltered Spot).

0.25 inch in 8 minutes $=0.03$ inch per minute

$0.50,16,=0.03, "$

The movement of the ripples even in a strong breeze is achieved almost entirely during the gusts. Thus during a gust lasting only 45 seconds I have seen a small ripple in an exposed position advance nearly I inch.

When a patch of blown sand, drifted from a distance, is deposited in a fairly exposed position the surface is smooth and the texture of the sand uniform at first, but almost as soon as rippling commences the sand on the crests is seen to be coarser than elsewhere. This difference becomes more marked as the ripples grow in size. Even during my first observation of the occurrence I thought I could detect two modes of motion of sand-grains, and the two modes of motion appeared to be connected with this sorting of the sand. The large grains which accumulated at the crests rolled upon the surface, but the finer grains seemed to be caught up in the air and whisked away. I shall describe presently how I verified this by experi- 
ment. As long as sand is being so plentifully supplied that the deposit accumulates, or does not become depleted, the growth of the ripples is slow, they never attain a very large size, and the sand upon their crests does not become coarse. But when the supply of sand from the windward is scanty or fails altogether the ripples grow to larger dimensions and the sand-grains upon the crests are coarser. This coarse sand, which becomes of the dimensions of small gravel, ultimately collects in a sheet, which covers and completely protects the upper part of the ripples. The completeness of this protection depends upon the circumstance that individual particles of coarsest sand or very fine gravel lie wholly above the general surface and, being thus exposed to the horizontal pressure of the wind, roll freely, whereas when they are collected in a sheet the wind glides ineffectively over their surface. The rate of their subsidence, or fall, in air is, moreover, such that it would need a very strong eddy to suspend them. Thus when this sheet of coarse sand, or "lag gravel," has been formed it protects the sand below it and the ripples grow by deepening of their intervening troughs. These are dug out in sand which has become somewhat compact owing to superincumbent pressure. This kind of erosion-ripple not 


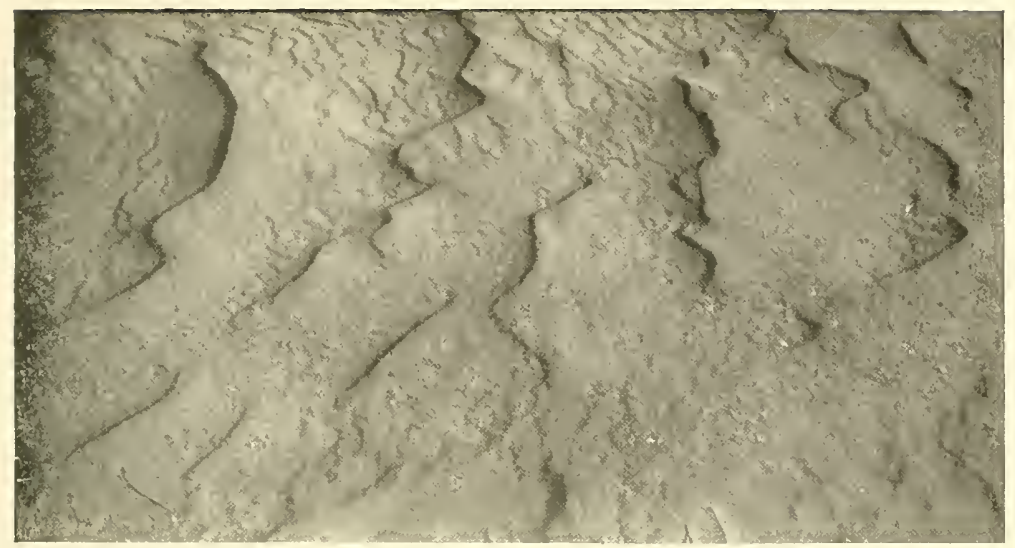

Plate II.-Acolian sand-ripples at Southbourne, in which the sand grains have been much sorted.

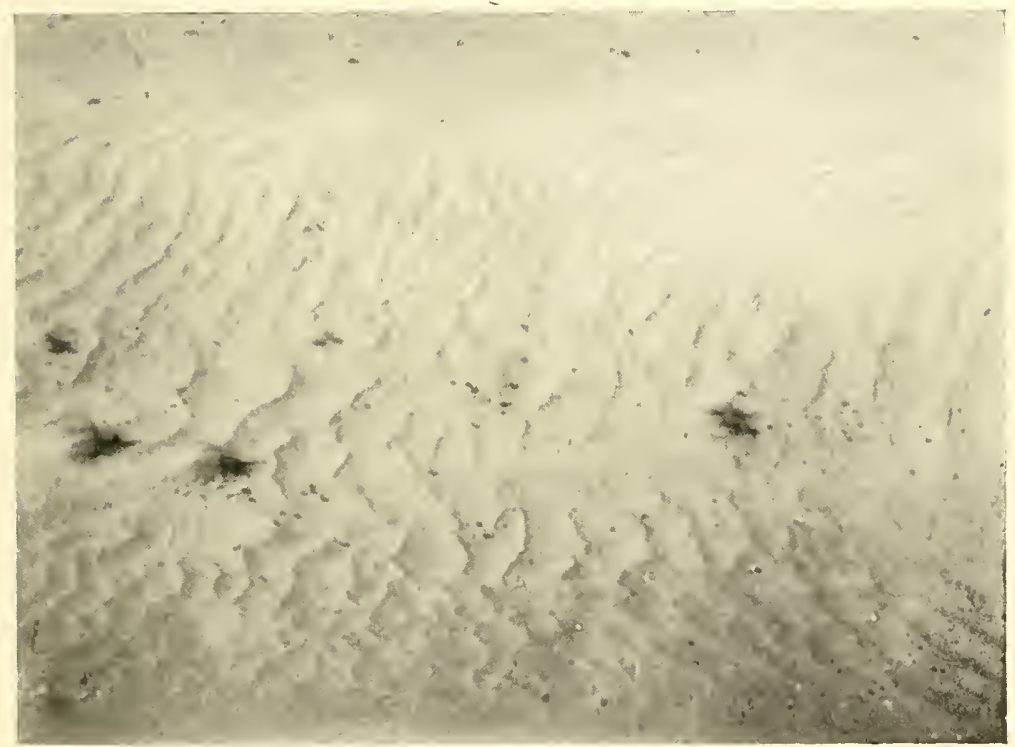

Plate II.-Aeolian sand-ripples at Ismailia to leeward of a sand-dune where there is an upward current of air. 

only attains a greater wave-length than that of ripples formed in quite loose sand, but a greater steepness also. Thus on the nearly flat top of a sandhill near Lake Timsah, in Egypt, I measured such ripples with a wave-length of 7 feet 2 inches and a height of 6 inches, being a ratio of length to height of 143 . This kind of rippling is quickly produced in positions where the supply of drifting sand is small and the wind is swirling upwards. The lower photograph of Plate XI. shows this erosion rippling in such a position to leeward of a sand-dune at $\mathrm{Abu}$ Racan, near Ismailia. The crest of the ripple is more nearly in the middle than is the case with the ripples in quite loose sand, and this form suggests that these erosion ripples were almost or quite stationary.

The fact that there is a sorting of sand-grains during rippling, the coarser grains accumulating at the crest, affords a clue to the problem of the simultaneous formation of two orders of undulation, the ripple and the wave, upon the sandbank at Helwan and elsewhere. The theory of the formation of the wave has already been given. Its rippled surface is due to the circumstance that the sand-grains are of various sizes. I have been at considerable pains to investigate the precise manner in which the wind acts upon particles of 
different size so as to produce this result, and the outcome of the inquiry is one of considerable importance in its application to many phenomena of the transport and accumulation of fragmentary materials both by wind and water.

Having hired a room and the necessary appliances at a factory where designs are cut in stone and glass by means of a blast of hot sand, I proceeded to experiment with a strong, steady blast issuing from a nozzle upon materials obtained from natural sands by a process of grading. I spread out a bed of coarse sandgrains of nearly the largest size ordinarily found upon sand-dunes-the "lag gravel," in fact-and I turned upon it a strong blast of air under which this small gravel moved with such freedom that the grains rattled as they rolled. Nevertheless, even under prolonged action of the blast there was no sign of rippling. I then stopped the blast, and taking some fine sand which was at hand, I mixed a quantity of it with the lag gravel. I then turned on the blast again, and almost instantaneously ripples appeared and quickly became regular. Their fronts were convex, being everywhere at right angles to the direction of the blast issuing from the nozzle. The large grains quickly collected on the ridges in transverse barriers, whilst the rapid 
accumulation of haze in the room' attested the fact that the finer particles were being thrown into suspension. Watching the process at work, I was quickly convinced that the rippling action was due to the concurrence of two modes of motion. In the lee of the large grains eddies were formed which caused the small grains there to be thrown into suspension. The large grains, when apart, rolled freely owing to their projection above the surface, but when gathered in groups were less readily moved owing to mutual shelter and interlocking, so that they tended to mass themselves together. The more they massed the stronger was the eddy on their lee and the more rapid the erosion of the fine sand there. Thus the barriers of gravel became the crests of ripples, which had finer sand in the troughs. The relative mobility of heavy and large and of small and light particles under the action of wind depends upon its direction, the mobility of the larger particles being almost entirely due to the component of the wind which is parallel to the surface, whereas that of the fine particles is largely due to the upward component of the wind's motion.

At Hayle, on the north coast of Cornwall, the sand of the beach is mainly composed of fragments of shell. When I visited the place one 
August day in dry and breezy weather the wind had covered the loose sand of the beach with ripples 3 inches in length, which extended laterally as much as 27 feet without a break. They had, however, a feature not seen in the ripples of the quartz sand near Bournemouth, each ridge having notches at intervals, where the straight front was interrupted for a space of about 3.5 inches, the apex of the recess being rather more than $I \cdot 5$ inches behind the general frontage. The trough was deeper in the notches than elsewhere and the sand coarser in grain. The crest was not, however, any higher at these places. The notches occurred at somewhat irregular intervals of about $\mathrm{I} 2$ inches on each ridge, but were repeated exactly from one ridge to another, being arranged in lines parallel to the wind. Apparently, therefore, any pit formed in the trough tends to be deepened, but there is no compensating formation of peaks on the crests. The stronger eddy pumps up more sand from the trough, but apparently the flat particles of the shell-sand cannot withstand the ploughing-off action of the direct current. 


\section{PART II}

SNOW-WAVES AND SNOWDRIFTS 



\section{CHAPTER III}

\section{SNOW-WAVES AND SNOW-RIPPLES}

Ripples in Moist Snow.

Damp snow and dry snow-Ripples in moist snow during snowfalls observed in Hyde Park-They face up-windRecede by erosion of wind-facing cliff-During lulls travel up-wind-Mode of erosion of partially consolidated snow : first transverse, finally longitudinal ridges, with a transition stage between-Stratification shown by erosion.

Waves in Dry, Drifting Snow.

Formed near Montreal at minus $8^{\circ}$ Fahrenheit-Length and height-Flatter than sand-waves-Movement visible and more rapid than that of sand-Surface unrippledMeasurements of snow-waves, in Manitoba, formed during removal of snow-Waves formed during snowfall-Their formation upon a plane surface free from obstructions.

Crescentic Snow-waves or Snow-barchans.

Formed in patches of loose snow travelling on a hard surface-Finer lines than sand-barchans both in profile and plan-Formation of crust on surface of snow and its effect in arresting growth and movement of snow-wavesExplained as due to sublimation-Increase in density of snow which has been drifted by wind-Compared with increase of density due tc pressure. 
Ripples in Snow-sand.

Mode of formation of granular snow or "snow-sand"Rate of movement-Growth and movement more rapid than those of sand-ripples-Measurements of length and height-Obliteration in lee of larger ridge.

Forms Produced by Wind-erosion in Compact Snow (Studies in Canada).

Measurements of transverse ridges, facing up-wind-Shape of pits-Longitudinal structures-Note on the longitudinal sand-dunes of the great Indian Desert.

The Eddy Form of Snow-waves and Snowdrifts.

Complex forms of drifts produced by fixed obstacles-All contained by a boundary curve having blunt head and fine tail-This is the boundary of the eddy caused by the obstruction-Complex forms are stages of filling in of eddy-space and due to insufficient supply of snow-The eddy-curve and its relation to the forms of fish and cetaceans-Of the wings of birds-Of the submerged part of ships-Of torpedoes and non-rigid airships-Forms of holes scoured out in snow round the trunks of treesRelation of snow-barchans to the eddy-curve-The relation of form and movement between the travelling crescentic snowdrifts and the swirl made in water by an oar-Shape of the eddy in snow-waves-Inference as to the distance to which hedges and belts of trees extend shelter from wind.

On the Three Modes of Deposition of Drifted Material depending upon Rate of Subsidence.

Behaviour of gravel, sand, and dust before the wind-Of shingle, sand, and mud under the action of waves and currents-Single tail of sand behind a narrow obstacle- 
Double tail of snow-powder--Single train of black smoke, but double track of steam, from chimneys-How fallen leaves drift before the wind-On "banner clouds" and on sandbanks to leeward of promontories-On the action of an obliquely crossing wind upon the swell of the sea.

Loose snow has two conditions, which depend upon temperature. Near the melting-point, $32^{\circ}$ Fahrenheit, the particles are soft and adhesive. Near zero Fahrenheit and below this temperature they do not adhere but glide easily over one another. In England and Scotland I studied ripples in the first kind, or moist, snow. In order to see the effect of wind upon the second kind, or dry, snow, I spent a winter in Canada, crossing from Montreal to Vancouver and back again. I also studied there the forms of the banks or drifts produced by the action of wind in the neighbourhood of fixed obstacles. I examined, too, the forms which gravity gives to the caps of snow which collect upon prominences in still weather. This last piece of research being naturally incidental to the tour, may, I think, be properly described in this book, although the forms are not waves, or produced by eddies.

Ripples in Moist Snow.

The following observations were made in England and Scotland at temperatures but little 


\section{WAVES OF SAND AND SNOW}

below the freezing-point. The first observations were in Hyde Park, London. On January 23 and 24, 1907, there were about 2 inches of snow upon the ground, and snow was still falling. There was a moderate breeze blowing, which in exposed positions was removing snow from the surface and drifting it, although not copiously. The whole surface was covered by small ripples about $I$ inch in wave-length and $\frac{1}{20}$ inch in height, which had nearly vertical faces on the up-wind side. They therefore faced in the opposite directicn to the ripples formed by wind in loose, dry sand. Their motion was more rapid than that of aeolian sand-ripples. The movement was usually a recession, each little cliff retreating owing to the removal of its substance by the attack of the wind. But every now and then every ripple would simultaneously advance up-wind with a swift rush lasting for about one second. The slower but longer-lasting retreat to leeward then re-commenced. These changes accompanied the gusts and lulls of the wind. During the gusts there must have been an active eddy with a horizontal axis and vertical whirling on the weather side of each little cliff. When the wind suddenly lulled it ceased to erode the cliff, and the falling snowflakes, entangled in the eddy, plastered up the face of the cliff, building it out 


\section{SNOW-WAVES AND SNOW-RIPPLES 97}

to windward, and thus giving a sudden and swift but momentary motion up-wind. A similar effect was sometimes produced during moments of heavier snowfall.

On Arthur's Seat, near Edinburgh, on the Pentland Hills, and near Grantown-on-Spey I observed the action of wind upon a snow surface when there was no snowfall. The first case which I will describe was during the removal of the surface layers of a recent snowfall where the material was light and loose. The surface was beautifully covered with ripples having wave-lengths of from 3 to 15 inches, with their cliffs facing up-wind. The cliffs, though broadly extended, were sinuous, none being straight for more than a few inches. The concentration of the wind in the re-entrant angles or notches threatened to cut through the ridges and thus destroy by erosion the transverse, or rippled, form, but the drifted particles which were concentrated here were sufficiently adhesive to mend the threatened breaches. The salient angles, too, tended to become more prominent, and thus destroy the transverse arrangement, but they were undercut by the wind, and the overhanging cornices receded by collapse, so that the transverse arrangement was preserved.

But the rippled, or transverse, arrangement of 


\section{WAVES OF SAND AND SNOW}

inequalities did not long survive when the wind had cut down to lower layers of snow which had become compact owing to the pressure to which they had been subjected by the superincumbent layers.

The density of 'snowfall varies from minute to minute, and the result is to produce an incipient stratification. Pressure develops this, so that the deeper layers when uncovered have a strongly marked horizontal stratification, the beds being usually a fraction of an inch in thickness. The result of this is that at first the wind here forms long transverse cliffs of minute height facing upwind, but the hard particles eroded therefrom do not adhere to the smooth surfaces, but, on the contrary, erode after the manner of a sand-blast. Thus, wherever a notch or re-entrant angle is: formed in a cliff it is rapidly increased, and soon the transverse ridges are cut quite through. The last structures to survive are longitudinal ridges with a cliff, or sometimes an overhanging cornice, facing the wind. These are, I believe, the structures often referred to in narratives of polar travels as sastrugi.

These observations of the change from transverse to longitudinal structure during erosion of compact snow were confirmed and extended during. the following winter, which I spent in Canada. 


$$
1
$$





\section{Waves in Dry Drifting Snow.}

I arrived in Canada on December I 5, I 900 , and found the country around Montreal snowcovered, but until January 5 th I saw no undulations with their steeper side turned to leeward-nothing, indeed, but groovings facing the wind. After the New Year, however, the temperature fell, we had what is called in Canada "zero weather," and the newly fallen snow particles being dry and not adhering by dampness or by regelation to one another, behaved quite differently.

On January 5th I went out at I0.30 a.m. to the fields on the west of Montreal. The temperature was $8^{\circ}$ below zero Fahrenheit; i.e., there were $40^{\circ}$ of frost, the sun was shining, and the wind blew with a velocity of thirty miles an hour, recorded at the McGill College Observatory. During the preceding night 3 inches of fresh snow had fallen upon the hard re-frozen surface of the old snow. This new, light, dry snow the wind was rapidly removing to places of shelter. On the lee side of a swell in the ground I found a group of waves, some of which are shown in Plate XII. They resembled the aeolian waves in dry sand which I observed at Helwan, having the cliffs on the lee side, but they were flatter than 


\section{WAVES OF SAND AND SNOW}

the sand-waves and their motion was much more rapid. The weather faces were being rapidly scoured away, whilst the lee cliffs were built out by the arrival of snow from two directions, some pouring over the edge of the cliff from the windward, some being swept back to it along the surface from the leeward. Their advance was sufficiently rapid to be easily visible, and the effect of the silent, stealthy creep of the whole series of waves across the field was extremely weird. The snow thus travelling in waves was only a part of what the wind was drifting, for much was permanently in suspension, whirling along at a great rate in the air as a thin haze extending high above my head. The waves were in isolated ridges with hard snow between. They had an average wavelength of 15 feet 10.4 inches, and an average height of 4.9 inches, so that their length was 38.86 times their height, or in other words, they were only half as steep as the aeolian sand-waves. The profile of passive waves in granular material simply shows the form of the wind eddy. A ridge of the loose snow, which is less resistant than a ridge of sand, cannot withstand as strong a pressure. If the ridges were built artificially to greater steepness, the horizontal thrust of the wind would plough off the upper layers. 


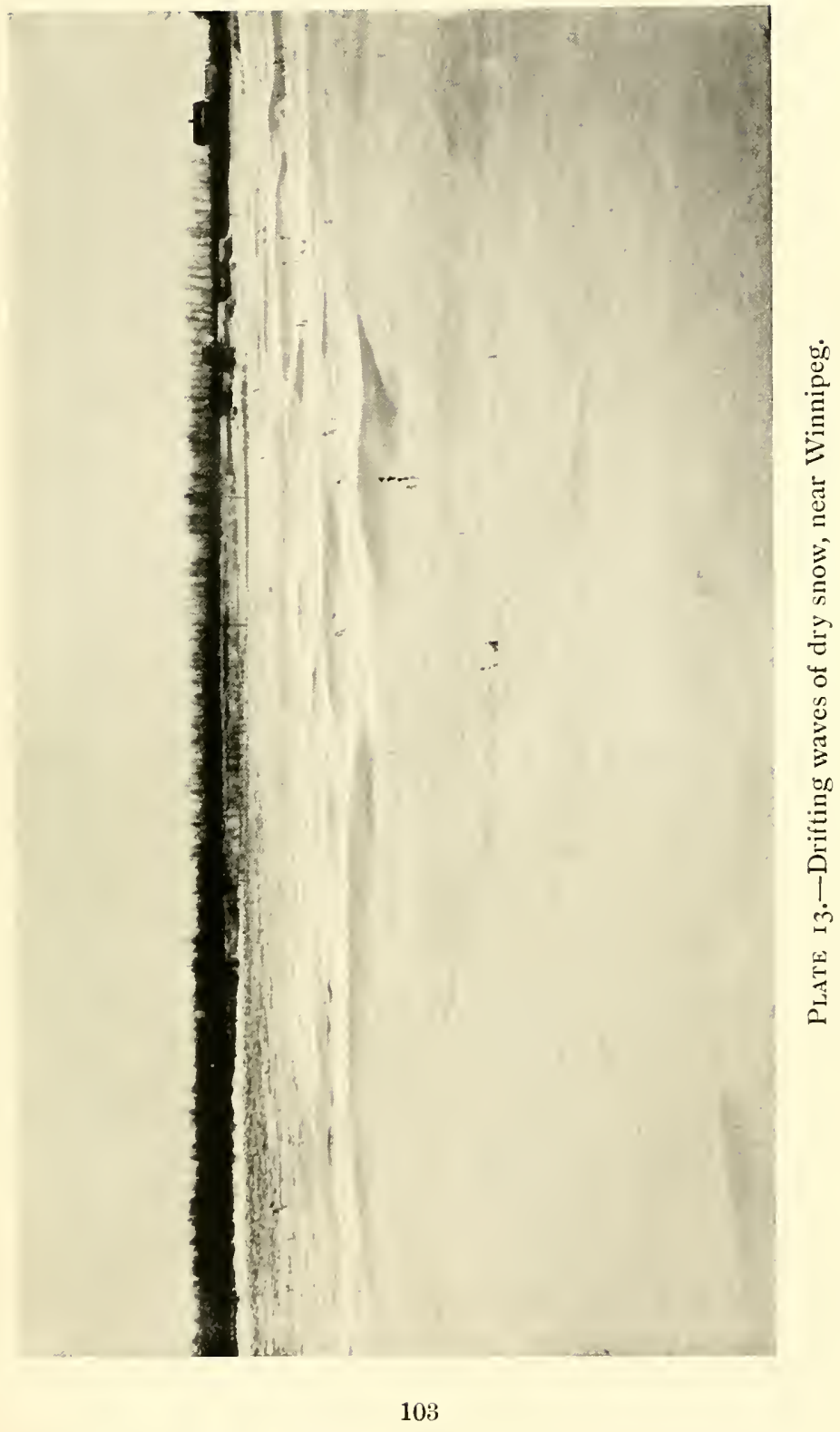





\section{SNOW-WAVES AND SNOW-RIPPLES 105}

The snow-waves advanced 6 feet 6 inches in forty minutes, or at the rate of 2 inches per minute, which is about two hundred times as fast as the rate of advance which I observed in aeolian sand-waves in a wind of rather less strength. The speed of the sand-waves was, however, measured by the advance made during forty-eight hours, and the wind dropped during the nights. If the measurements of the waves of sand and snow had been made under precisely similar conditions, the rate of advance of the latter would have been, perhaps, fifty times as great as that of the former.

The snow-waves were not rippled upon the surface. The reason of this is, no doubt, that the friable snowflakes provided no obstructions to take the place of the coarser sand-grains which, travelling only on the surface and forming an eddymaking barrier where they accumulate, produce the rippled surface of the sand-waves in the manner which I have already explained.

On the flat and more open prairie near Winnipeg snow-waves are formed in larger groups than in the fields round Montreal. On the I 8th of F.ebruary, the temperature being zero Fahrenheit and a strong wind blowing, I went out from the city of Winnipeg on to the open prairie. Five inches of fresh, dry snow had fallen in calm weather 


\section{WAVES OF SAND AND SNOW}

during the previous day and night. By io a.m. this was already drifting in low waves which occupied the whole prairie. I measured a series of twenty-nine which had an average wave-length of 30 feet $I$ inch and an average height of $7 \cdot 2$ inches, the wave-length being therefore fifty times as great as the height. The average difference between the length of each wave and of that preceding it was 22 per cent. of the mean wave-length. This percentage I term the variability of the wavelength. Its record gives a measure of the degree to which groups of waves depart from exact uniformity.

Later in the morning, when drifting had continued longer, I measured a series of I I O consecutive waves which had an average wavelength of 32 feet 10 inches. The variability of wave-length was 36.5 per cent.; i.e., they were less regular than those measured earlier. The reason for this deterioration was easily detected. As the waves rolled on, layers of snow in which pressure had made the particles adhere came to the surface, and this material was not sufficiently fluid to travel in waves. During the remainder of: this day and in the course of the two days following, during which the wind blew but snow did not fall, the appearance of the snow-covered prairie 


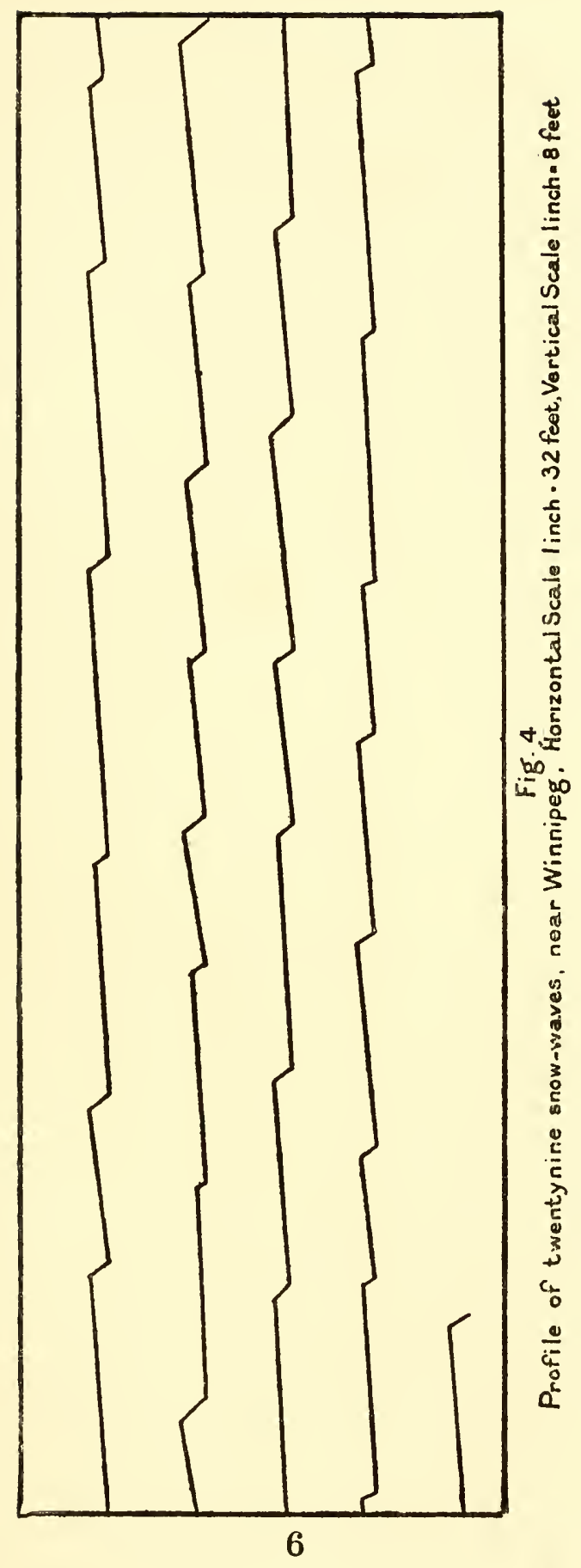




\section{WAVES OF SAND AND SNOW}

underwent a transformation, for ridges facing to windward were formed by erosion of the compact snow. The snow of the drifted waves (which face to leeward) had, moreover, set hard during the still nights, and remained immobile. Thus the snow exhibited two kinds of ridges-one with their faces towards the wind, the other facing to leeward: the former with a surface grooved and scarped, the latter with a surface generally smoother and more rounded. The appearance to the novice is a mere confusion of forms, but when I had learnt the secret of the two kinds of waved surface produced in loose and compact snow respectively I could always recognize the two sets of forms, and detect order where all at first had seemed chaotic.

I have now described two occasions upon which the formation of travelling waves occurred when wind was removing a level deposit of loose snow. On another day I saw the formation of such waves during the covering of the ground by a fresh snowfall accompanied by wind. The surface was hard and glazed, being that of old snow which had thawed and been afterwards frozen. The snowfall began at I0.30 a.m., at about the time I arrived upon the ground, and continued throughout the day, accompanied by a light to moderate breeze. 


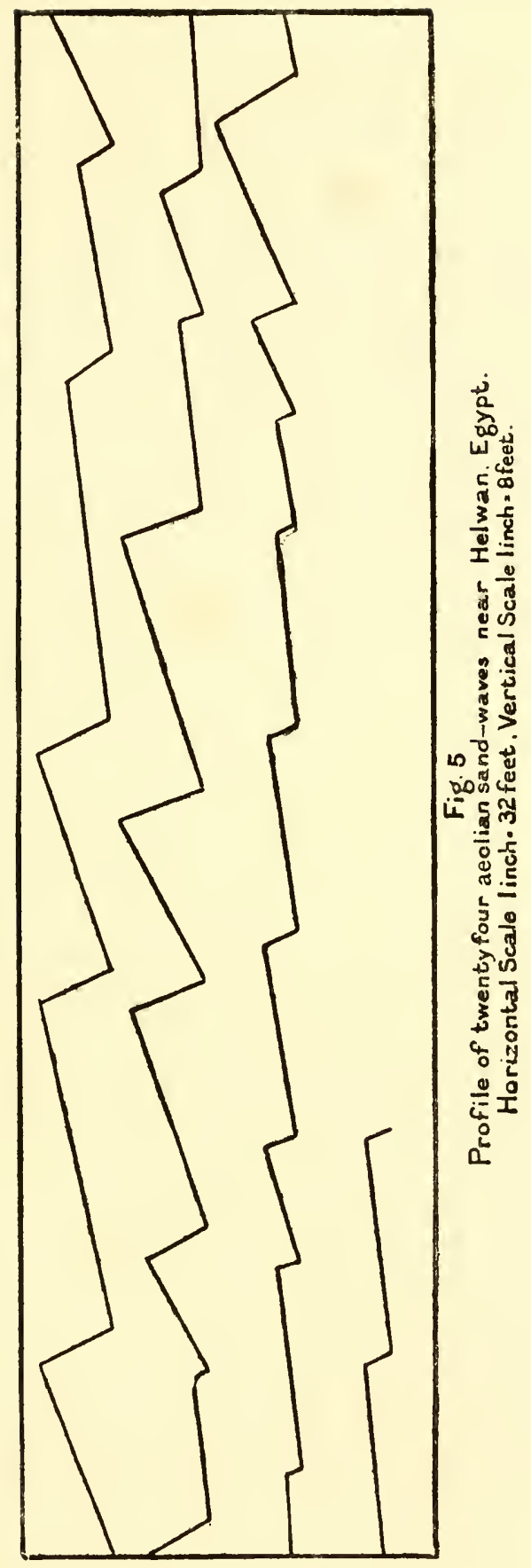




\section{WAVES OF SAND AND SNOW}

The rate of snowfall was about half an inch per hour, but footprints were filled up by fall and drift at the rate of $\mathbf{I}$ inch in fifteen minutes, so that the accumulation by drifting over the icy surface was nearly eight times as rapid as the rate of deposition by snowfall. After half an hour of snowfall and snowdrift, viz., at I I a.m., numerous patches of fresh snow had formed. Their number and size increased, but up to 12.30 p.m., when I adjourned for luncheon, they remained irregular. Returning at 2.30 p.m., i.e., after snowfall and snowdrift had lasted four hours, I found that the irregular patches had become ridges transverse to the direction of the wind, with the steeper faces to leeward. The distances between the ridges of a series were 6, I 2, 6, 8, and 7 feet. A boarded, or "plank" path at the side of a road near by was still uncovered by snow at 4. I 2 p.m.-i.e., after nearly, six hours of snowfall, when enough had fallen to have covered it to a depth of nearly three inches if there had been no wind. Under the actual circumstances of fall and drift the path could never be covered except by submergence by a travelling. wave of snow.

The snow-waves as they roll on leave behind a shallow deposit of partially consolidated snow on which fresh snow drifts but slowly. From what I 


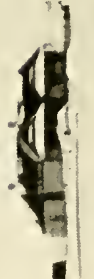





\section{SNOW-WAVES AND SNOW-RIPPIES 113}

saw subsequently on frozen lakes I concluded that the increased friction upon the surface of these remnants rendered possible the complete covering of the ice when the snowfall was accompanied by wind.

It was with peculiar interest that I found, not only that more regular and extensive series of travelling snow-waves were formed upon the flat and open prairie than in undulating and enclosed country, but that the waves formed also on perfectly level and smooth ice of a large frozen lake. The latter observation afforded a remarkable confirmation of the view I had already advanced, that waves in granular material do not require for their formation the existence of an eddy-making obstruction, as was formerly held, but inevitably originate upon an unobstructed surface from the silting and scouring action which is exercised when the wind (blowing as it always does with variable velocity) has a speed, even in the lulls, sufficient to pick up the particles, which must be themselves of such a density and size that they do not follow the lines of flow of the air, but subside at an appreciable rate.

Crescentic Snow-waves or Snow-barchans.

When there is only a small amount of loose, dry snow drifting over a hard surface it does not accu- 


\section{WAVES OF SAND AND SNOW}

mulate in transverse ridges but in low, narrow mounds, having on the lee a cliff, which is highest in the centre and projects forwards on either side in horns or cusps. The shape is that of the crescentic sand-dunes known as medaños or barchans, but with finer lines, the snow-barchan

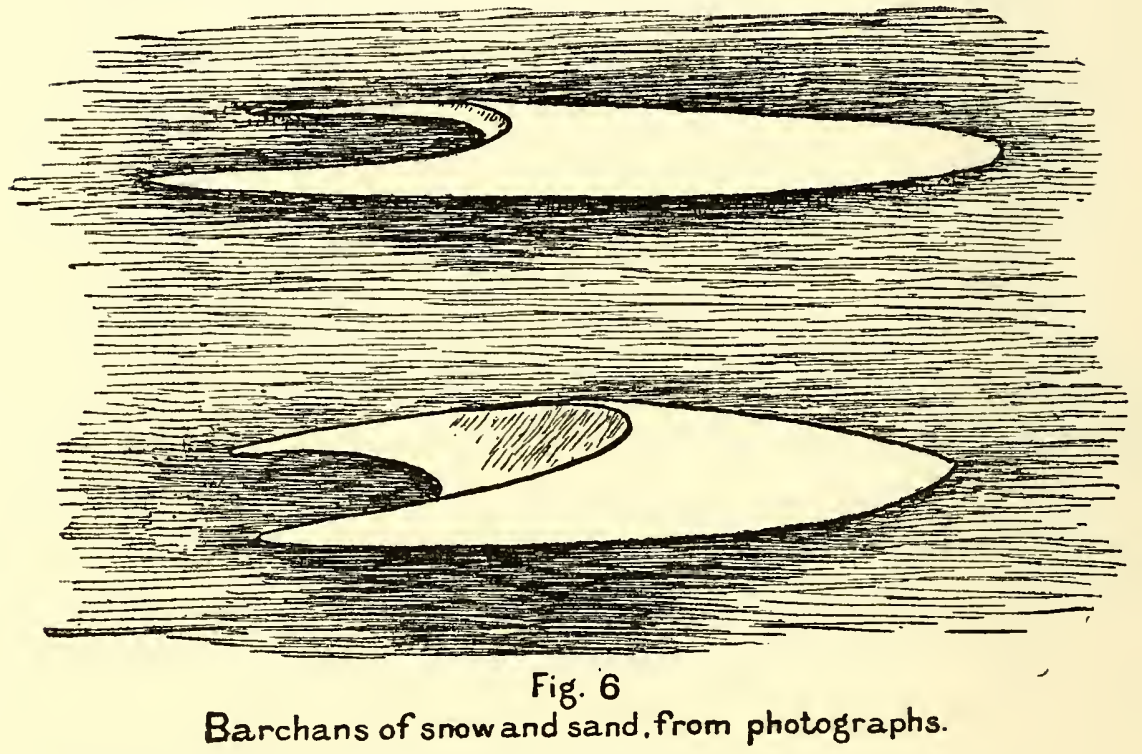

being both narrower and flatter (Fig. 6). I saw many hundreds of these structures which had been produced in ordinary fresh-fallen dry snow, but in the absence of any steep eminence to give me a good view-point I was unable to obtain a photograph showing how the prairie was dotted over with these structures. 


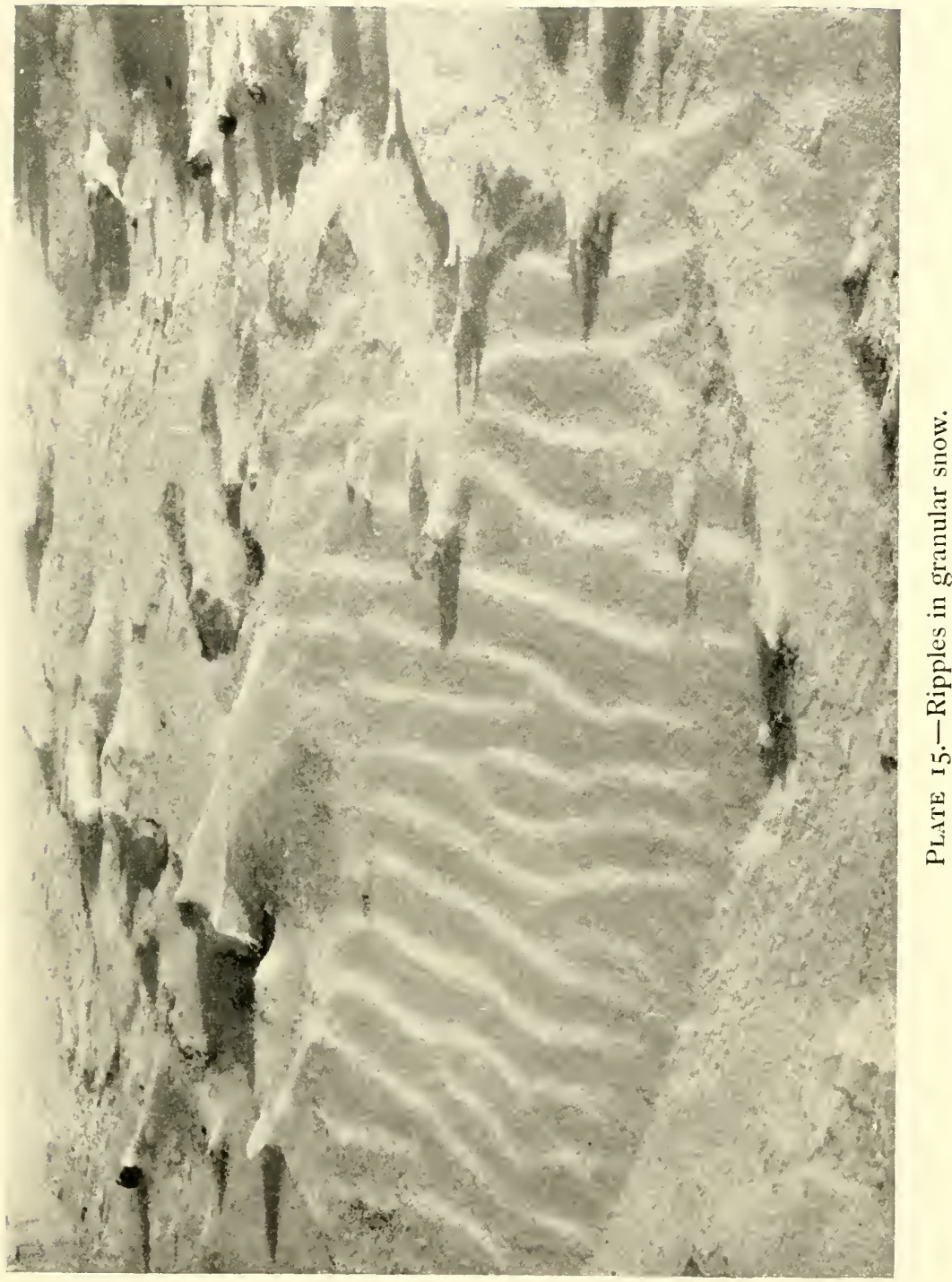





\section{SNOW-WAVES AND SNOW-RIPPLES 117}

They do not have a long life as travelling waves, for in the still nights their surface sets hard. It is the setting of the surface of the snow in exposed positions, which occurs without any melting and re-freezing, which prevents snow-waves growing, as sand-dunes grow, to large dimensions. Thus in weather when the temperature never rose to the melting-point, and when there was no sign of melting in the sun, I found that snow-waves which were formed on the prairie near Winnipeg on January

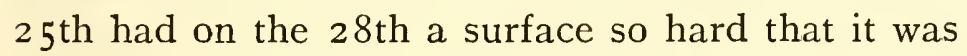
scarcely dented by the heel of my moccasined foot. I found that this resistance was due to a hard surface-layer $\frac{1}{8}$ inch thick. Pieces of this crust when broken off and held up to the sunlight were seen to be a mosaic of small, translucent, icy blocks cemented firmly by opaque ice. In copses near by the snow had no crust upon it. I suggest that the setting of the drifted snow upon the prairie is due to sublimation, ${ }^{\mathbf{I}}$ the lower layers evaporating under the action of the earth's heat, with direct condensation to the solid form in the pores of the surface, which is chilled by radiation. I may recall in this connection my observations

r That is to say, the transformation of a solid into a gas and re-condensation to the solid state without the intermediate formation of liquid. 


\section{WAVES OF SAND AND SNOW}

upon the formation of dew among desert sanddunes (see ante, p. 69), for I suppose the cementing matter of the hard-set snow to be, so to speak, solid dew.

Below the icy crust the snow in the snow-waves, though not hard, was dense, having a specific gravity of 04 , which was twice that of the snow in a copse near by, which was $0^{\circ} 2$. At Glacier House, in the Selkirk Mountains, where the atmosphere is calm and there is no drifting, the density of the snow at the surface was $O{ }^{\prime}$, at a depth of I foot 0.2 , and at a depth of 4 feet 0.354. Increased density of snow is due to removal of air from the interstices, and the above figures show, not only that the minute snowflakes which fall in the dry climate of Manitoba in midwinter pack tighter than the large flakes which fall in the Selkirk Mountains, but also that the wind, in turning over the material, gives it an additional compactness greater than that imparted by the pressure of a superincumbent layer of about 3 feet in thickness.

Ripples in Granular Snow or "Snow-sand."

The loose particles of waves of fresh-fallen dry snow remain unrippled, the surface of these waves 

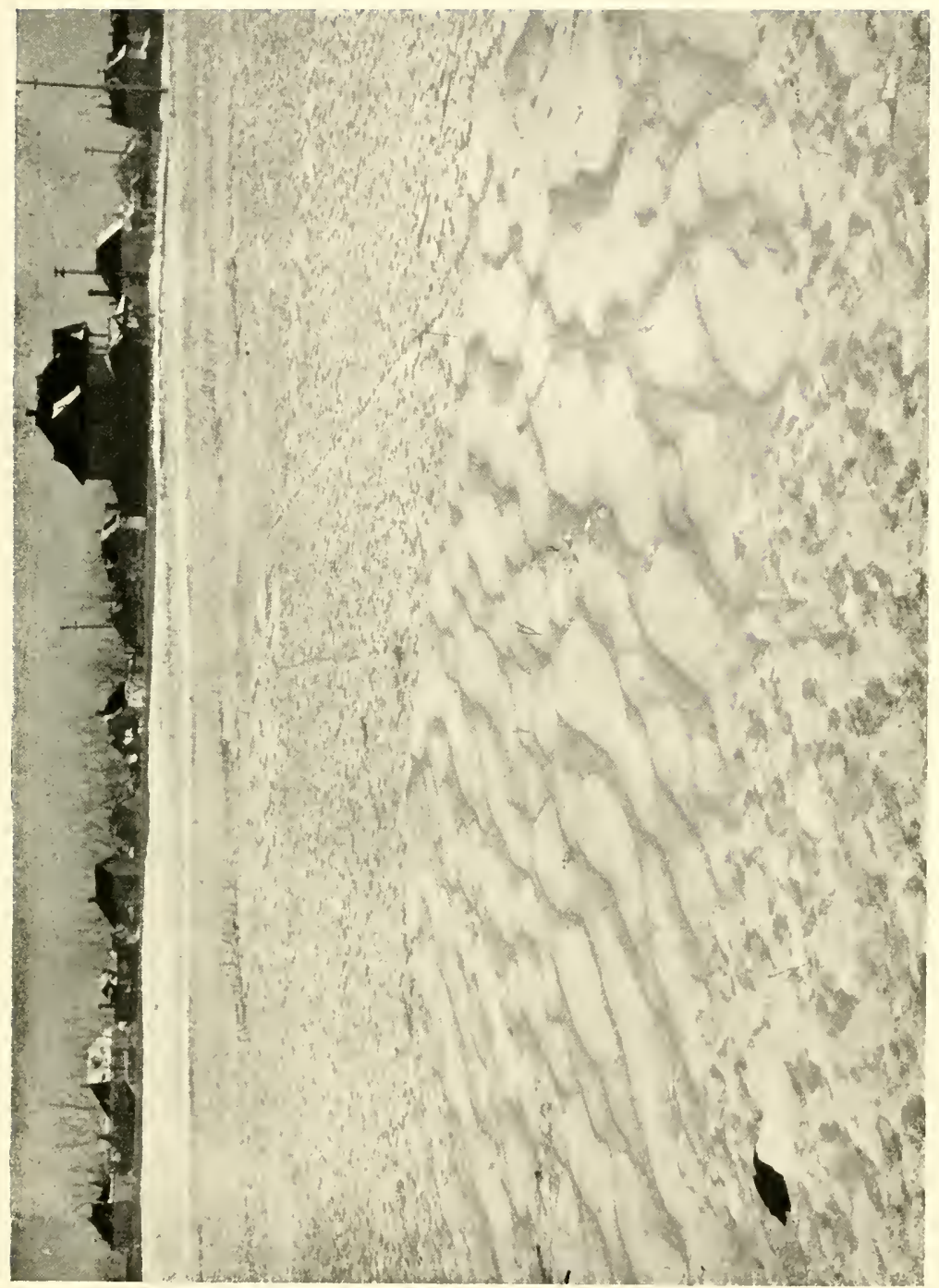

क
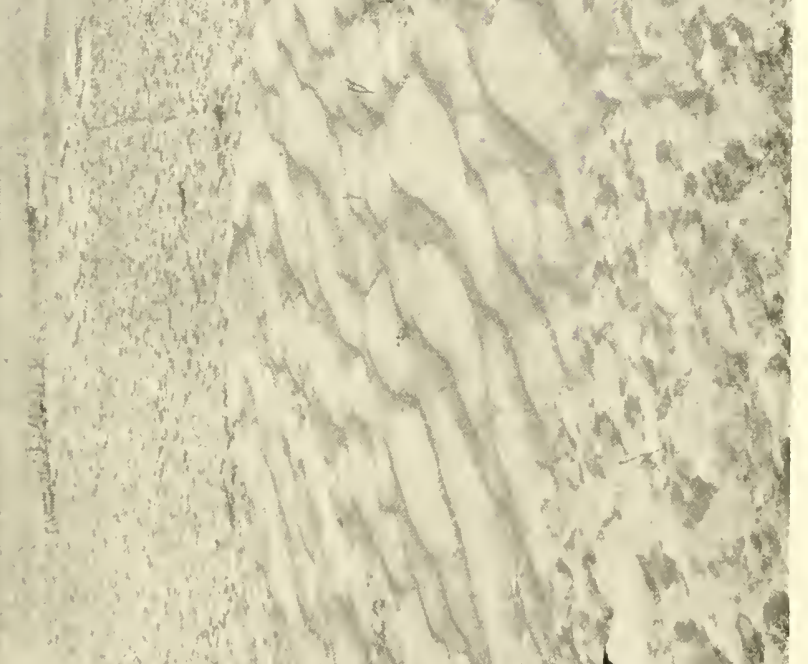

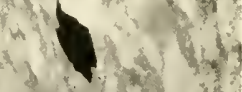

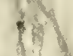

$x^{2}+y^{3}$ 



\section{SNOW-WAVES AND SNOW-RIPPLES 121}

being smooth except where transverse grooves are cut in the partially consolidated material which is exposed during the turning over of the wave. In this respect waves of snow differ from those of sand, for the resistance of the larger sand-grains produces rippling on the surface of the sandwaves.

On the prairie around Winnipeg, however, there lay during January and February a good deal of altered snow, composed of rounded icy grains, which varied in size from $\frac{1}{32}$ inch to $\frac{1}{7}$ inch in diameter, the former being the size of somewhat coarse sand, the latter of the "lag gravel," which is rolled along by wind but not ordinarily thrown into suspension. This snow-sand, as I shall call it, fell into ripples of great regularity, much resembling those in sand. I lingered on at Winnipeg in the hope of observing the formation of this snow-sand, but was unable to do so. It is, however, certain that it is sometimes produced by the breaking up of the ice formed by re-freezing of melted snow. The doubtful point is whether there is any other way in which it is produced. Snow merely consolidated by pressure did not ripple. I watched the action of wind upon the material when it was composed of fairly spherical particles $\frac{1}{64}$ inch in diameter-i.e., of the 
size of fine sand-but these particles were too friable to maintain themselves intact as projections upon the surface.

The almost icy crust formed during the night upon the surface of the snow-waves would, I think, when broken up form snow-sand capable of rippling, and I have explained how this might perhaps be produced without melting and refreezing.

On the afternoon of January $25^{\text {th }}$ on the prairie near Winnipeg much of the snow-sand was drifting low over the hard, unlevel surface of the old snow, never rising more than a few inches above the ground. The temperature was about zero Fahrenheit, and the wind had a velocity of 27 miles an hour-i.e., that of a strong breeze. The low sun, casting shadows from the steeper lee faces, threw the ripples into relief. The drifting snow-sand accumulated in the shallow depressions in the surface of the old, hardened snow. These deposits quickly fell into ripples. The increase of their wave-length was more rapid than that of aeolian sand-ripples, and their motion was also more rapid. In one of these patches of snow-sand, ripples having a wave-length of 9 inches advanced that distance in 1 minute 50 seconds-i.e., at the rate of 4.9 inches per 


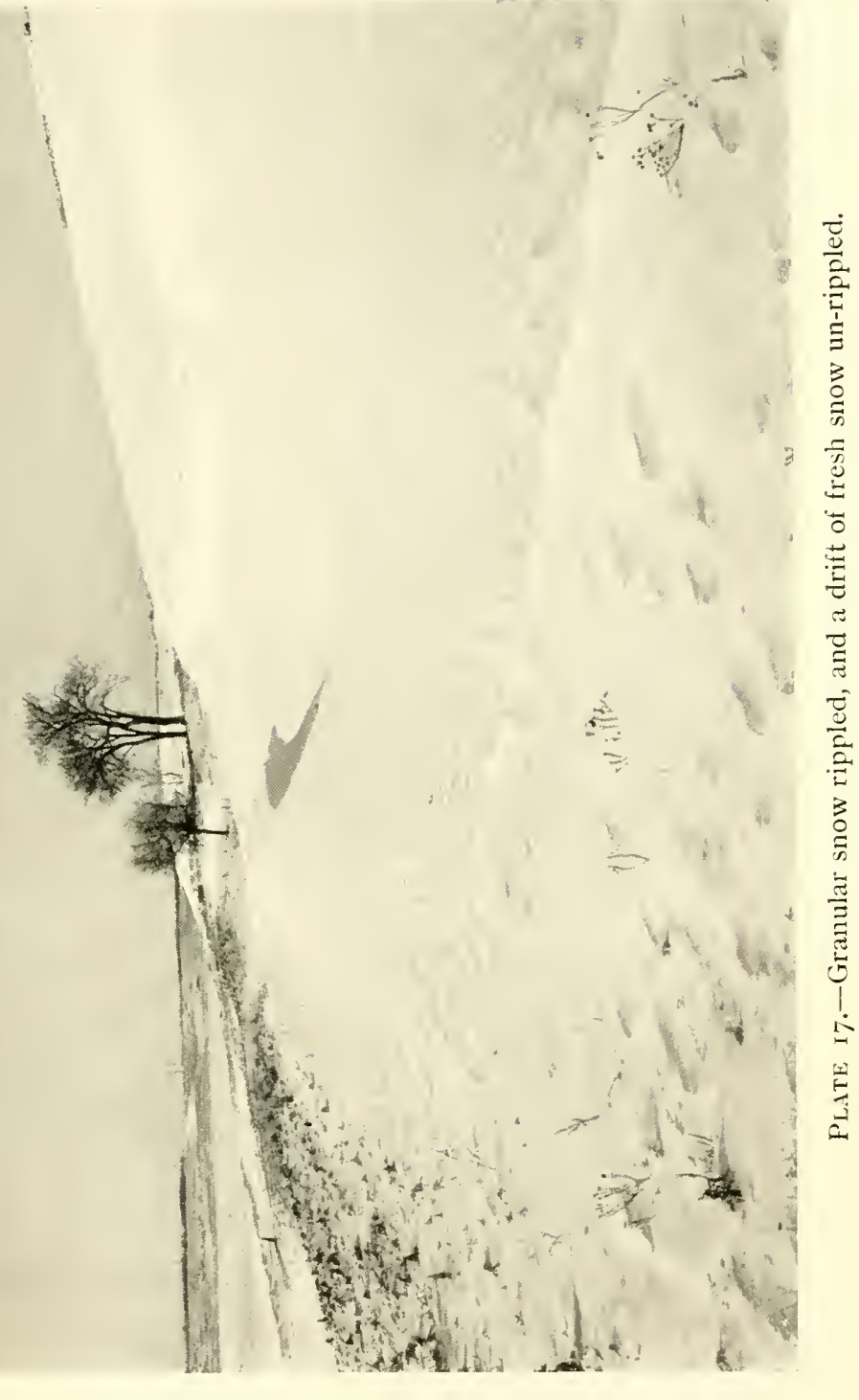





\section{SNOW-WAVES AND SNOW-RIPPLES 125}

minute, whereas the aeolian sand-ripples of the same wave-length which I observed in 1896 travelled under the action of a wind of the same strength at the rate of 0.5 inch per minute.

For a time all the ripples in the above-mentioned patch of sand-snow grew pari passu, each ripple of the group having approximately the same length and height, but after a time this state of affairs suddenly changed, the rear ridge-that is, the one most to windward-beginning to increase in height very quickly. I think the change began as soon as the patch of drifted snow-sand rose above the level of the surrounding hard surface. When the windward ridge raised its crest above the others I saw that the wind eddied in its lee, and observed that some of the snow-sand in the centre of the patch was travelling backwards towards the weather ridge. The other ripples, hitherto so sharply defined in the low sunlight, became indistinct and were soon quite obliterated, except in two very small areas on the sides of the drift at its lee end. The patch of snow-sand had now become crescentic, a space in the middle having been swept bare by the return current. It had become, in fact, a crescentic snow-wave or snow-barchan, and the small areas where rippling remained were the tips of the horns or cusps. At first the profile 


\section{WAVES OF SAND AND SNOW}

of the barchan differed from that shown in the preceding illustrations, the summit being near the weather end ; but the position of the summit shifted to leeward until there was a long, gentle weather slope and a short lee cliff. By this time erosiongrooves began to appear at the weather end, showing that the patch of snow-sand, or rather so much of it as was not required to fill up the depression in the old, hard surface, was now travelling forward (Figs. 7, 8, and 9).

The best measurements which I obtained of ripples in snow-sand were those of the group shown in Plate XV., which were taken after the wind had ceased. They are as follows:-

\begin{tabular}{c|c|c|c}
\hline No. of Ripple. & Length. & Height. & Length. \\
\cline { 2 - 3 } I & Inches. & Inches. & Height. \\
2 & $2 \cdot 625$ & 0.09375 & 28 \\
3 & $2 \cdot 625$ & $0 \cdot 09375$ & 28 \\
4 & $2 \cdot 562$ & $0 \cdot 09375$ & 273 \\
5 & $2 \cdot 344$ & $0 \cdot 09375$ & 25 \\
6 & $2 \cdot 062$ & $0 \cdot 0625$ & 33 \\
& $2 \cdot 000$ & $0 \cdot 0625$ & 32 \\
\hline
\end{tabular}

The ripples of this group, which diminish slightly in size from windward to leeward, covered a patch of snow-sand which had filled a depression in the surface of the old, hard snow. 


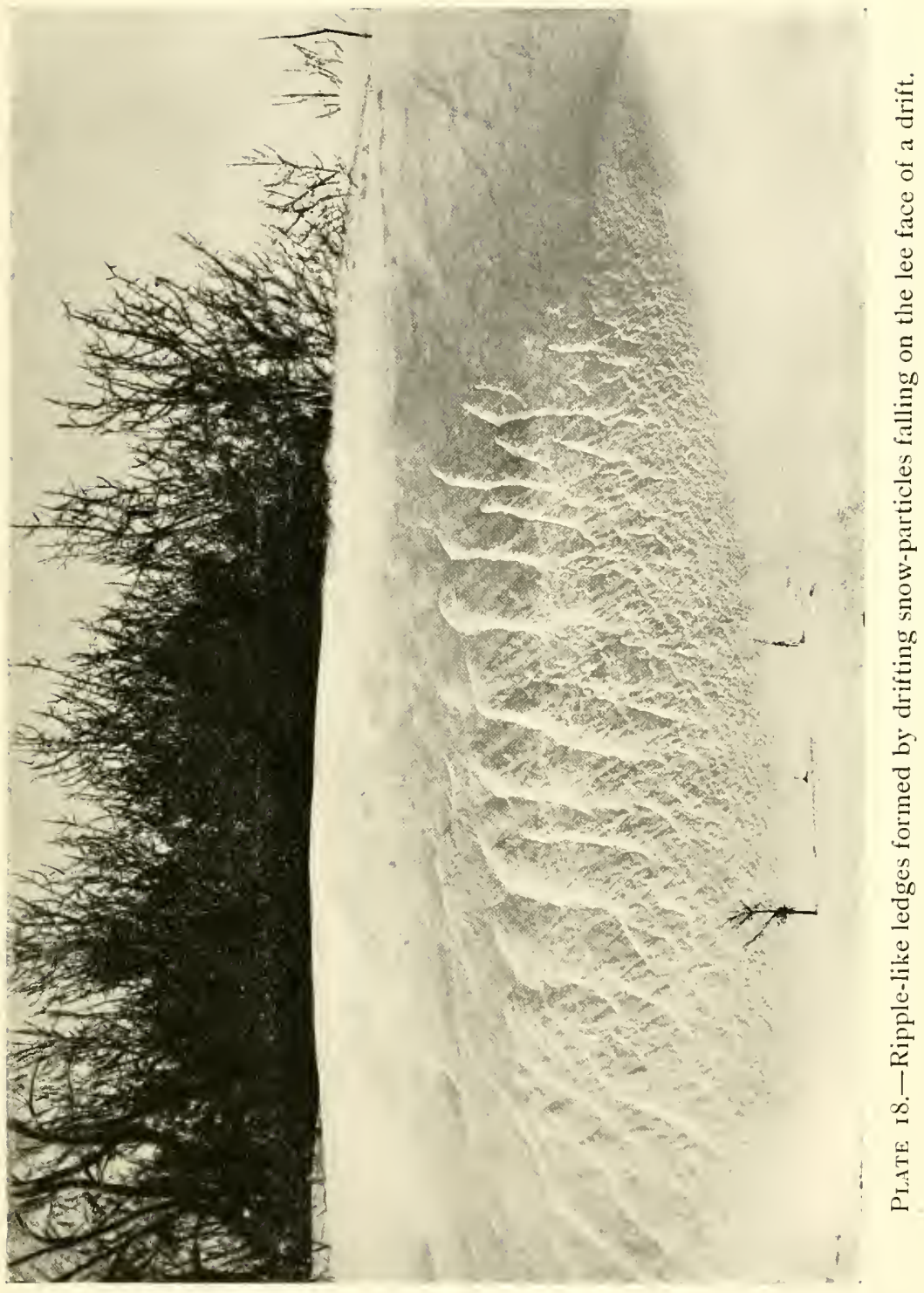





\section{SNOW-WAVES AND SNOW-RIPPLES 129}

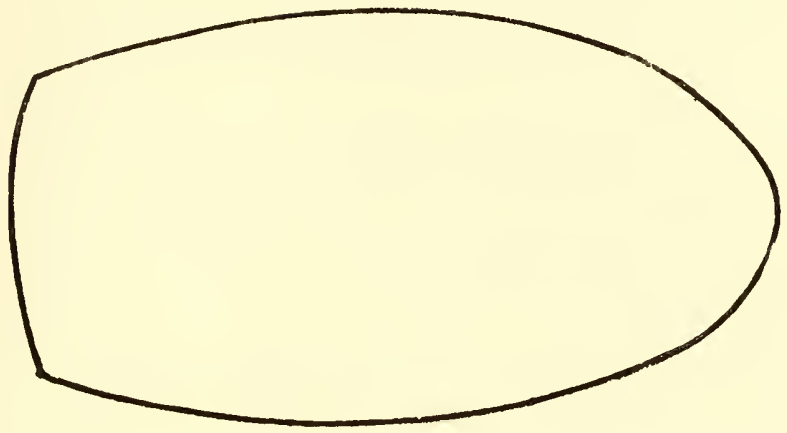

Fig. 7

A patch of rippled snow. plan. wind from the right hand.

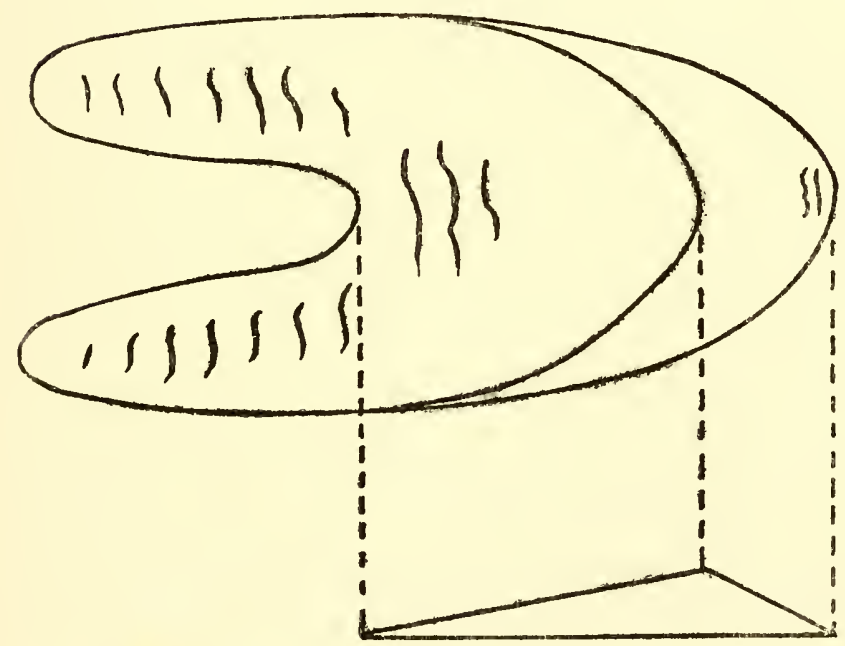

Fig. 8

Conversion of above to a Barchan,early staga. 
The forms Produced by Wind-erosion in Compact Snow.

On the prairie near Winnipeg I measured series of the transverse ridges which are formed when wind is removing the upper layers of consolidated snow. They are minutely grooved, or rippled,

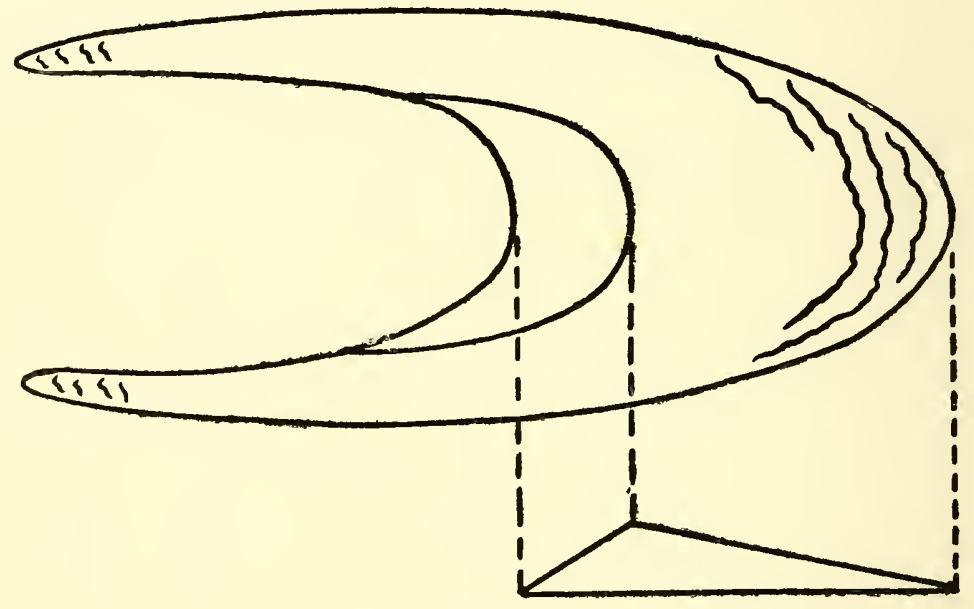

Fig. 9

The same at a later stage

owing to their stratification. Inasmuch as they recede before the wind, preserving their relative positions, they may be considered to be a group of surface waves, but the movement is due solely to a difference in the quantity of the material removed from the two faces, there being no 


$$
1
$$





\section{SNOW-WAVES AND SNOW-RIPPLES 133}

adhesion of the drifted particles to the windward cliffs and no accumulation of them on the lee side, where there is but little shelter. Six transverse erosion-ridges had an average wave-length of I 3.75 inches, the wave-length being twenty times the height. The average variation of wave-length from one ridge to the next was $2 \mathrm{I}^{\circ} 5$ per cent. In another case a single erosion-wave was measured across seven sections, giving an average wavelength of 12.95 inches, which was I 5.62 times as great as the height.

Four erosion-waves in unstratified snow on the smooth ice of the Assiniboine River had an average wave-length of 23.7 inches, which was 19.2 times as great as their height.

In the following series, of which a diagram is given showing the stratification (Fig. IO), the length and height of each wave was measured:-

Measurements of a Group of Erosion-waves in Compact SNow.

\begin{tabular}{|c|c|c|}
\hline Wave Length. & Height. & $\frac{\text { Length. }}{\text { Height. }}$ \\
\hline $\begin{array}{c}\text { Inches. } \\
29^{\circ} 750 \\
21 \cdot 625 \\
32 \cdot 125 \\
29^{\circ} 500 \\
31 \cdot 625\end{array}$ & $\begin{array}{l}\text { Inches. } \\
I \cdot 875 \\
I \cdot 750 \\
I \cdot 750 \\
I \cdot 375 \\
I \cdot 250\end{array}$ & $\begin{array}{l}\text { Height. } \\
\text { I5.87 } \\
\text { I } 2 \cdot 36 \\
\text { I } 8 \cdot 36 \\
21 \cdot 45 \\
25^{\circ} 3^{\circ}\end{array}$ \\
\hline
\end{tabular}

Average variation of wave-length $=20 \cdot 2$ per cent. 


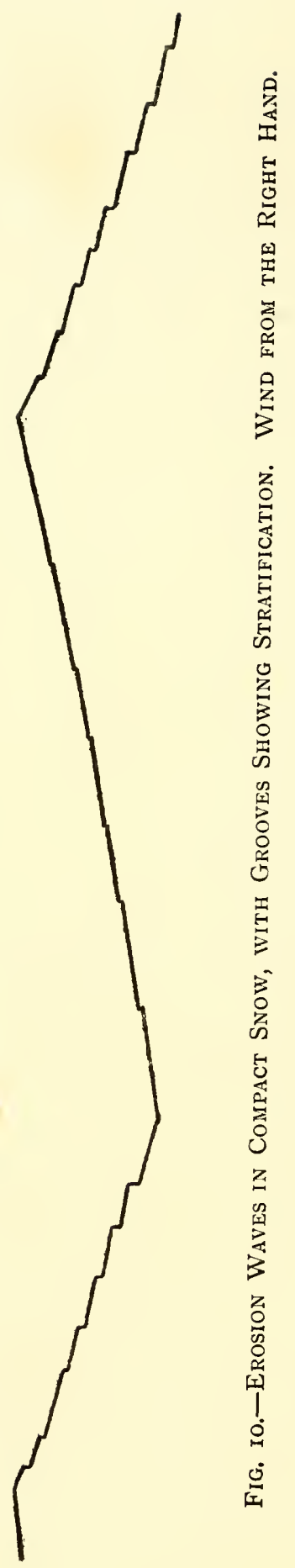




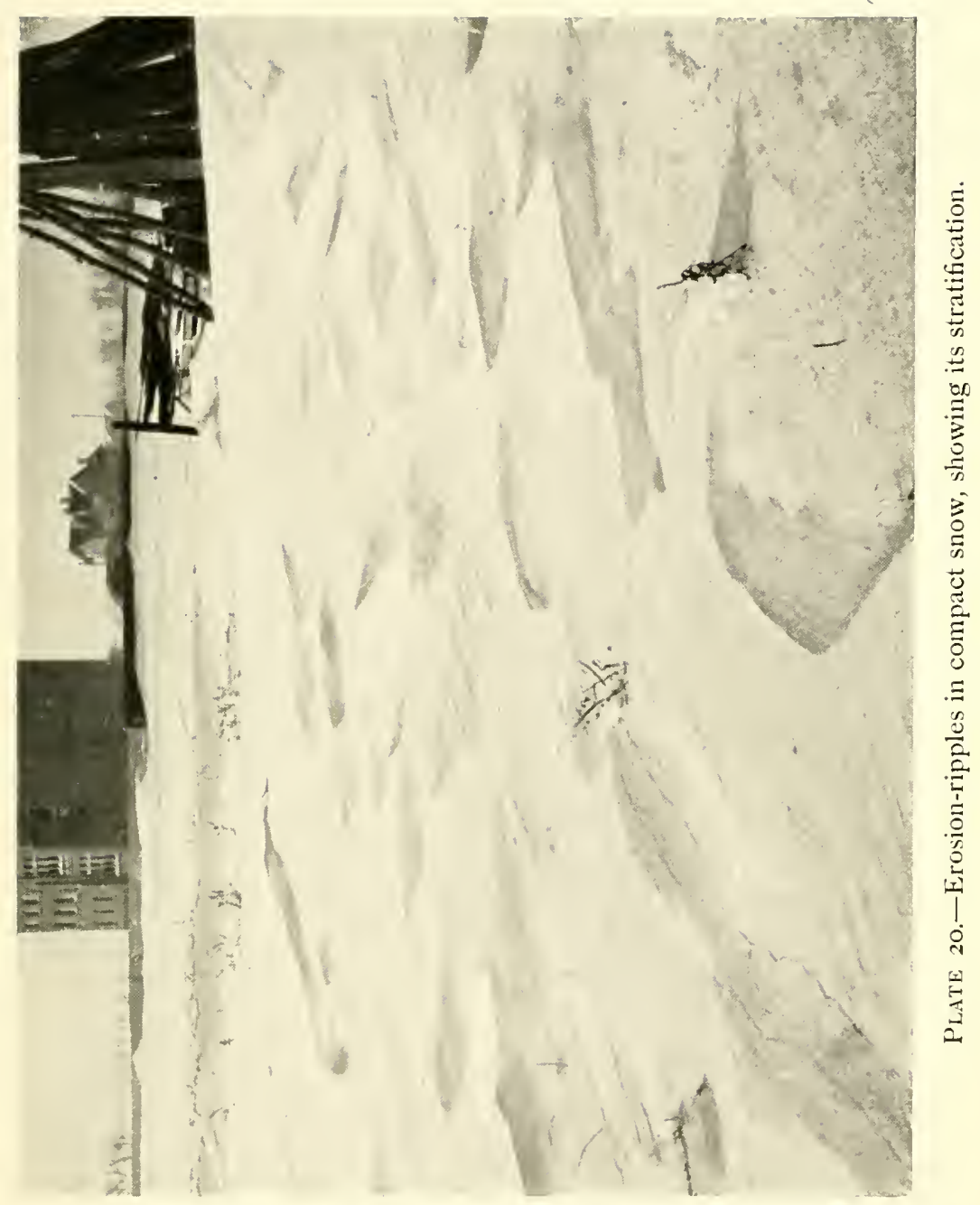





\section{SNOW-WAVES AND SNOW-RIPPLES 137}

The four groups of erosion-waves referred to above have an average proportion of length to height of $\mathrm{I} 8.225$; i.e., their steepness is equal to that of waves in loose sand but less than that of the large ripples produced when the wind cuts down into slightly coherent sand.

The erosion-waves in compact snow are, as I stated when describing my observations in Scotland, an initial form which is finally replaced by longitudinal ridges having a similar profile. During the intermediate stage it sometimes happens that the depressions and not the elevations of the eroded surface are the most noticeable forms. Sometimes these depressions are pits, roughly elliptical in plan, and of which the profile has one long and gentle and one short and steep slope. They have therefore a resemblance to the pits which I described in the loose sand at Helwan, but in the erosion form the steep cliff faces the wind. I have not been able to make out from the accounts of travellers whether the sides of the fuljes, or pits, in the sand of the Arabian Nefud are invariably composed of loose sand or whether it is sometimes "set" and compacted. In either case the profile due to wind action would have the two characteristic slopes, one long and gentle, one short and steep, but whereas pits left among accumula- 


\section{WAVES OF SAND AND SNOW}

tions of loose sand would have their steep face turned away from the wind, pits excavated in cohering sand would have their steep side facing the wind.

The last erosion form in snow to which I need refer was an uncommon one of crescentic shape, of which I give a drawing for the purpose of comparison with the form of the crescentic waves, or barchans, in loose snow (Fig. I I). The cliff faces the wind instead of being turned away from it, and the gently sloping side is concave, instead of convex, towards the sky.

Note on the Longitudinal Sand-dunes of the Great Indian Desert.

I deal in this book almost entirely with what I have myself observed in the field, but the following paragraph relates to sand-dunes which I have not seen but which have been elaborately mapped and mineralogically examined.

The prevailing winds in the region of the Great Indian Desert are south-west and north-east, of which the south-west is the stronger. Far inland the dunes are transverse to this common direction and face north-east. Near the sea they consist of very long ridges with equally steep slopes on either side and trend from south-west to north-east. At 


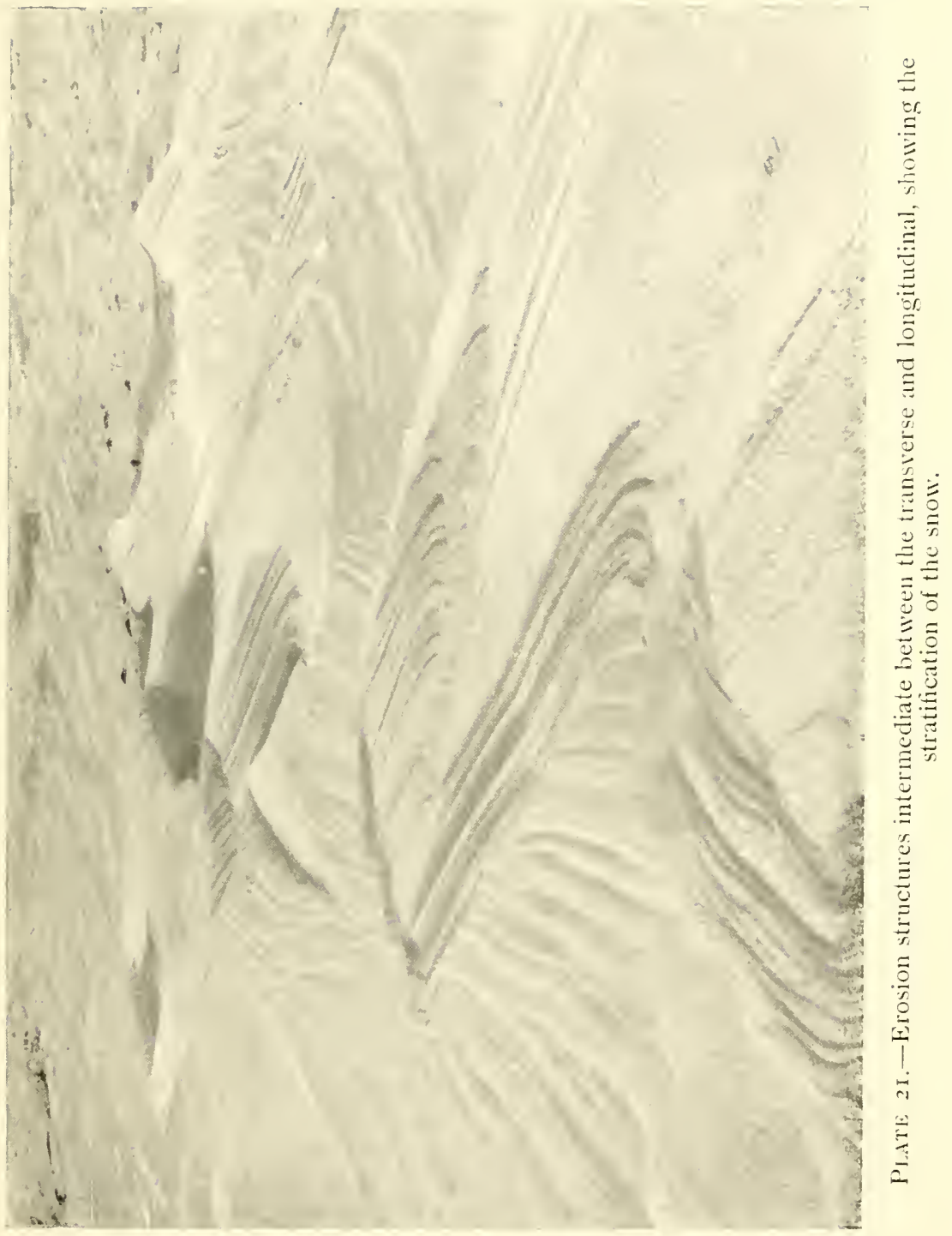





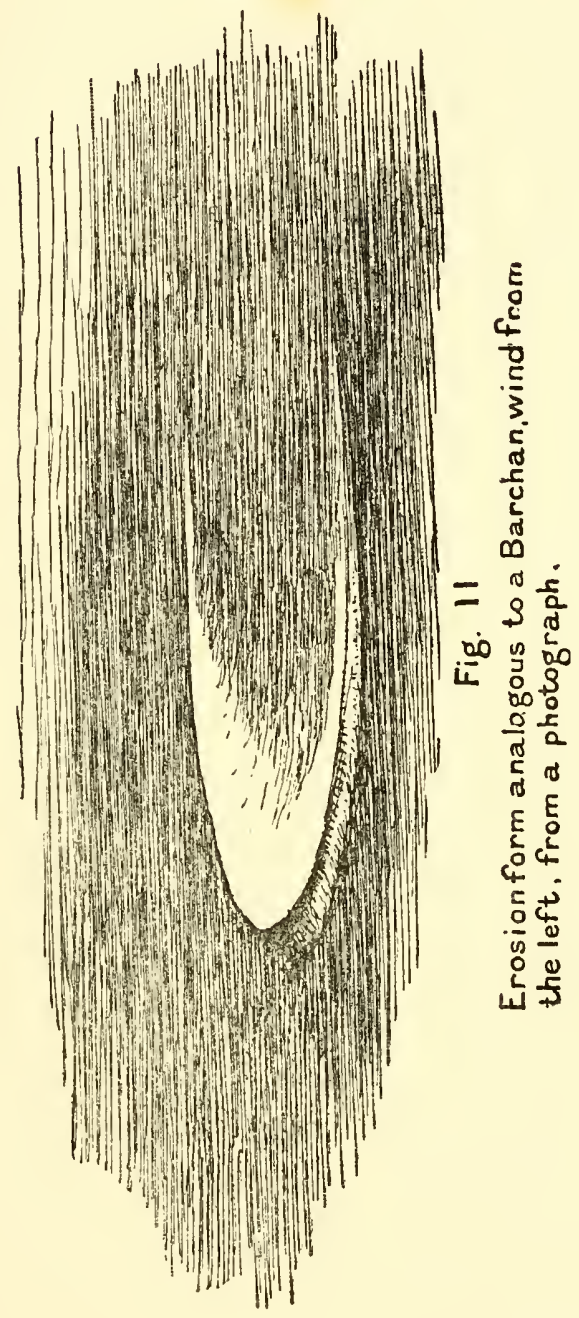


intermediate positions they have an intermediate form, consisting of ridges transverse to the wind with the weather slopes longitudinally furrowed. There are minute shells of foraminiferce, composed of carbonate of lime, in the sand of these dunes. The source of the foraminiferce is the sand blown in from the sea-shore. The percentage of carbonate of lime in the sand decreases with the distance from the sea.

My theory of the origin of the longitudinal ridges, some miles in length, which occur near the sea is as follows: viz., that when the sand was loose it was laid down in transverse ridges; that the presence of a large quantity of minute grains of carbonate of lime caused the sand to consolidate or set under the action of moisture; that the wind then cut through the dunes, forming longitudinal ridges; and that the sand removed from the surface of the dunes collected from right and left under the lee of these residual ridges and finally united in sequence the longitudinal ridges carved out of successive sand-dunes. The gradual change in habit from longitudinal to grooved and ultimately to transverse dunes in proceeding inland I attribute to the recorded diminution in the percentage of carbonate of lime. I intended to have tested this explanation on the spot, but have been 


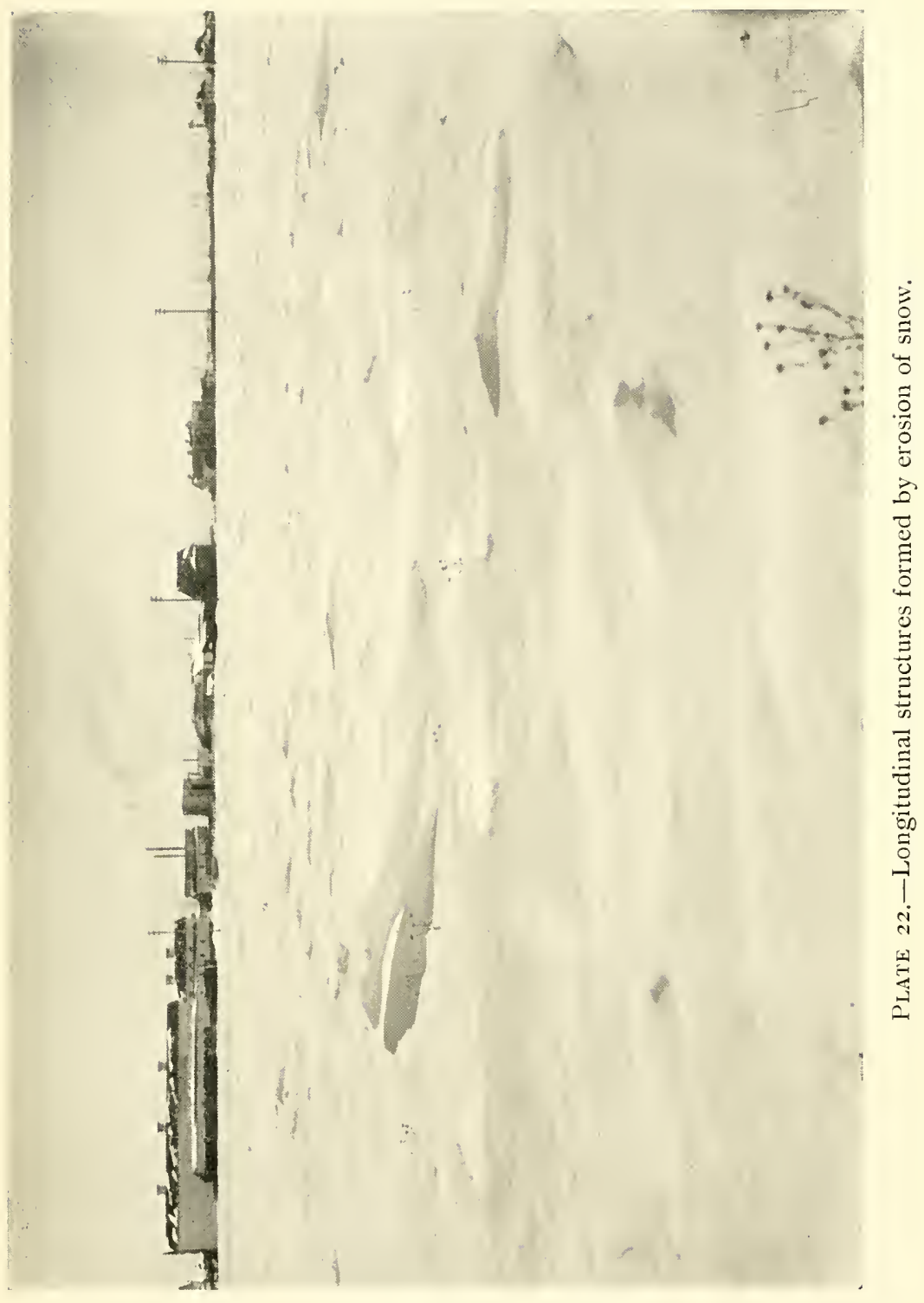






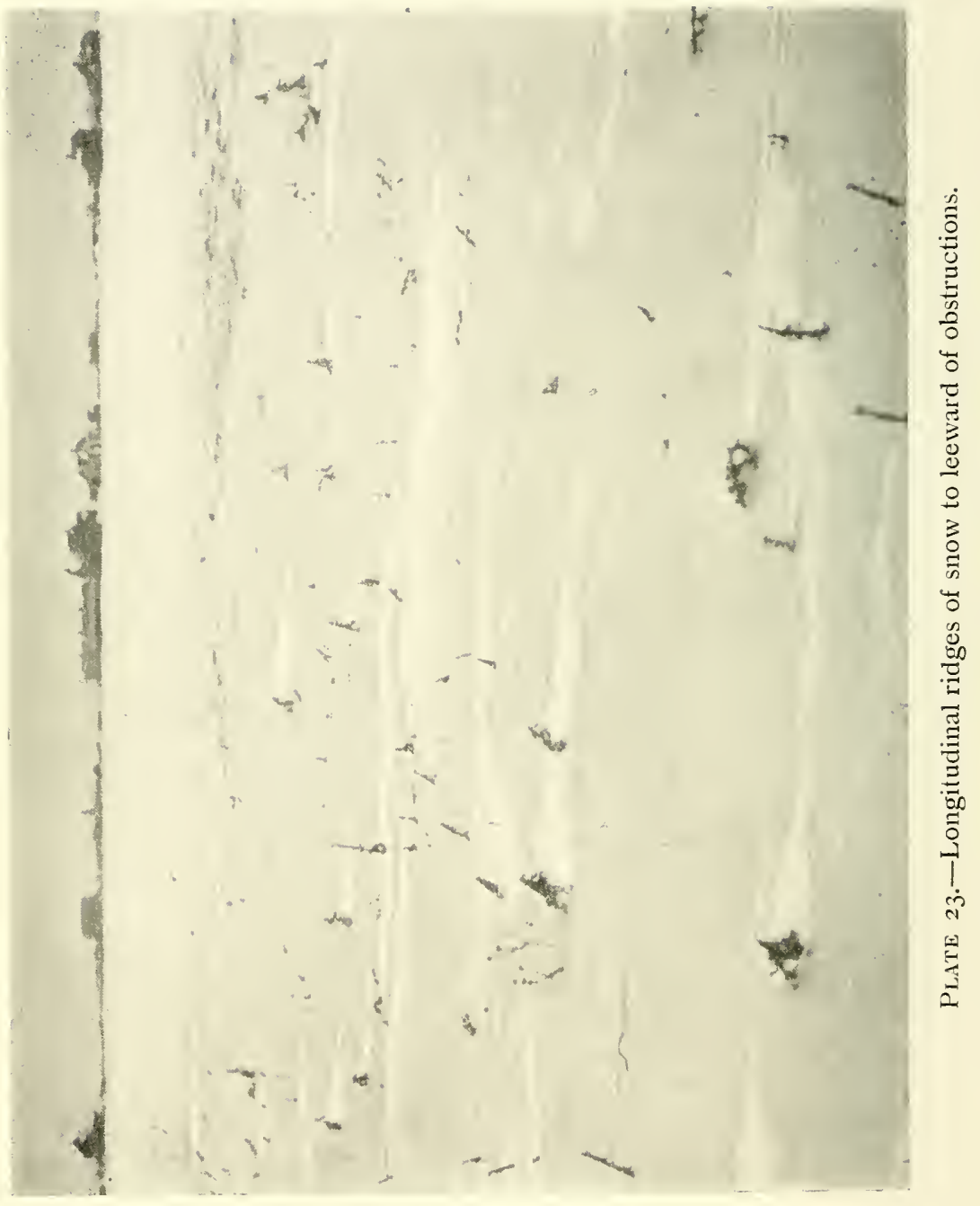


unable to do so, and I hope that some one resident in the neighbourhood will see if the explanation of their origin as due to setting produced by carbonate of lime will stand the test of a detailed examination in the field. ${ }^{\prime}$

\section{The Eddy Form of Snow-waves and Snowdrifts.2}

On the lee of quickset hedges, of post and rails, and of hurdle-fences snow accumulates in drifts or banks. I examined many of these drifts near Montreal in December, near Winnipeg in January and February, and again in Montreal in February and March. In the early part of the winter at Montreal they had the form which is most familiar in such accumulations, the profile being somewhat similar to that of a water-wave about to break, a moderately steep weather slope, with a diminishing gradient near the summit, succeeded " See Geographical Fournal, April, 1908, "On the Observation of Desert Sand-dunes," by Vaughan Cornish.

2 "In the range of inorganic nature I doubt if any object can be found more perfectly beautiful than a fresh, deep snowdrift, seen under warm light. Its curves are of inconceivable perfection and changefulness; its surface and transparency alike exquisite; the light and shade of inexhaustible variety and inimitable finish; the shadows sharp, pale, and of heavenly colour; the reflected light intense and multitudinous, and mingled with the sweet occurrences of transmitted light" (Ruskin, "Frondes Agrestes"). 


\section{WAVES OF SAND AND SNOW}

by the sharp edge of a cliff or, in damper snow, an overhanging cornice with a steep and hollowed lee side. As the winter wore on more snow accumulated in the shelter of the fence. The bank apparently soon attained its full height, its subse-

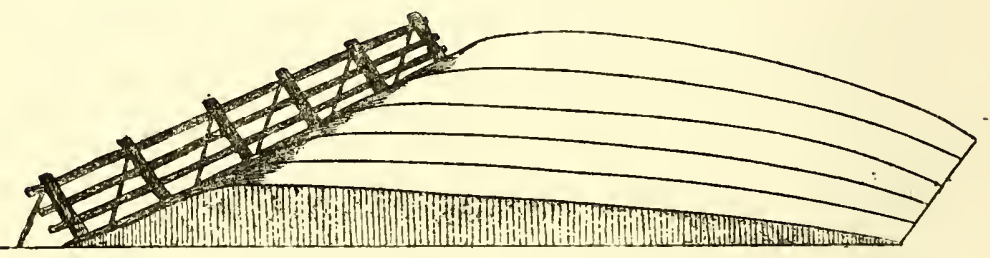

Fig. i2.-Fence and completed Snow Drift.

quent growth being by extension to leeward. The cliff edge was, however, no longer at or near the summit of the bank, and its height progressively diminished as the bank extended to leeward. In its final form the bank merged with gentle slope

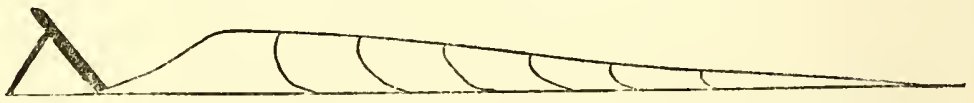

Fig. I3.-Stages of Growth of Snow Drift formed by a Fence.

to leeward in the general level of the surrounding snow surface, there being no lee cliff (Figs. I 2, I 3, and I 4). This completed drift, though containing more snow, was a much less conspicuous object than the cusped bank produced after the first snowfalls. In our own country, where snow 


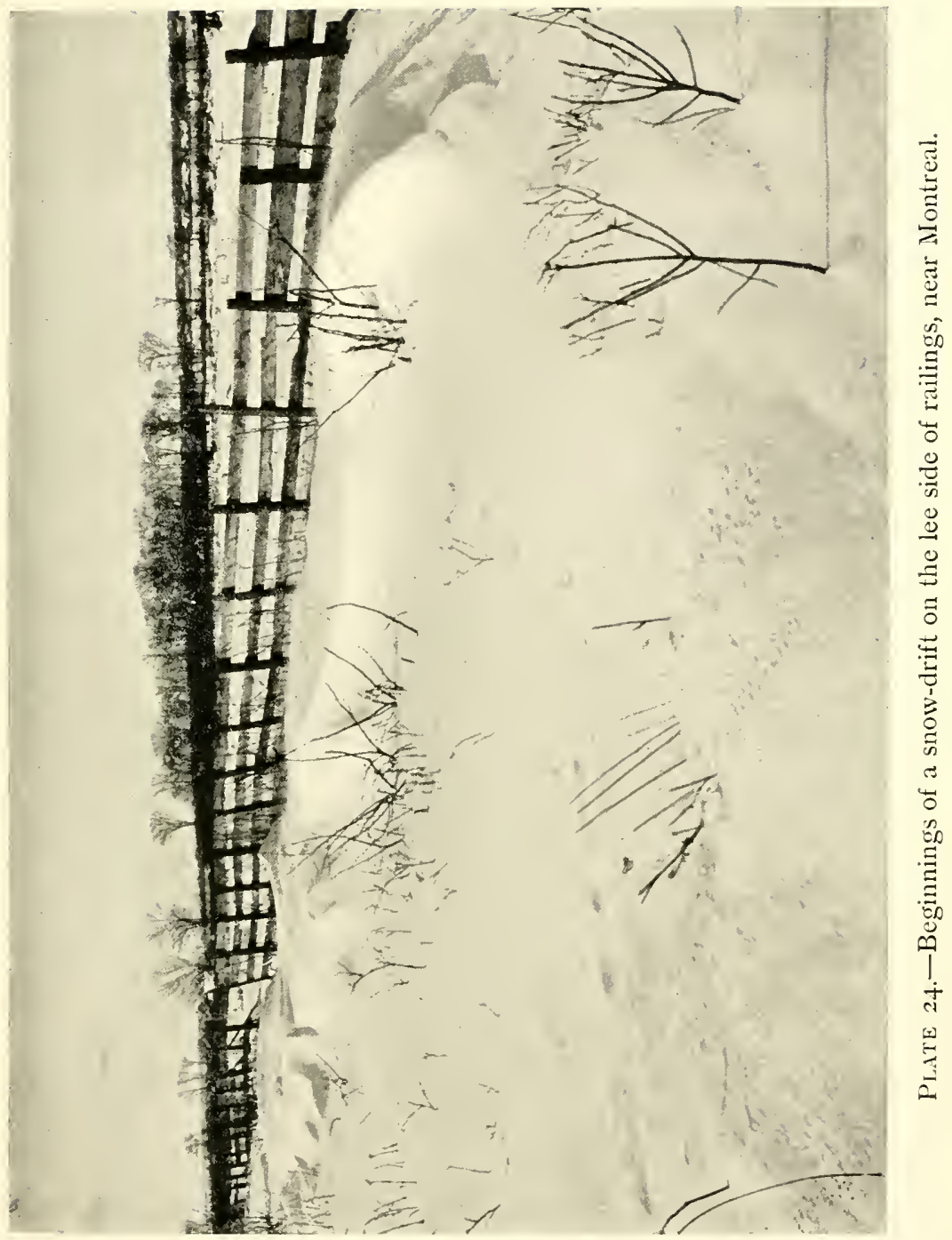






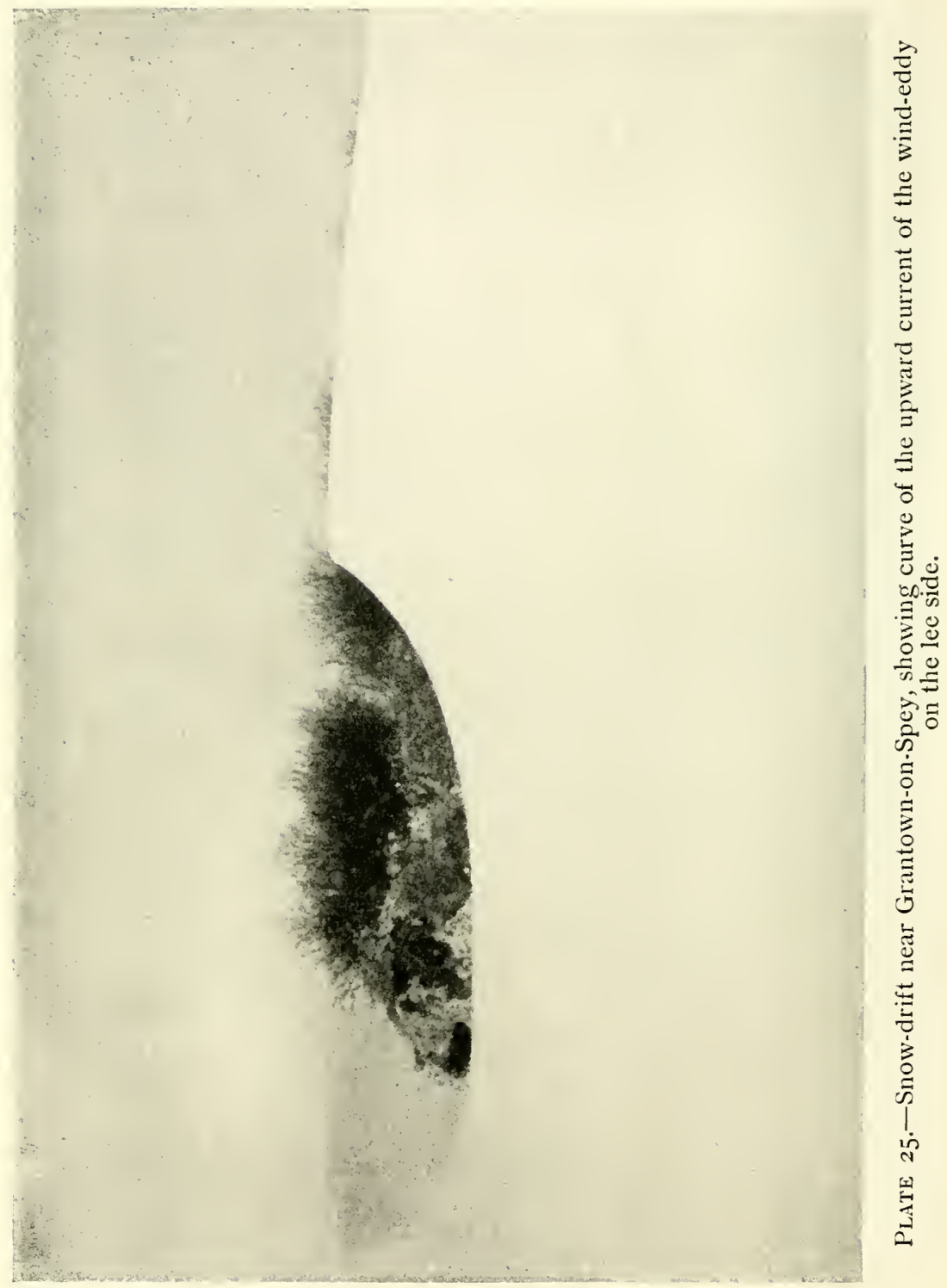




\section{SNOW-WAVES AND SNOW-RIPPLES 153}

does not lie continuously throughout the winter, it must be rarely that the drift on the lee side of any large obstruction attains completion, the amount of drifted snow not being as a rule sufficient to fill the whole of the eddy-space, and in all countries it is the incomplete snowdrift, with its overhanging cornice, which attracts attention. Thus it was not until near the end of my winter in Canada that I learnt what was the completed form of a stationary snowdrift.

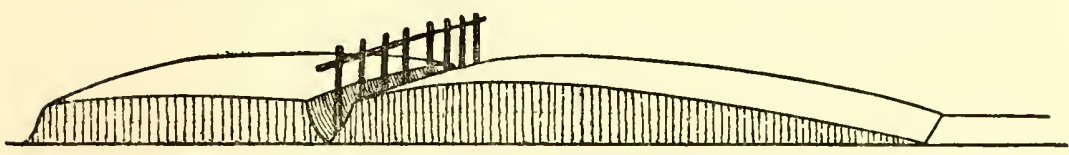

Fig 14

Snow drift on both sides of a fence, on the right completed. on the left incomplete. from a photograph.

I drew the profile from my observations of drifts on the lee of fences. I drew the plan, profile, and cross-section of drifts caused by houses and smaller buildings. I also drew the plan, profile, and cross-section of the hollows kept open by wind round tree-trunks in the loose snow of the woods near Montreal. I also drew the profiles of transverse travelling snow-waves, and the plan, profile, and cross-section of the travelling crescentic snowwaves, or snow-barchans. I was satisfied that there was one kind of curve, which had a blunt 


\section{WAVES OF SAND AND SNOW}

and a fine end, which was a containing, or boundary, curve for all these structures, but that for the stationary structures the curve had its blunt end to windward and for the travelling drifts or waves to leeward, at least as far as their vertical profile was concerned (Fig. I 5).

The stationary drifts, when complete, filled the whole curve. The travelling drifts or waves occupied only part of it. I was at first satisfied by the mere fact that $I$ had recognized unity of form among the fantastic shapes assumed by snowdrifts

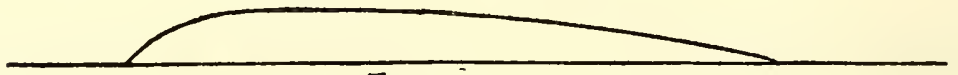

Fig. 15

The fundamental curve of snow drifts.

at various stages of their growth in the neighbourhood of obstructions of diverse kinds, but I presently realized that the general curve which I had drawn so as to satisfy my eye had a wide significance, that it was one familiar in other aspects of nature than snowdrifts-that it was, in fact, the containing curve of eddies. The recognition of this fact made it much easier to understand the mode of formation and the movements of the structures I had been examining in both sand and snow, particularly when extending their study to three dimensions and not dealing merely 


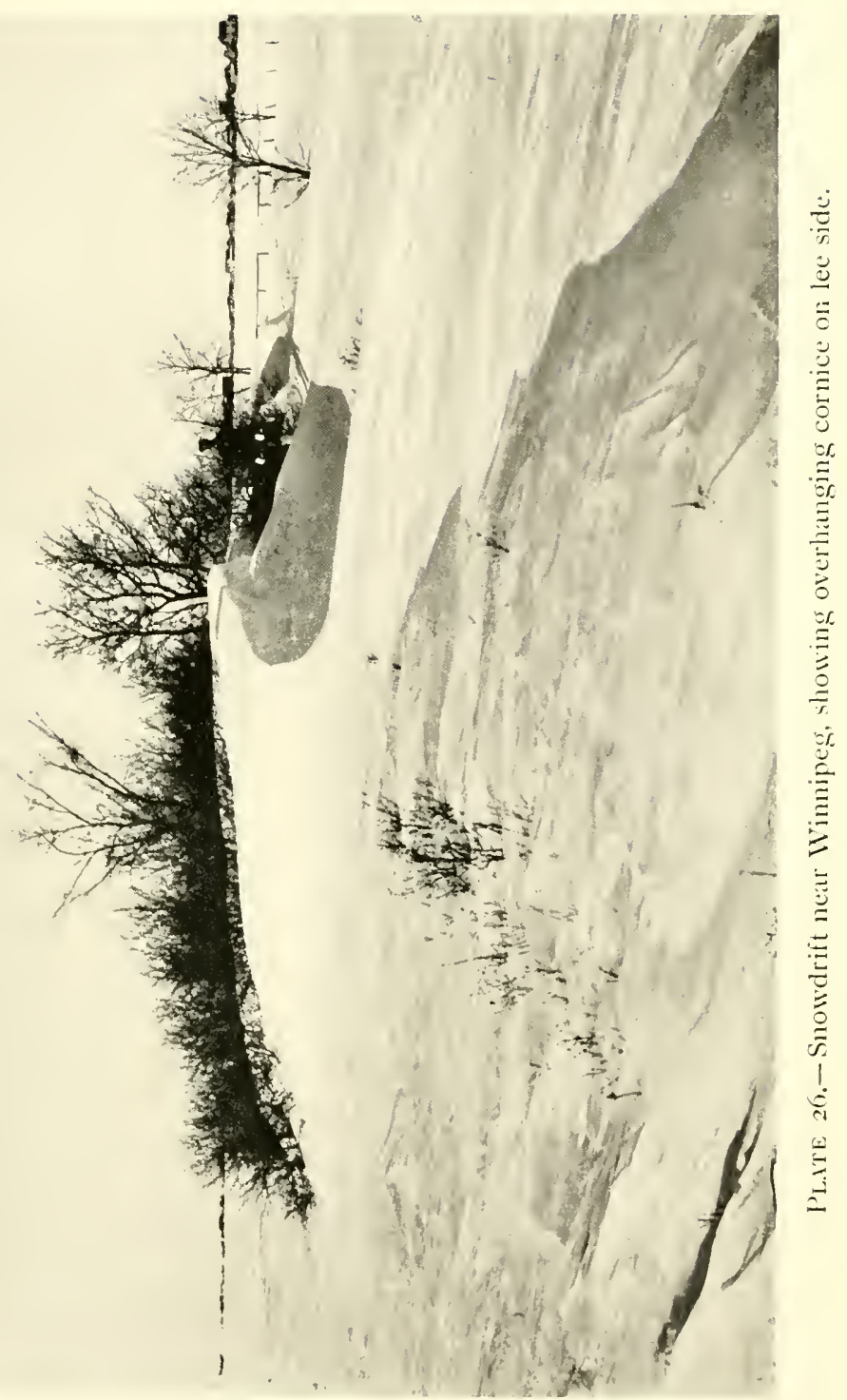

155 

with the profile, which is all that is generally studied in waves.

The general form of an eddy can be observed by fixing a board in a vertical position athwart a stream, the board being just submerged. The containing curve of the eddy is then easily traced by the disturbance on the surface of the water. There is seen to be eddying disturbance for a short distance up-stream; its margin passes close to the edge of the board in a direction slightly inclined outwards, the greatest width of the eddycurve being a little to leeward of the obstruction. From this position the border of the eddy closes in very gradually, so that the tail of the disturbance is situated far to leeward of the obstruction. The distance from the shoulder, or position of greatest width, to the tail is several times greater than that from the commencement of eddying on the weather side to the shoulder. The outline as one looks down upon the surface of the water is similar to that of fish as we see them from above lying head up-stream. The eddy-curve (on which, as I shall endeavour to show, sanddunes, snow-waves, and snowdrifts are moulded) is the boundary-line on either side of the axis of the eddy, the curve being precisely repeated, as in a reflection, by the other side. When I refer 
to the eddy-curve I mean therefore only one-half of the curve which encloses the area where the surface of the water shows eddying disturbance. If we suppose the eddy-curve to be rotated about its longer axis, it would trace out a cigar-shaped form, which is that which, after much experiment, was adopted for torpedoes. At first these were driven with their sharp end foremost, although

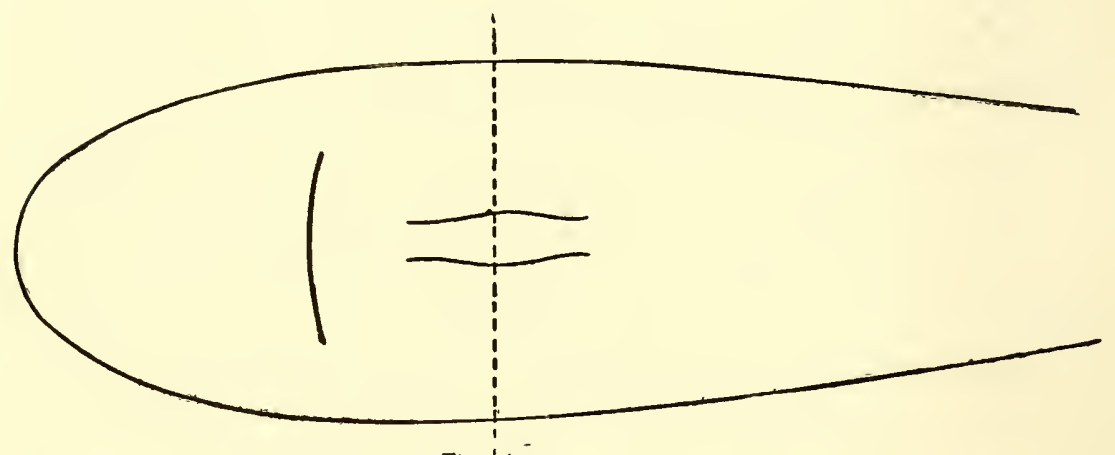

Fig. i 16

Plan of gnow drift caused by clump of bushes, wind from the left:

every seaman knew that a spar is best towed blunt end foremost. They steered badly, and the form was gradually changed until the head was blunter than the tail. Professor Hele Shaw has proved by experiment that cigar or torpedo-shaped bodies have greater resistance if towed with their sharp end first, and has shown that this is due to the drag of the eddying wake formed behind the blunt 


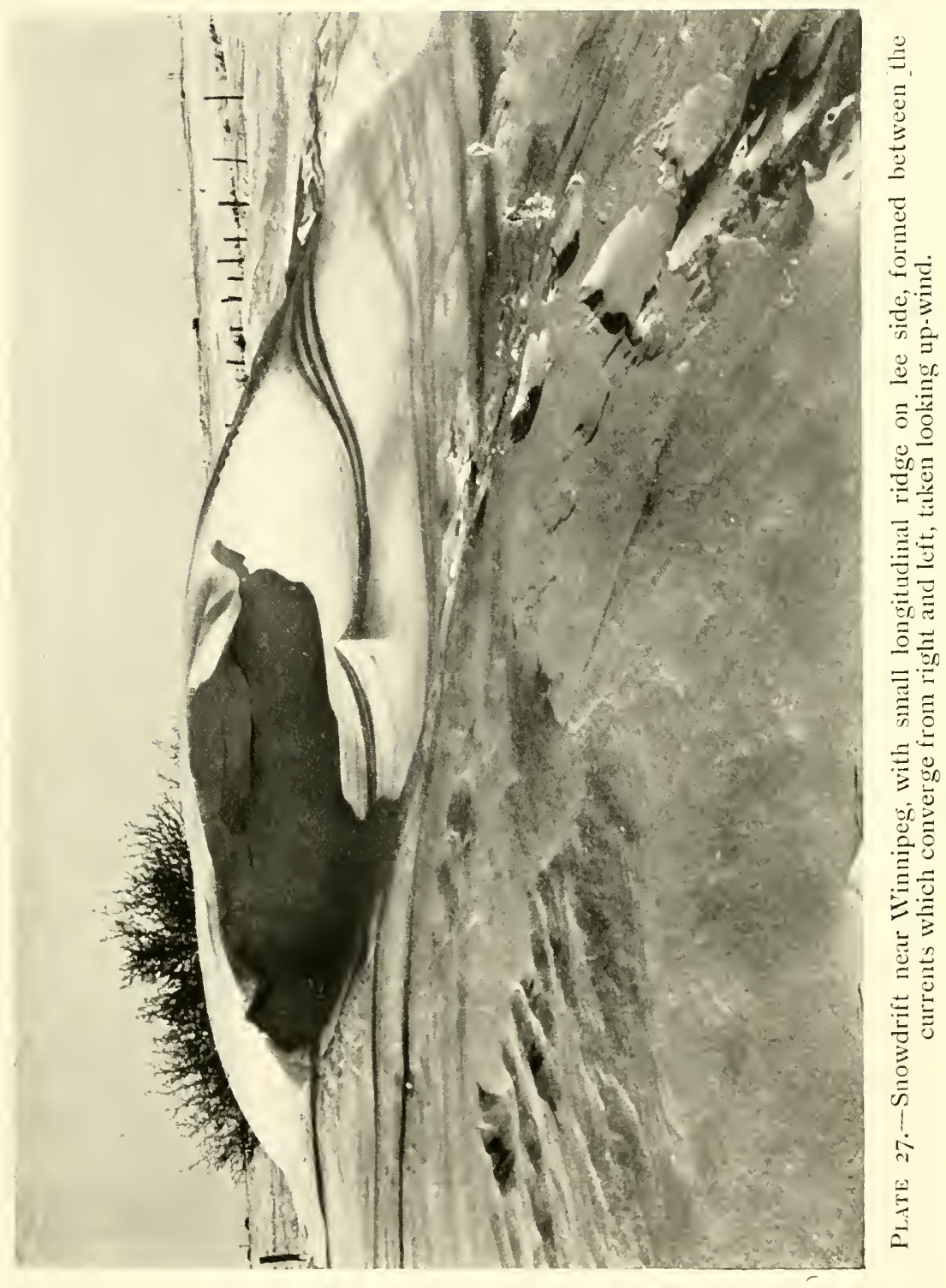






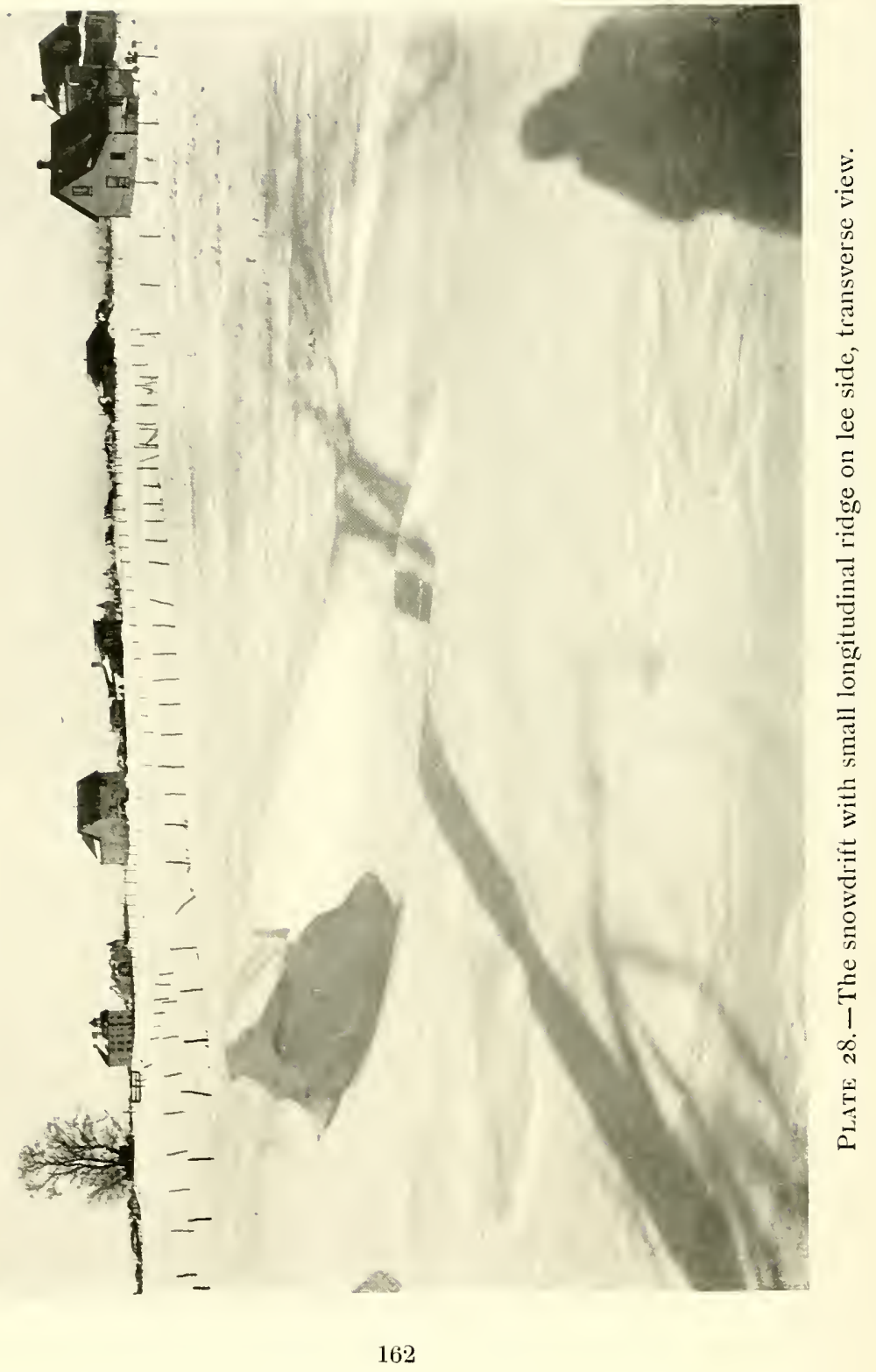


stern. If a wedge-shaped solid body has to be driven through another solid the business end of

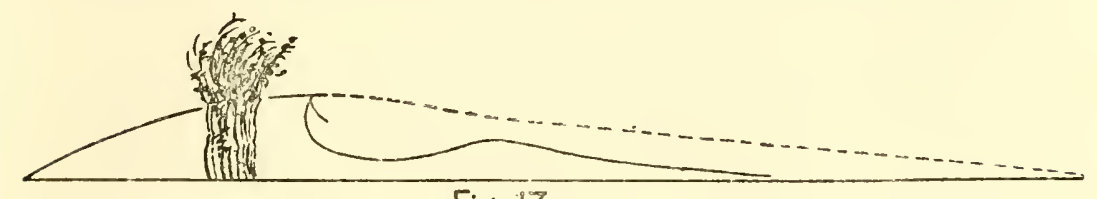

Fig. 17

Profile (dotted) and central longitudinal section of the same drift

the wedge is the thin end, but if a solid has to be driven through a liquid the blunt end is the business end. ${ }^{t}$

The plan of a snowdrift formed by a clump of bushes, of which a photograph and drawings are given, is the whole of the head or "entrance"

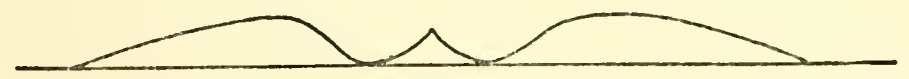

Fig. 18

Section across the dotted line of Fig 16

and part of the "tail" or "run" 2 of the eddycurve (Figs. I6, I 7, and I 8 ).

" Thus the wings of birds have "thick leading edges" (see Nature, June I9, I9I3, Wilbur Wright Memorial Lecture by Mr. Horace Darwin).

2 "Entrance" and "run" are terms used by naval architects for the swelling fore part and the narrowing after part of a ship. The lines of the submerged portion of a ship which are integrated in the "curve of immersed areas" should have a bluff entrance and a fine run, which is also the form given to non-rigid airships. 


\section{WAVES OF SAND AND SNOW}

Small houses, nearly square in plan, situated on the prairie near Winnipeg, produced a remarkable effect upon the extremely fine, dry, drifting, snow (Figs. I 9, 20, 2I). The principal part of the accumulation which they caused was a bank, the plan of which had the form of a much elongated horseshoe. It was high to windward of, and on

Fig 19

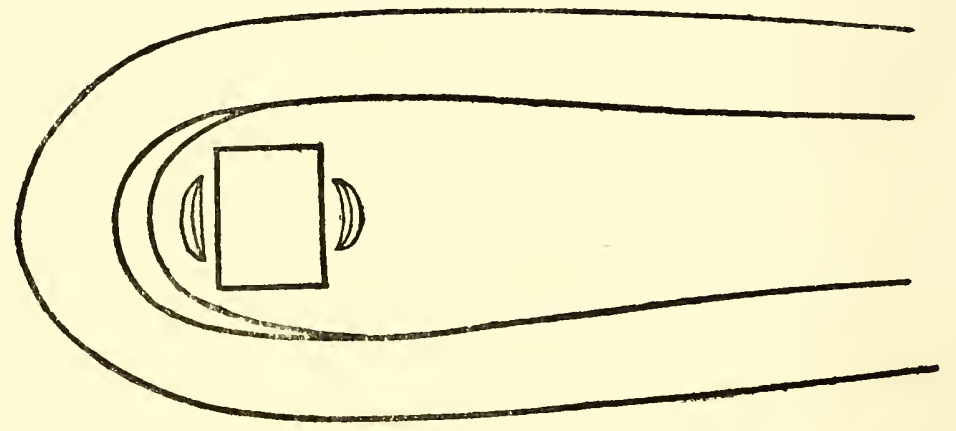

\section{PLAN}

of the principal snow drift around a hause on the prairio.nearWinaipeg. wind from the loft.

either side of, the house, becoming gradually lower to leeward, until it merged in the general level of the old hardened snow at a distance to leeward which was several times greater than the length or breadth of the house. The broadest part of the. horseshoe was not far from the lee wall of the house, from whence the sides closed in very gradu- 


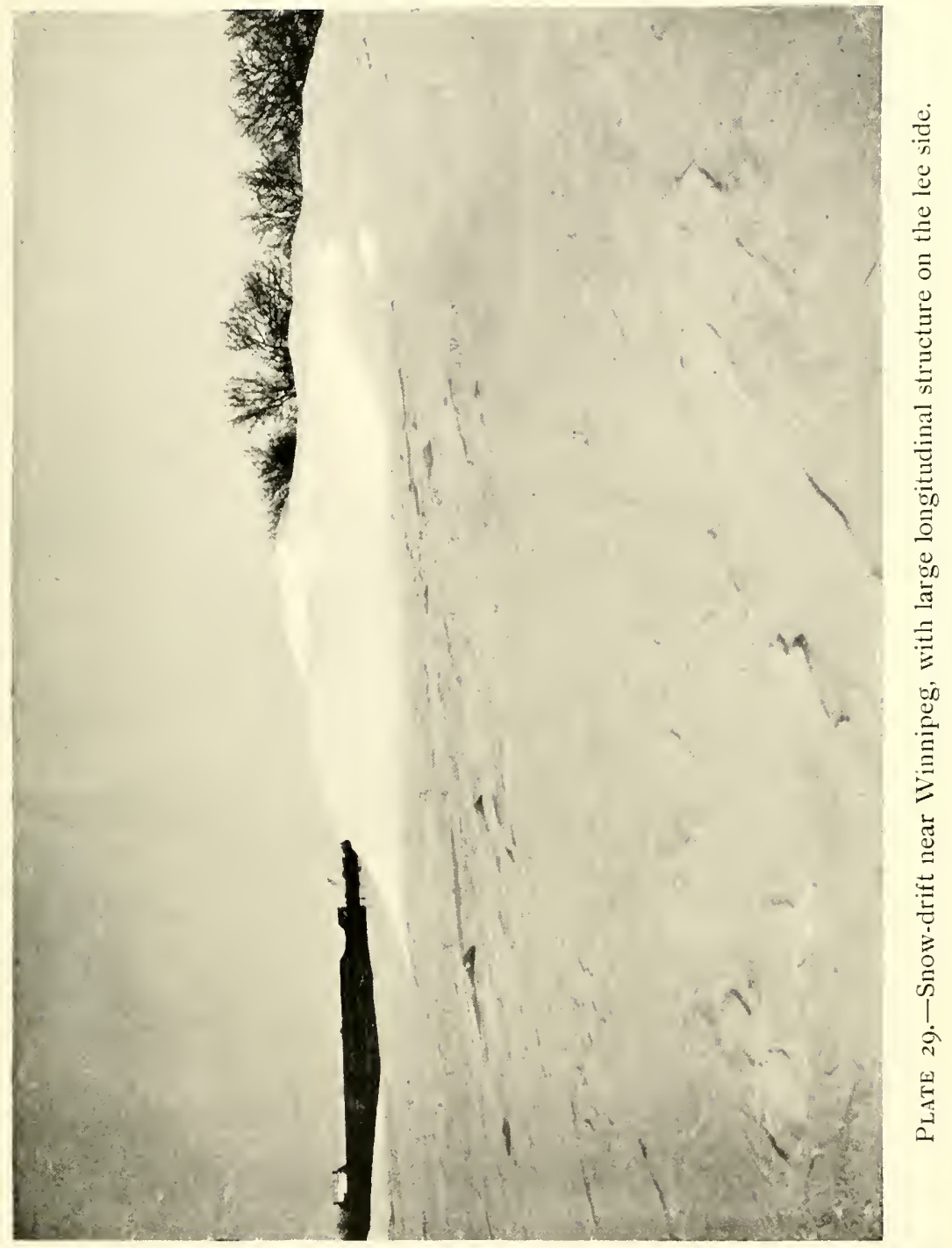



ally to leeward. The plan of the bank therefore, as in the case of that formed by the clump of bushes, comprised the whole of the head, or entrance, and part of the run, or tail, of the eddy-

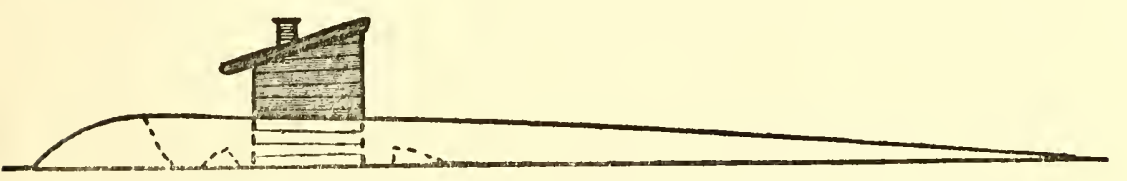

Fig. 20.-Profile and Central Longitudinal Section of same SNOW DRIFT.

curve. Inside the elongated horseshoe bank the ground was quite bare of snow, the black earth of the prairie being visible, and this bare strip extended beyond the place where the horseshoe bank

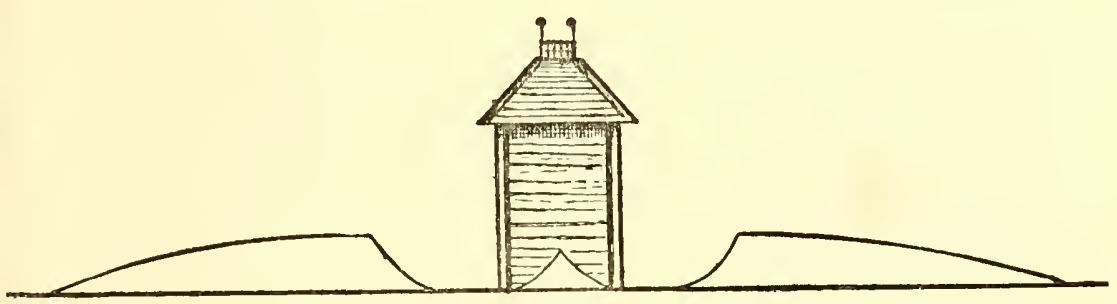

$$
\text { Fig. } 21
$$

Transverse section of snow drift onlee side of an outhouse on the prairie.

merged in the general level of the hardened snow, which lay on the prairie to a depth of a few inches. When the wind was blowing I watched the long wake of high-whirling snow in the lee of these 
houses, the cloud of extremely fine particles stretching to leeward beyond the tail of the horseshoe bank.

In December the snow in the woods near Montreal was neither the fine dust nor the sand-like grains seen on the Manitoba prairies in January and February, but seemed to consist of the original flat crystals in which snow falls when the air is moderately dry and cold, but more or less broken

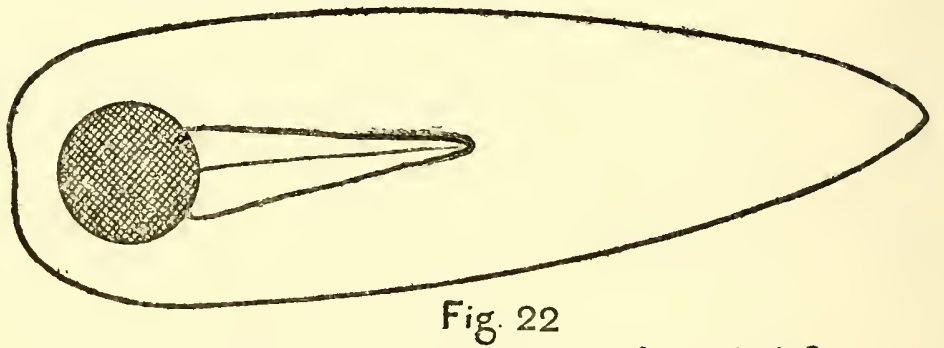

Plan of hollow round a tree, wind from the left.

up. The trees stood in many cases fairly far apart with little or no undergrowth, and the wind swept through the wood. The snow remained quite loose and light, and had no crust upon the surface. It embraced the saplings closely, but a space of peculiar shape remained unfilled round each larger tree, for the larger tree causes eddying motion of such intensity as to toss away the snow (Figs. 22, 23, 24). Round the trunk from either hand the wind sweeps in a spiral, or corkscrew, fashion, 


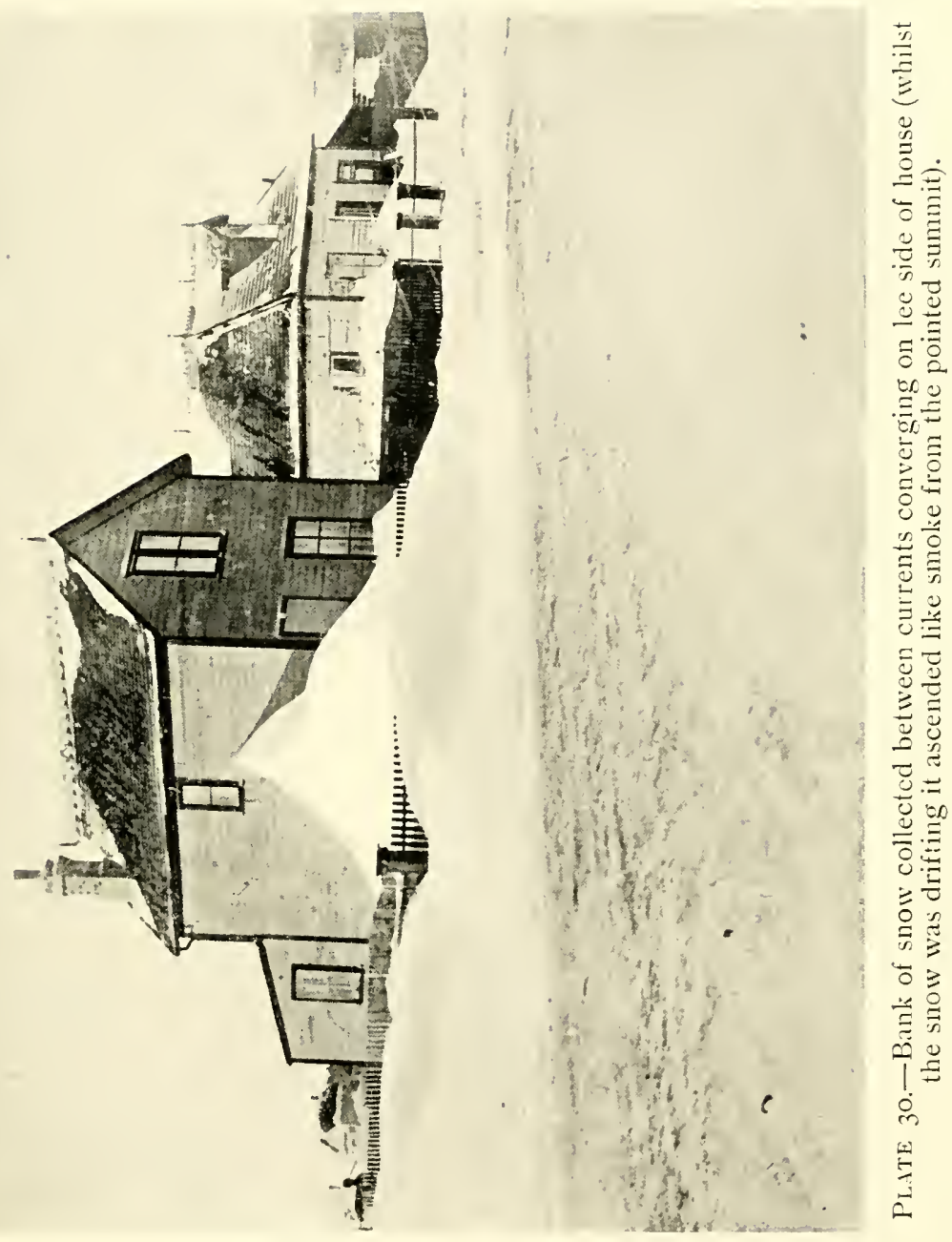





\section{SNOW-WAVES AND SNOW-RIPPLES 171}

which gives great transporting power over snowflakes, which, owing to their slow rate of subsidence, are very readily suspended, but which, as they, lie close and flat, are not much exposed to the

Fig. 23

\section{Longitudinal section of the same.}

direct current of wind as it flows parallel to the surface. The hollow space round the tree has the eddy form both in plan and profile, and corresponds to the space enclosed within the bank of snow.

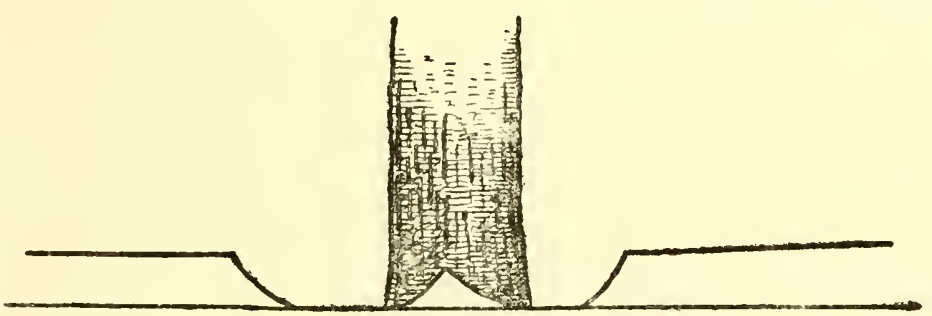

Fig. 24

Cross section of the same. lee side.

which accumulates round the houses on the prairie near.Winnipeg. Similarly shaped hollows are kept open where boulders project above the level of loose-lying snow (Figs. 25 and 26). 
Isolated mounds of loose snow or sand travelling, before the wind assume a crescentic form with cusps, or horns, pointing to leeward-the form to which the name "barchan" is given. What, then, is the connection between the shape of a barchan,

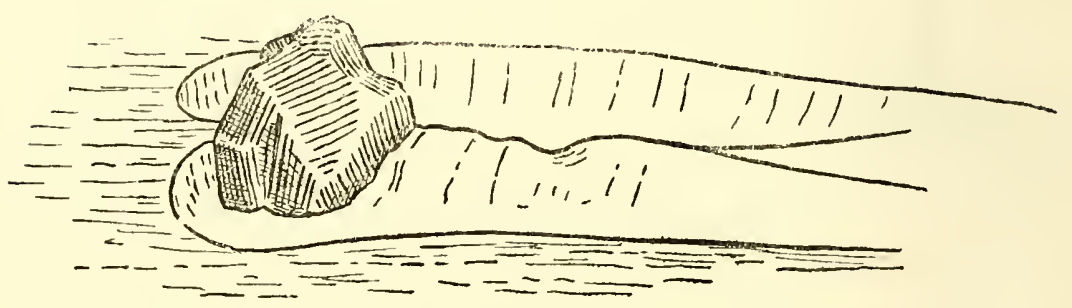

Fig: 25

Hollow etc cut by wind, from left, around a stone, from a photograph raken in Scotland Fobruary 1900.

or crescentic mound, of particles drifting before the wind, and that of an eddy space? When a patch of loose sand or snow happens to form during drifting upon hard ground it tends to grow, because other particles driven by the wind have their progress retarded when they pass over the soft and porous surface. The low mounds are at first roughly elliptical in plan, with their longer axis parallel to the direction of the wind, and are highest near the middle; but eddy action soon occurs. Its first effect upon the plan of the mound is to truncate the lee end, which becomes a nearly; straight line transverse to the wind (see ante, 


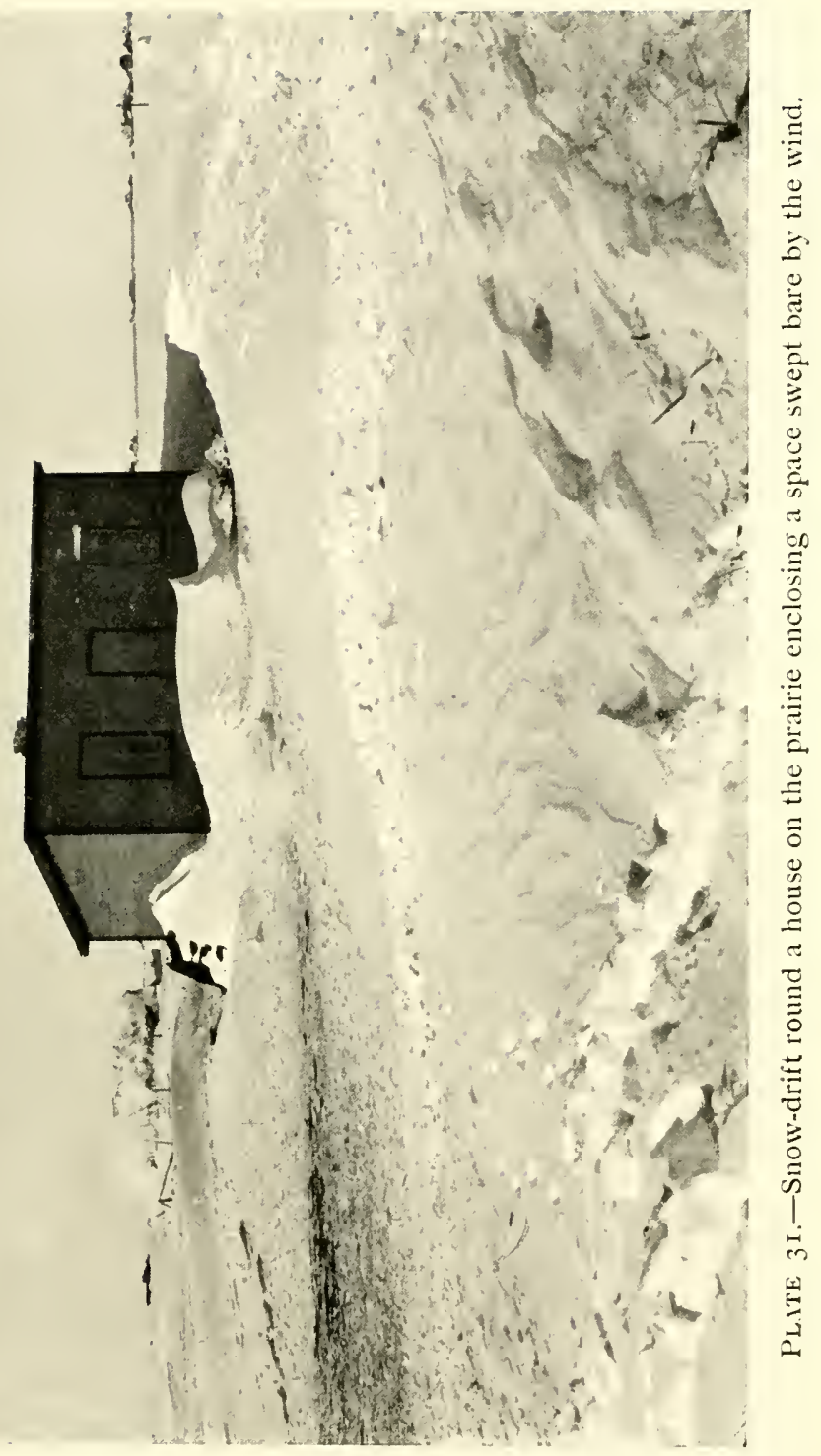

$17: 3$ 

Fig. 6, p. I I 4). The concentration' in the centre of the eddies from the right and left hand, however, sweeps the snow back more rapidly there, so that the line becomes crescentic with the extremities advanced to leeward. The plan of the crescentic mound is not always the same in either material. In some cases the cusps are short compared to the fore and aft length of main mass, and sometimes long. In the latter case the plan somewhat resembled that of the elongated horseshoe-shaped bank of snow formed around clumps of bushes or around houses on the prairie. Owing, however, to the retreat of the mound the lines of the weather end remain finer, both in plan and profile, than

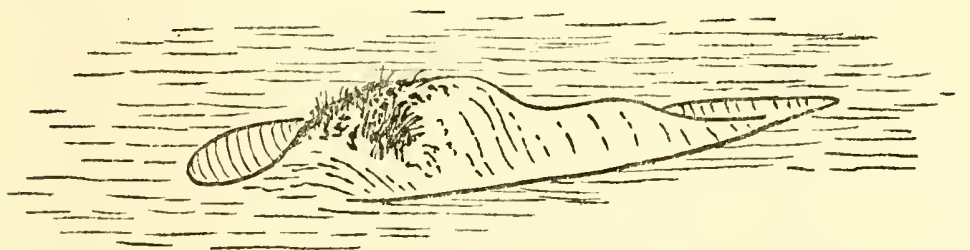

Fig. 26

Hollow cut by wind. from left, around a heap of manure on a field, from a photograph.

those of a bank which occupies the eddy-space of a fixed obstruction, but I think the whole space occupied by the mound itself and the eddying wind to leeward has generally, perhaps always, the bluff head and fine tail arrangement, so that if it were 8 


\section{WAVES OF SAND AND SNOW}

roofed over the cover would have the shape of a sole, plaice, or other flat-fish lying head upstream.

In the case of both snow-barchans and sandbarchans there is sometimes a longitudinal ridge projecting to leeward from the middle of the cliff (Fig. 27). When the barchan possesses this adjunct it is more easy to realize its structural similarity to the swirl left when an oar leaves the

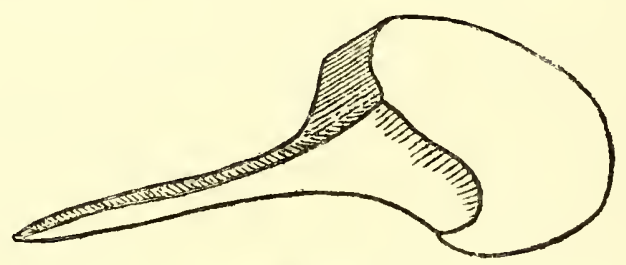

Fig. 27

Longitudinal growth on lee side of a travelling snow-drift.

water at the end of its stroke. The surface of the water shows an eddying disturbance travelling astern with a boundary convex to the direction of its motion and on the bow side, or side towards the oar, a right-handed and a left-handed spiral or vortex in which the water revolves round a vertical axis. A current is visible flowing astern and entering the whirlpool between the right and left-handed spirals, supplying water to replace that 


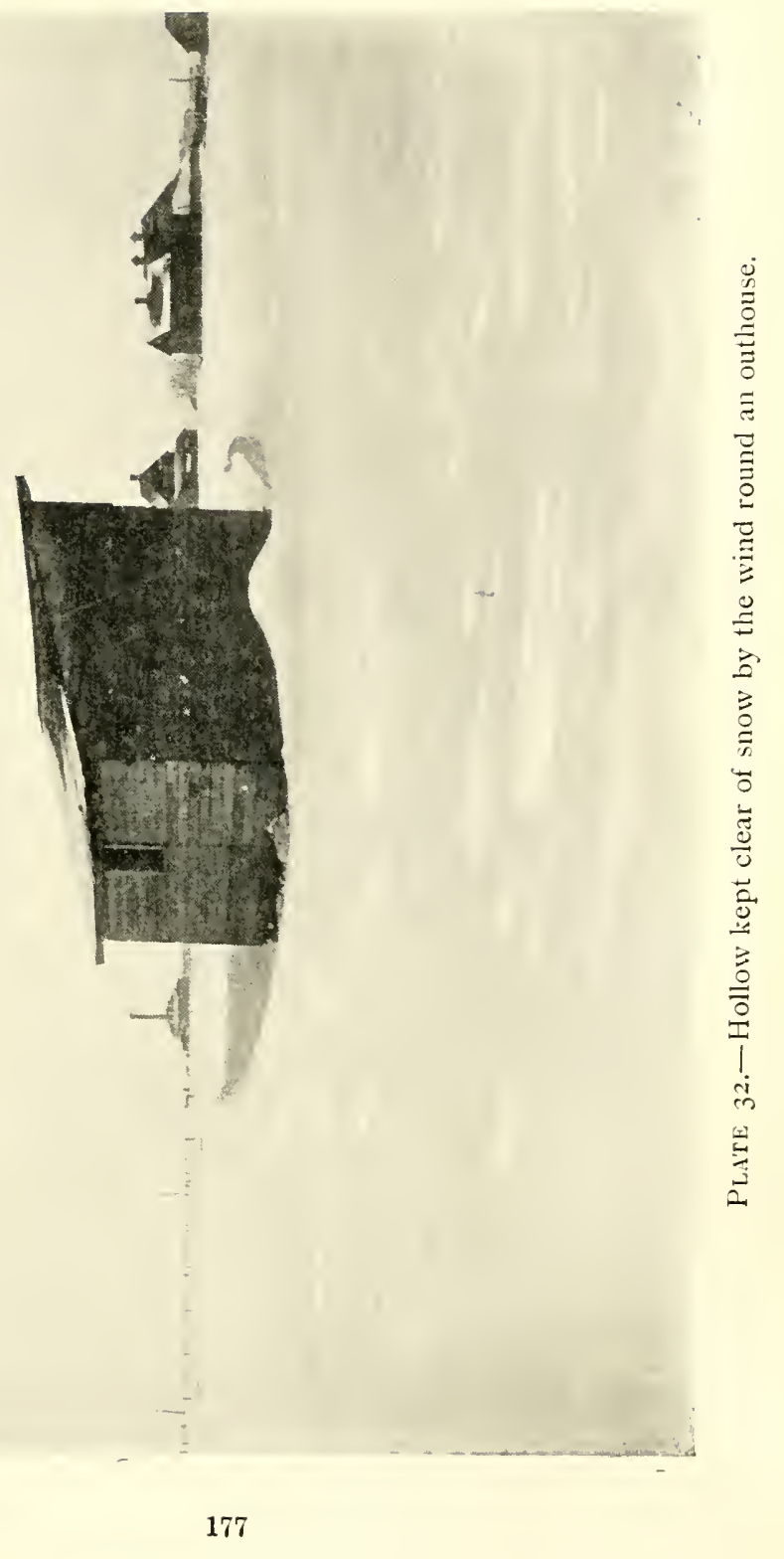



driven below by their suction. This current corresponds to the "tongue" of the barchan, the right and left-handed swirls to its cusps, and the convex boundary sternwards to the convex boundary which the mound of sand or snow presents to the wind. It must be remembered that as the disturbance from the oar travels astern, so also is the motion of the barchan relatively to the wind in the direction of its convex front, although relatively to the ground it travels in the opposite direction.

In foaming waves, nearly breaking, there are numerous double eddies with a forward current between, and as the wave passes on it leaves the foam in the form of a squat figure of 8-i.e., a double ellipse with a bridge of foam common to both along the line of advance of the direct current. This line of foam corresponds to the longitudinal tongue sometimes formed on the lee of barchans of sand and snow.

It is of interest to consider the profile of the eddy-spaces left unfilled between the transverse ridges of a group of travelling waves in sand and snow. These, it must be remembered, can only have their truly typical form if there be a deposit of granular material below the troughs, for, if a hard floor be exposed, it necessarily interrupts the vertical sinuosity of the aerial current. The direct 


\section{WAVES OF SAND AND SNOW}

wind-current leaves the surface at the crest and, descending, strikes it again somewhere on the weather slope of the next ridge. The surface current of the eddy sweeps backwards from that point to the preceding crest. The steep lee slope and the gentle weather slope of the sand surface show the blunt head and the fine tail of the lower half of the eddy. The measurements of sand-waves and sand-ripples showed their wave-length to be eighteen times as great as their height. If the node, or point of divergence of the surface currents, which is at the tail end of the eddy, be halfway between the trough and crest, then the length of the eddy is nine times as great as the height of the sand-wave and, as the height of the eddy cannot be much greater than the height of the sand-ridge, the eddy must be about nine times as long as it is high. The core of air which revolves under the lee of each broad sand ridge has therefore a cigar or torpedo-shaped profile, with its blunt end upwind.

A group of snow-waves near Winnipeg, with loose snow below the troughs, had a wave-length fifty times as great as the height. The eddy-space had a blunt head and fine tail form, and the length of the eddy must have been about twenty-five times as great as the height. 


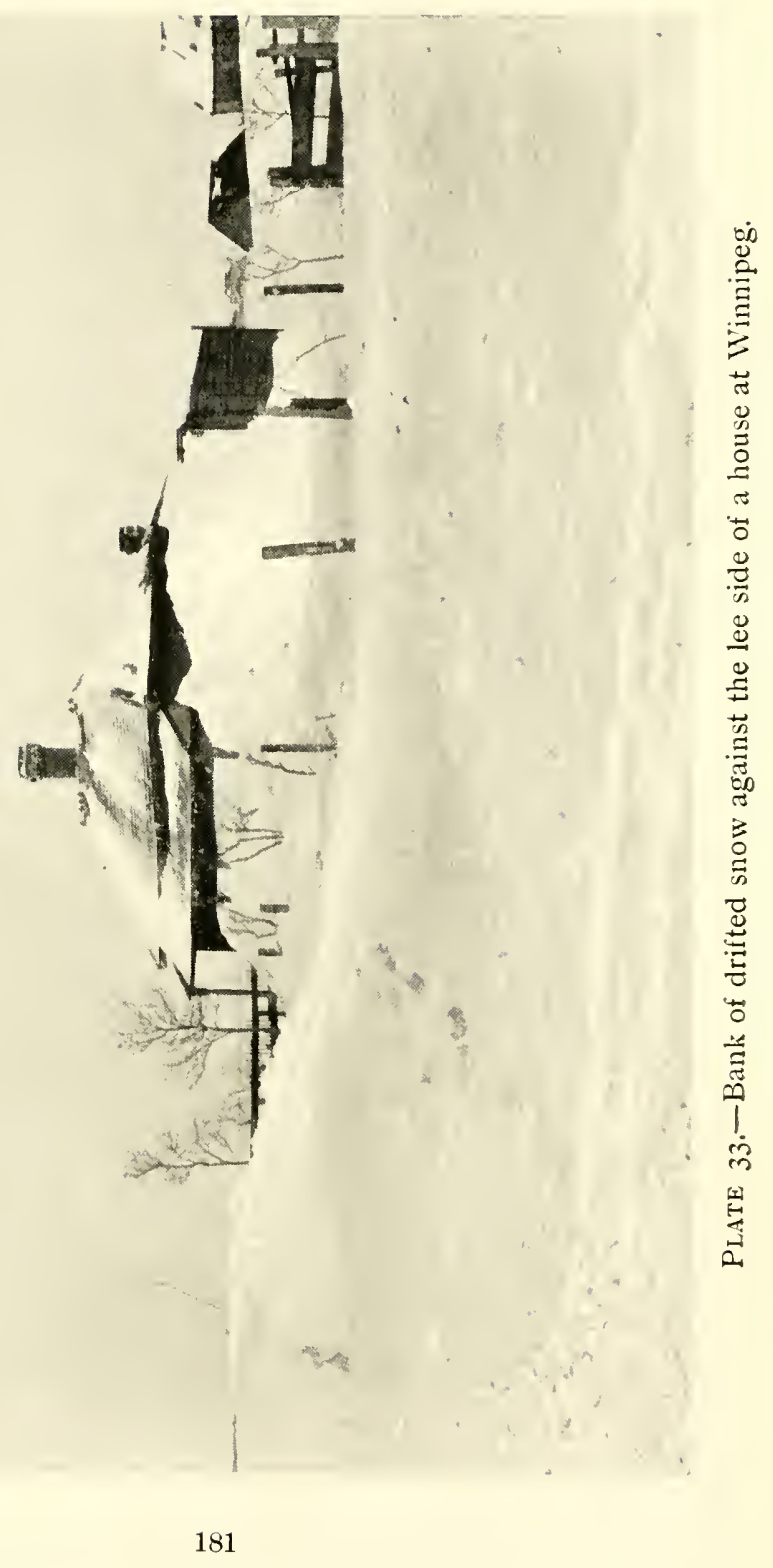





\section{SNOW-WAVES AND SNOW-RIPPLES 183}

On the Distance to which Hedges and Belts of Trees Extend Shelter from the Wind.

The wind curves round the sides of a narrow obstruction, and its direct horizontal movement is therefore already felt not far to leeward. In the case of a quickset hedge, or a wall, or a belt of trees, the distance to which shelter extends depends upon the height of the obstruction. In the snowwaves the direct forward wind was kept away from the ground for a distance twenty-five times as great as the height of the ridge. 'Applying this to the case of fields enclosed by thick quickset hedges, I conclude that a hedge 5 feet high would give effective shelter from the wind to young growing crops for a distance of at least I 25 feet. Trees planted in long, narrow belts, in the way more common in Scotland than in England, must extend effective wind-shelter for a considerable distance, that for trees of 30 feet high being at least $75^{\circ}$ feet or 250 yards.

On the Three Modes of Deposition of Drifted Material Depending upon Rate of Subsidence.

The circumstance that size, density, and shape each have an influence on the mobility of solid particles under the action of a current of air or water has hampered observers and writers in their 


\section{WAVES OF SAND AND SNOW}

efforts to classify the materials whose drifting has to be studied, classification by size being insufficient, owing to the fact that the greater mobility of smaller particles may be compensated by higher density or a more compact form. There is, however, a single constant which suffices for the classification of solid particles in the order of their mobility of drift, 1 and this is their rate of subsidence. All solid particles may thus be arranged in three classes. There are first the least mobile particles, whose rate of subsidence is so great that they only travel on the surface and are never more than momentarily suspended. In the desert this order of material is represented by the gravel. When dealing with the movement of detritus by tides and waves it is represented by shingle. If we care to study the way in which the winds of autumn drift fallen foliage, we shall find that the leaves of the plane-tree come in the same category.

Passing by for the moment the middle, or second, class, we have as the third, or most mobile, particles those whose rate of subsidence is so slow that they are held in suspension as long as there is any upward movement of the encompassing fluid.

I See Geographical Fournal, April, 1908, pp. 421-2, remarks by the author on Dr. J. C. Owens' "Experiments on the Transporting Power of Sea-Currents." 


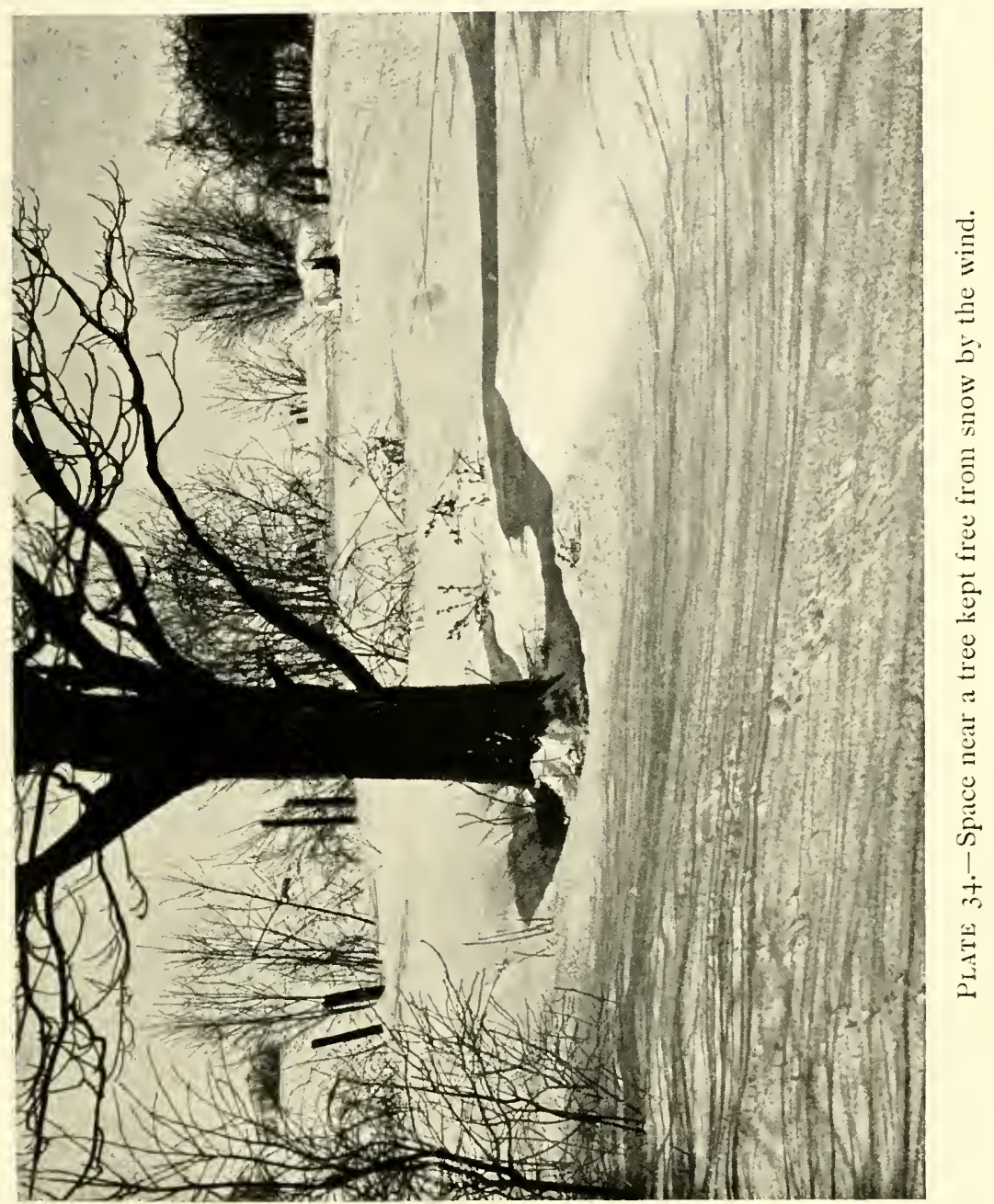





\section{SNOW-WAVES AND SNOW-RIPPLES 187}

The surface layers of a deposit of such material also drift superficially before even a very slow current. In the case of aeolian transportation this third or most mobile class of particles is dust. In the case of the movement of detritus by water it is mud.

The middle, or second, term of the series comprises particles which subside at a moderate rate, and material of this order is called sand, whether it be found on land or under water. It has in different places a different mineral composition, but on the whole its chief component is quartz, whose hardness and texture are such that when the diameter of the particles is from about $\frac{1}{50}$ to about $\frac{1}{2} \frac{1}{00}$ of an inch their mutual attrition by collisions when drifting is very slow.

When dry sand is drifting before the wind on a beach where stones lie scattered on the surface, a single tongue of loose sand deposits behind each projecting stone, with a sharp crest or ridge exactly in a line with the centre of the stone. Each side of the ridge has a concave surface.. It fills the space of dead air between the right and lefthanded halves of the vortex or eddy produced by the stone. Much sand is whirled in the eddy, but some of it works its way out and drops in the deadair space. A similar ridge of sand collects behind a walking-stick thrust into the beach. Neither 
gravel nor dust collects thus, for the gravel is not, caught up by the eddy, and the dust which the eddy. catches up cannot escape.

On the prairies of Manitoba in mid-winter I found that a projecting lump of hardened snow or a post in the ground had two tails of drifted snow behind it, one on either side of the central line, each having a gently convex surface. The drifting material of which these tails were formed was a fine powder or dust to which much of the snow had been reduced. This conforms so precisely to the movement of the eddying air that it can only deposit during lulls or calm. The rapid setting of finely powdered snow when lying in a heap helps to make these two-tailed drifts permanent.

White steam issuing in large quantity from a factory chimney forms a two-tailed streamer, and the spiral motion of the condensed steam in each half can be easily seen. As it leaves the mouth of the chimney it rolls downwards and inwards from either side. When once this dual motion has been seen in white steam it is not difficult to detect the double whirl in the single streamer of black smoke issuing from the funnel of a steamer.

The action of a transverse barrier upon the drift and deposition of dust is quite different from that by which it arrests the superficial travel of heavier 


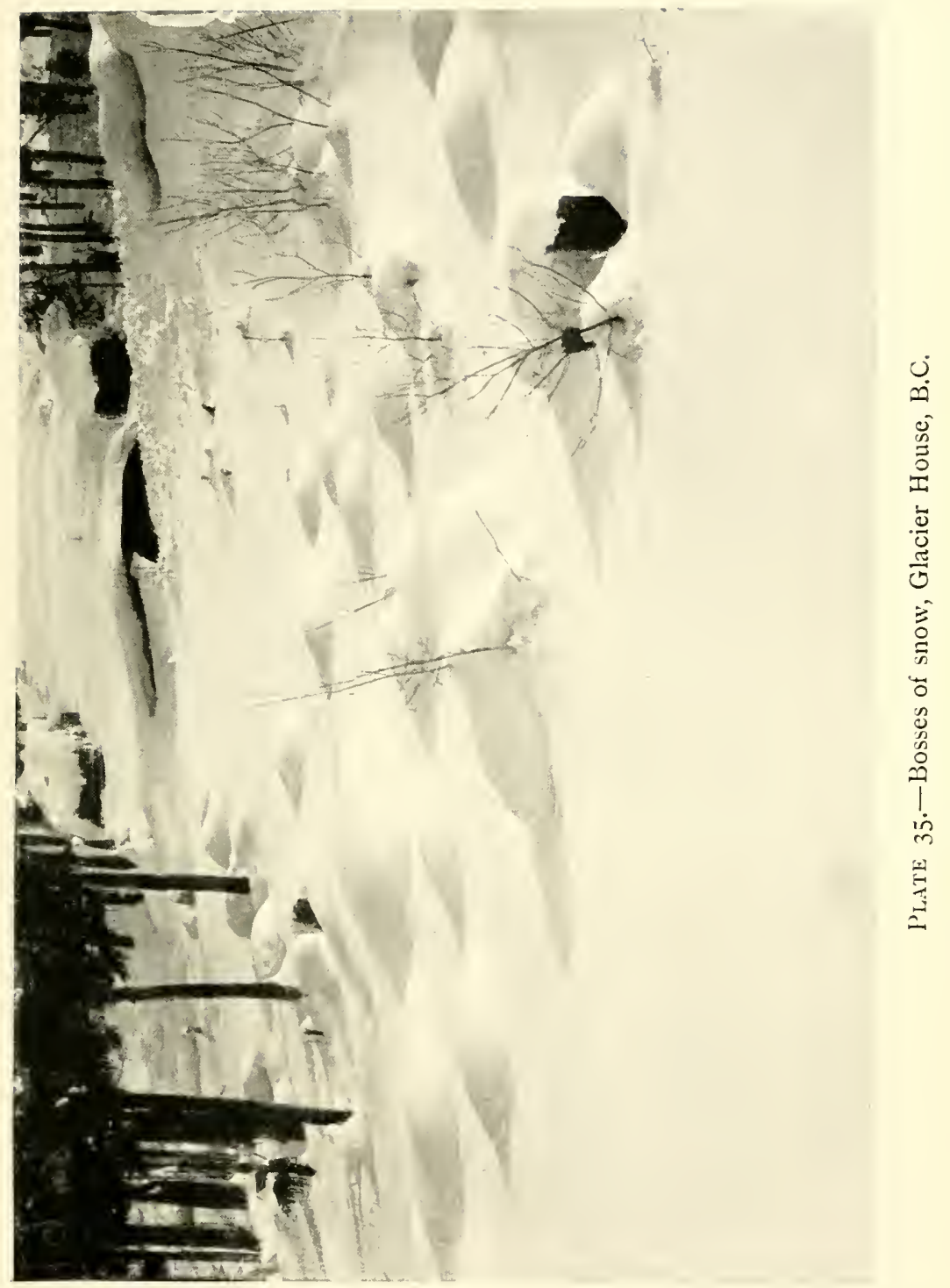



bodies. The single track of the Canadian Pacific Railway is slightly raised above the level of the prairies. When iI crossed these great plains they were covered to a depth of some inches with snow, but the railway line was clear. There was a rise of the air in passing over the obstruction, and this was evidently sufficient to carry the snow-dust clear of the line. There must have been an eddy, with horizontal axis and vertical whirling formed by the obstruction, and it seems as if the snow-dust must have travelled over it, borne along in the unbroken sweeping curve of the main current of air.

Particles less fine, whose rate of subsidence was the same as that of sand, would certainly have formed some deposit on the lee side of the obstruction, for some of them would have subsided through the eddy and been held back by its return draught, which flows along the ground.

I also observed that the fine snow-dust of the prairie used to fly quite over the city of Winnipeg. Looking out from the suburbs to the prairie on windy days, the snow was seen to be drifting there so as to obscure the lower story of the farmhouses, the upper story and roof standing out clearly. In the streets of the city there were no flying particles of snow, but high above the air was hazy with the poudrette, or cloud of minute snow particles, which 


\section{WAVES OF SAND AND SNOW}

formed a translucent screen upon which haloes and mock suns were seen in beautiful opalescence.

The above observations bear upon the question of the best form of fence for arresting drifting snow. Fine drift which would be wafted over a closed fence would quickly form a deposit in the minor eddy spaces to leeward of an open fence. Different forms of fence might ultimately collect the same maximum quantity of snow, but the best form would be that which collected it most quickly, and this would be one with, so to speak, a fine mesh.

In the late autumn I have watched the drifting of the large leaves of plane-trees in London. As the leaf drifts some part of it is generally in contact with the ground, and although it is occasionally in the air its flight resembles a jump or skip, the course of the leaf being, in the language of golf, almost all "run" and hardly any "flight." One day, with a southerly wind, I saw these leaves banking up against a stone step at one of the entrances on the south side of Kensington Gardens. The obstruction quite stopped their progress until a sufficient quantity had collected to provide an inclined plane reaching the level of the top of the step. Then, as other leaves arrived, they glided up the slope, and, sliding along the upper surface of the stone step, invaded the gardens. 


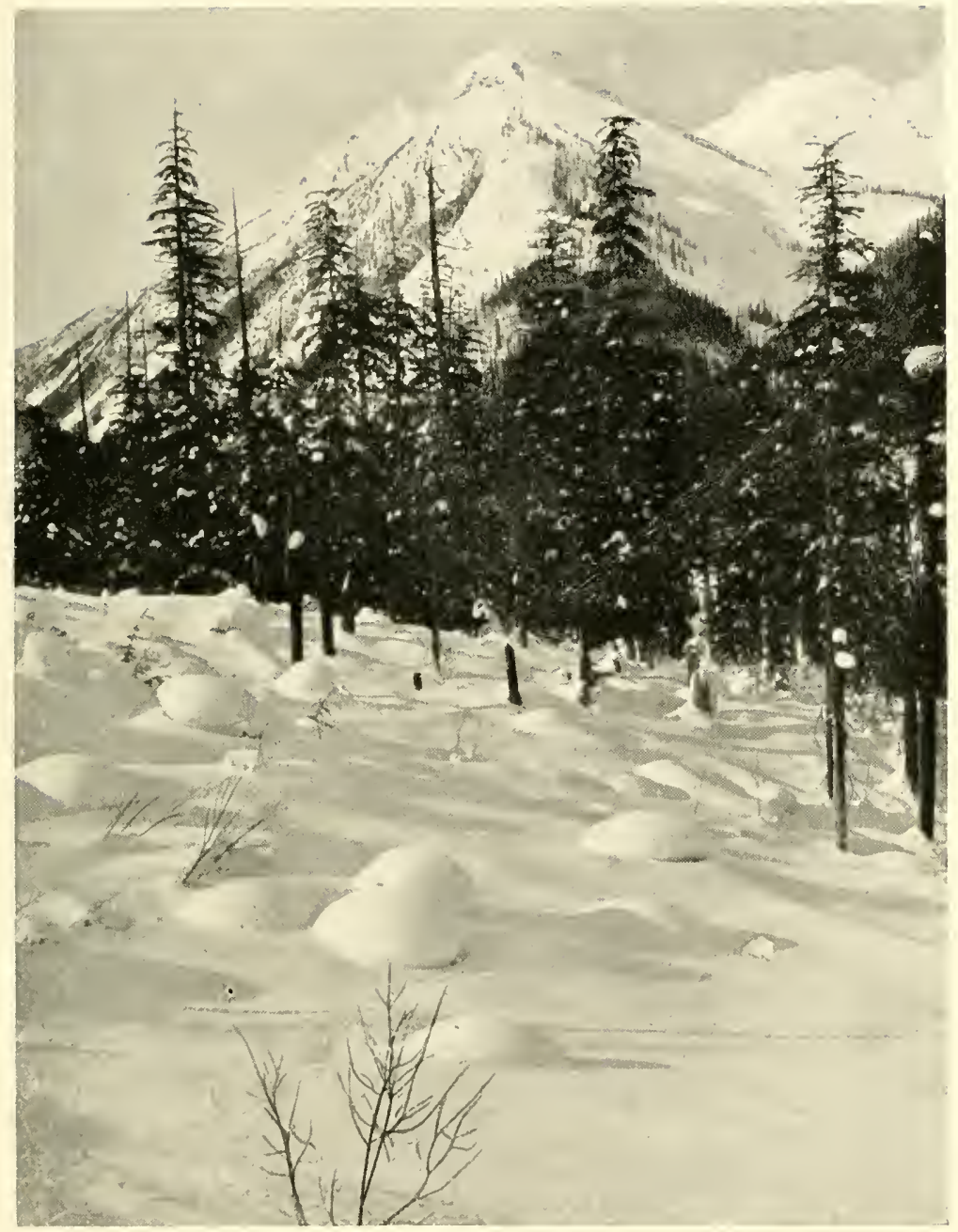

Plate 36.-Bosses of snow, in a valley of the Selkirk Range, B.C. 

The next observation relates to the action of the eddy with a vertical axis upon the drifting leaves of the plane-tree. The place was the broad pavement in front of the Imperial Institute. The building projects at the principal entrance, on the west side of which there are two high walls facing south and west respectively. For some time in the autumn I noticed every day a large circular heap of leaves of the plane-tree within this angle, the outer edge of the heap being several feet from both walls. As other leaves arrived, gliding over the pavement, they circled round nearer to the walls, but, after a time, approaching the heap, they were either deposited against its side or were lifted and dropped more centrally upon it. The course of events was clear. The leaves continued to travel until they approached the centre of the eddy, where the air, in order to escape, had to travel upwards. Here the horizontal motion of the air ceased, and the leaves, even if momentarily lifted by the upward current during a gust, quickly settled.

This accumulation of heavy material is in a position similar to that in which eddies of water scour out circular depressions in a sandy bottom, of which the particles are readily suspended. On the pavement in Cromwell Road I found all the plane-leaves banking against the high wall, but 


\section{WAVES OF SAND AND SNOW}

there was a strip of road-dust composed of sandsized particles at a distance of a foot or two from the wall. The reason of this is that the wind, ascending when it reaches the wall, drops the heavy, leaves there, their motion ceasing where the horizontal current ceases, but much of the finer material is dropped outside the eddy.

The wearing of roads made with flints produces a grit of the size of coarse sand. This collects in two strips on pavement under a wall, a narrow strip against the wall and a broad strip commencing about a foot away from the wall. The former lies in the dead air between the inner curve of the eddy and the angle of wall and pavement. The latter, I presume, lies outside the space where the eddy-current sweeps the pavement.

I have not had an opportunity of observing where the finest kind of dust would deposit under such circumstances, but I think it would lie between these positions, for it would remain entangled in the eddy as long as the wind blew and then would drop out, forming a strip below the line where the eddy had been.

In dealing with the intricate phenomena of the simultaneous transport of shingle, sand, and mud by the sea I find it best to analyse the motion of the water into its horizontal and vertical com- 


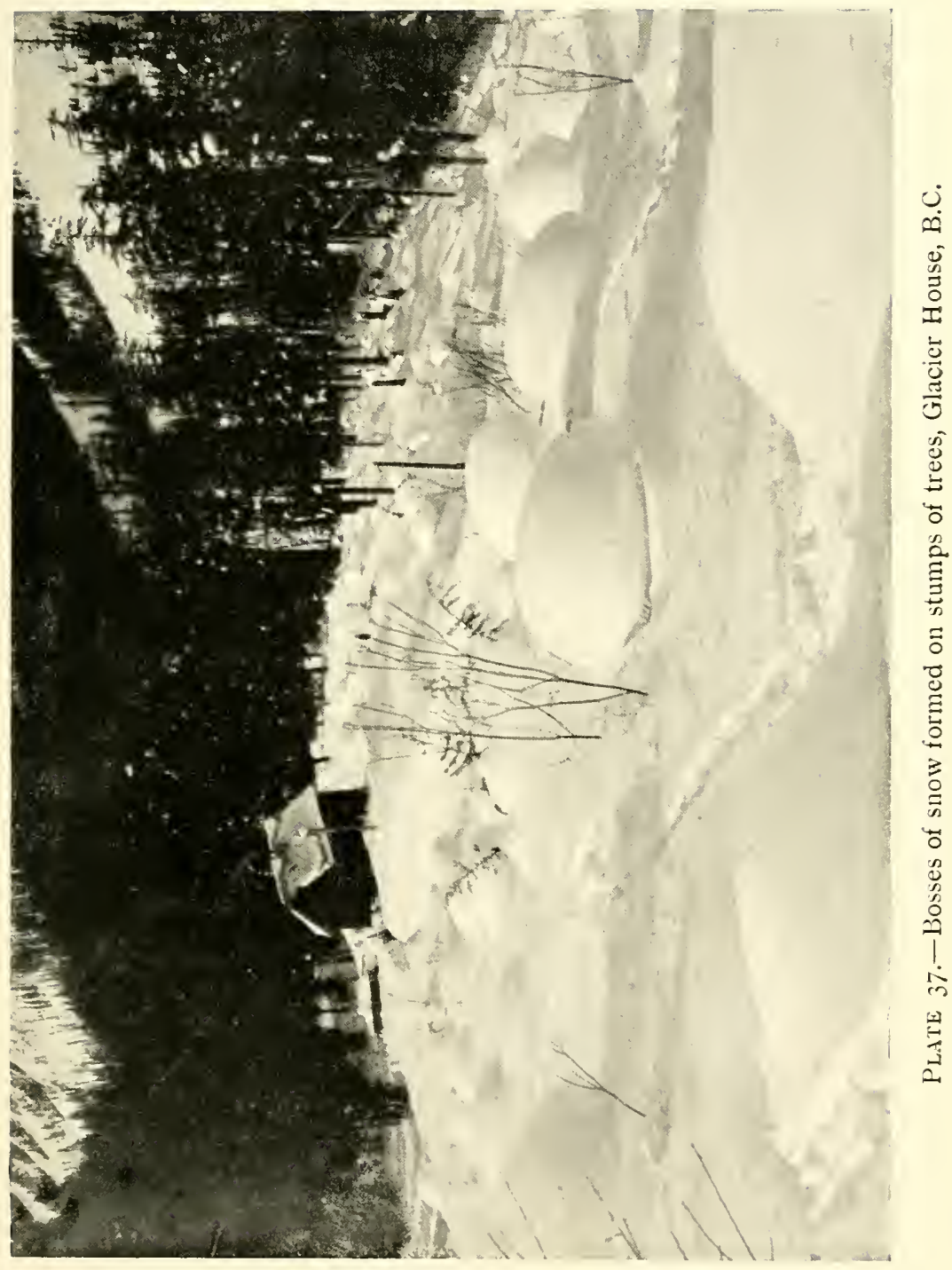



ponents, Where change of their relative velocity occurs there is a change in the proportion of the three grades of material deposited.I

On "Banner Clouds" and on Sandbanks to Leeward of Promontories.

The following remarks are in continuation of what has been said of structures taking the form of tails or streamers to leeward of a narrow obstruction.

When wind blows over a peak on a mountain ridge the eddy on the lee side brings up air which is in a different condition as to temperature and moisture from that which comes over the ridge; and when the two bodies of air mingle with one another the chilling of the warmer part frequently results in the formation of a cloud-the "banner cloud," which is so often seen as a stationary streamer stretching to leeward of a mountain peak, revealing the long eddying wake left in the wind by this projection. Although the cloud is stationary in position, a whirling movement can often be seen in its substance.

On the coasts of England are several sandbanks

"See "Waves of the Sea and other Water Waves" and Fournal of the Royal Society of Arts, November 8, 1912, Cantor Lecture by the author on "Ocean Waves, Sea-beaches, and Sandbanks." 
which recall by their position relatively to a headland, and also by their shape, the banner cloud of mountain districts, the difference being that the sandbank is produced in the eddy formed by a horizontal projection, the banner cloud in that due to an upward projection. The Shambles Shoal, near Portland Bill, is an excellent example of a shoal analogous to the banner cloud. It is on the east side of the promontory, which is the lee when the current of the flood tide is running. There is no corresponding shoal on the west side. The same arrangement is found near Start Point, in Devonshire, viz., a shoal on the east, but none on the west. I have offered as an explanation that when the current flows up-channel-i.e., eastwards-it is for most of the time above mean sealevel and carries much sand from the beaches with which the water is then in contact and which are then stirred up by waves. During most of the time when the current ebbs westwards, downchannel, the water is below mean sea-level, it is not in contact with the thick and steep part of the beach, and the waves beat less strongly upon the flatter part which is submerged. ${ }^{\text {I }}$ Thus, as far as the formation of sandbanks is

I See "Waves of the Sea and other Water Waves," by Vaughan Cornish, Part II, p. 206. 


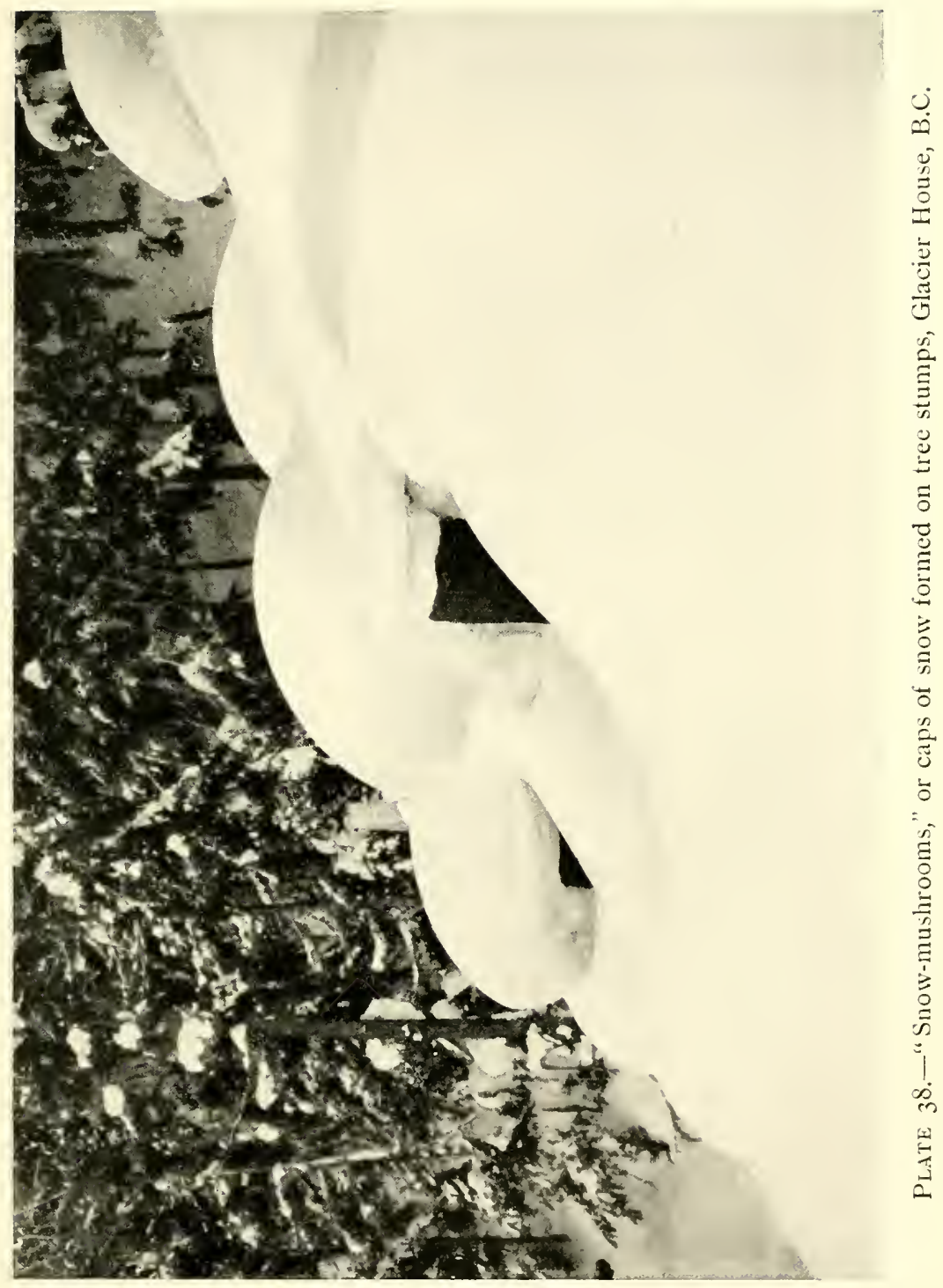



concerned, the flood tide is far more effective than the ebb.

On the Action of an Obliquely Crossing Wind upon the Swell of the Sea.

My observations upon the different effects produced upon sand and snow by wind-eddies with horizontal and vertical axes respectively led me to notice certain effects of wind upon water waves.

The following observations relate to two different conditions of the commencement of the wavemaking action of wind upon water; first when there is a swell-i.e., pre-existing waves, already running in the direction of the wind; second, when the following wind blows obliquely across the swell.

First Case.-On December 20, I9 I I, I was on the P. and O. S.S. Egypt, not far from Cape Finisterre, homeward bound. There was a heavy westerly swell, of which I took measurements at 3 p.m. Its length was 640 feet, speed $39^{\circ} 8$ statute miles per hour, and height about 20 feet. During the ensuing night the wind came on to blow very hard in precisely the direction in which the swell was running. The force of the wind at $4 \mathrm{a} . \mathrm{m}$. on the 2 Ist was between 9 and Io of Beaufort's scale, or 48.5 statute miles per hour. We were at this 


\section{WAVES OF SAND AND SNOW}

time already in the Bay of Biscay. At 8 a.m., when I began observations, the wind had still a force 9.25 of Beaufort's scale, ${ }^{1}$ and therefore a velocity of 46.5 statute miles per hour. The sea was running perfectly true; i.e., there were no crossing waves, neither did I notice any waves longer or shorter than the great billows which followed one another in a procession of regular ridges. The ship being hove-to on account of the violence of the waves, I was able to measure their size and speed with greater accuracy than usual. Their height was approximately uniform, being rather more than 3 I feet from trough to crest, their length was 9.33 feet from crest to crest, and their speed 47 statute miles per hour. The wind maintained its direction unaltered throughout the morning, but by noon its velocity had decreased to 35.5 statute miles per hour. The waves by this time had considerably diminished in height, length, and speed.

The course of events is clear. When the wind came on to blow strongly it went into eddies having long horizontal axes, on the lee side of the levelcrested ridges of the swells, which were the only, waves running. As long as the velocity of the

- The numbers are the average of those given by different officers observing at the same time. 


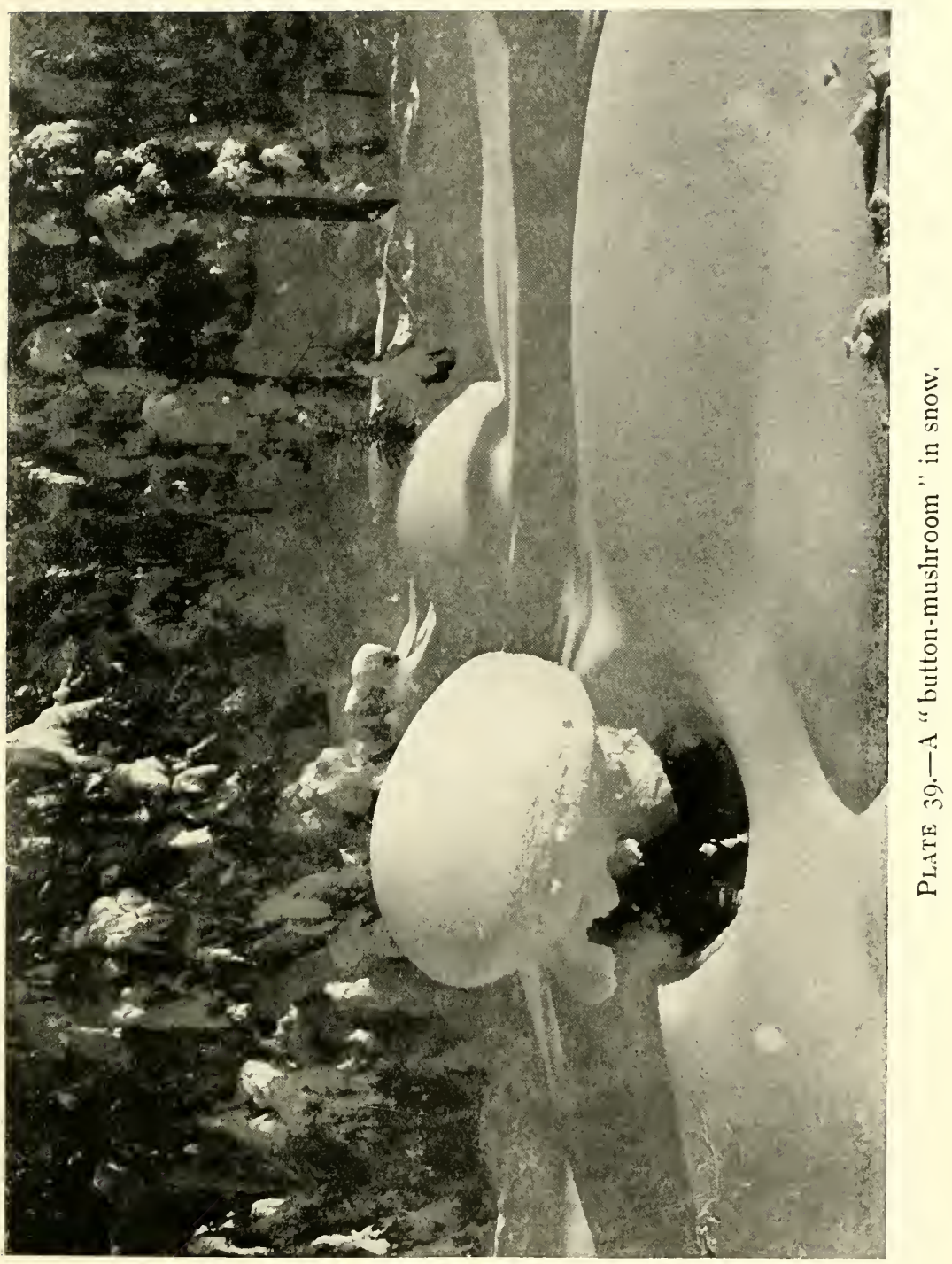



wind exceeded that of the waves an eddy with horizontal axis was maintained on the lee of each, and the ridges were rapidly increased in height.

'Second Case.-During a voyage from Southampton to Colon and back in I 9 I 2 I carefully observed the sea when the following wind blew obliquely across the swell. I was much struck with the extreme slowness with which new waves grew and the small effect of the wind upon the height of the swell. When the swell and the waves which cross it do not differ much in height there are no windeddies with long horizontal axes, but on the contrary, the eddies are cut up into small lengths and have their axes tilted. In this form they can have little effect in raising waves, and, as far as the circulation of the air is in the horizontal plane, it tends to create whirlpool motion instead of waves.

When wind begins to blow upon the plane surface of an enclosed sheet of water, its wave-making action is at first slow but afterwards proceeds quickly. The rapidity with which short but angry waves are formed upon lakes is a matter of common report. Whether this is appreciably increased by the amount of disturbance reflected from the shore I do not know, but the rapid growth of waves is, 


\section{WAVES OF SAND AND SNOW}

I think, partly due to the fact that although in lakes there is no concurrent swell to assist the action of the wind, there is no crossing swell to hinder it, as there usually is at sea. 


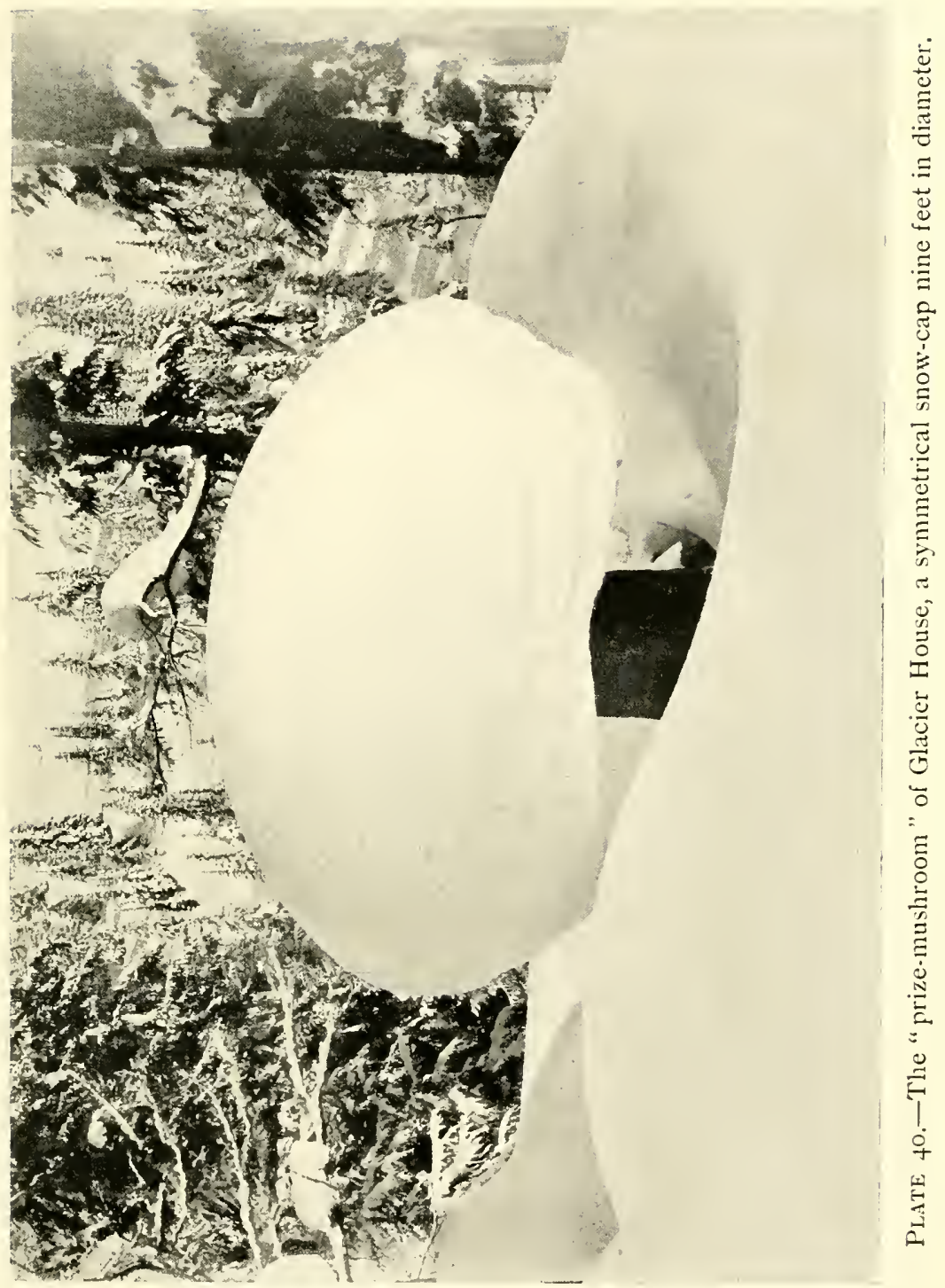





\section{CHAPTER IV}

\section{SNOW-MUSHROOMS AND CAHOTS}

Snow-1nushrooms.

Weather and snowfall in the Selkirk Mountains, B.C.Snowcaps on high stumps of felled trees at Glacier House resemble large mushrooms-Diameter 9 feet-Weight about I ton-Shape due to bending under its own weightMode of growth-Reason of their permanence.

On the Sparseness of the Falling Snowflakes.

Cahots, French name for undulations made by sledges in snow-Formed on the ice of the St. Lawrence-In the streets of Montreal-None in Manitoba during midwinter - Similar undulations on an ordinary rough road at Coniston, Lancashire, produced by a sledge. Experiments with a small model sledge-The undulations are produced without an initial inequality-And during slow and steady motion-They are due to a loose but adhesive condition of the road - Other examples of transverse inequalities of roads.

On 'Snow-mushrooms.

My Canadian tour was undertaken for the study of the forms and movements imparted by wind 


\section{WAVES OF SAND AND SNOW}

to drifting snow, but, as usually happens both in travel and research, unlooked-for things forced themselves upon the attention, and I shall deal here with two of these. The first is the form of snowcaps, determined, not by wind but by gravity; the second, the surface-waves on snowcovered roads, which are made, not by wind but by sledge traffic.

Travelling by train westwards from Banff, in the Rocky Mountains, I noticed that the snow was of the clinging kind and collected in protuberances around the base of trees and in mushroomshaped caps upon broken stumps. It was in the Selkirk Mountains, west of the Rockies, however, that the forms of clinging snow were most strikingly exhibited. Near Glacier House, the altitude of which is 4,000 feet above the sea, the railway traverses a forest composed of tall, straight pine-trees. Great numbers of these on either side of the railway have been cut down to provide timber for the long snow-sheds which protect the trains from avalanches. The base of the trunk being tough, the trees are not cut through at the level of the ground but at a height of about 6 feet above. The result is that there are on both sides of the railway-line hundreds of wooden pillars about 6 feet high and of a nearly uniform diameter 


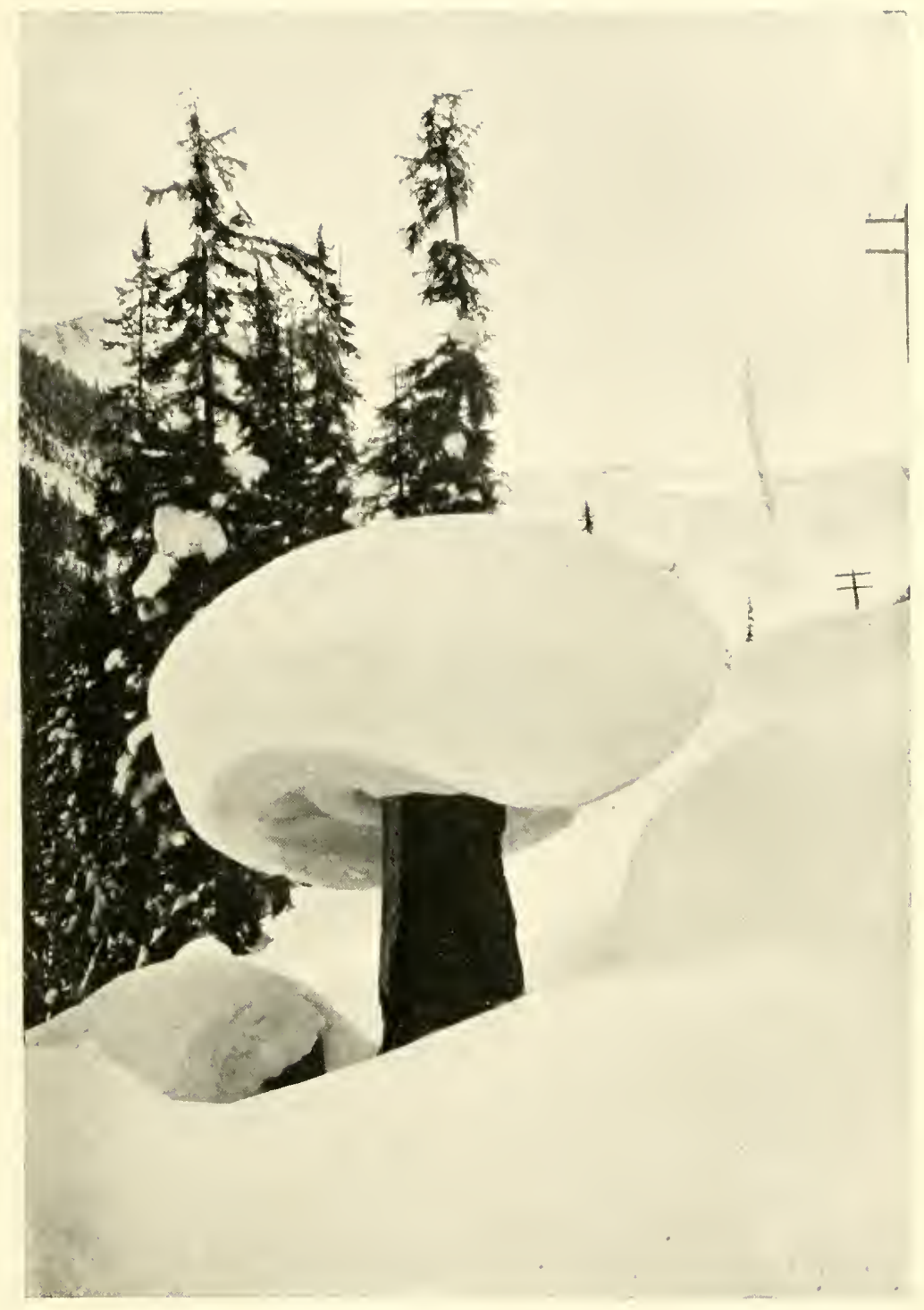

PLATE 4I.-A nine-foot snow-mushroom seen from below. 



\section{SNOW-MUSHROOMS AND CAHOTS 215}

of 2 feet. Upon their circular table-tops the snow collects. When the tree-stump is shorter the cap appears as a boss projecting above the general surface. In such cases there is a hidden cave beneath, into which one may easily fall, and from which it is difficult to get out when hampered by snowshoes (Fig. 28). The moist air from the Pacific Ocean, rising to the summits of the

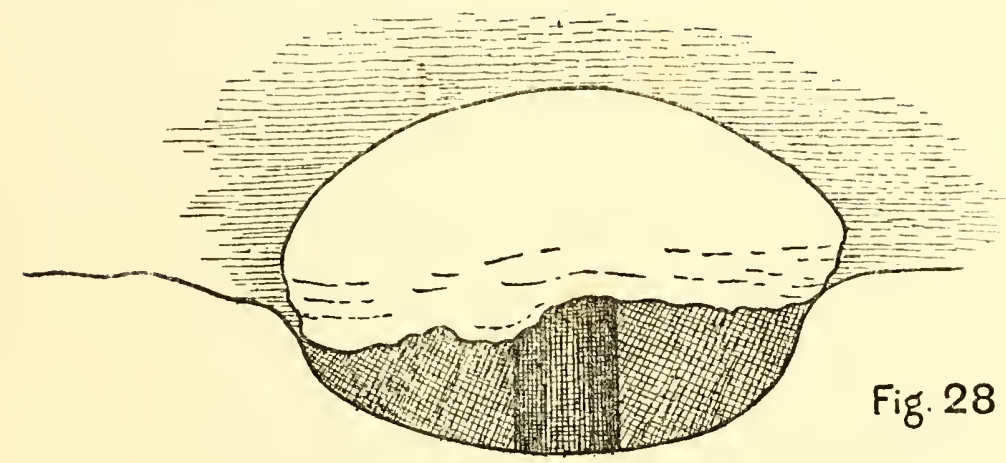

Snow Mushroom with hollow beneath.

from a photograph.

Selkirk Range, which attain an elevation of about I 0,000 feet, deposits a vast amount of snow. On February 4, I $90 \mathrm{I}$, the registered snowfall for the winter already amounted to $25 \mathrm{feet}$, although this had packed on the ground to a total thickness of 5 feet. The atmosphere of the valley at Glacier House is very still, and there is no drifting. The snowfalls are often very rapid, sometimes as much 


\section{WAVES OF SAND AND SNOW}

as 12 inches collecting in one hour. The temperature, I understand, often rises at such times to near the melting-point, and the flakes are then very large, as well as being adhesive. I stayed nine days at Glacier House, in order to study the snow-mushrooms, or caps, upon the tree-stumps. When I first saw them from the train I thought they might at any moment break under their own weight and that they would be readily dislodged. In fact, after passing through Glacier House to Vancouver, whither I was bound, I took the long journey back by the next train lest I should lose a transitory opportunity. I found, however, that the caps were so firm upon their pedestals that I could not dislodge them, and I was assured by the railway and hotel people, who were the only inhabitants of the district, that the caps remain to the end of the winter. I noticed, too, the singular circumstance that all these hundreds of snowcaps were perfect, none having broken by their own weight. Yet their weight was sometimes as much as one ton, as I found by taking their measurement and determining the specific gravity of the snow. On driving a pole into a snowcap. I found that the material was neither loose on the one hand nor icy on the other, but tough and tenacious, which accounts for the diffi- 


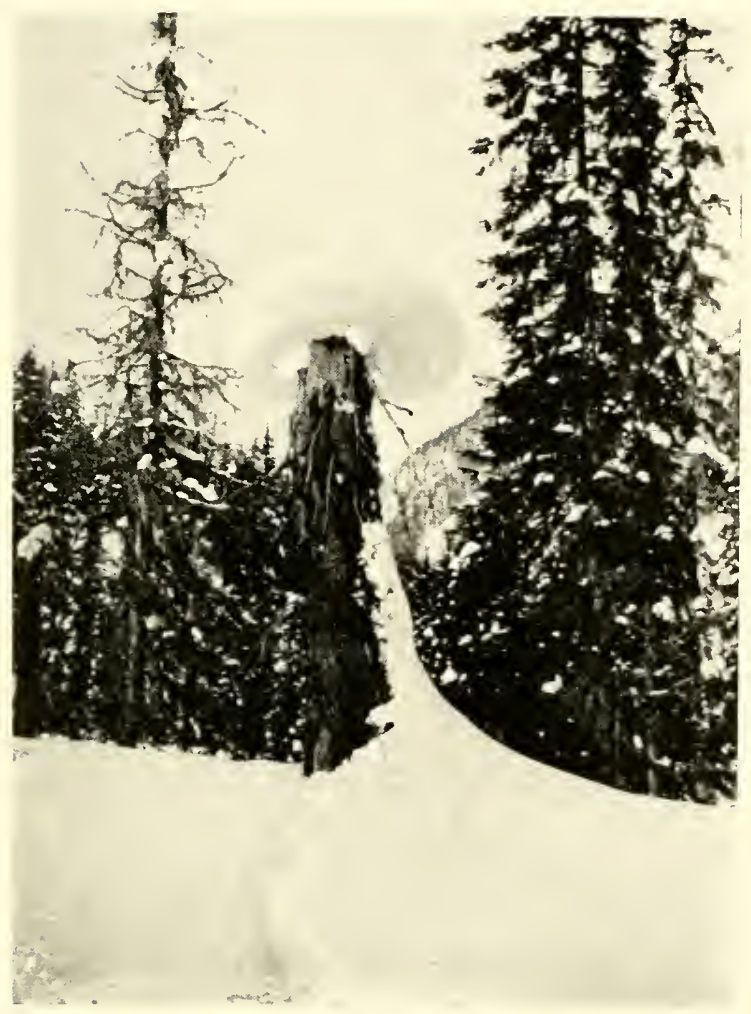

Plate 42.- Twelve-foot snow-cap on a broken tree at Glacier House. 




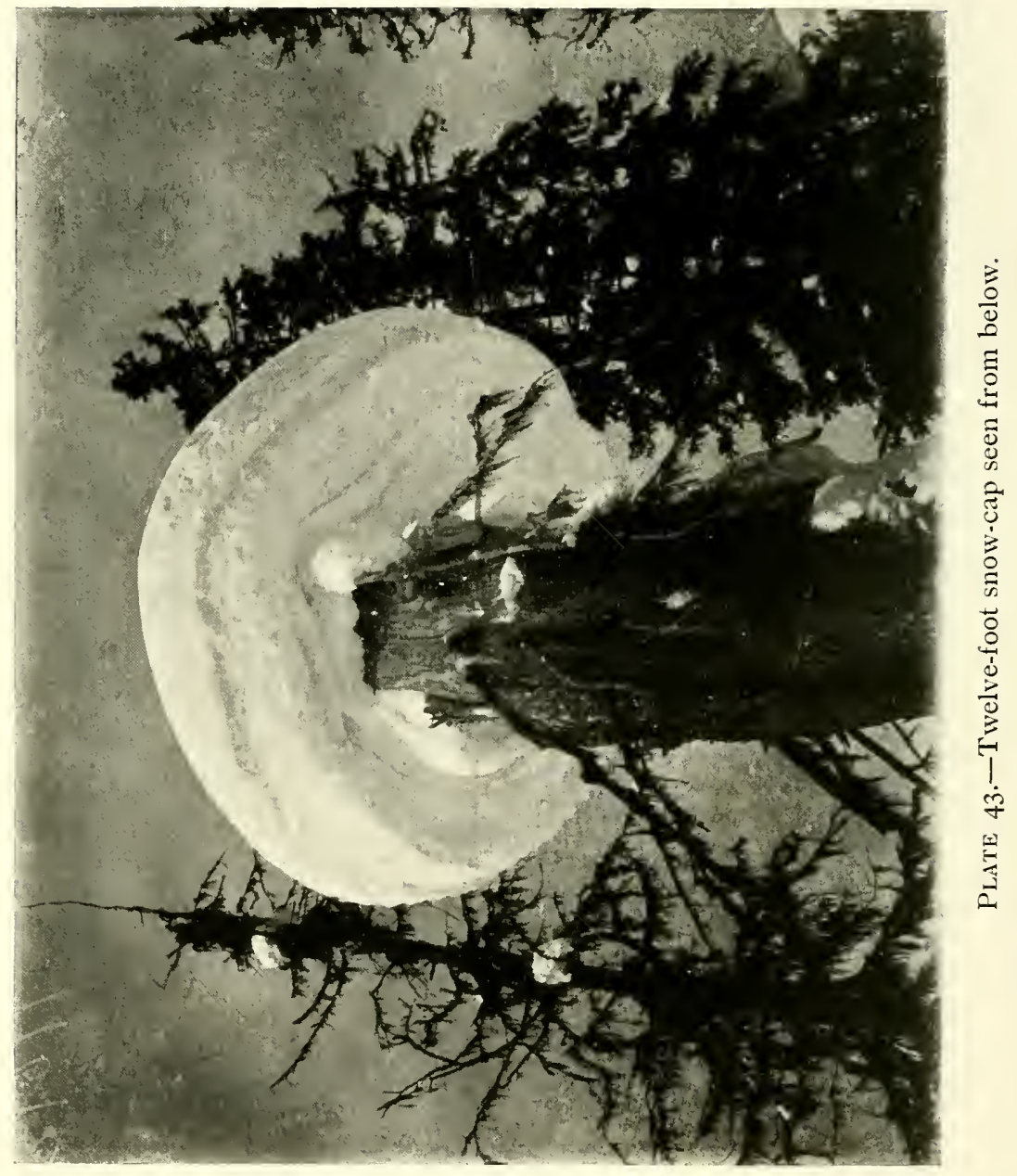


culty in dislodging them. The circumstance that the overhanging caps do not when overloaded break off close against the tree-trunk is due to the fact that the material which has accumulated during many snowfalls is stratified, and that the strata bend down steeply near the edge of the cap. Thus if there be an overloading at the rim or edge a small break occurs at once without any extension of fracture to the main mass. Moreover, the dome-shaped top is so steeply inclined at its margin that an additional load of snow would readily slide off. The photographs show clearly the contrast between the smooth surface of the upper stratum of snow, bent into a dome shape, and the rough edges of the pendent strata below, where the snow breaks away. The tree-stump pedestals had generally a diameter of 2 feet, and the caps were of the nearly uniform diameter of 9 feet-i.e., the snow projected $3 \frac{1}{2}$ feet all round. The depth of the snow upon the pedestal was about $4 \frac{1}{2}$ feet. Perhaps the most striking of all the snowcaps was one which had formed upon an unusually large tree which had been broken off by lightning, or some other agent, at a height of more than 20 feet above the ground. The diameter of this tree where broken was about 4 feet, and the diameter of the cap was about $\mathrm{I} 2$ feet. It must 
not be supposed, however, that the larger the treestump the more striking will be the appearance of the snowcap. On the contrary, the remarkable winter scene in the neighbourhood of Glacier House is due to a chance proportion between the size of the pedestals and the quantity of the adhesive snow. Mr. Howard Chapman, of Victoria, B.C., sent me photographs of snowcaps upon the stumps of the giant red-wood trees which grow farther west, and upon these snow about 4 feet thick merely gives the appearance of a white thatch with somewhat projecting eaves, there being no mimicry of the mushroom. On the other hand, snow cannot form a perfect, overhanging mushroom top upon the stumps of small trees, because the base is not large enough for the accumulation of a deep deposit; without depth there can be no welding into a tenacious mass, and without tenacity there can be no overhanging eave.

It is obvious that the dome shape of the snowmushroom is due to the increased bending of the material at a greater distance from the central support, and it may not be without interest to remark that many trees also acquire a dome-shaped top owing to the bending of their boughs under the action of gravity. 


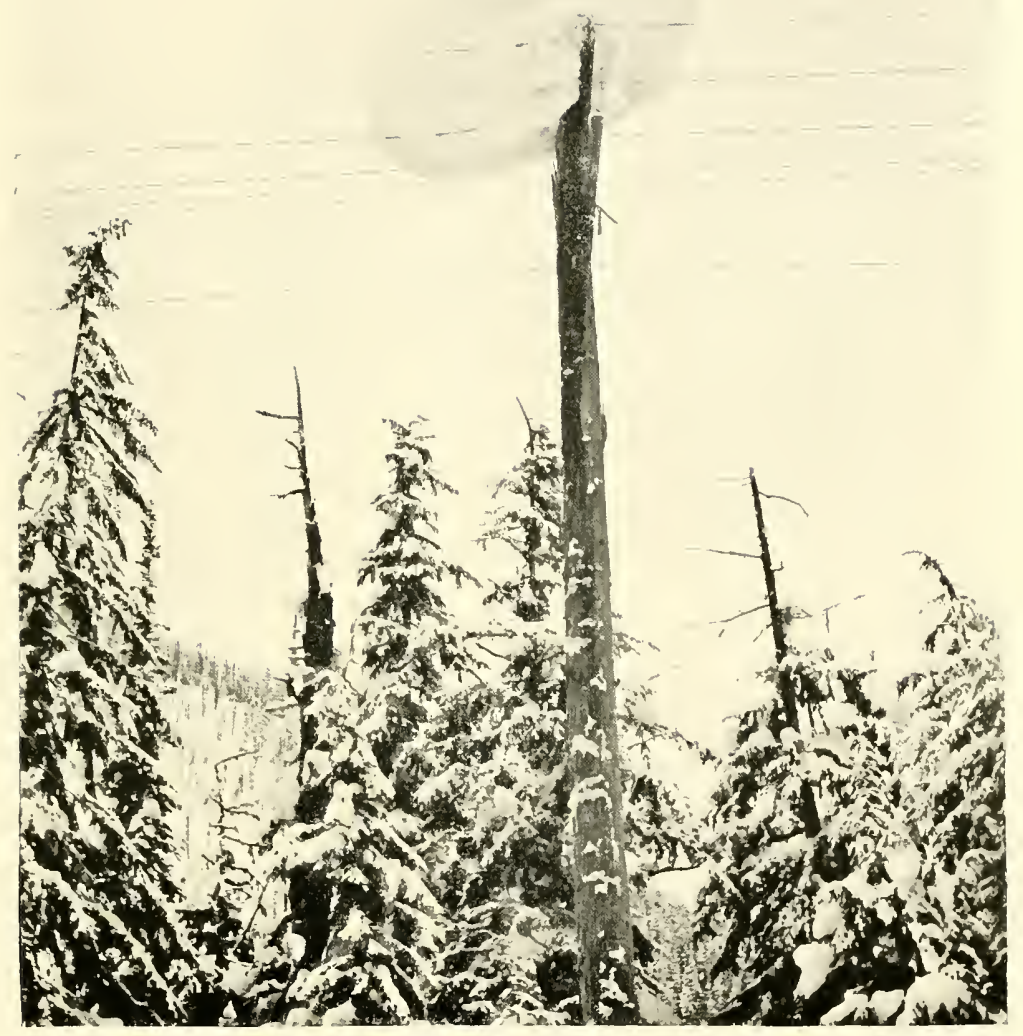

PLATE 44.-Snow-cap formed upon the crosspiece of a telegraph pole and upon the wires. 




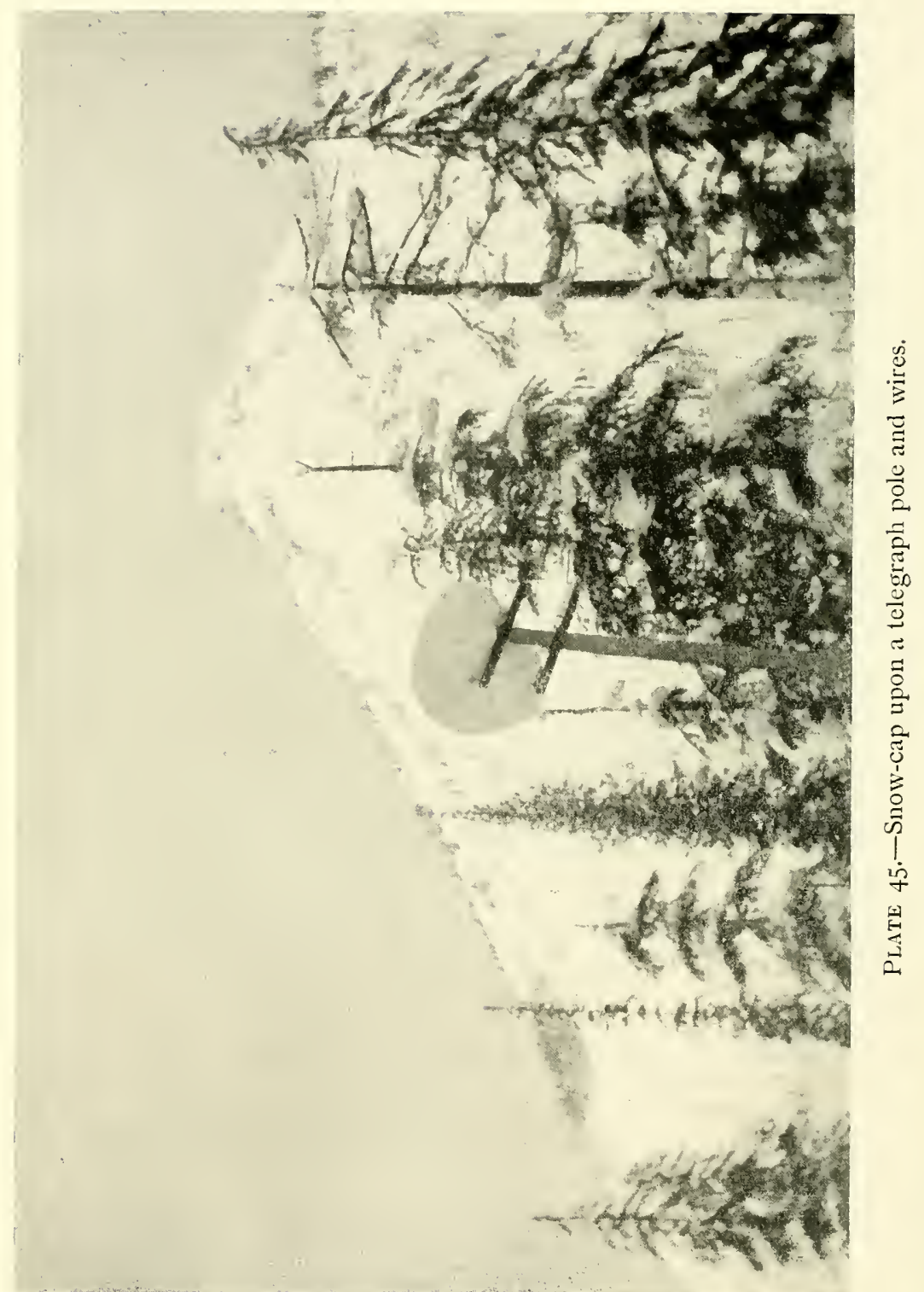




\section{SNOW-MUSHROOMS AND CAHOTS 227}

\section{On the Sparseness of the Falling Snowflakes.}

During a heavy snowfall the air appears thick with snowflakes. When the fall is so heavy that it accumulates to the depth of I foot in an hour, as sometimes occurs at Glacier House, the air must look so full of snow that the flakes would seem to occupy a considerable proportion of the whole space. I found, however, by timing the descent of many snowflakes and taking an average, that their rate of settlement was 2 miles per hour. Therefore when snow collects at the rate of $\mathrm{I}$ foot in an hour a column of the snowy air 2 miles, or I 0,560 feet, high and of I square foot section only contains enough snow to form a deposit of I cubic foot in bulk. Thus the falling flakes occupy less than one part in ten thousand of the space in which they seem to be so crowded.

On "Cahots," the Surface Waves Produced by Sledges.

In December, I90I, I noticed that the snow in some of the streets in Montreal and on the driving track across the frozen St. Lawrence had a remarkably undulating surface, obviously due to the sledge traffic. The average length of these undulations from crest to crest was $\mathrm{I} 3$ feet. The length of the sledge-runners varies, but 5 to 6 feet 
is a common size. The height of the undulations varied considerably, 8 inches being, however, about the usual height, reckoned from trough to crest. The profile was symmetrical both in the single track across the frozen St. Lawrence and in the streets, where the track is double and the sledges keep to the right-hand side. In the streets, however, the ridges were not quite at right angles to the course, the ridge being pushed slightly at both ends in the direction in which the sledges are driven, indicating a small amount of movement since their formation.

These undulations are known by their French name cahots, or jolts, which is the same word as is used for " holes" in ordinary roads.

A long series of cahots was very quickly produced upon the frozen St. Lawrence in snow about Io inches deep; indeed, it was surprising to see how soon the flat snow surface overlying smooth ice was thrown into waves by the sledge traffic. In one of the streets of Montreal I saw the old cahots being hacked up and the consolidated snow relaid. It was, indeed, more like ice than snow. At Winnipeg, during the great cold of January and February, the snow did not form cahots, except where, a snowdrift having consolidated, there were one or two slight undulations, obviously made by 


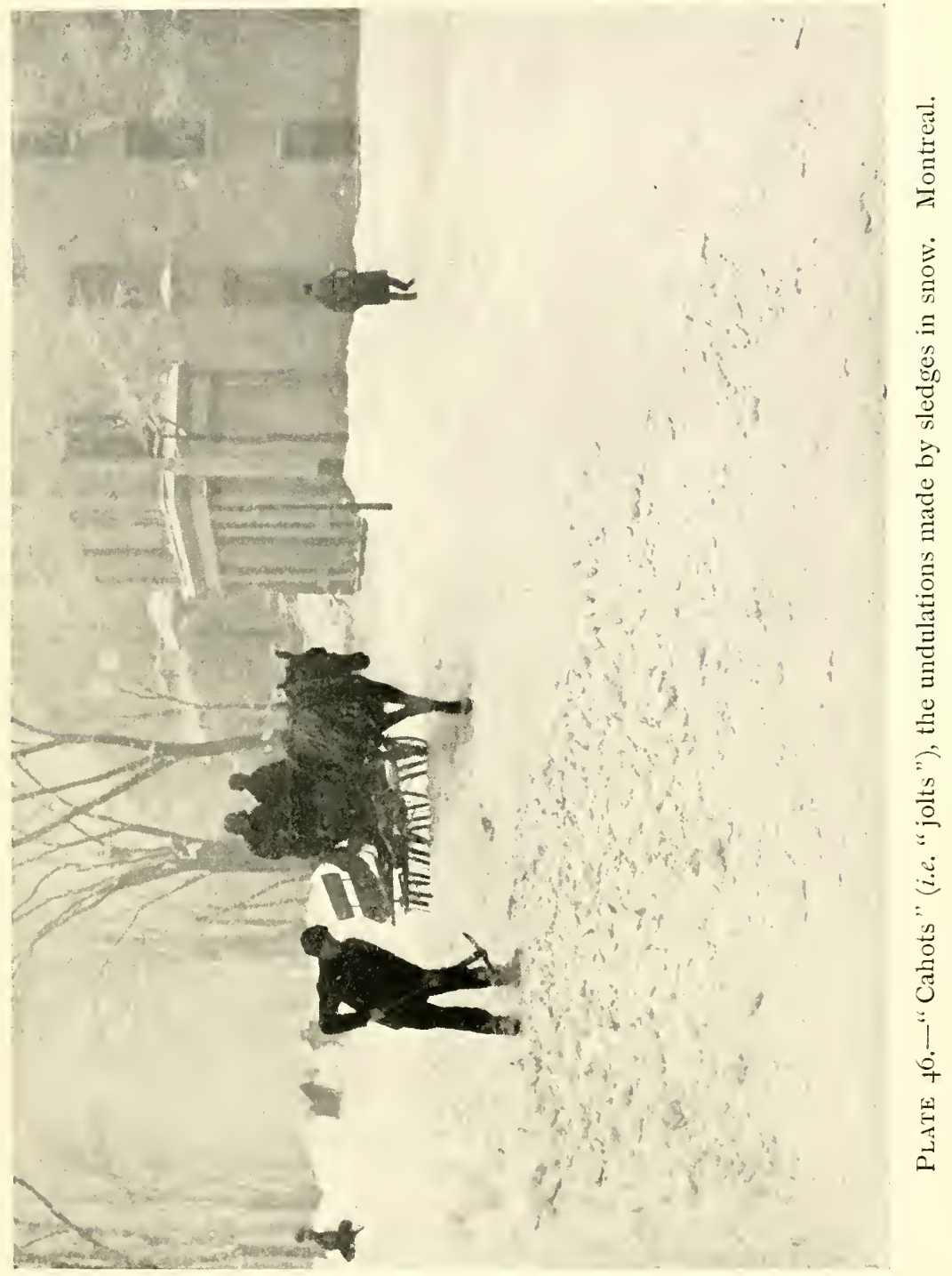



the bumping of the sledges in passing over the obstruction.

Those persons to whom I spoke about cahots had no doubt as to their origin. The transverse ridges and furrows, they said, were only produced when some obstruction made the sledge bump. This was usually hardened snow-e.g., a drift blown across a road. Sometimes, however, the sledge started bumping on account of a hole in the roadway beneath the snow. I decided, however, to examine for myself the conditions of their formation, both with respect to the movements of the sledge and the character of the surface over which it travels.

The motions of a sledge differ greatly from those of a wheeled vehicle. The gliding runner meets obstructions at a very slight, or grazing, angle, and is very easily deflected from its course. If the deflection be in a vertical plane, the sledge pitches as a boat does. If the deflection be in a horizontal plane, the sledge skids-i.e., swings sideways, and is then apt to capsize. Both these pernicious tendencies are minimized in carts by the rotation of the wheel. The skidding, or swinging, of the sledge is responsible for the fact that the undulations produced by it are broad, instead of being as narrow as the runners. 
It is not only in snow that sledges produce cahots, as I learnt after my return from Canada, during a visit to Coniston, in Lancashire, in September, I 90I. The road from Saddlestone slatequarry, on the hill called the "Old Man of Coniston," is in places so steep that precautions have to be taken in bringing down the slate. Half the load is placed on a two-wheeled cart and half on a sledge, which, being hitched on behind the cart, serves as a drag for the steeper parts of the track. When a gentler slope is reached the sledge is run on to a wheeled truck. The steep parts of the road down which the sledge passes are all in undulations of symmetrical profile, having, like the cahots in snow, rounded crests and troughs. The sledges pass over them in only one direction-viz., downwards-the empty sledges being taken up in the wheeled cart.

The length of the bottom of a sledge-runner was measured, and found to be 4 feet 8 inches, which is a little less than one-third of the wavelength of the undulations, which was I 4 feet 8 inches.

I arrived at Coniston on my second visit on August 6, I902, and occupied myself until August I6th with a further examination of the undulations caused by sledges. 


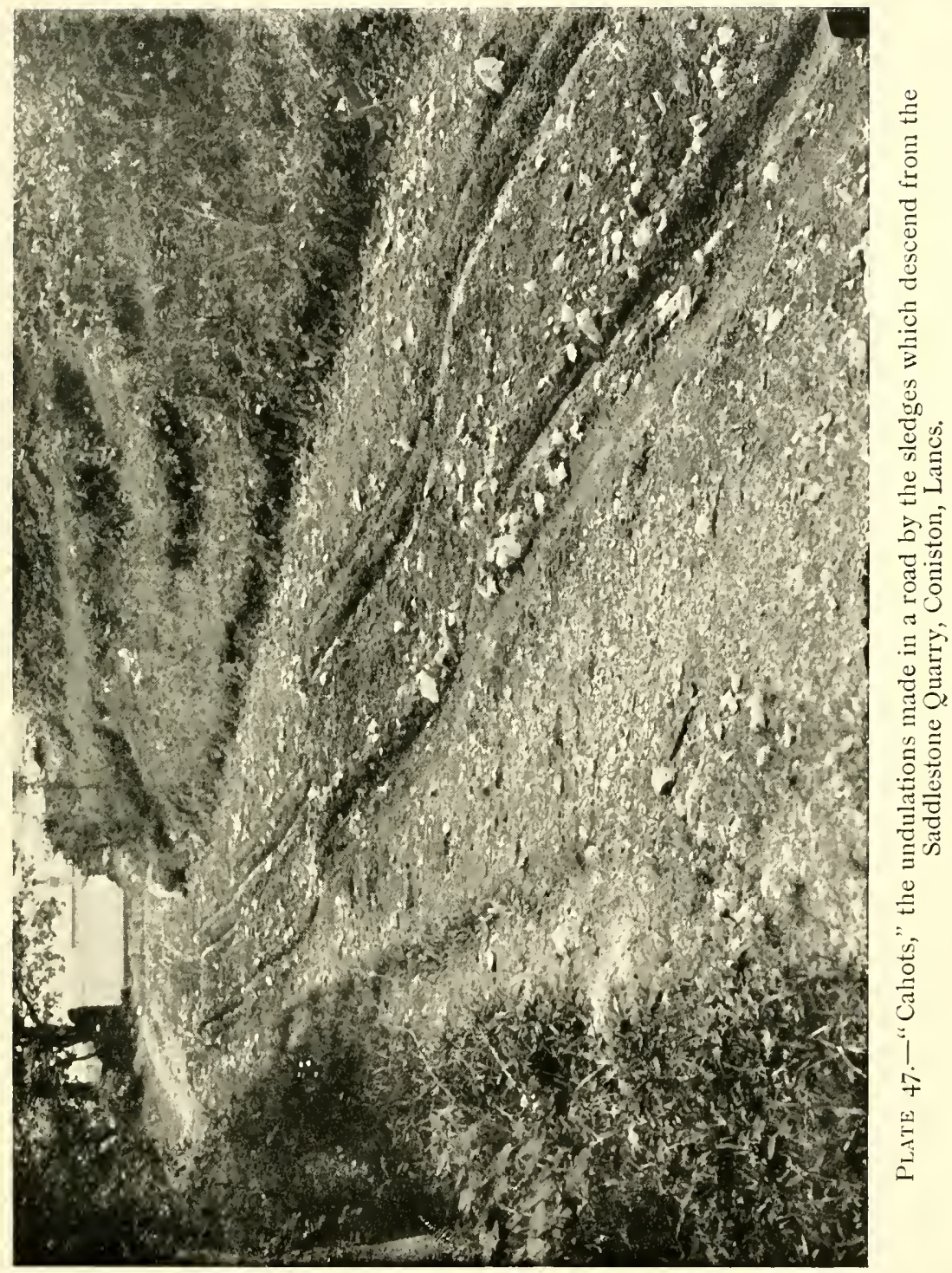





\section{SNOW-MUSHROOMS AND CAHOTS 235}

My first observation on ascending the steep portion of the quarry road just above the railwaystation was that the undulations were of considerably greater height, and that there were more ridges in continuous series than was the case in September, I90I. This I attribute to the circumstance that the summer of I90 I had been a dry one, whereas that of 1902 had been unusually wet at Coniston.

Plate XLVII., from a photograph taken on August I 3, I 902, shows a series of the undulations. The dimensions of the ridges, proceeding uphill, were as follows, the height being taken at both sides of the track:-

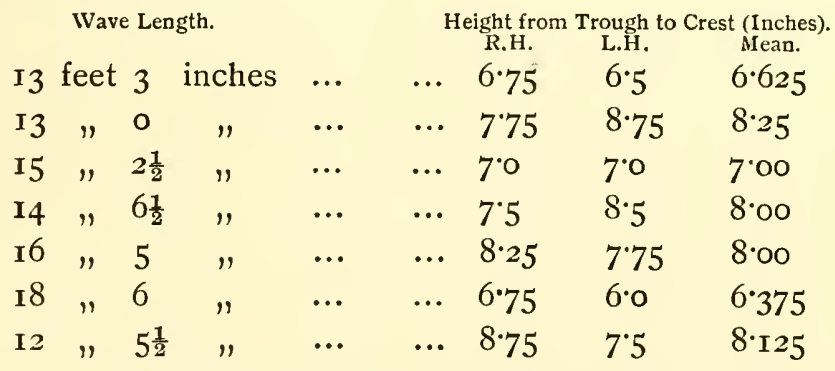

Mean length $=\mathrm{I} 4$ feet 9.2 inches. Mean height $=7.5$ inches. Wave-length divided by height $=23.685$.

Wave-length divided by length of sledge $=3 \cdot 165$.

It will be observed that the length of the undulations was practically the same as in I90I, the same sledges being in use. 
On another side of the hill is a track from another slate-quarry (Cove Quarry), on which sledges are also employed. On this track also I found undulations, but they were not so highly developed as on the Saddlestone Quarry track. The roadway itself was very loose, wet, and slushy. A group of four ridges measured from crest to crest I 3 feet, I 8 feet, I 3 feet, and I 5 feet, with an average wave-length, therefore, of 14 feet 9 inches. The sledges were similar to those used upon the Saddlestone Quarry track. The experiments subsequently made convinced me that the inferior development of the cahots on the Cove Quarry track was due to deficiency of binding power of road material.

Experiments upon the Production of "Cahots."

I proceeded to experiment upon the production of cahots. Obtaining a large basket which had a form something like a Laplander's sledge, I repaired to the little beach of sand and shingle on the shore of Coniston Water, near the steamboat pier. Having weighted my "sledge," which was not on runners, and should, therefore, have produced undulations more quickly, I hauled it about on the coarse sand and fine shingle of the highest portion of the beach, several feet 


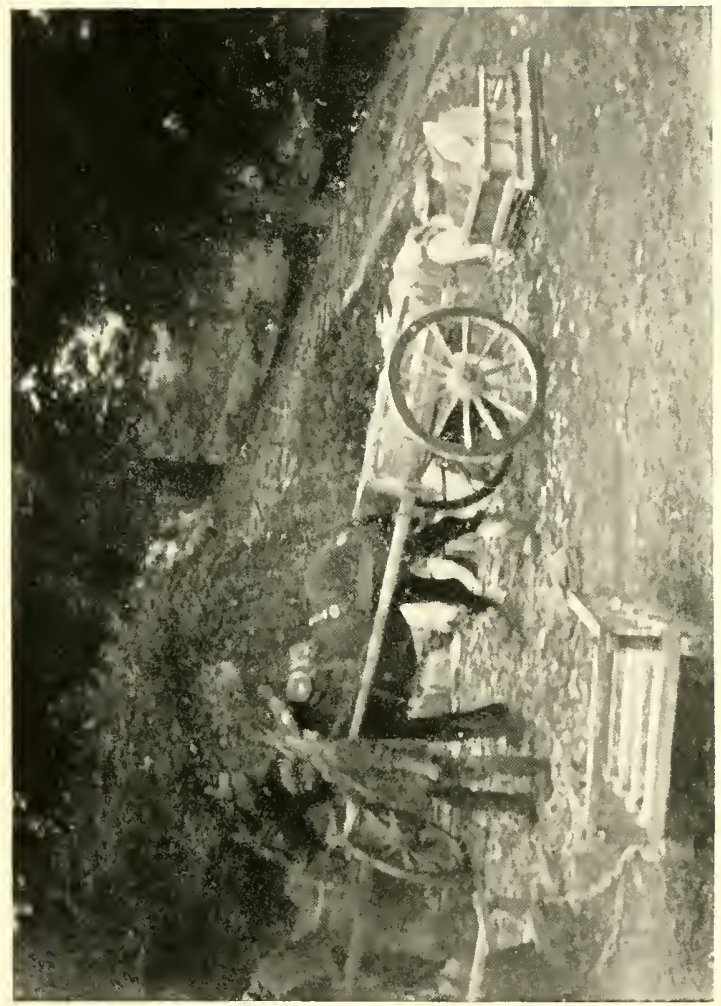

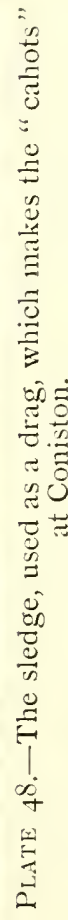






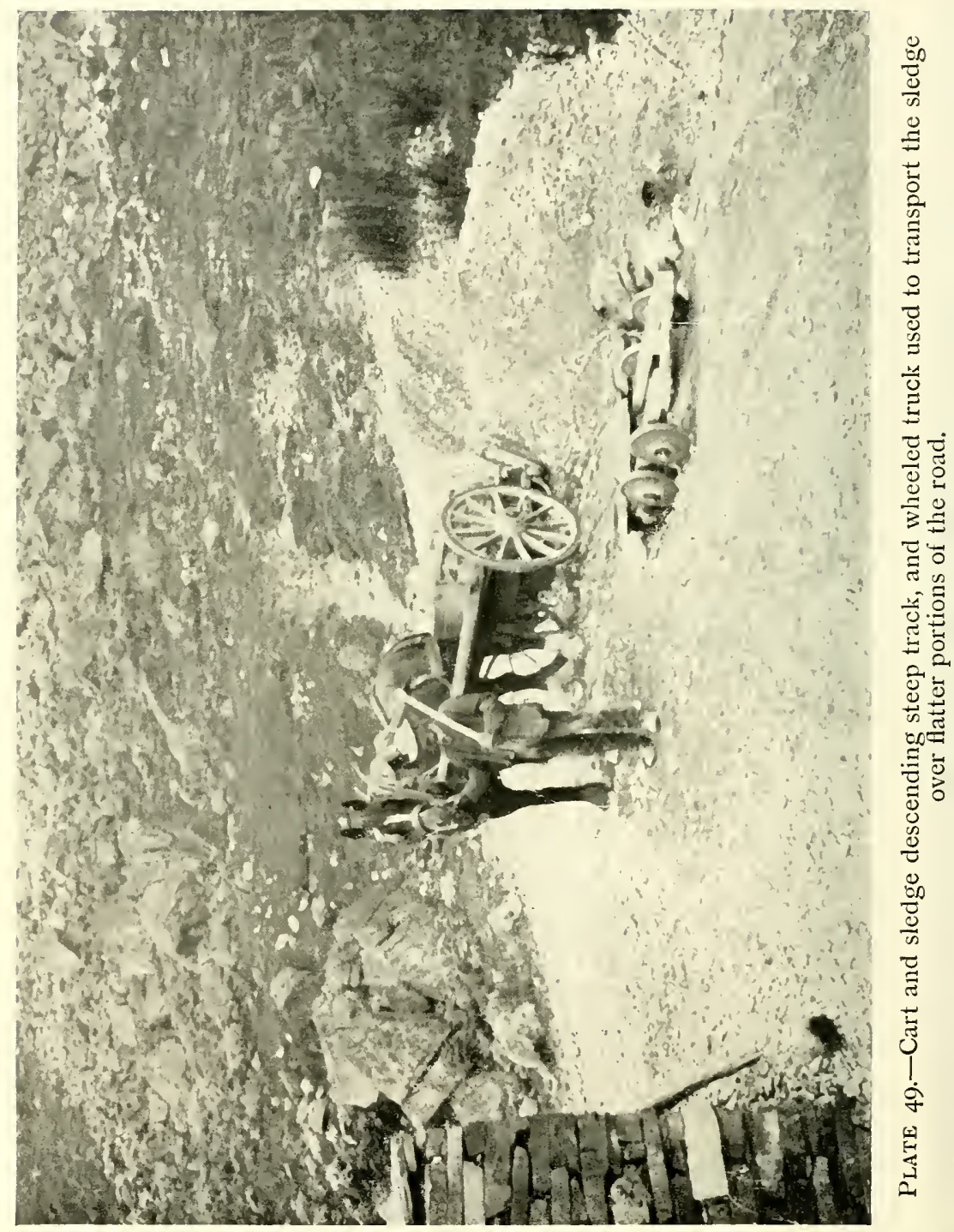


above the level of the lake. It displaced the loose material in a wave before its bows, but the track which it made was flat.

I then tried the effect of drawing it backwards and forwards over the same track, thinking that in this way I might produce some undulation; the track, however, remained flat. I was careful not to draw the sledge over my own footprints.

Friends having come to my assistance, a higher speed was tried, the sledge being dragged at about 8 miles an hour. I thought an undulation might arise from the tendency of small inequalities to make a sledge jump when moving rapidly, but in spite of a good deal of hard work the track of the sledge remained quite flat.

I had been trying whether undulations would form upon a level surface, because my experience with waves of sand and snow had shown me that the formation of surface-waves does not require the pre-existence of appreciable inequalities. However, as I had so far failed with the cahots, I made a heap of loose sand, and the sledge was run quickly over it again and again, always in one direction. In this way an undulating surface of regular wave-length was speedily produced by the jumping and bumping of the sledge. First a 
depression was scooped out to leeward of the initial inequality, then a mound was thrown up to leeward of the depression, and another trough was scoured out to leeward of this, and so on, wave by wave, the group of undulations continually extending. There was, however, one important difference between the experimental cahots and those usually produced by sledge traffic. The former, as the experiment was continued, became more and more unsymmetrical in profile, with a gentle weather slope and a steep lee slope, whereas the latter are symmetrical.

I decided to change my model sledge, and obtained a small mould, 9.25 inches long, used for casting lead, which was very heavy, weighing I $4 \mathrm{lb}$., and was suitably shaped, having the form of a barge.

With this I began again, drawing it along slowly and without the employment of an initial inequality. The small, heavy sledge sank somewhat in the loose, dry, sandy, or gravelly surface of the higher parts of the beach, driving before it a mound of loose particles, as in the former experiments. The furrow quickly deepened as the sledge was drawn backwards and forwards over the same track. My back was turned as I hauled, so that I did not see the sledge, but presently I noticed a change 


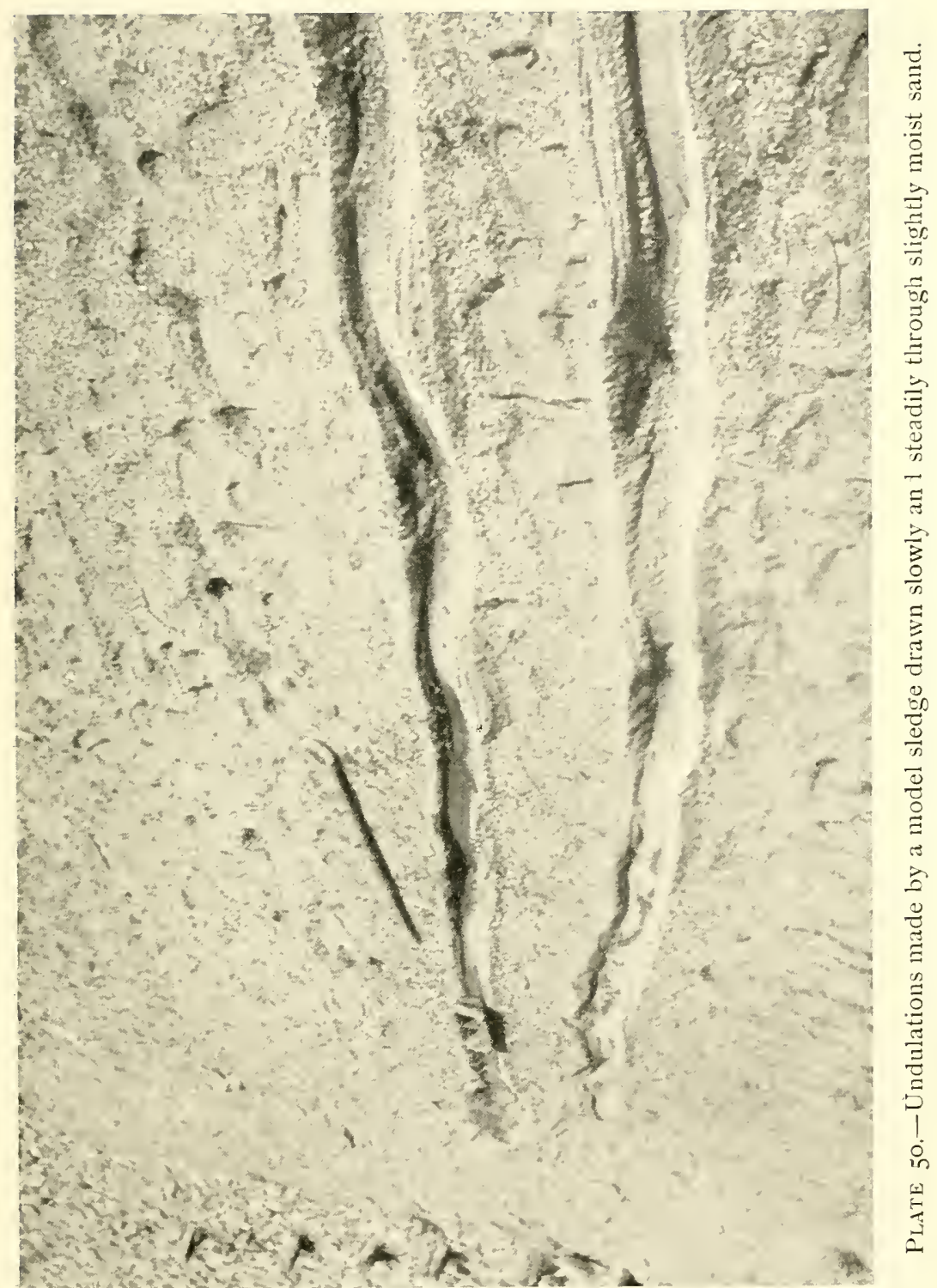





\section{SNOW-MUSHROOMS AND CAHOTS 245}

in the pull of the cord and, almost simultaneously, a change in the sound made by the sledge. The rattling over dry gravel had given place to a muffled note, and the prow of the sledge had begun to rise and fall. On turning to watch the sledge the cause of this was immediately apparent. The level of slightly damp, coarse sand had been reached, and the pressure of the sledge soon welded into a coherent mass the travelling mound of material in front. The sledge then rode over the obstruction, which after its passage was found to be perfectly incorporated with the road-bed, forming a gentle convexity of the surface. The sledge at once began again to scoop up more material and drive it in front. Presently it overrode the new obstruction, and a second wave-crest was thus formed.

The undulations increased very rapidly in amplitude, not only when the sledge was drawn backwards and forwards but also when drawn only in one direction. The undulations were symmetrical in profile, and similar in appearance and steepness to the cahots of the quarry track. No appreciable inequality was present to originate them, the speed of the sledge throughout was only that of a very slow walk-i.e., about $2 \frac{1}{2}$ miles per hour-and the pull was as steady as I could keep it. The 


\section{WAVES OF SAND AND SNOW}

principal condition for the formation of an undulating track by sledge traffic is, therefore, that the material scraped from the road should be adhesive. Neither pre-existing inequality of surface nor rapid driving of the sledge is necessary for their formation. The undulations produced by dragging the iron mould backwards and forwards over the same ground averaged 2 feet 8.52 inches in length from crest to crest, i.e., 3.52 times the length of the sledge. The cahots on the quarry track were 3.225 times as long as the sledge.

In order to ascertain if the ridges on the quarry track travelled downhill I put in iron pegs to mark their position, hoping that observations could be made after my departure; but the pegs could not then be found. The opinion of the manager of the quarry is that the ridges do not travel'; he says they become "too hard to move, being all as if crusted and cemented together." The road, he informs me, has to be remade from time to time, the ridges being hacked up, with considerable labour, and the material strewn in the hollows. The symmetrical form of the ridges supports the impression of their immobility, particularly as the sledge only traverses them in one direction. It must not be forgotten that the condition of the track varies with the weather. When the road is 


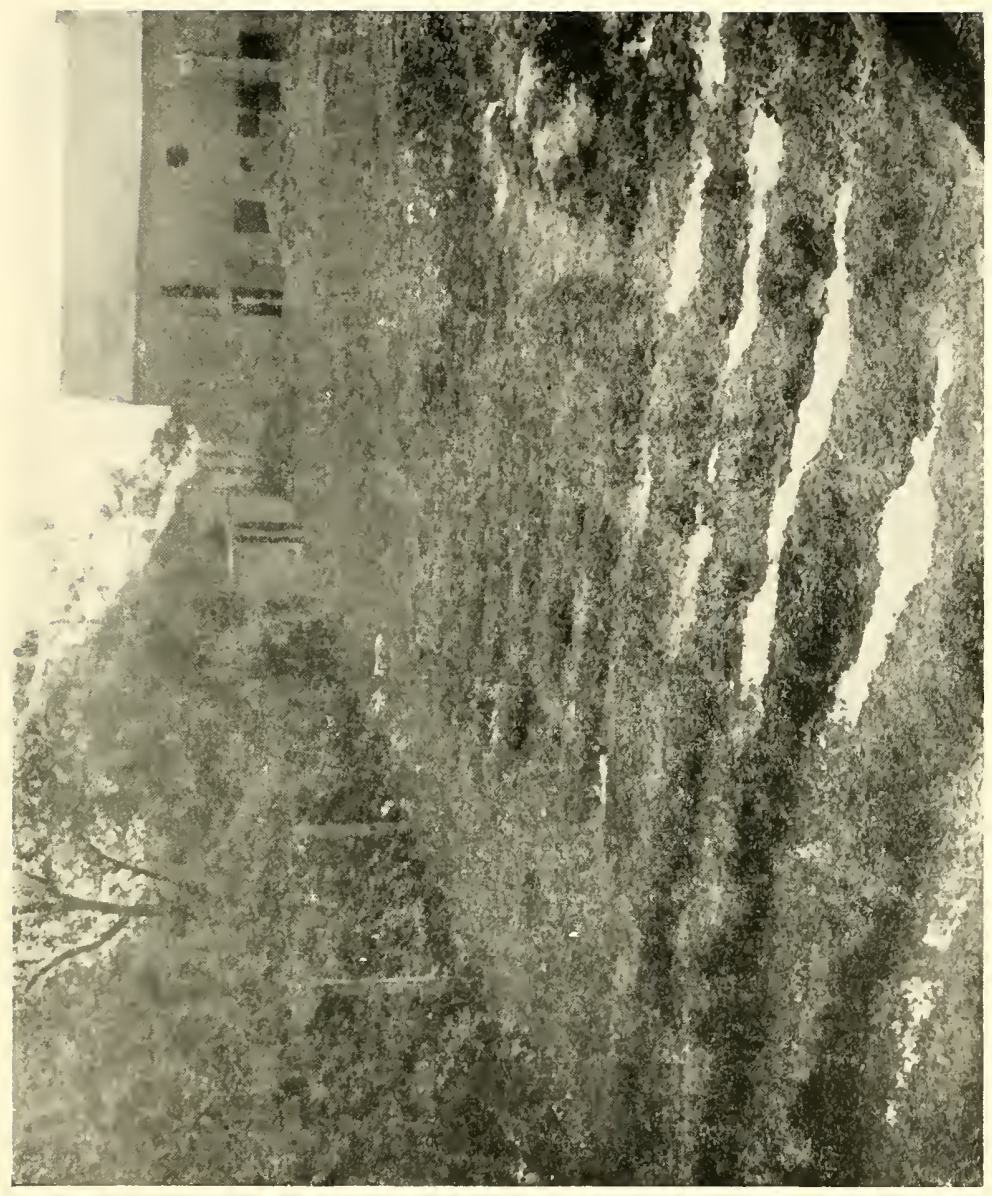

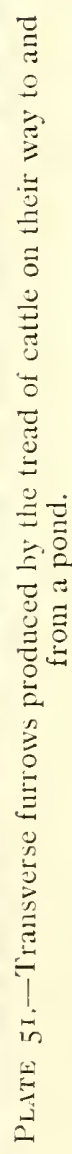





\section{SNOW-MUSHROOMS AND CAHOTS 249}

wet the cahots might at first travel, but when dry weather supervenes the ridges would set in a hard mass and become stationary.

Other Examples of Transverse Inequalities of Surface in Roads and Paths.

The principal inequality produced by wheeled traffic on a soft road or track is, of course, the rut, or longitudinal furrow, but in harder roads small transverse inequalities are often produced, although $I$ have never seen them attain regularity. On macadamised roads the first step in their formation seems generally to be the kicking out of a stone by the horse's hoof. The wheel soon enlarges the hole, and when the inequalities thus produced are examined it is seen that they are generally a succession of arcs of wheel-tyres separated by a: rather large stone firmly wedged. If an initial inequality be caused in a wood pavement by a bad, soft block, this is speedily multiplied in both directions by the bumping of the wheels.

The action of a wheel to make holes in a stony road is exactly the reverse of that of a roller employed for smoothing out the inequalities of paths. The roller, however, is drawn slowly. It is reasonable to assume that the depressing effect 


\section{WAVES OF SAND AND SNOW}

of a wheel or roller upon a projecting stone is proportional to its weight and to the time it remains upon the excrescence; that is to say, it is inversely proportional to the speed, whereas the impact against a projecting stone will increase, I presume, as the square of the speed. Hence the effect of slow, heavy wheeled traffic and of light, rapid traffic will be different in respect to the production of ruts and of transverse inequalities respectively, the latter being produced chiefly by rapid driving. The difference would be more noticeable but for the fact that vehicles used for rapid driving are generally provided with better springs than the heavy, wagons which go mostly at a foot's-pace.

While these matters deserve attention, it must be well understood that wheeled traffic does not produce large and regular undulations like those formed by sledges.

A slight transverse undulation in footpaths, such as the Broad Walk in Kensington Gardens, has not necessarily any connection, except that of form, with waves. This path is highest in the centre, so that rain runs off transversely to its length, making transverse grooves. The places first lowered are thus kept damper, and therefore softer, than the intervening spaces, so that the hollows wear away more readily than the convexi- 


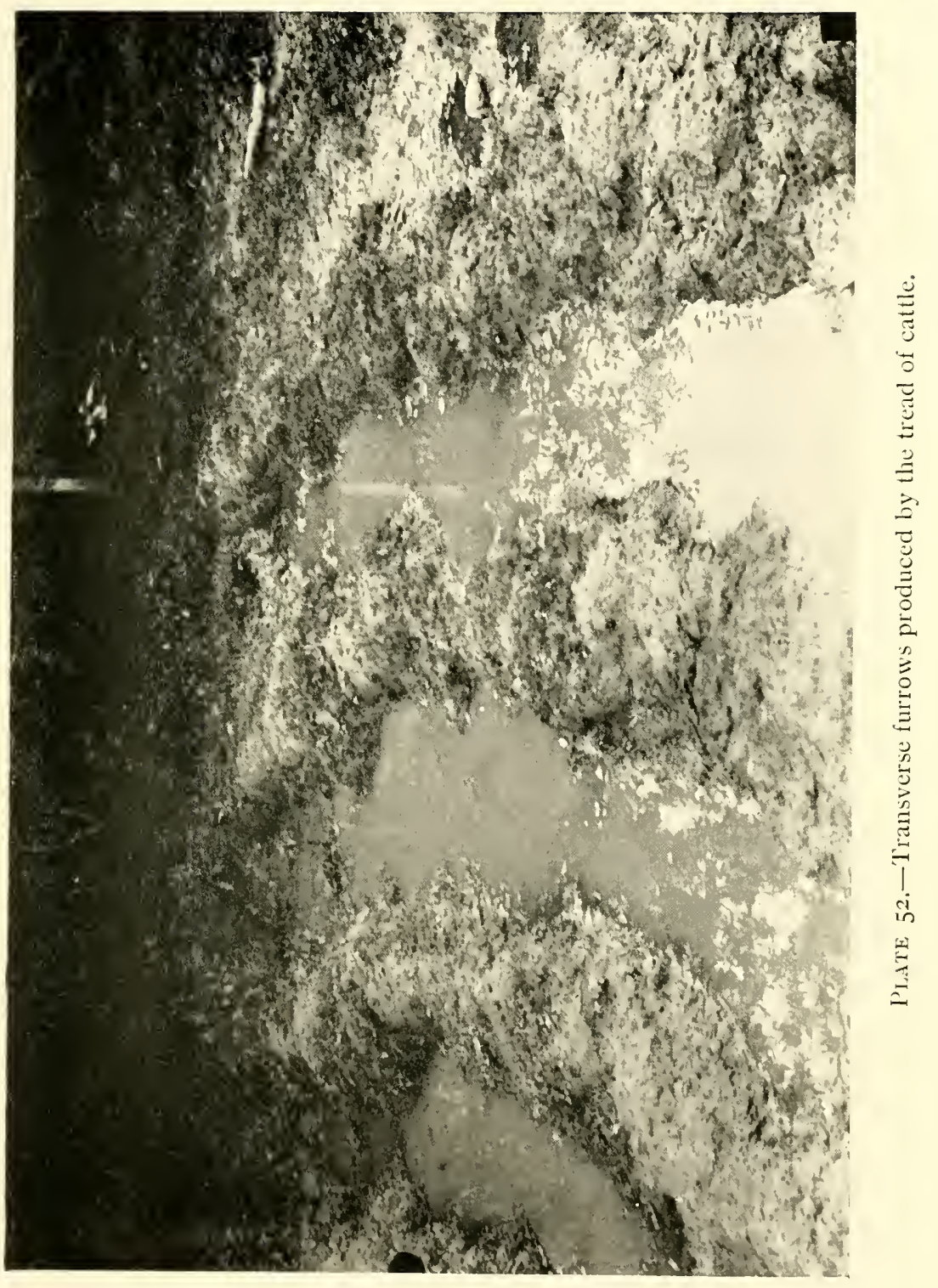



ties, and the tendency is for the path to acquire a slightly undulating surface.

Muddy lanes are sometimes trodden into transverse furrows by cattle, the intervening ridges being separated by a uniform distance, which is equal to the length of stride of the beasts. I have come across several examples, the best of which was on the track to a pond where the cattle drank, but I have not watched the process of treading. I presume, however, that the cattle, seeking the firmer ground, tread where their predecessors trod, thus deepening and regularizing the troughs and leaving the weaker ridges untrodden. 



\section{PART III}

SUB-AQUEOUS SAND-WAVES 



\section{CHAPTER V}

\section{RIPPLE-MARK AND CURRENT-MARK}

Ripple-mark.

Sir G. H. Darwin's experimental reproduction of ripplemarks-My measurements of natural ripple-mark-Osborne Reynolds' experiments.

Current-mark.

In very slow streams with a smooth surface-Effect of making the course of the stream straight-Action of current upon a body projecting above the bed of the streamCurrent-mark in shallow streams with a waved surface and a velocity of $\mathrm{r} 5 \mathrm{f}$ feet per second-Moving down-stream -The same in a stream with a velocity of $2 \cdot 2$ feet per second move up-stream-Dr. Owens' experiments on the diminished rate of settlement of sand in sandy waterExplanation of the up-stream movement of the currentmark or sand-ripples in a shallow stream with a rapid motion-Effect of progressive water-waves upon the current-mark of streams-Ratio of length to height of current-mark compared with that of ripple-mark.

Ripple-mark.

THE best known example of a sub-aqueous sandwave is the ripple-mark of the sea-shore, produced 


\section{WAVES OF SAND AND SNOW}

by the alternating currents of the swell. If the bottom of any vessel be covered with sand submerged by water, similar ripple-marks are produced almost at once when the vessel is rocked. The late Sir George H. Darwin ascertained the motions of the water during this process by observing the convolutions and dispersion of a dark, heavy liquid, a kind of ink, in fact, of which he introduced a small quantity into the water.I In these experiments the time of a complete oscillation of the water was about one second, which is nearly that of the smallest waves formed by wind, and less than that by which the natural ripple-mark is usually formed, the period of the swell of the sea being usually from about three to twelve seconds. In Sir George Darwin's experiments the ripples under the action of rapidly alternating currents could be seen to be built up from both sides by eddies which acted in quick succession, first on one side and then on the other, a very different action from that of a simple current. The ripples formed in a trough are symmetrical, as are those produced

${ }^{x}$ Mrs. H. Ayrton used, instead of ink, well-soaked ground black pepper, from which the finer particles had been washed away. This showed the eddying during violent motions which would have dispersed the ink. See "The Origin and Growth of Ripple-mark," by H. Ayrton, Proceedings of the Royal Society, Ser. A, 84 (1910). 


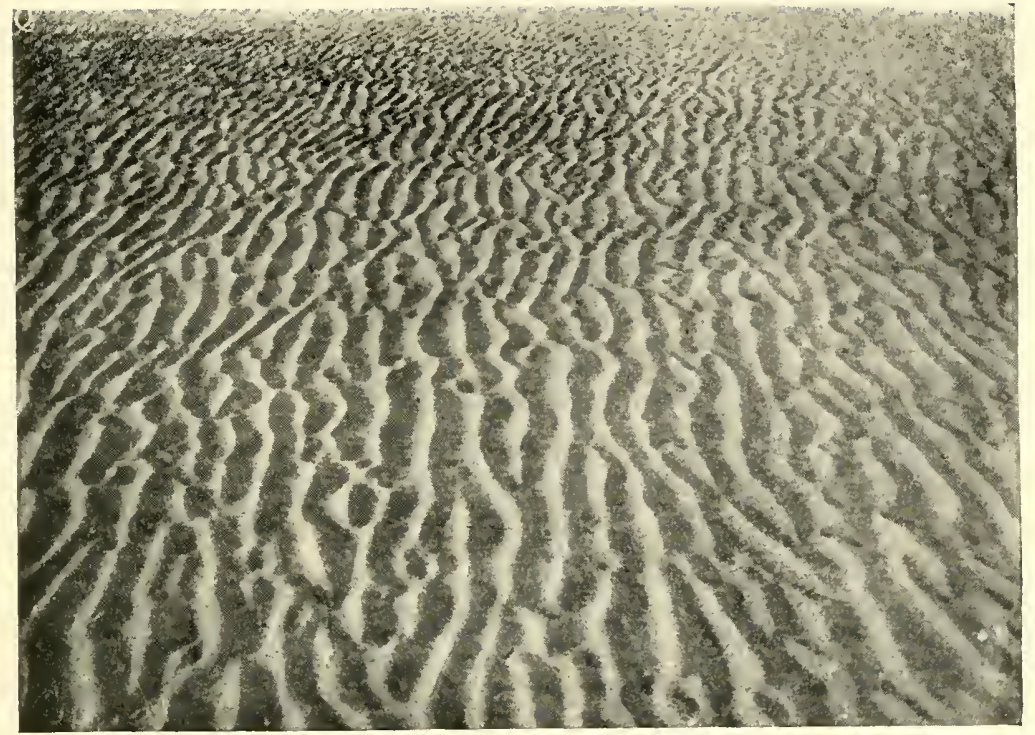

Plate 53.-Symmetrical ripple-mark produced by waves of the sea ; at Montrose.

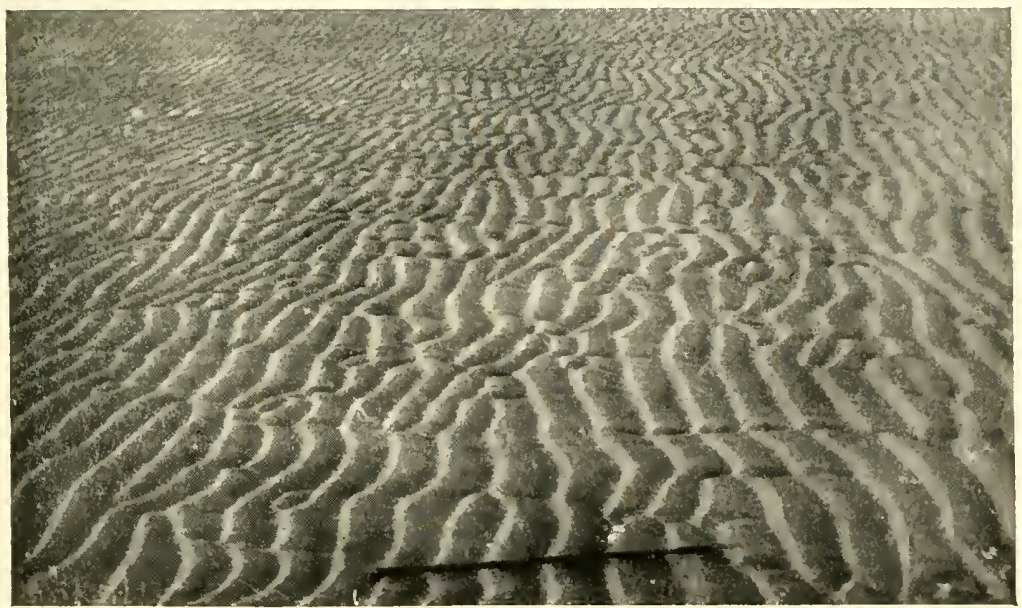

PLATE 53.-Unsymmetrical ripple-mark produced by waves of the sea. 259 



\section{RIPPLE-MARK AND CURREN'T-MARK 261}

by the swell of the sea in pools off-shore or where the waves are not near the breaking-point. Both are steeper than the sand-ripples formed by a simple current. I measured a series of eighty-six consecutive ripple-marks formed by waves on the flat shore of the Mawdach estuary in North Wales, and found that they had an average length of I. 99 inches and height of 0.36 inch, so that the length was only 5.53 times the height. The measurements were made after the water had receded, and, as the ridges had not preserved the sharp crests which they have when under water, I presume that the height had been originally somewhat greater. The ridges extended in broad, straight lines, and the wave-length had an appearance of almost perfect regularity. The measurements gave io per cent. of the mean wave-length as the average difference between the length of succeeding waves.

At Felpham, near Bognor, on the Sussex coast, I found almost symmetrical ripple-marks left dry on a plank. Seven ridges had an average height of 0.534 inch and an average length of 3.24 inches, so that the length was 6.07 times as great as the height.

The late Professor Osborne Reynolds in his working models of estuaries used "tides" with periods of from thirty to sixty seconds, which is 


\section{WAVES OF SAND AND SNOW}

considerably greater than those of the waves of the sea. When the model estuary was symmetrical, the oscillating currents, which represented natural tides, followed the same course during ebb and flow. In channels wholly submerged even at low water they produced ripples in the sand which were similar to the ripple-mark of oscillating sea-waves in being symmetrical-i.e., having equal slopes on either side; but they were not so steep, the length being twelve times as great as the height.

\section{Current-mark.}

The miniature sand-waves seen at the bottom of clear streams have been called "current-mark."

I have made numerous observations of the sandripples in a little stream which flows across a sandy. beach close to where I used to live on the Dorset coast, between Bournemouth and Poole Haven, and have from time to time verified these observations in other places.

The stream issued from a culvert, and flowed at first at a speed of only 0.63 foot per second, with a depth nowhere greater than two-thirds of an inch. The surface of the water here was smooth and unrippled. The sandy bottom was irregular, having pools in places with little cliffs on their upstream side one-third of an inch in height. The 


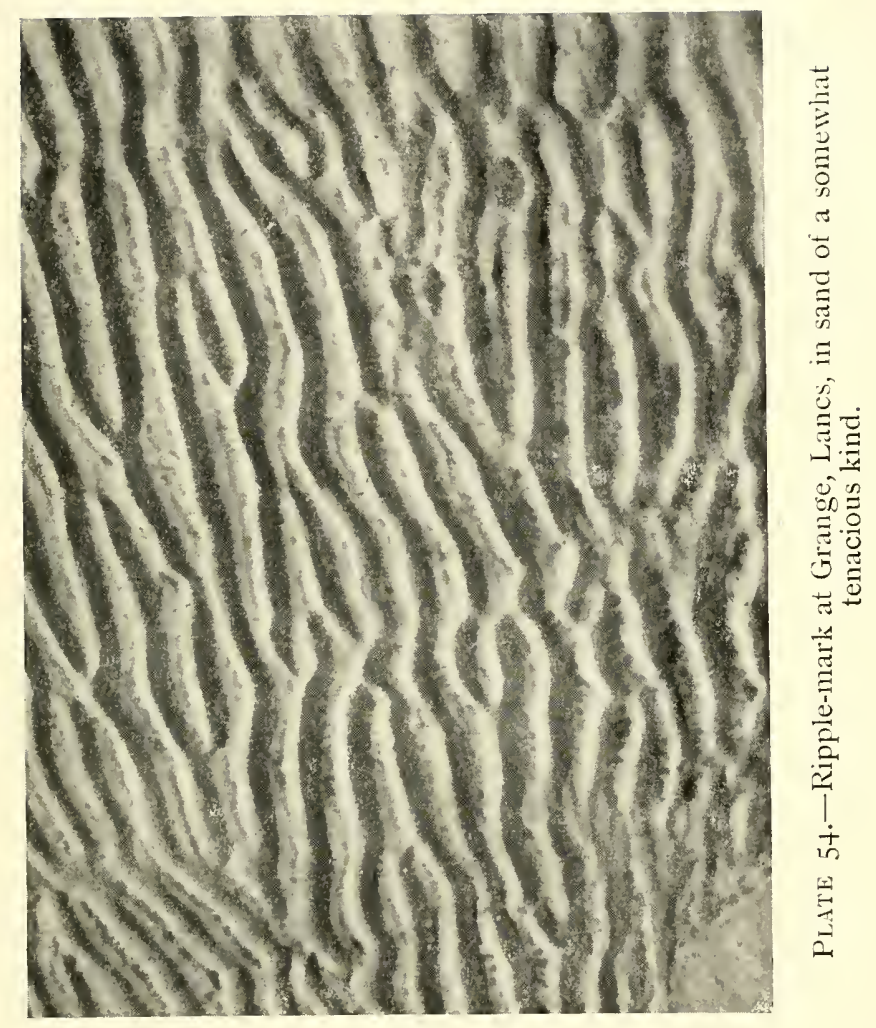





\section{RIPPLE-MARK AND CURRENT-MARK 265}

distances from one cliff to another were irregular, and although there was some approach to transversality, yet in this respect, as in that of wavelength, they did not satisfy the ideal of ripples or waves. Two opposing influences seemed to be at work, one trying to make transverse, the other longitudinal cliffs. The surface of the sand was compact and firm.

In a deeper stream which makes its way through the sandy beach at Mundesley in Norfolk, the velocity where it issues from its culvert was about the same as in the last case, viz., 054 foot per second, but the depth was greater, viz., 5 to 6 inches. In this stream the cliffs were at intervals sufficiently regular to give the impression of ripples or waves, and the average wave-length was 5.5 inches. There was a position to leeward of the deepest places from which I could see the sand departing in two directions, backwards towards the foot of the preceding cliff and forwards towards the brow of the next. The approach to each cliff from the up-stream side was by a slope so gentle as to be hardly perceptible. The surface of the stream was perfectly smooth and the water quite clear. No sand could be seen in suspension except a little which was churned up in the pool or trench on the lee of each cliff. 


\section{WAVES OF SAND AND SNOW}

The last case which I shall cite of one of these very slow streams is that of the upper part of the Bourne, the little brook which gives its name to Bournemouth. This has been canalized where it flows through the Pleasure Gardens. In the upper part, beyond the gardens of the Corporation, where the stream flows through the Durrant estate, there are some reaches where the bottom is covered with clean sand. In one of these the course of the: stream is perfectly straight, and it flows between perpendicular banks about seven feet apart. The depth was 3.75 inches, and the current flowed at the speed of 0.85 foot per second. The sand was in ripples of the form just described-i.e., with broad and nearly flat crests, and were not only fairly regular in wave-length but stretched almost the whole way across the stream in continuous ridges at right angles to the banks. Forty-six consecutive ripples had an average wave-length of 6 inches, and an average height of approximately 0.35 inch. I saw these in I 9 I I, fifteen years after I first observed the same type of sand-ripple in winding channels. Not until I saw the regularity of the ridges in the canalized stream did I realize that so slow a current could produce such regular ripples. I had noticed, however, something of the same kind with regard to water-waves. I have 


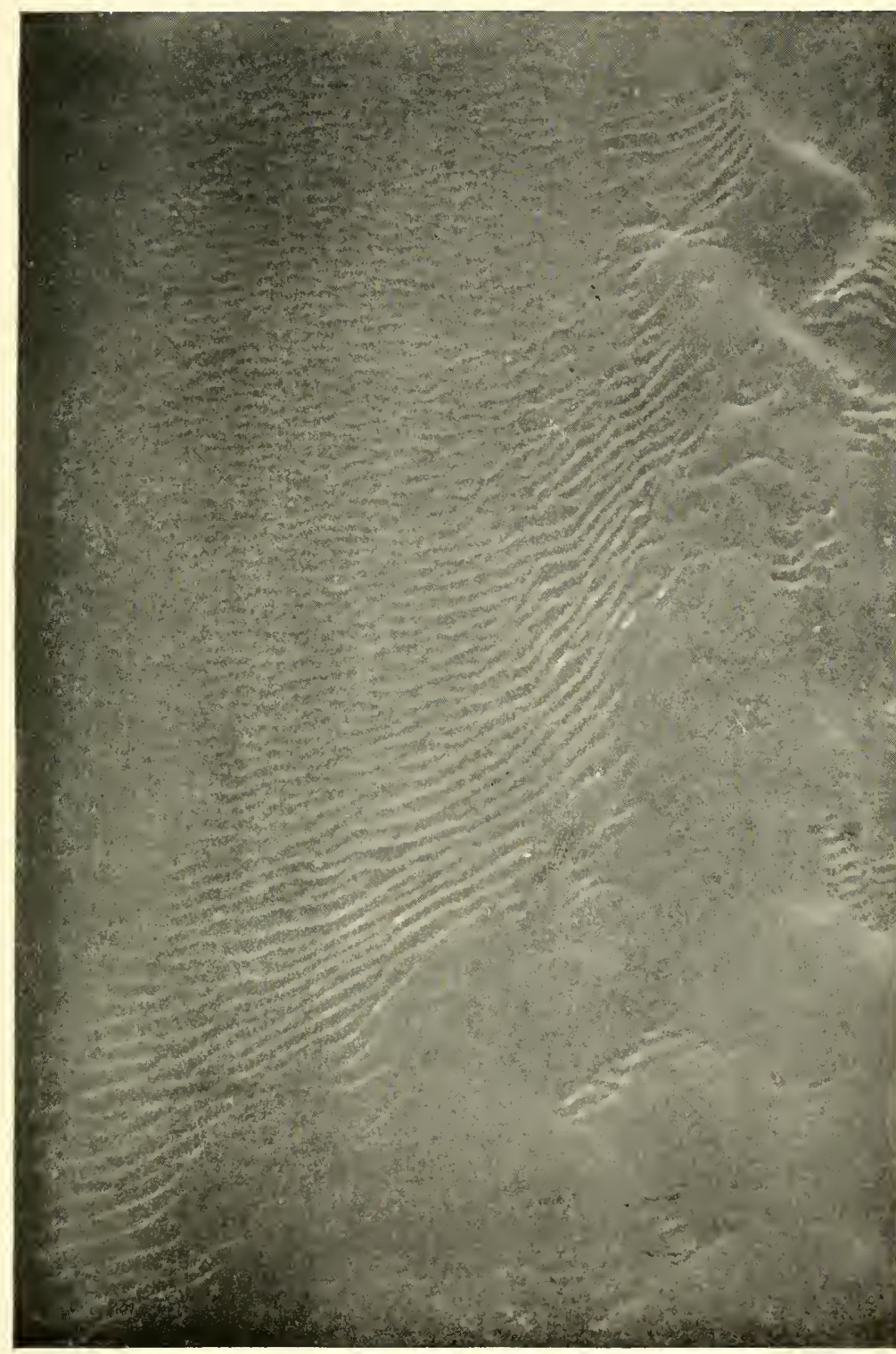

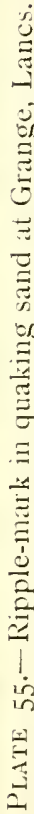





\section{RIPPLE-MARK AND CURRENT-MARK 269}

pointed out elsewhere I that a winding course is inimical to the formation of river waves of fixed position and size, because the lower layers of water do not flow in the same vertical plane ${ }^{2}$ as the upper, so that there is always a tendency to set up whirlpool motion instead of wave motion.

The presence of bottom currents crossing the direction of those of the surface is likewise inimical to the formation of transverse sand-ridges.

I was at first much puzzled by the fact that although the sand ripples in the Bourne were so numerous, regular, and well-developed, they appeared to be scarcely stirred by the water. I put sticks into the sand at the edge of the little cliffs, and after a quarter of an hour I found that the cliffs had not moved. Now, the sand ripples in the Branksome brook had moved half an inch per minute under the action of a somewhat slower current. I came to the conclusion that the current of the Bourne had had time and opportunity to do all it could to the sand. The troughs were covered with coarse-grained material. The broad, nearly

I See "The Travels of Ellen Cornish" (published by W. J. Ham-Smith, I9I3), p. I34, on the waves of the whirlpool rapids of Niagara.

"See James Thomson "On the Winding of Rivers in Alluvial Plains," 
flat crests had a very smooth surface of close-lying, fine-grained, clean yellow sand. The slow current, flowing with a close approximation to absolute steadiness, both of velocity and direction, could only move material on the nearly flat summits or crests by pushing it along the surface. Now, it is an accepted fact that the film of water next a solid is almost stationary, and such must be nearly the state in this case where the surface of the sand is so smooth and compact. Only larger grains projecting from the surface into the region of appreciable current would be pushed along. This process I conceive to have already gone on until all the available larger grains had been rolled over the cliff, where they had formed a covering to the surface of the succeeding pool.

Now, in the pool to leeward of the cliff the straightforward movement of the current is stopped, being replaced by a gentle pumping action. The power of the eddy to remove the sand depends, therefore, upon the slowness with which the sandgrains subside-i.e., for any particular kind of sand upon its fineness. The eddy could not toss away the coarser materials which the direct current had rolled over the cliff, nor even raise them sufficiently to get at the underlying finer material. The very slow current appears therefore to be only able to 


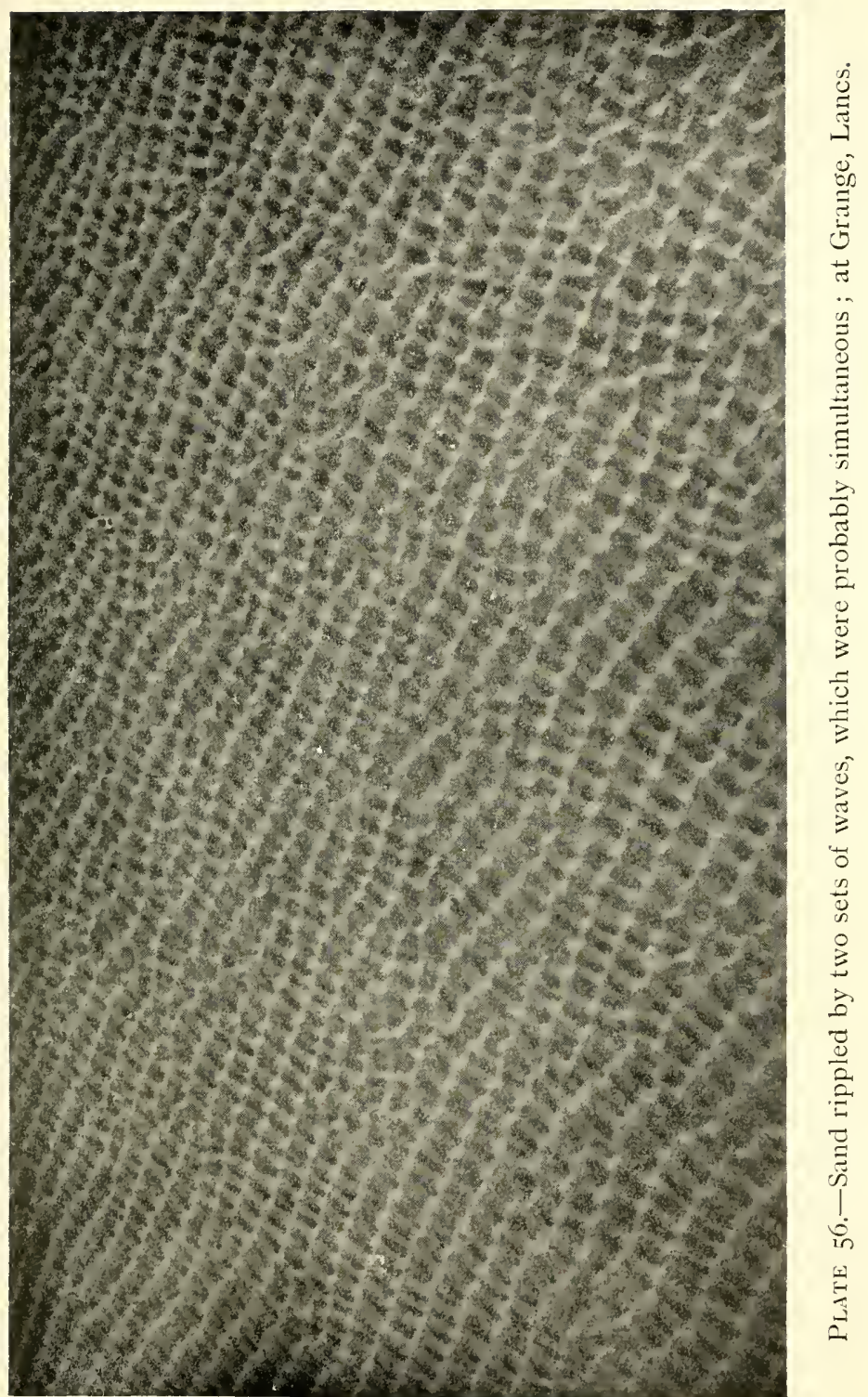





\section{RIPPLE-MARK AND CURRENT-MARK 273}

make and move the ripples foir a time, both processes coming to an end owing to a redistribution of material. I have not yet been able to test the above explanation by further observations.

Returning now to the Branksome brook, I will describe the ripples in the lower part of its course across the sandy beach, where it flows more swiftly. Where the velocity attained $I^{\circ} 5$ feet per second the surface of the water was in waves 3 inches in length and of no great breadth of front, and under each was a sand-wave with a rounded crest and nearly the same profile as the water-wave. The sand-waves had a height of $\frac{1}{2}$ inch. They travelled down-stream at the rate of $I$ inch in $3 \frac{1}{2}$ seconds, or 024 foot per second, the sand continually pouring over from the weather to the lee side of the crest. This progression was, I thought, due to that of the superincumbent water-waves, although these were of the form called stationary, or standing, waves. The circumstance that the water-waves themselves travelled down-stream was apparently due to erosion at the place of their origin, where the sandy bank or bed was eaten away by the action of the undeflected current. Accordingly, when I produced a train of waterwaves by placing in the stream a stone too heavy for the current to move, the sand-waves which 


\section{WAVES OF SAND AND SNOW}

formed beneath the stationary water-waves did not move, although the sand-grains could be seen to travel pretty freely over their corrugated surface. Where these things happened, with a current of $\mathrm{I}^{\cdot} 5$ feet per second, the water was quite clear.

On some days it happened that the stream acquired in its lower reaches a higher velocity, and churned up the sand so as to form' a turbid current. Whenever this happened a train of waterwaves, each with an underlying sand-wave, immediately arose. Unlike the waves last described, their fronts quickly broadened until they extended across the whole width of the stream. These waves were formed when the velocity of the current was $2 \cdot 2$ feet per second. Their length on different days was from 6 to 9 inches. The following is the most complete measurement which I obtained of one of the sand-waves and its superimposed water-wave. The length of both was 9 inches. The height of the sand-wave from trough to crest was $\frac{3}{4}$ inch, which is $\frac{1}{12}$ of the length. The height of the water-wave from trough to crest was I inch. The depth of water was $1 \frac{1}{4}$ inches on the crest of the sand-wave and I inch over the trough. The trough of the water was therefore $\frac{1}{4}$ inch higher than the crest of the sand. It is, 


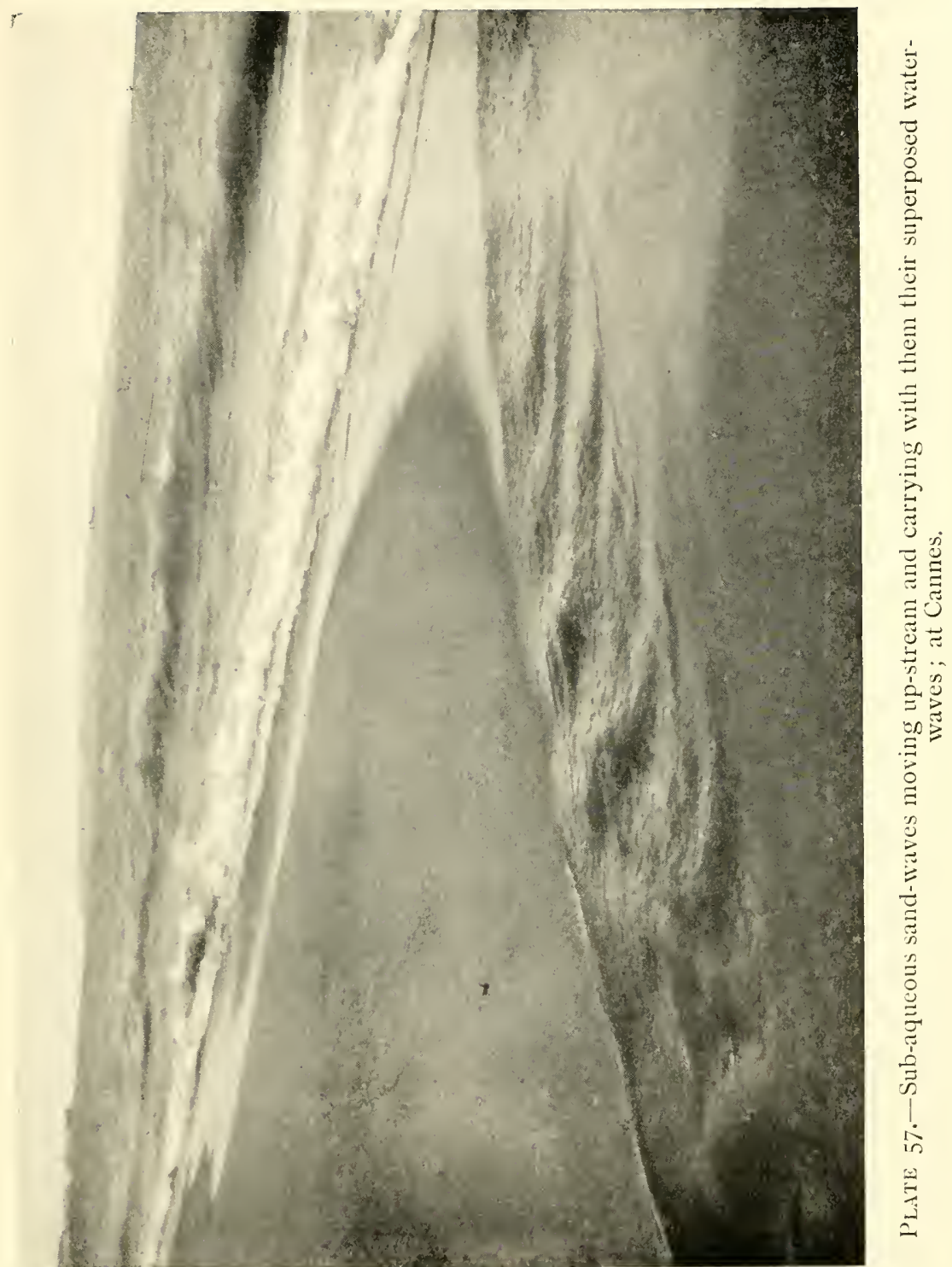

275 



\section{RIPPIE-MARK AND CURRENT-MARK 277}

however, difficult to be certain of the exact level of the surface of the sand, for below the turbid water the superficial layers of sand are gliding along. The superposed water-wave is, unlike the standing waves, usually formed in natural streams in that its front extends in a straight line quite across the stream at right angles to the current. It evidently owes its existence to the sand-wave, and not vice versa. The reason why these sandwaves suddenly arise when the velocity of the water is sufficient to throw large quantities of sand into suspension is, I think, revealed by a discovery made by Dr. J. C. Owens.I He found that sand-grains settle more slowly in sandy water than in clear water. Thus wherever erosion of a sandy bottom becomes so rapid as to make the water thick the rate of settlement is thereby diminished. Now, the level of a sandy bottom affected by the action of a current is only maintained constant when the amount of erosion and deposition are equal. It appears, therefore, that the velocity at which large quantities of sand are thrown into suspension is a critical velocity at which any minute depression due to erosion will be immediately deepened. If the sand, or some part of it, be heavy enough to

× Dr. J. C. Owens on "Experiments on the Settlement of Solids in Water," Geographical Fournal, January, I9II. 


\section{WAVES OF SAND AND SNOW}

stand in a ridge against the horizontal thrust of the current, as is the case with the sand of the Branksome brook, ripples or waves will immediately form. If the sand be too light, the level of the surface of stationary sand will be uniformly lowered, and above it there will be a stratum of water heavily charged with sand in suspension.

The most remarkable property of the sand-waves produced in very shallow water when the velocity attains about $2 \cdot 2$ feet per second is that they travel up-stream. This I have observed in the Branksome brook; at Mundesley, in Norfolk ; at Grange, in Lancashire ; at Torquay, at Cannes, and in other places. These sand-ripples which travel up-stream are indeed formed wherever tidal waters make their way swiftly through sand in a shallow current. The rate of up-stream motion in the case of the sand-ripples of the Branksome brook, of which the dimensions have been given, was $0^{\circ} 4$ inch per second, or 2 feet per minute. It is very curious to see a group of these sand-ripples moving in procession up-stream against the current which produces them. The sand can be seen to be accumulating on the up-stream face of each, whilst the down-stream face is scoured away. If a stone be placed in the trough between two ridges, it is soon covered by the advances of the ridge below 


\section{RIPPLE-MARK AND CURRENT-MARK 279}

it, and presently will be uncovered as the ridge passes on up-stream. The up-stream sand-ripples occur, as I have said, in groups, and each member of the group moves up-stream, but the first member -viz., that which is exposed to the undeflected current-is being flattened out all the time and soon disappears, number two succeeding it as the head of the group. This in like manner continues to travel up-stream, but its life is short, for the current planes off the top, making the ridge flatter until it vanishes.

I have already put forward an explanation of the origin of these sand-ridges in a current of this velocity. I proceed to offer an explanation of their up-stream motion.

The shallowness of the stream causes the surface of the water to rise at once in standing waves, and there is no eddy on the side of the ridges, a sort of stream-line motion being substituted. Thus the weather face of the ridges is exposed to a shower of the subsiding particles from the turbid liquid denser than that which falls upon the lee side. This is one-half of the process of up-stream motion. The other half is, I think, due to the circumstance that below the sandy water is a stratum of watery sand, which is just visible and appears to be dragged along. The firmly bedded sand, with only 


\section{WAVES OF SAND AND SNOW}

stagnant water in its interspaces, is lower down and cannot be seen.' Now, the superincumbent water, being in standing waves, flows almost exactly parallel to the surface of the sand-ripples, so that the watery sand must be dragged up the weather slope more slowly than it slides down the lee slope, and there is no eddy to bring it back on the lee side. Therefore, both on account of the sand which travels in suspension and on account of that which travels superficially, the ripples grow on the weather side and lose on the lee side, consequently advancing up-stream.

I do not think that up-stream sand-waves would be formed in deep water, for unless the water surface were in waves there would be an eddy on the lee side of the sand-ridges which would ensure a down-stream motion.

In mountain torrents I have often seen progressive waves assisting in the formation of the sandripples called "current-mark." The broken water of a waterfall descends intermittently, each lump of descending water sending out a travelling wave, ${ }^{2}$

I I examined a sample of firmly bedded sand taken from the bed of a stream where the velocity was only 0.54 foot per second, and found the volume of the interstices to be $\frac{5}{7}$ that of the real bulk of the sand-grains-i.e., $\frac{5}{12}$ of their apparent bulk.

"See "Waves of the Sea and other Water Waves," by Vaughan Cornish, p. 346. 


\section{RIPPLE-MARK AND CURREN'T-MARK 281}

and in each pool among the boulders the whole body of water can be seen to be heaving. On the little beaches in backwaters the progressive waves become steep-faced, with straight, broad fronts, and can be seen charging obliquely upon the shore in rapid succession. In this position the sand-ripples are almost entirely due to the progressive waves. Thus in a backwater below Spey Bridge, near Grantown, in Scotland, when the river was swollen during a rapid thaw, I observed progressive waves coming in upon the shore, thirtyfour to the minute, making sand-ripples. These were parallel to the shore, with a steeper front on the shore side, but I could see the sand-grains drifting with the current along the ridges, parallel to the shore. This existence of the two modes of motion in the sand, one general, parallel to the ridges, the other differential, at right angles to them, is a good illustration of the fact that sandripples, though passive, are truly waves.

Except near the shallowing shores the progressive water-waves in rapid rivers travel in the direction of the river and not athwart it. They, are not very noticeable, but can often be detected by half-closing the eyes so as to blur the outline of stationary bodies such as standing waves, a device which brings moving objects into relatively 


\section{WAVES OF SAND AND SNOW}

greater prominence. When the current and the progressive water-waves are in the same direction the latter no doubt assist in producing the unsymmetrical sand-ripples called current-mark, and, I expect, make them a little steeper than they would be if formed by current alone. In a shallow rock basin in a mountain torrent in Switzerland I found a patch of rippled sand left bare. From its position I could be sure that the ripples had been produced by a throbbing and pulsating current. The sand was sufficiently tenacious to stand vertically, so that I was able to cut a longitudinal section and make an impression of the profile on paper. I found that eleven consecutive ripples had an average wave-length of 0.443 inch and an average height of 0.057 inch, the length, therefore, being 7.8 times as great as the height, which, though less steep than the ripple-mark of the sea-shore, is steeper than the ripples and waves which I have measured in steadier currents.

At Grange, in Lancashire, I measured unsymmetrical sand-ripples still covered to a depth of 2 inches by water. The water was then stagnant owing to the subsidence of the tide, but the ripples had been obviously formed in a current, and the situation was such that there was probably some 


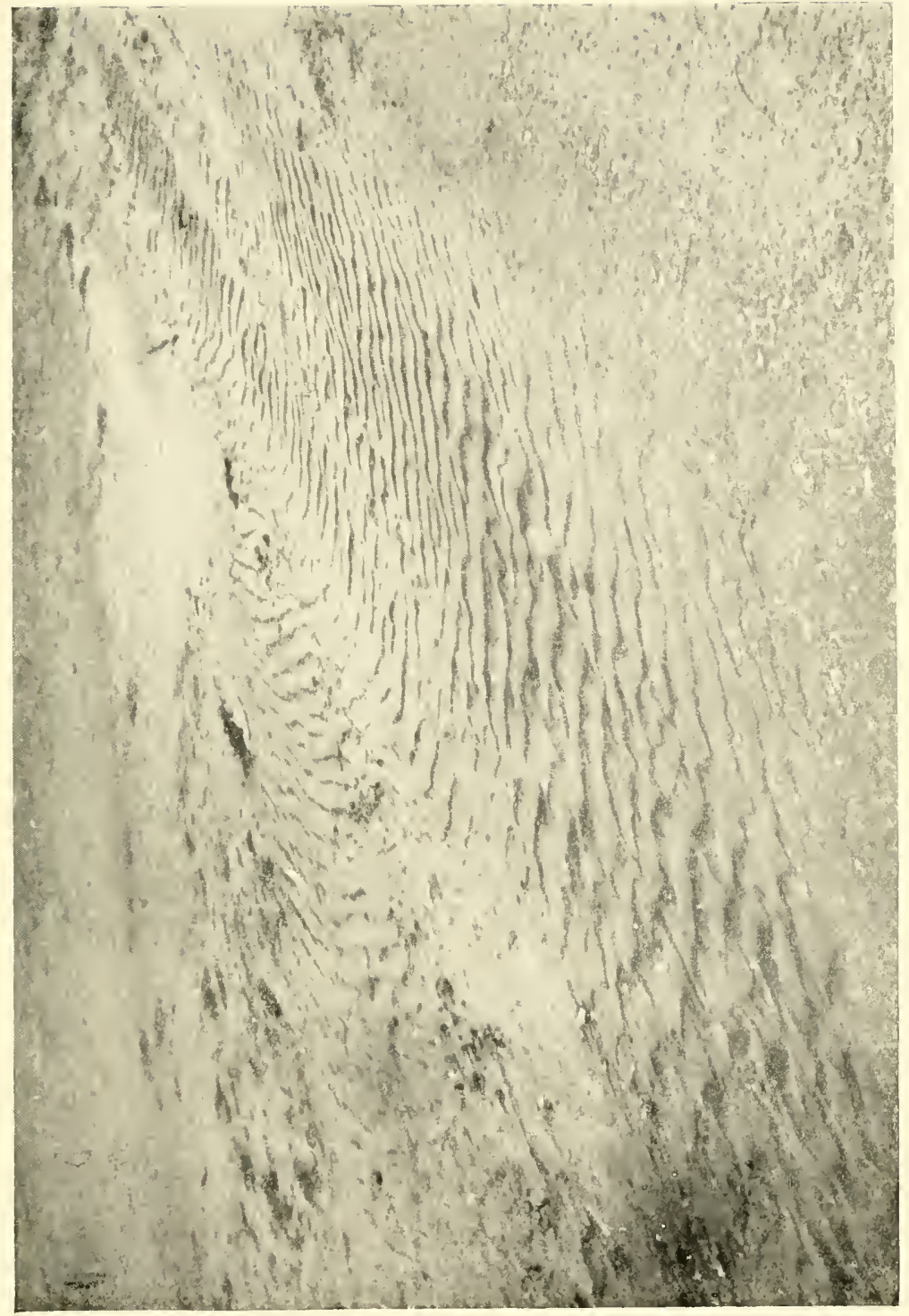

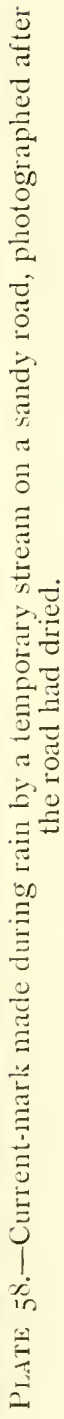





\section{RIPPLE-MARK AND CURRENT-MARK 285}

co-operation by progressive waves. Eight ripples had an average length of 6.156 inches and height of $0.6 \mathrm{I}$ inch, so that the length was IO.I times the height. They were sharp-crested, and therefore of a very different appearance from the sandripples of the same length formed in the creeping current of the canalized Bournemouth brook, which had almost flat summits, and were only about half the height. On the sandy road on the top of the East Cliff at Bournemouth I found current-mark

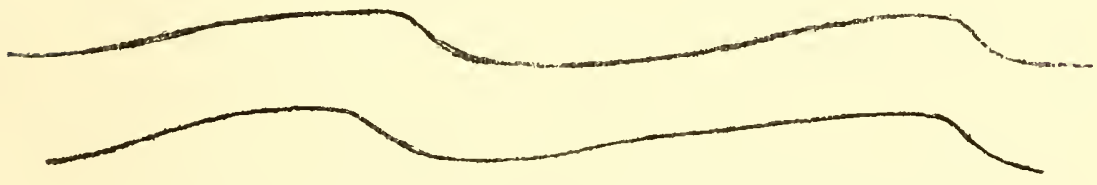

Fig. 29--CuRrent-Mark on ROAD AFter Thunderstorm.

left after a thunderstorm. Where a pool had formed the ripples had a wave-length of 3 inches, and the ratio of length to height was I $24 \mathrm{I}$; but where the water had run off instead of escaping by subsidence the ripples were left flatter, the wavelength being 16.80 times the height. Fig. 29 shows four consecutive ridges.

In many clear rivers which have a sandy bottom sand-ripples are a noticeable feature, ranged in long series, sharp-crested, with gentle slope on the weather side and steep on the lee. I may 


\section{WAVES OF SAND AND SNOW}

recall their appearance to the memory of many readers if I mention particularly the rippled bed of the Tiber at Rome and of the Arno at Florence. At Innsbruck I saw them grouped in an interesting way on a sandbank to leeward of a broad pier of the bridge. In this backwater the current flowed towards the pier, and then, turning, bifurcated and made its way to right and left to the main streams on either side of the pier. All these complicated currents were faithfully recorded in the direction of the current-mark of the sands.

In the Leven, in Lancashire, I saw current-mark arranged in regular ridges at right angles to the course of the river and extending from bank to bank. The place was where the railway crosses the tidal river on the way from Ulverston to Windermere. I was myself a passenger in the train and unable to reach the sands, but I judged the wave-length of the current-mark to be about 9 inches.

I am not able to establish by observation the continuity between current-mark having a wavelength of about 9 inches or I foot, which is commonly seen in clear, shallow streams, and the larger sand-waves, which are generally unseen during their growth owing to their situation or to 


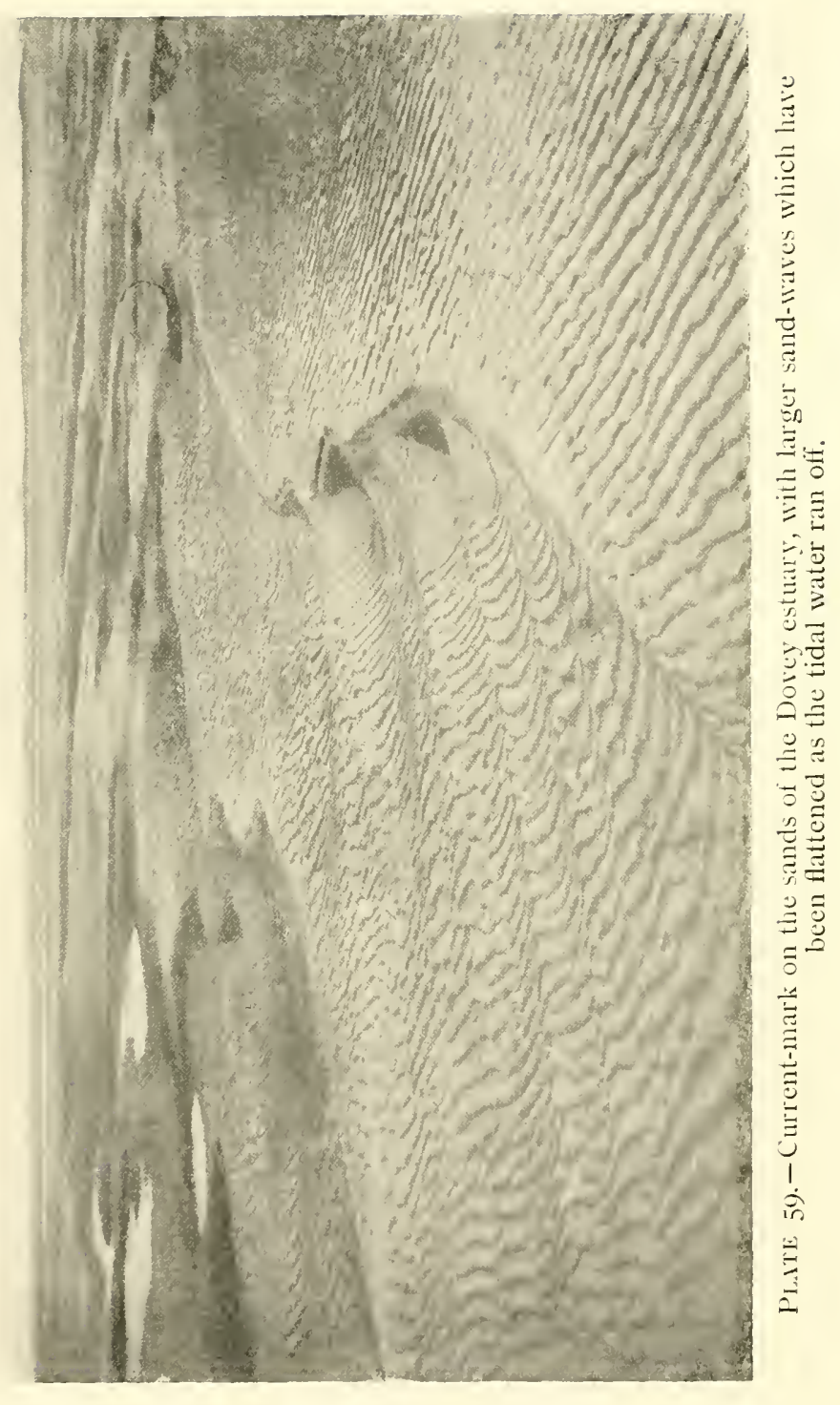





\section{RIPPLE-MARK AND CURRENT-MARK 289}

the depth or turbidity of the water. The shortest of these which I have measured had an average wave-length of 4 feet. Most of my observations of these larger sand-waves have been on sandbanks which dry out at low water in tidal estuaries. Their situation was generally such as to show that they were produced either by the current of the flood tide or by that of the ebb, and their unsymmetrical form supports this conclusion. In deep-water channels up and down which the tides flow and ebb the alternating currents form, we are told, large sand-waves of symmetrical form ${ }^{\mathbf{}}$; but I have not had an opportunity of examining these submerged ridges.

The question I should like to answer somewhat more definitely than I am able is whether the smaller current-mark and the larger current-formed sand-wave grow at the same time and place, as do ripples and waves formed by the action of wind in dry sand. When one examines the larger sandwaves on the dried-out sandbanks of tidal estuaries one sees them rippled over with the current-mark, and this led me to think that pulsations of the

- See Osborne Reynolds in Reports of the Committee of the British Association appointed to investigate "the Action of Waves and Currents on the Beds and Foreshores of Estuaries by means of Working Models," I889-9I. 


\section{WAVES OF SAND AND SNOW}

current were producing the small ripples at the same time that the large waves were being formed by the general drift. I find, however, on reexamination of my photographs that the currentmarks occur close to the lee of the cliff of the large sand-waves, and that even here they face with the direct current. But if they were formed while the eddy was active they would, I suppose, face towards the cliff-i.e., in the direction of the return current. The current-mark left on the driedout sand-waves may therefore only be what is formed during the subsidence of the water when the depth is insufficient for the growth of the larger sand-waves, and when they are, on the contrary, being flattened out. If so, the sand-waves may perhaps have an unrippled surface during their growth. Further observations are required on this point, to which my attention was called by $\mathrm{Dr}$. J. C. Owens. 


\section{CHAPTER VI}

\section{SAND-WAVES IN TIDAL CURRENTS}

The Mawdach Estuary, Barmouth, N. Wales, its drying sandbanks and their waved surface-Measurements of length and height-D shape of estuaries, influence on course of tidal currents and effect in producing unsymmetrical sandwaves upon the drying sandbanks-Measurements showing how far these sand-waves depart from uniformity-Ratio of length to height-Sand-waves in the estuaries of the Findhorn and South Esk-The estuary of the Severn: smooth sandbanks at Severn Bridge, waved sandbank near Severn Tunnel; explanation of the difference-Sandwaves in estuary of the Dovey, North Wales-Stakes fixed in sandbank and measurements of size and movement of sand-waves during seventeen days-Effect of velocity of current and depth of water upon the sand-waves-Sandwaves upon the North Goodwin Sand-Pools left after partial obliteration of sand-waves, similarity of their form to that of the pits called fuljes which occur in sandy deserts.

Sand-reefs in the Mississippi.

Their size and movement - Not true transverse wavesTheir formation in freshly deposited sediment-How the size of the sand-grains limits the size of the sand-wave- 


\section{WAVES OF SAND AND SNOW}

Suggested effect of greater heterogeneity of material to increase the limiting size of the sand-wave-On the relation of velocity of current to size of sand-wave in water of sufficient depth.

When visiting Barmouth, North Wales, in December, I899, I was struck by the appearance of the sandbanks left exposed at low water in the lower portion of the Mawdach estuary. Their surface was in waves, the length of which was generally about 20 feet from crest to crest. The ridges, which were sometimes nearly straight and sometimes sinuous, extended in broad wave-fronts, and the number which followed one another in unbroken series was often large. The variation of length from one wave to the next was generally about one-quarter of the average wave-length. An unbroken series of forty-five waves was measured on January 9, I900, on the shoal above the railway, bridge. The waves had their steeper face in the direction in which the flood tide runs. The greatest wave-length was 29 feet, and the least 8 feet. On January I Ith eleven consecutive waves were. measured on the same shoal below the railway bridge. These also faced in the direction of the flood tide. They varied from $2 \mathrm{I}$ to 34 feet in length, and the greatest height was 2 feet 2 inches. This part of the shoal is 2 feet lower than the sand 


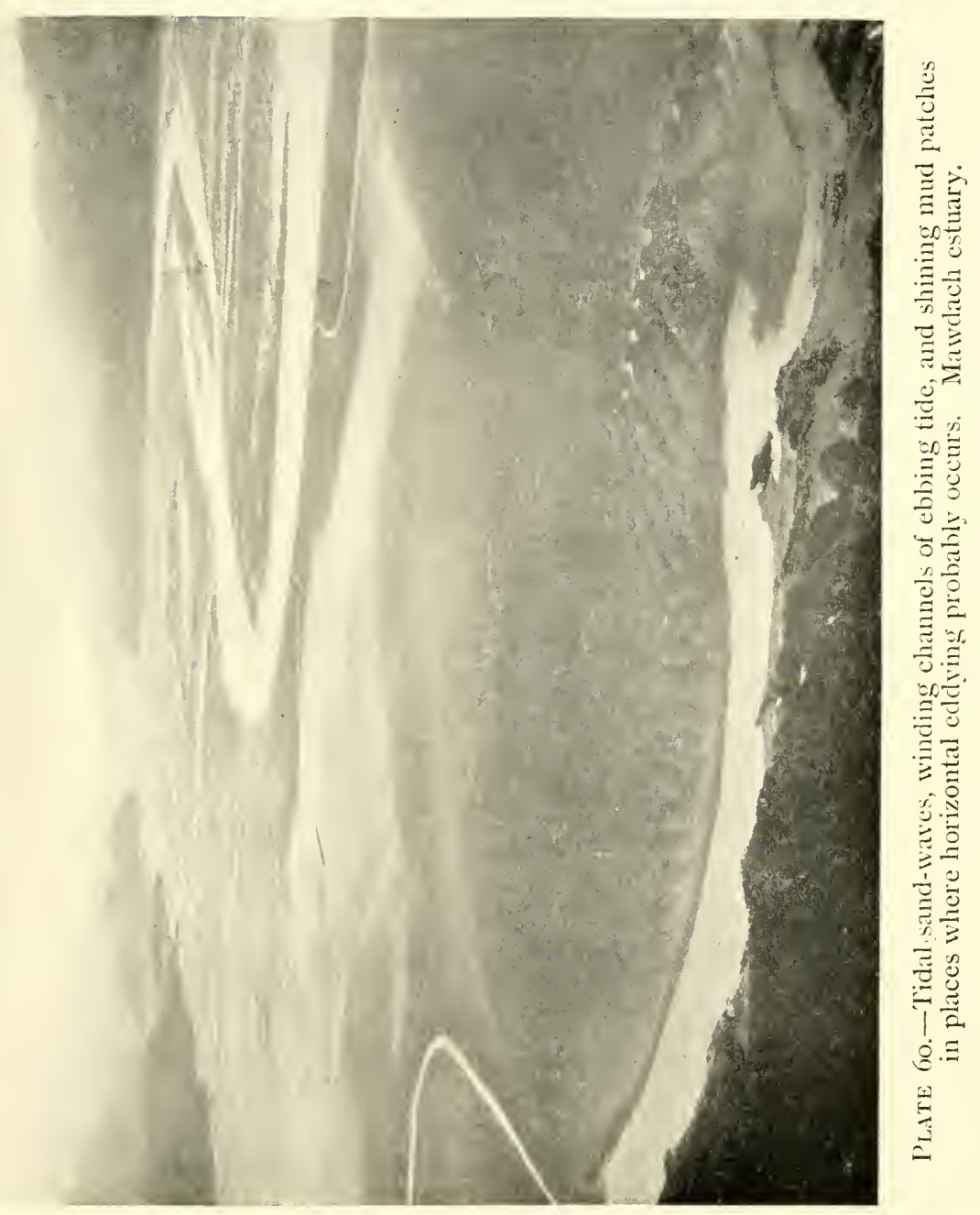

293 

above the bridge, the greatest depth of water upon it, according to the chart, being 5 feet at high water of neap tides and 9 feet at high water of spring tides. The thickness of the sandbank itself, or at all events of the soft deposits overlying rocky bottom, is here about 60 feet, as has been proved in sinking for a solid foundation to the piers of the railway bridge.

Similar sand-waves were seen on the shoals exposed at low tide on each side of the narrow lowwater channel between the island of Ynys y Bawd and the town of Barmouth, but whereas on the town side the ridges faced with the flood, on the other side of the channel they faced with the ebb. The Mawdach estuary has a very narrow entrance, but when the tide has risen above the level of the sandbanks it spreads over a wide interior basin. Another character of the estuary is that a shingle spit has grown out from the south, which is the side on which there is the more open expanse of sea, forcing the low-water channel close against the hills on the north. This shape of estuary is connected with the formation and preservation of sand-waves upon the drying shoals, for it has the effect of checking the current over them during the first part of the flood tide and last part of the ebb, allowing the currents, however, to flow strongly 


\section{WAVES OF SAND AND SNOW}

when the shoals are covered by a considerable depth of water.

Shortly after my visit to Barmouth I went to Scotland in order to take advantage of a spell of severe weather for the study of snowdrifts. When the thaw came I sought upon the map of Scotland for estuaries of a form similar to that of the Mawdach, and visited those of the Findhorn River, and of the South Esk, at Montrose, which were shown to have the required shape. In both estuaries I found drying sandbanks covered with the large kind of sand-waves. In the wide interior basin of the estuary at Montrose some of the drying banks were covered with mussels, whilst others were of clean sand. Of the latter, one, near the main channel by which the tide ebbs, was in large waves, facing with the ebb-i.e., seawards. I measured here on March 6, I 907, a series of fifteen waves, which had an average length of I 3 feet 2.4 inches and an average height of I 183 inches. The variation of length from one wave to the next was 22.3 per cent. of the average wave-length, so that their departure from' perfect regularity was about the same as that of the sand-waves upon the shoals of the Mawdach estuary at Barmouth.

The mean difference between the heights of con- 


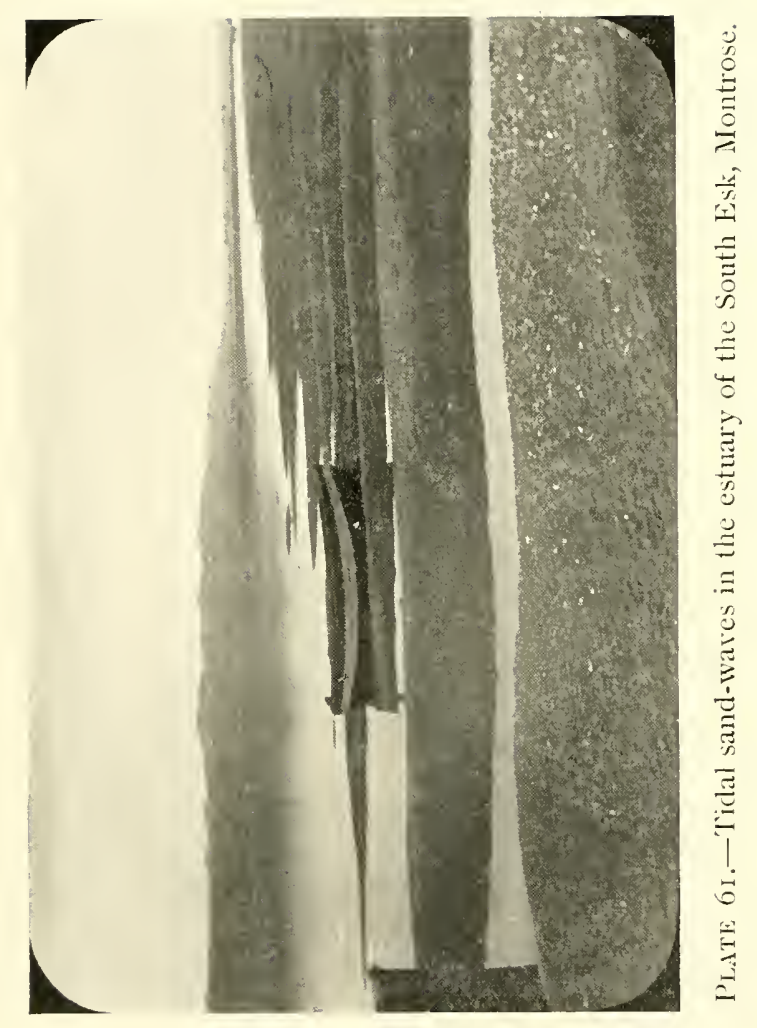





\section{SAND-WAVES IN TIDAL CURRENTS 299}

secutive sand-waves was 23.57 per cent. of their average height.

The following table shows the details of the measurements :-

Series of Fifteen Sand-waves in the Estuary of the South Esk at Montrose, PRoceeding DownwardsI.E., IN the Direction in which the Waves Face.

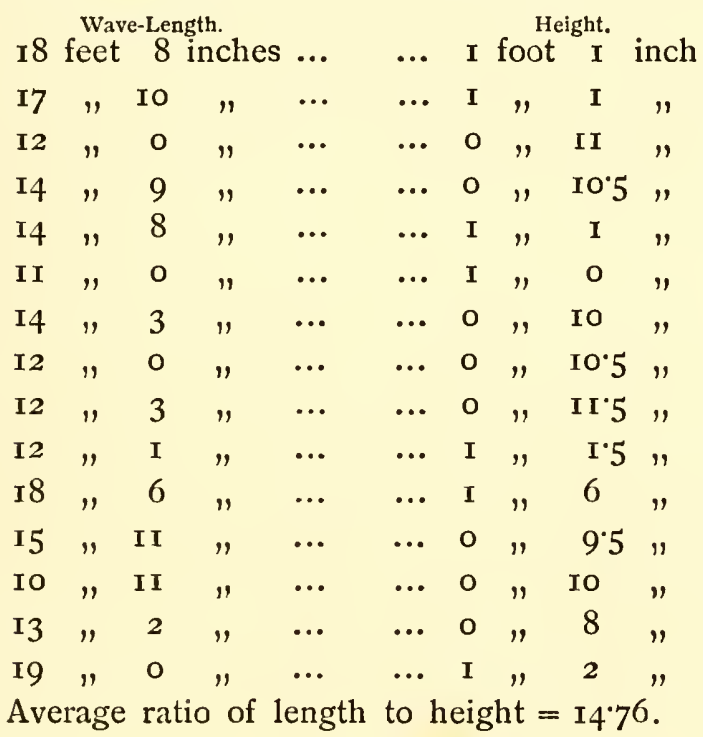

All my measurements of these large sub-aqueous sand-waves have been made after the tide had wholly receded and left them bare. The last runnings of the ebb over the crests (which I observed from; a boat to be rapid) probably 
flattened the waves somewhat by ploughing off the crests and depositing sand in the troughs. On the other hand, the final escape of the water is by a current which flows laterally along the troughs and may perhaps deepen them.

The rate of advance of three of the ridges was measured with the aid of stakes driven deeply into the sand. Between March 7th and 8th-i.e., as the result of two ebb tides - the ridges had advanced 25 inches, 25.5 inches, and 27.5 inches respectively-i.e., an average of 13 inches during one ebb tide.

During April, I 900, I went to see the sandbanks in the estuary of the River Severn. The first which I examined were those just above Severn Bridge, more particularly the shoal nearest the west bank which is named on the ordnance map the Waveridge Sand. Its surface when left dry was almost smooth, except for the minute ripples called "currentmark." On April 26th, at the time of spring tides, I watched the commencement of the flood from the Severn Bridge, which is nearly roo feet above the water. The Waveridge Sand has on its west side the main channel followed by the ebb current and on the east a blind channel, or swashway, between it and the Ridge Sand. I could see the first rising of the water progressing slowly up- 


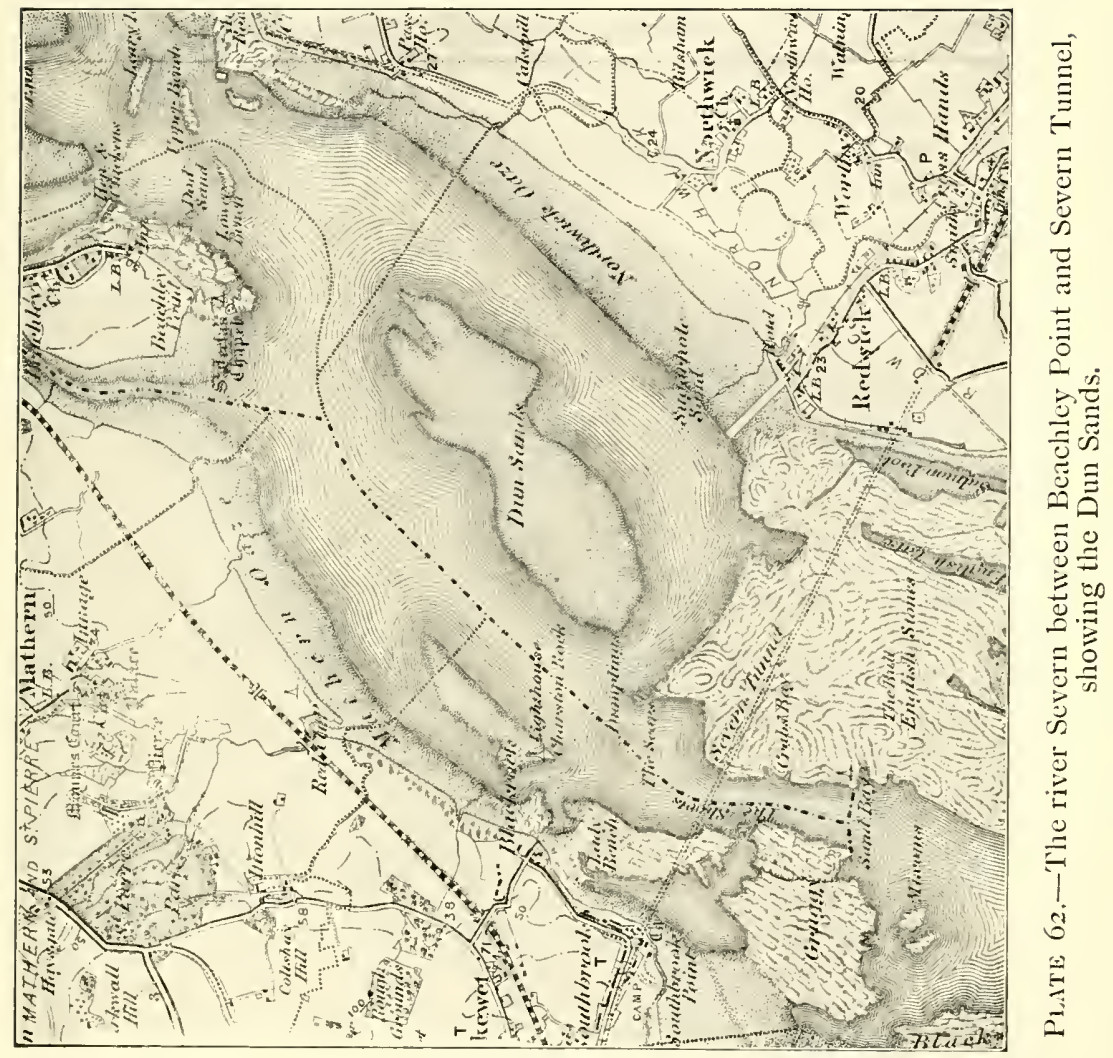






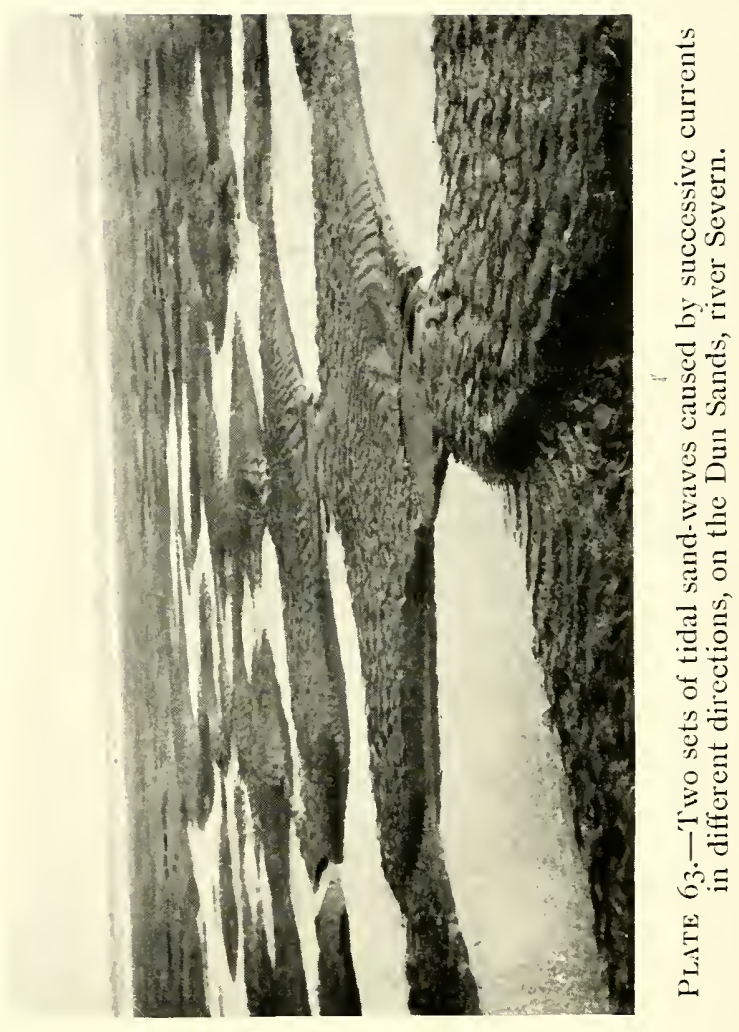




\section{SAND-WAVES IN TIDAL CURRENTS 305}

stream below the bridge. The ebb current in the main channel under the west bank, flowing swiftly on a steep bed, was not stopped by it, but, on the contrary, turned it aside, and the flood waters passing under the bridge filled up the blind channel on the east of the Waveridge Sand. Everything went quietly until the critical moment when the incoming tide, having filled the blind channel to the brim, overtopped the Waveridge Sand. Then suddenly a broad sheet of water swept laterally over from the blind channel to the main channel, covering the shoal so quickly that the air in the interstices of the dry sand was trapped, and could only escape by flinging up jets of water which spouted with great violence from all over the shoal. Thus the flow commences as a swift current from side to side across the shoal. At a later stage when there is deep water the flood tide is free to travel longitudinally over the shoal. As the tide at ordinary springs rises 27 feet at Sharpness, just below the bridge, the depth on the Waveridge Sand at high water must be somewhere about 20 feet. During the early stages of the ebb I watched the water flowing quietly over the shoal, but later, when there was less water upon it, the ebbing current rushed violently across stream over the shoal with much noise, the surface of the water 


\section{WAVES OF SAND AND SNOW}

being moreover in waves. Thus the circumstances of the flow and ebb of the spring tide over the Waveridge Sand are such as to leave it nearly smooth, although the currents are strong and the waters deep. The circumstances to which attention should be chiefly drawn are the steep gradient of the river, or estuary, and the presence of a side channel into which the flood tide is diverted at its commencement.

The sand or shingle spits outside the estuaries of the Mawdach, Findhorn, and South Esk prevent the flood tide there from finding an alternative channel.

Lower down the estuary of the Severn, where the Severn railway tunnel has been made, there is a rocky shoal called English Stones, which compels the incoming tide to stem the current of the ebb and follow the principal channel under the right bank. Thus the reach of the Severn immediately above the English Stones resembles the estuaries of the Mawdach and South Esk. The gradient of the channel in this part of the Severn is also much less than at Severn Bridge. A little higher up than English Stones is the shoal called Dun Sands. Hearing that this, unlike the Waveridge, was often in large waves, I went down by boat next day, April 27th. I passed many 


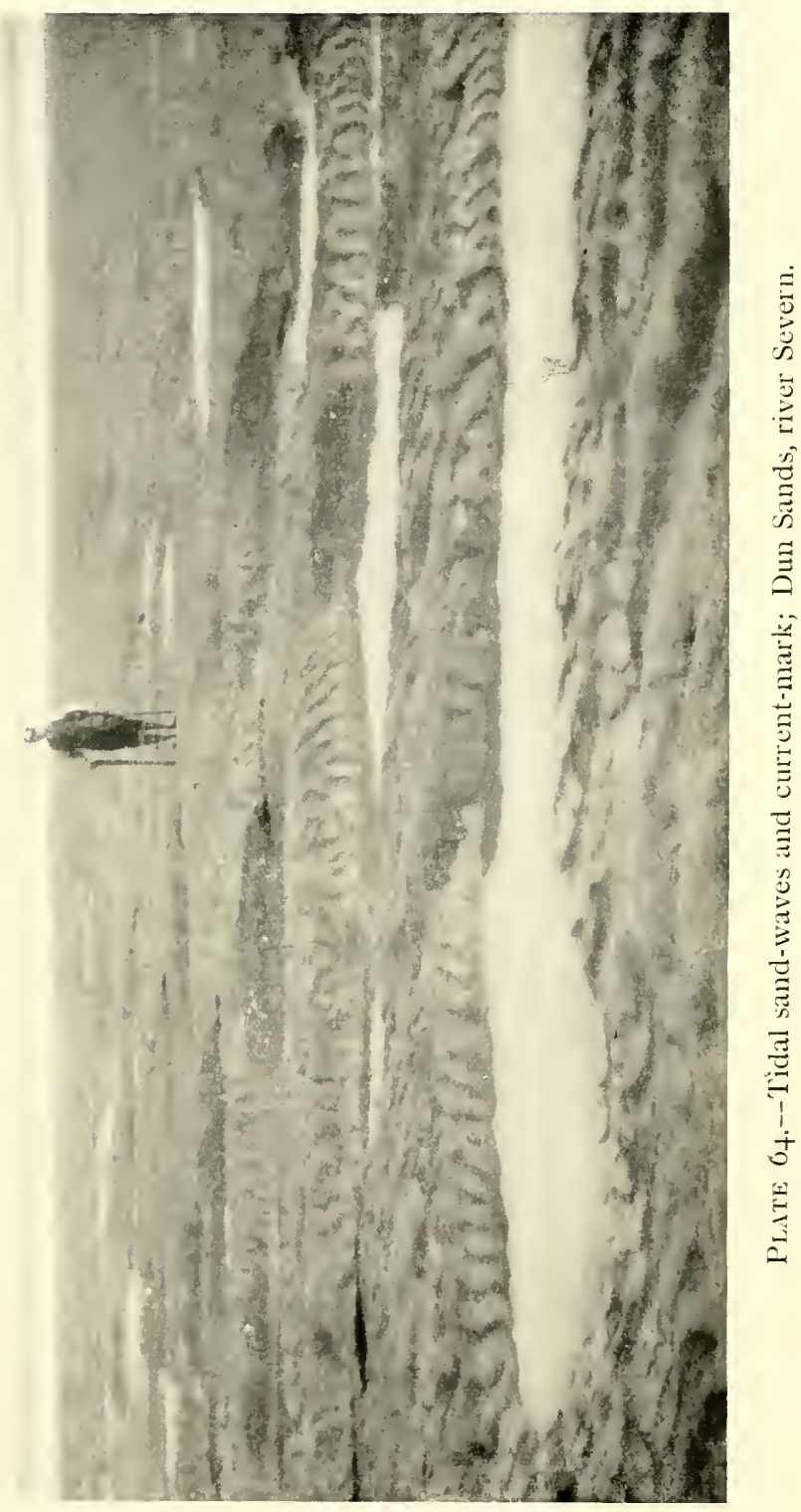

307 



\section{SAND-WAVES IN TIDAL CURRENTS 309}

sandbanks in that part of the Severn below the bridge where the gradient of the channel is steep, all of which had dried out with a smooth surface. The Dun Sands, however, was all in large sandwaves. A series of fifteen had an average length of 37 feet $8 \frac{1}{2}$ inches, and an average height of I foot II.22 inches, the length being, therefore, I 9.49 times as great as the height. The mean difference between the lengths of successive waves was 26.4 per cent. of the average length, and the mean difference between successive heights was 37.7 per cent. of the average height. These ridges had somewhat undulating crests and sinuous fronts, and in many places pools of water are left in the troughs, where, my boatmen told me, salmon are sometimes impounded. This state of things is no doubt due to a current which sets across this part of the shoal after the higher south-west part uncovers during the ebb. In some places there were two sets of ridges of almost equal size crossing one another. The fact that the variation of height is much greater than the variation in wave-length is probably due to the effect of the cross current. Its action, I think, would be more to scoop out holes in the troughs than to raise peaks on the crests.

I was on the Dun Sands at noon. At 2 p.m. the water began to rise. I left for the western 


\section{WAVES OF SAND AND SNOW}

shore at 2.20 p.m. and watched from Beachley Point. The sands were covered by 3.45 p.m., but the English Stones were not covered until nearly an hour later. A local pilot told me that the sands were in an "eddy tide" during the commencement of the flood, and that at high water on this day there would be a depth on them of fully twenty. feet. Thus the tide covers, and, I think, leaves the sands gently. The situation, the depth of water, and the low gradient of the channel are such that there must be fairly strong currents on flood and ebb running over the sands for a considerable time when the water is deep. Thus they are thrown into the larger kind of sand-waves which are not obliterated when the water leaves them'.

The estuary of the River Dovey in North Wales has extensive sandbanks, many of which are covered with the larger kind of sand-waves. I made observations here from May 3 I to June 20, I 900. The tidal entrance clings to the north shore of the valley, a long spit of sand and shingle having grown out from the southern side. As in the case of the estuaries at Barmouth and Montrose, the spit formed by littoral drift has grown from the side exposed to the longest stretch of sea, and behind it the estuary has partially silted up. These estuaries may be classed as D.-shaped, 


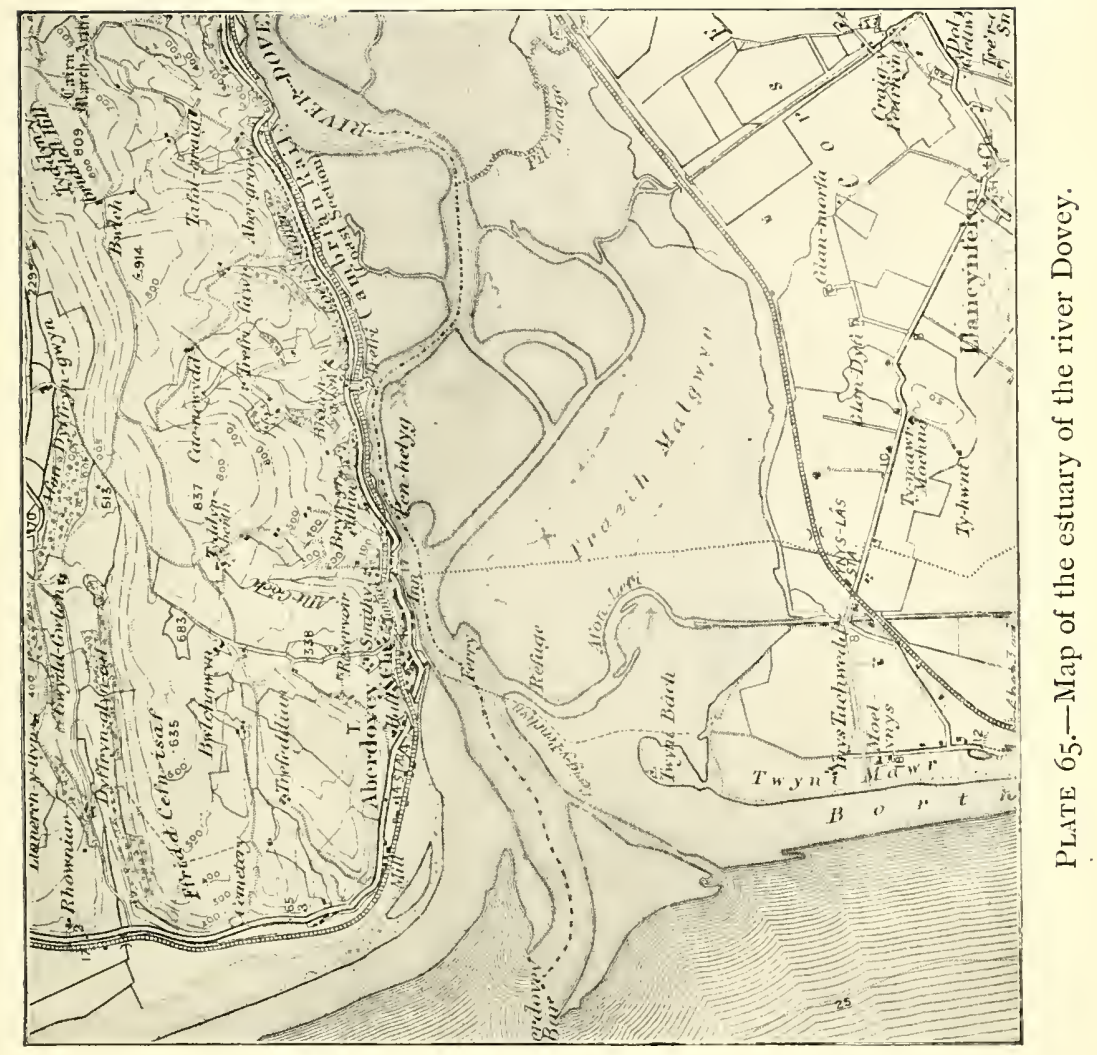






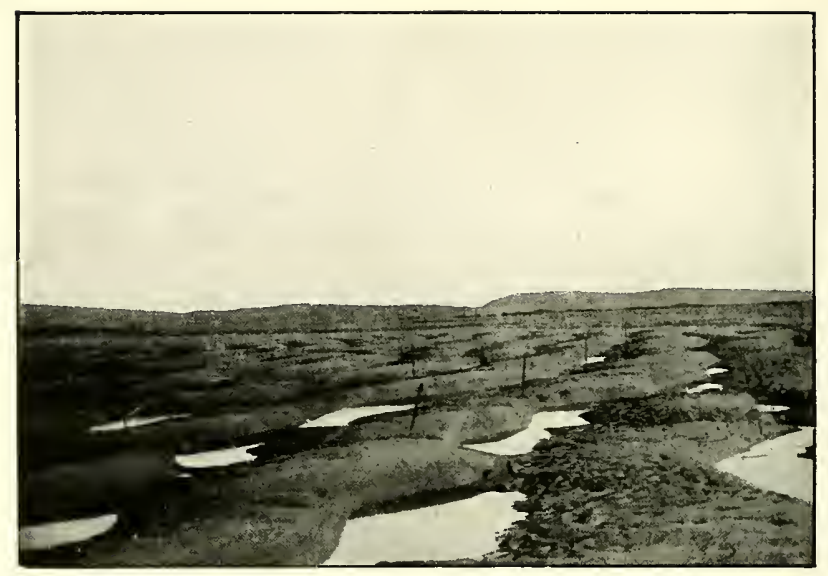

PLATE 66.-Tidal sand-waves of which the daily movement was measured; Dovey estuary.

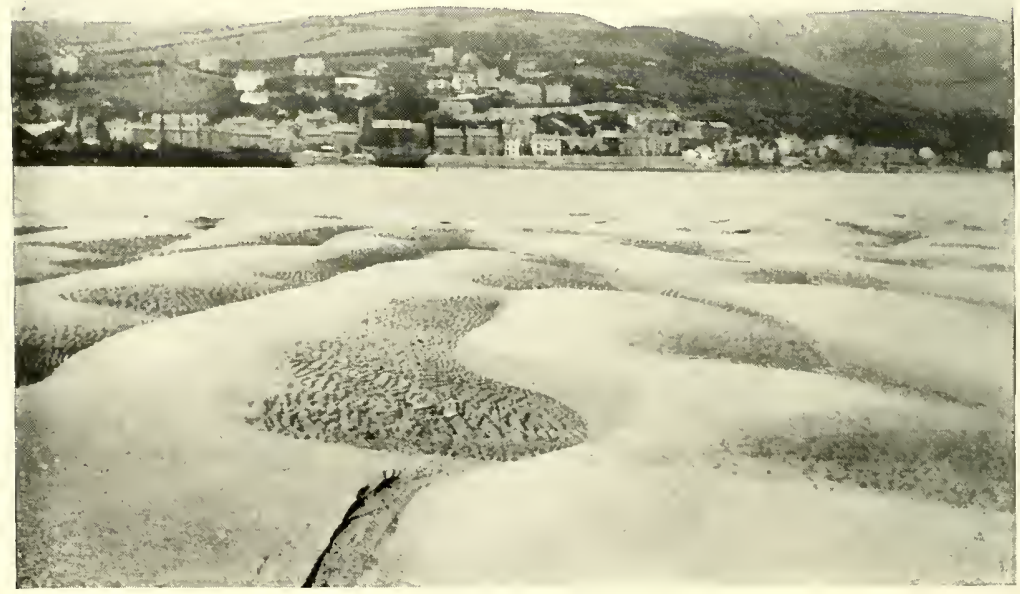

Plate 66.- Tidal sand-waves with current-mark in troughs ; Dovey estuary. 


\section{SAND-WAVES IN TIDAL CURRENTS 315}

the tidal entrance being up the straight stroke, while the space enclosed by the bow of the letter is encumbered by sandbanks which are covered and uncovered during the rise and fall of the tide.

From the high hills on the north shore a good view is obtained of the whole estuary, and at low water the arrangement and direction of the sandwaves on the surface of the shoals is so clearly seen that they form an excellent map of the strength and direction of the tidal currents above low-water: mark. The sand-waves which face with the flood have generally broad, straight fronts, those facing with the ebb are more sinuous.

On a sandbank called Traeth Malgwyn, in a position bearing south from the north end of the Pier and north-east-by-east from the Refuge, I pegged out a plot 60 feet square, putting in five rows of stakes parallel to the ridges, four stakes in each row, driving them 3 feet into the sand. Threads, stretched from stake to stake at the two sides of the plot, were used for the measurement of the height of the waves from trough to crest, and also served as a datum by which to ascertain whether there were any change in the mean level of the sand surface. The height and length of the waves were measured when the sands were uncovered from June Ist to 17 th inclusive, a period 


\section{WAVES OF SAND AND SNOW}

extending from one set of spring tides to the next with the time of neap tides between. At this time of year, however, the spring tides are of smaller range than near the Equinoxes. The tables (pp. 322-5) show the results of the measurements, and should be consulted before the reader proceeds with the text.

On comparing the table on p. I 89 with the first it will be seen that the slight diminution in average length between June Ist and 4th was due to the fact that the front ridges moved more slowly than those at the back. The ridges were not contour lines, as the ridges of swell-formed ripple-mark usually are, but lay along a slope inclining downwards to a lowwater channel on the north-west, so that the last runnings of the water from the plot were along the troughs of the waves-i.e., in a direction at right angles to the current which produced the waves. As the tides diminished after springs, the length of the waves diminished very slowly, but their height fell off rapidly, and at the time of neap. tides they were nearly obliterated, the surface of the sandbank being almost smooth. The average level of the sandbank was, however, unchanged. When the tides increased after neaps, well-defined, steep sand-waves were again formed, which grew in height and length. 


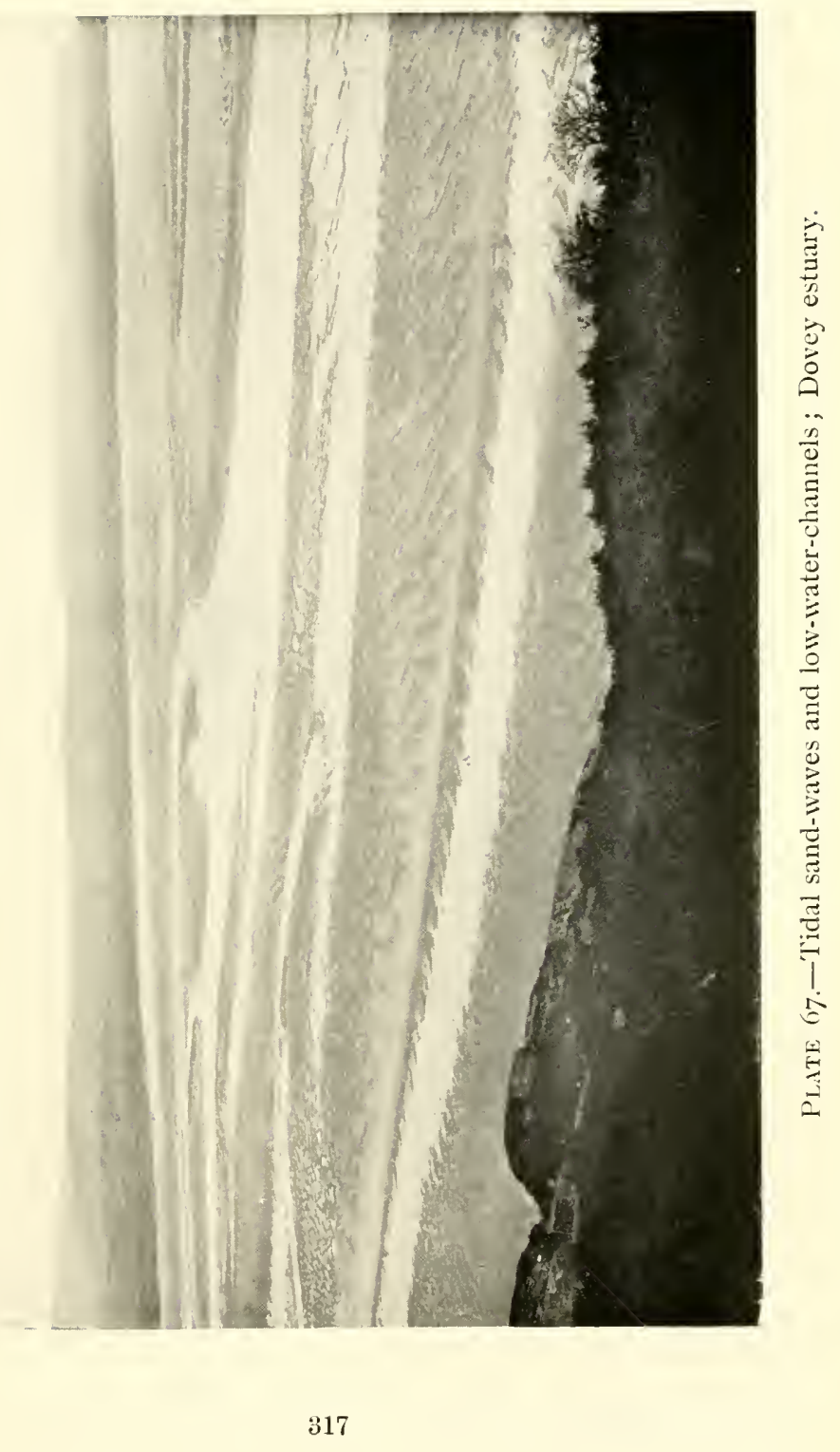






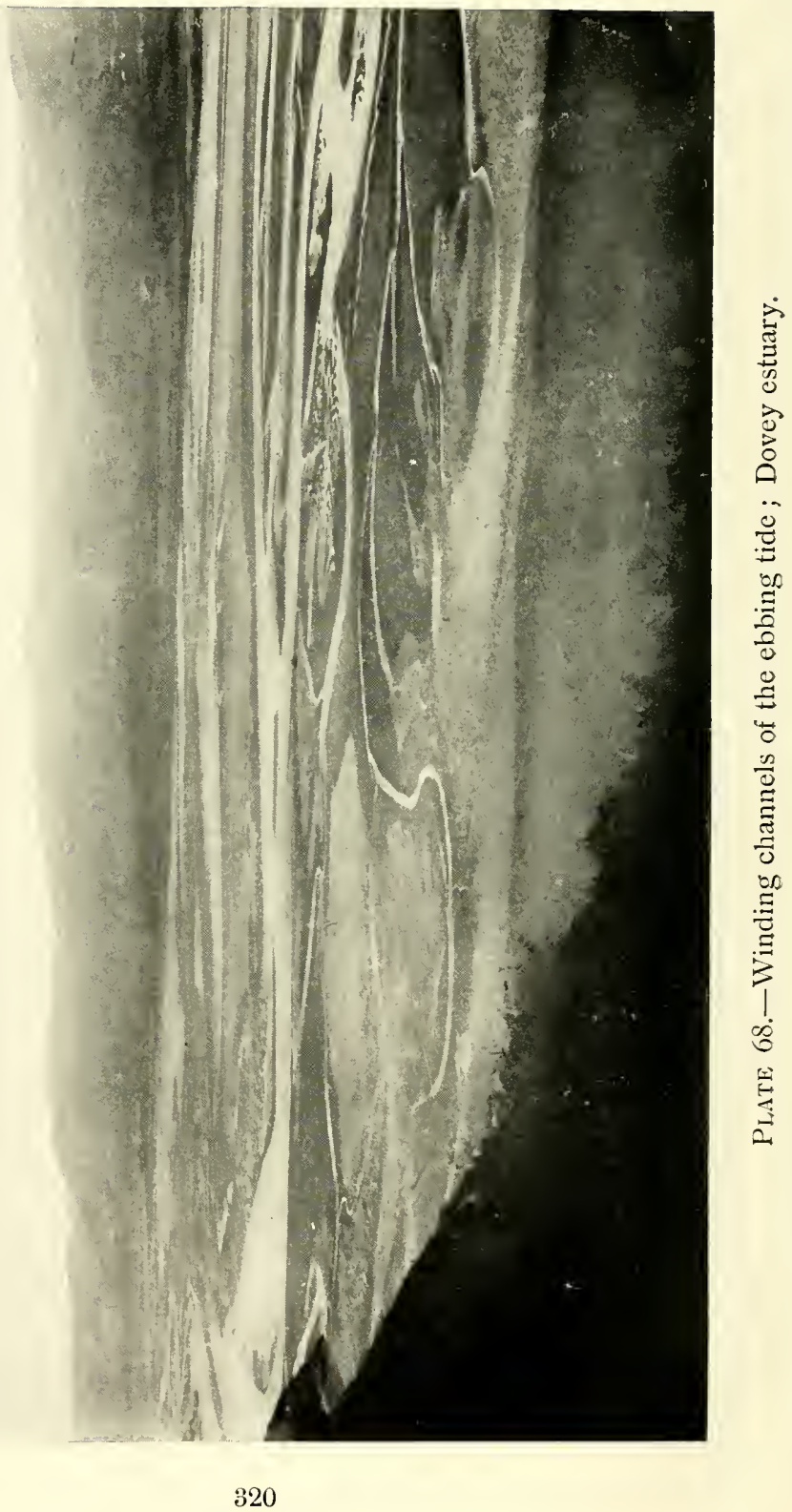




\section{SAND-WAVES IN TIDAL CURREN'IS 321}

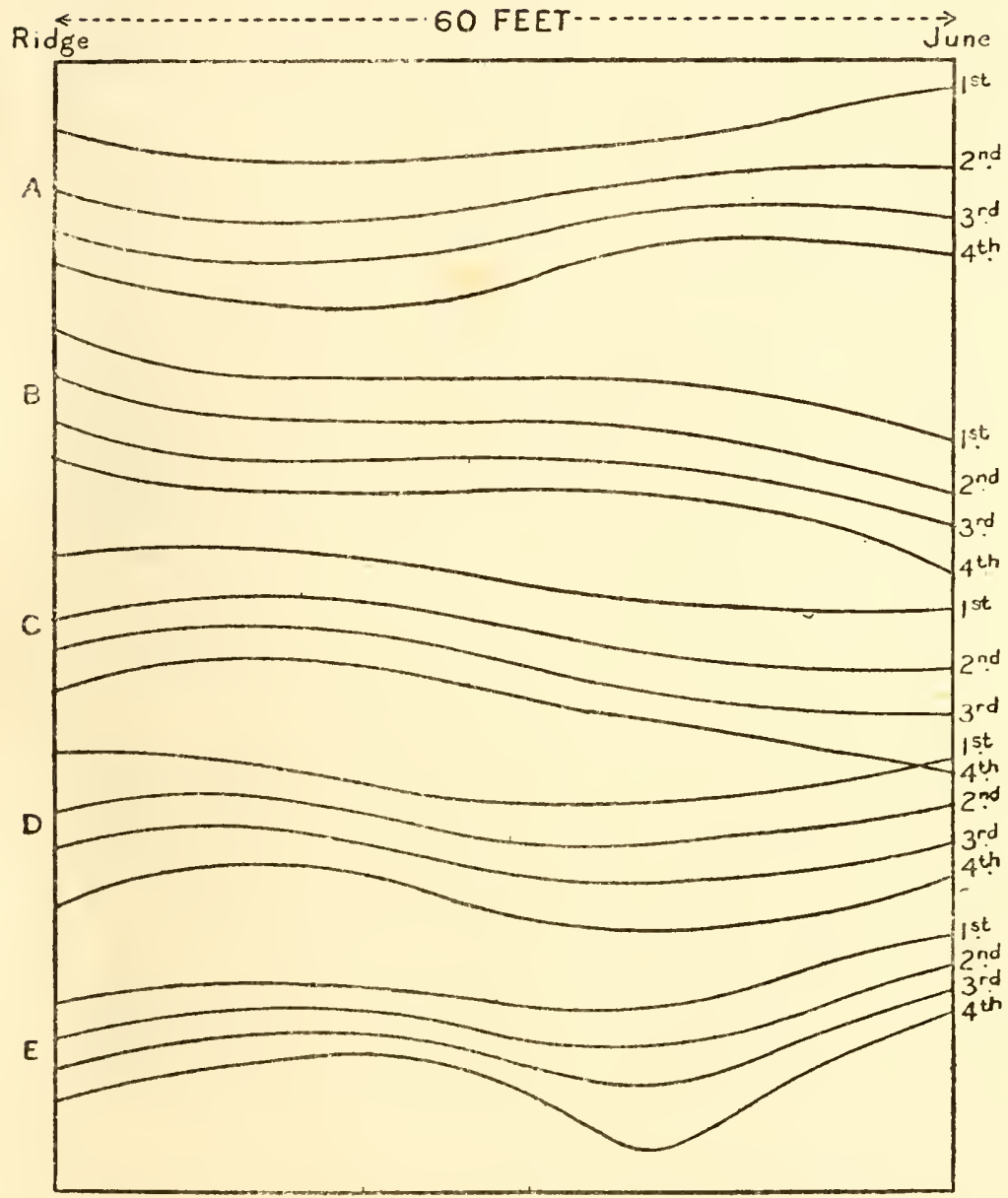

Fig. 3o.-Plan of Five Ridges Showing Positions on Four Succeeding Days, Dovey Estuary. Scale, $\mathrm{I}^{\prime \prime}=\mathrm{I} 6^{\prime}$. 


\section{WAVES OF SAND AND SNOW}

\begin{tabular}{|c|c|c|c|c|c|c|c|c|}
\hline 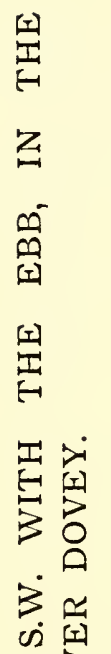 & 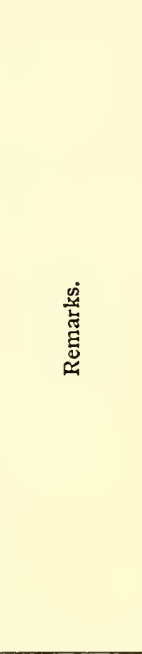 & 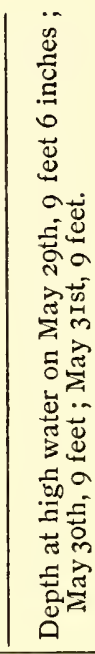 & 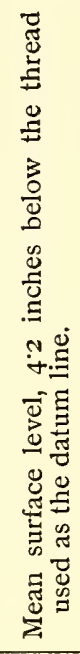 & 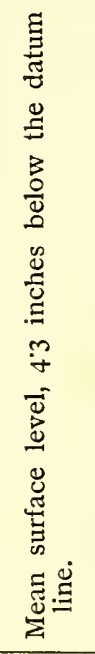 & 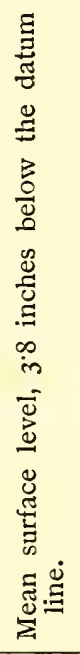 & 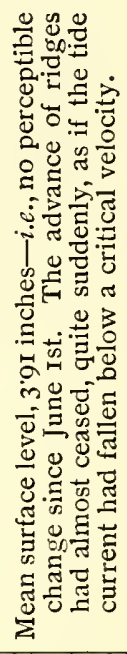 & & 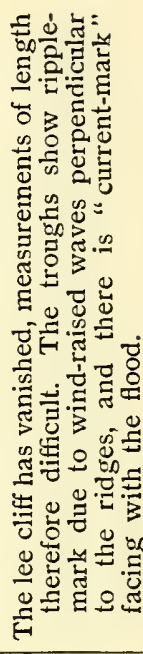 \\
\hline$\sum_{0}$ & 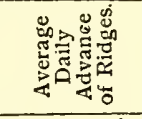 & 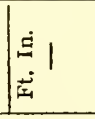 & $\begin{array}{l}\vec{a} \\
\text { n }\end{array}$ & $\begin{array}{l}10 \\
i n \\
\sim \\
N\end{array}$ & $\begin{array}{l}\dot{0} \\
\dot{0} \\
\text { r. }\end{array}$ & : & 跣 & 1 \\
\hline 焉 & 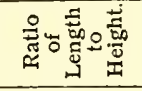 & 1 & 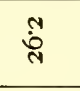 & : & $\overrightarrow{\dot{y}}$ & $\stackrel{\infty}{\ddot{q}}$ & 1 & 1 \\
\hline 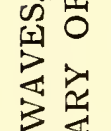 & 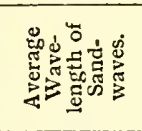 & 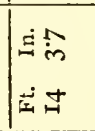 & 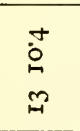 & $\begin{array}{l}\stackrel{n}{N} \\
\text { ñ }\end{array}$ & $\begin{array}{l}0 \\
\cong\end{array}$ & $\begin{array}{l}\dot{0} \\
\stackrel{\sim}{0}\end{array}$ & $\begin{array}{l}\text { is } \\
\infty \\
\infty\end{array}$ & 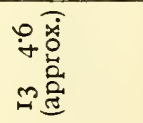 \\
\hline 它它 & 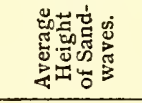 & $\Xi 1$ & 怂 & 孞 & $\underset{\text { d }}{+}$ & 萮 & 1 & 1 \\
\hline & 悹 & 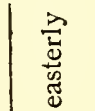 & $=$ & $=$ & $=\begin{array}{l}\overline{\bar{z}} \\
= \\
=\end{array}$ & $=$ & 言密 & 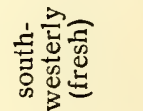 \\
\hline 空 & 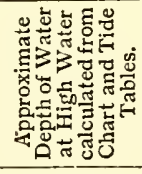 & $\begin{array}{l}\dot{10} 0 \\
\dot{\pi} \infty\end{array}$ & $\infty$ & $\begin{array}{l}0 \\
n\end{array}$ & $n$ & $n$ & $\begin{array}{l}0 \\
0\end{array}$ & $\begin{array}{l}0 \\
0\end{array}$ \\
\hline 易 & 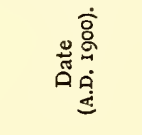 & 只 & a & $m$ & $\sigma$ & is & $\begin{array}{l}0 \\
=\end{array}$ & A \\
\hline
\end{tabular}




\section{SAND-WAVES IN TIDAL CURRENTS 323}

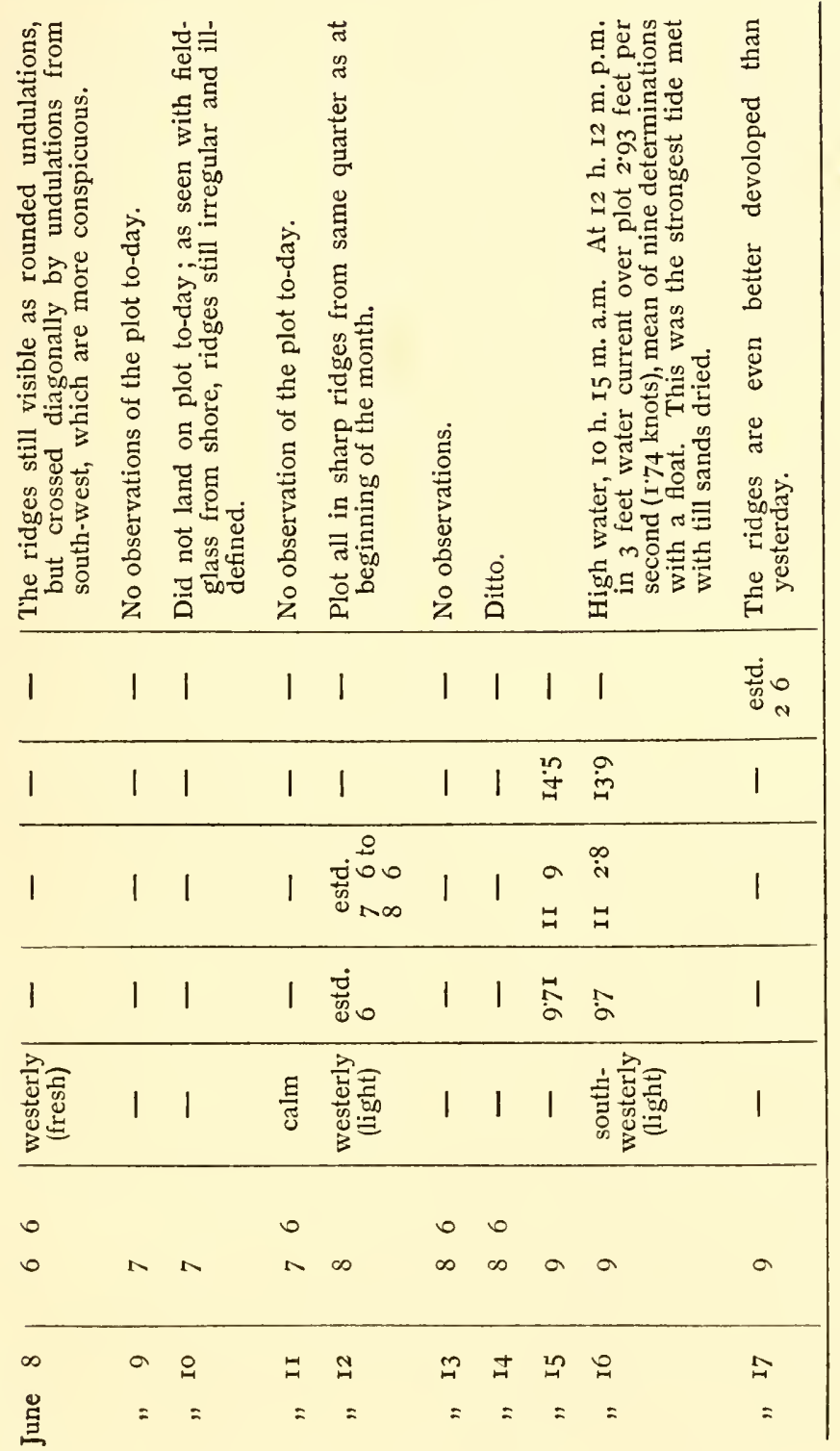


324 WAVES OF SAND AND SNOW

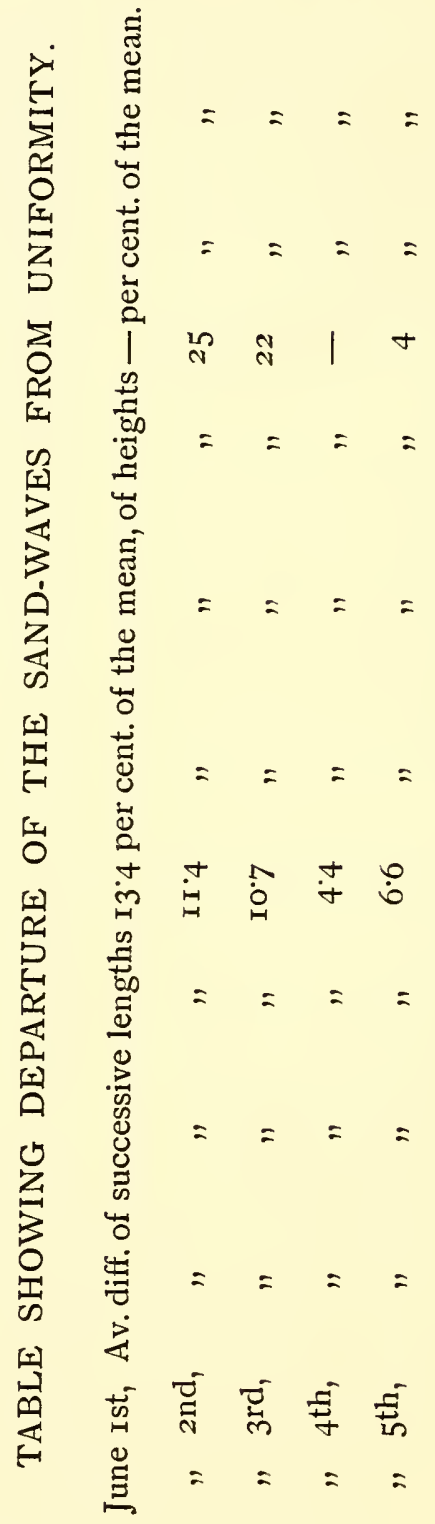




\section{SAND-WAVES IN TIDAL CURREN'TS 325}

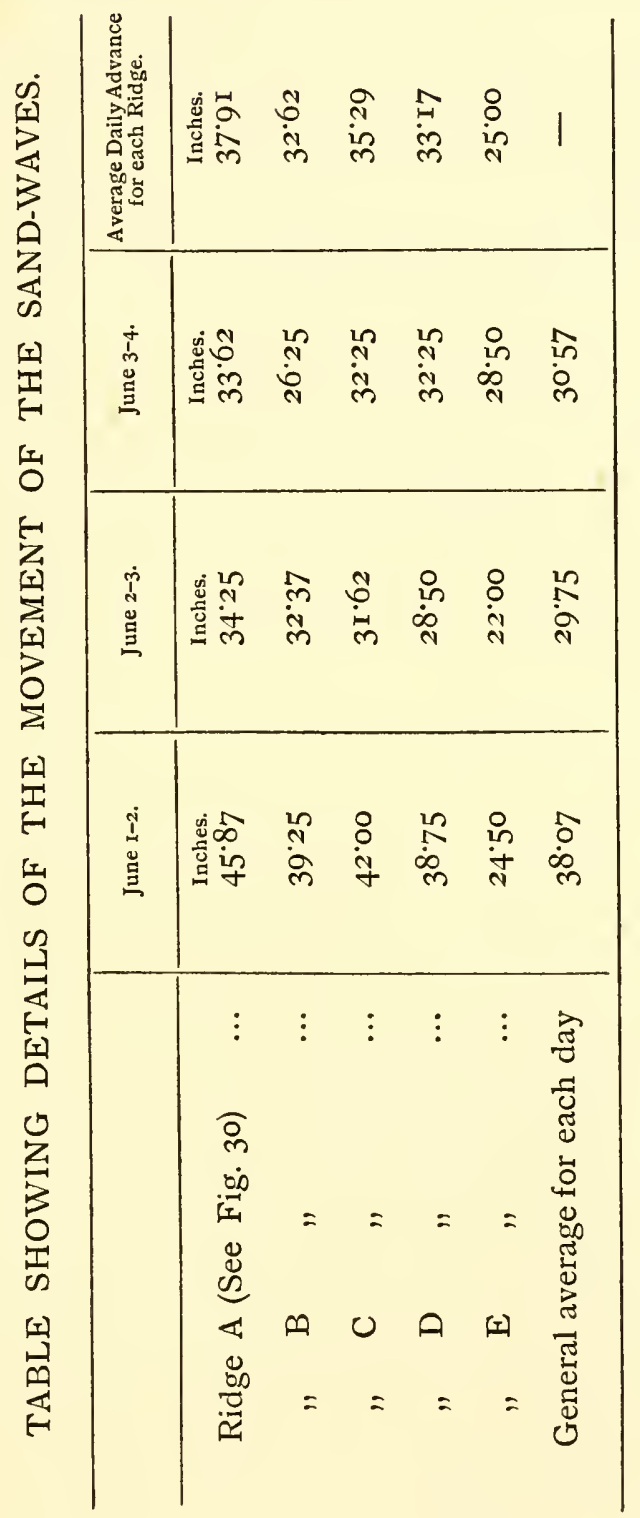




\section{WAVES OF SAND AND SNOW}

In order to examine the effect of the currents of the sea in forming the larger kind of sandwaves I visited Mundesley, on the north coast of Norfolk, where owing to the form' of the coast the tidal currents might be expected to run strongly parallel to the shore. On April I 5, I 900, with a light off-shore wind, the sands exposed at low tide were mostly smooth, but in the "low," or narrow, depression parallel to the beach there were well-preserved sand-waves, the crests of which were at right angles to the shore, whereas the crests of ripple-mark formed by waves are parallel to the shore. The length of the sand-waves was 4 feet. During the afternoon the wind came on to blow with moderate force in a long-shore direction, and next day the sand-waves in the "low" had a length of I I feet 6 inches.

The large sand-waves on the North Goodwin Sands are evidently formed by currents, not by. swell. I visited this sandbank on May I2, I 900. The ridges faced in a northerly direction-i.e., were opposed to the waves and to the light wind prevailing at the time. The reason why they faced with the flood and not with the ebb was evidently; that the higher sands to the north were uncovered three and a half hours after high water, whereas the ebb current does not commence until four and 


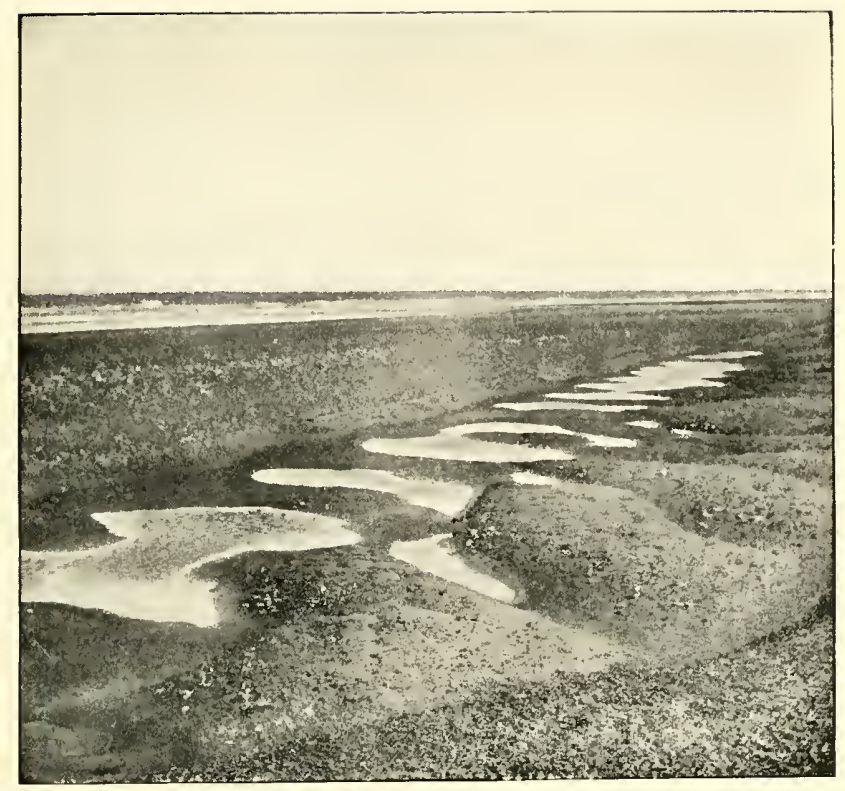

PLate 60.- - Tidal sand-waves at right angles to the sea shore in a "low," or depression; at Mundesley.

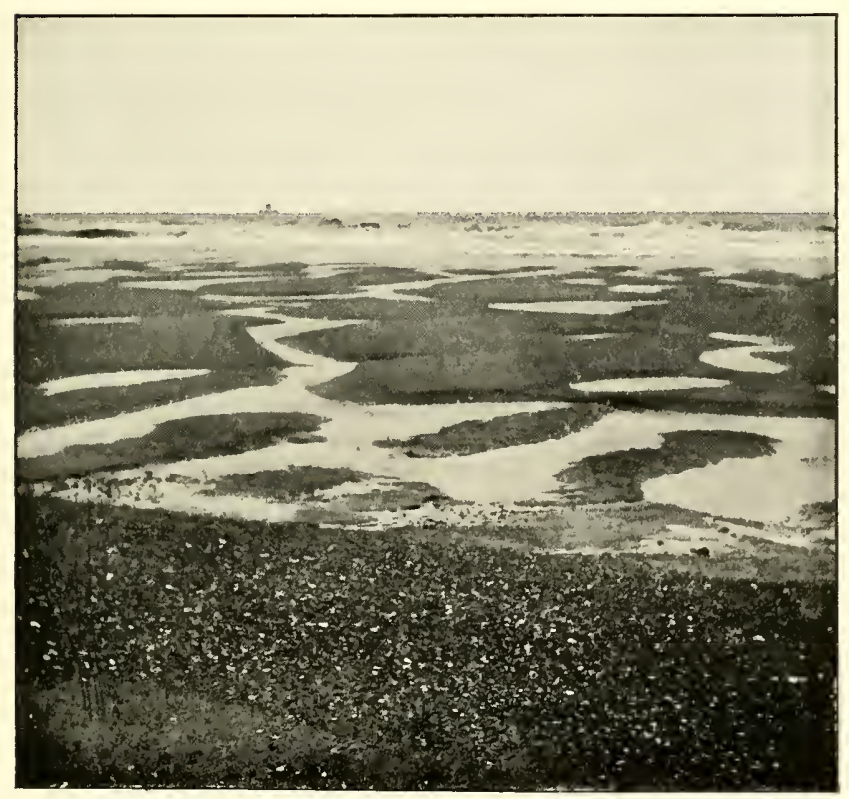

PLATE 69.-Cidal sand-waves partially obliterated on the sea shore; at Mundesley. 




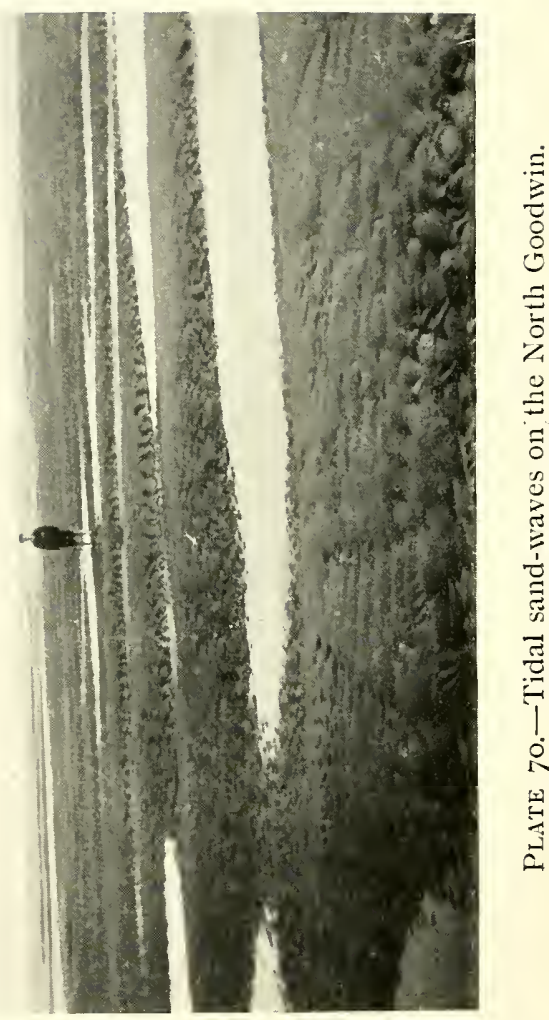

330 


\section{SAND-WAVES IN TIDAL CURREN'TS 331}

a half hours after. Thus the ridges are sheltered from the ebb current which runs to the south-west.

There were two sizes of large sand-waves superposed; three succeeding ridges with wave-lengths of 66,88 , and $64 \frac{1}{2}$ feet had upon their weather slopes smaller waves of about I 5 feet in length. The larger waves were apparently much flattened, and their height was only about $\mathrm{I}$ foot $\mathrm{I} O$ inches.

On one of the sandbanks in the estuary of the River Dovey there were ridges which reminded me by their size of the large ridges on the Goodwins. I found them to be almost immobile, the sand having become set. There are three conditions of the mobility of sand-quicksand (of which I shall have something to say later), ordinary loose sand, and sand which has set. Sub-aqueous sand-waves, even those which are periodically uncovered, are less liable to setting than the sand of dunes.

A process occurs in the obliteration of tidal sandwaves which is of interest in connection with the study of dunes. I refer to the formation of pools by the washing of portions of the crest into the trough during the recession of the tide. The longitudinal section of the pools, with the long, gentle slope on the one side and the short, steep slope on the other, is that of the peculiar hollows 
among the aeolian sand-waves called fuljes, which I described in a previous chapter (see Plate LXXI.).

Sand-reefs in the "Mississippi.

The engineers of the Mississippi River Commission have made many observations upon the ridge-and-furrow formation of the sandy bottom of the Mississippi near Bullerton and Fulton, where the waters of Mississippi and Ohio are not completely blended, although the distance below their junction is about 100 miles. These ridges or reefs are not exactly at right angles to the current, neither do they progress without change of form. They are, therefore, hardly to be considered as truly waves.

"The wave (as the sand-reef is termed by the engineers) retains its position until some change in velocity disturbs or displaces the eddy, when its rapid destruction, either partial or total, follows, after which a new wave is formed under the new. conditions . . motion rarely takes place except during the obliteration of the wave, when a part of the material scoured from it is deposited immediately below, thus flattening the front slope and carrying the crest down-stream'. After the wave has under this action entirely lost its original 


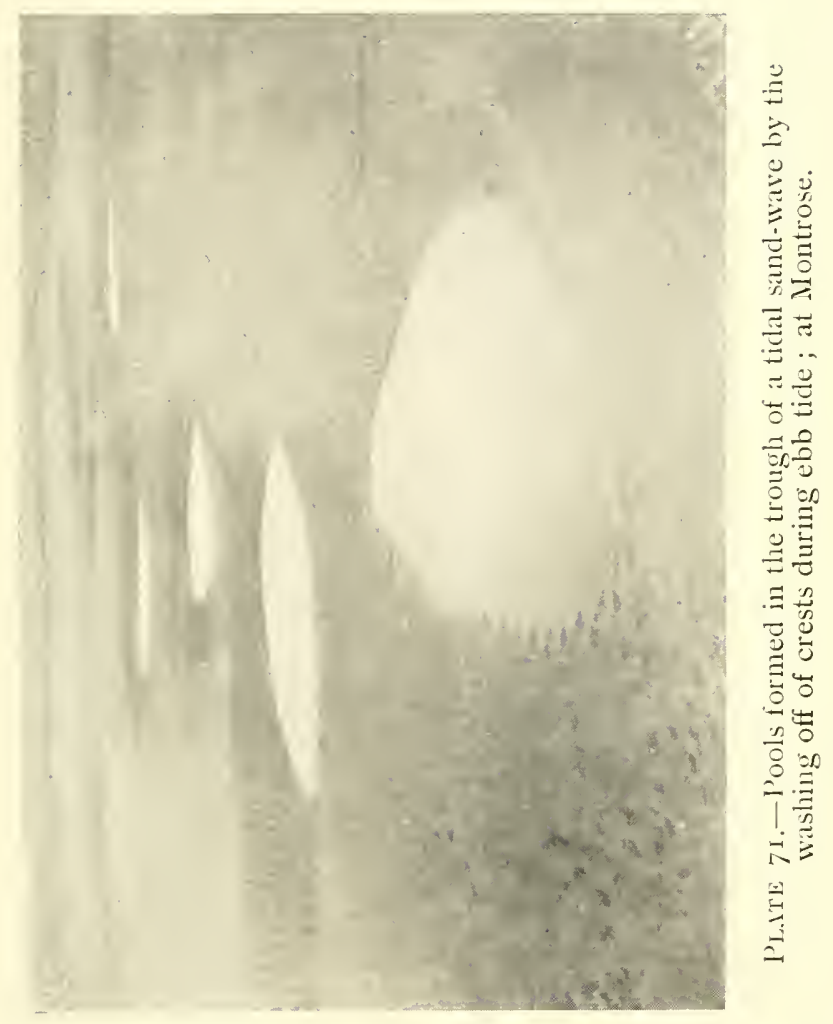





\section{SAND-WAVES IN TIDAL CURRENTS 335}

form, the whole profile may gradually move downstream. . . ." I

The average dimensions of the sand-reefs are as follows:-

At Bullerton (Wide River).

Distance apart $\cdots 4.4$

Daily motion $\cdots 3$

$13 \quad 11$

Depth of water ... Io to 30 ,

Velocity of river $\quad . . \quad 3.5$ feet per second
At Fulton (Narrow River).

47

feet.

600

22

45 to 60 "

$5 \cdot 8$ feet per second

On the nearly flat tops of these reefs series of regular sand-waves of about i 5 feet length are often observed, and these are at right angles to the current.

Although the travelling reefs, wholly or partly on account of the windings and the irregular crosssection of the river, are not true groups of travelling waves definite in length and permanent in form, yet the detailed examination to which they have been subjected throws light upon some problems of sand-waves. The engineers report that it seems probable that the reefs are forms which freshly deposited sediment tends to assume under the action of a current of sufficient velocity. The heavier portions of the eroded material taken from their weather slopes are deposited on the lee of the

I Report of the Mississippi River Commission, I882, p. Io8. 
crests, and remain there until the progression of the reef once more exposes them to the direct current. But the upward currents on the lee of the ridges carries away the lighter materials in suspension.

These conclusions at which the engineers of the Mississippi Commission have arrived help us to understand how the size and weight of the particles limit the height of sand-waves.

General Conclusions as to the Conditions of the Formation and Growth of Sub-aqueous Sandwaves.

Let us suppose waves in sand of uniform size to grow in a stream of sufficient depth under the action of a current of a certain velocity. What property of the sand itself will ultimately stop the growth of the waves? If the uniform sand be light-i.e., the particles be small-the limit will be reached owing to the inability of the upper layers at the crest of the waves to withstand the horizontal thrust to which they are subject between the direct current behind them and the eddy in front. Growth will therefore cease when the crests are ploughed off.

On the other hand, suppose the uniform sand to be heavy-i.e., the particles large-then for a 
current of a given velocity the pumping action of the eddy will become too weak before the direct current becomes too strong. Therefore the growth in height of the sand-wave will be arrested when the upward velocity, or pumping action, of the eddy in the trough is not greater than the rate of subsidence of the sand-grains. If this reasoning be correct, the large heights which the cliffs of the Mississippi sand-reefs can maintain is partly due to the heterogeneity of the material, hence their being characteristic of recent sediments.

The measurements which I have made are sufficient to give a rough indication of the relation of velocity of current to the length of the sand-waves which it produces. The measurements about to be quoted are those where there is sufficient depth of water to admit of full development of the waves. For two slow streams, taking the mean, I found that a current of 0.695 foot per second produced waves with a length of 5.75 inches. In the estuary of the Dovey a current of 2.93 feet per second produced waves with a length of $\mathrm{I} 24.8$ inches, so that the increase in length was much more rapid than the increase in velocity. The length of the sand-waves in the estuary was $2 \mathrm{I}^{\cdot} 7$ times as great as that in the slow streams. If the length increased proportionally to the square of the velocity, then the 


\section{WAVES OF SAND AND SNOW}

speed of the current required to produce waves I 24.8 inches long would be 3.24 feet per second instead of 2.93 feet per second.

The longest waves which I have measured were on the North Goodwins, which had a length of 847 inches.

Sand-waves 124.8 inches long in the Dovey Estuary were formed by a current of 2.93 feet per second. If the length be proportional to the square of the speed of current, then the sandwaves on the North Goodwins would require for their formation a current of $7 \cdot 6$ feet per second, or 4.52 knots, which is somewhere about the strength which would be met with at spring tides in such a situation.

The group of steepest sand-waves measured on a dried-out sandbank had lengths almost exactly fourteen times as great as their height. If the longest sand-waves measured on the Goodwins have at their full development the same shape, their height would be 5 feet. I do not know if heights as large as this have been recorded. The R'ev. John Gilmore, in a book called "Storm Warriors," relating to lifeboat work on the Goodwin Sands, speaks of the lifeboat continually grounding on "ridges 2 or 3 feet high."

The sand-reefs of the Mississippi are not groups 
of waves with definite length, and the ridges are separated by a distance which is often one hundred times as great as their height. It is of interest, however, to note the height of these ridges in relation to the speed of the current. Taking an average of the values found for the wide and narrow parts of the river respectively, we find that a current of 4.65 feet per second, with an average depth of 36 feet, maintained ridges of a height of 4 feet 6 inches. A velocity of 2.93 feet per second observed in the River Dovey gave a height of sand-wave 9.7 inches, so that, reckoning the height as proportional to the square of the velocity, a current of 4.65 feet per second should give a height of only 2 feet. The greater height of the sand-reefs in the Mississippi is, I think, mainly due to their not being true waves but ridges not at right angles to the current. Thus they are maintained partly by lateral scour, and are not wholly dependent for their upkeep upon the pumping action of an eddy with horizontal axis. 


\section{CHAPTER VII}

\section{ON THE SMALLEST DELTA, ON THE COMPOSITION OF QUICKSAND, AND ON "MACKEREL SKY"}

On the Transverse and Longitudinal Ridges formed in the Flow of Watery Sand, and on the Smallest Delta.

Settlement of sand through water and subsidence of water through sand-Transverse and longitudinal ridges formed during the latter process-Rapid deposition of the small longitudinal ridges in radiating branches-Their diameter equal to that of a fully grown drop of water.

On the Composition of Quicksand.

Observations of Mr. C. Carus-Wilson on presence of marsh gas-Experiments of Mr. C. E. S. Phillips on effect of included gas-Author's observations on effect of imprisoned air-On the effect of some finer earthy particles to prevent the escape of air from sand-The three kinds of fluid: gaseous, liquid, and granular, and suggestion that an emulsion of all three produces a quicksand.

On the Rippled Clouds called "Mackerel Sky."

Ruskin's remark-Mathematical investigations by Helmholtz and others-Sir G. H. Darwin's description-The author's observations-Shape of the clouds-Their wave-lengthDescription of author's photographs-The positive and 


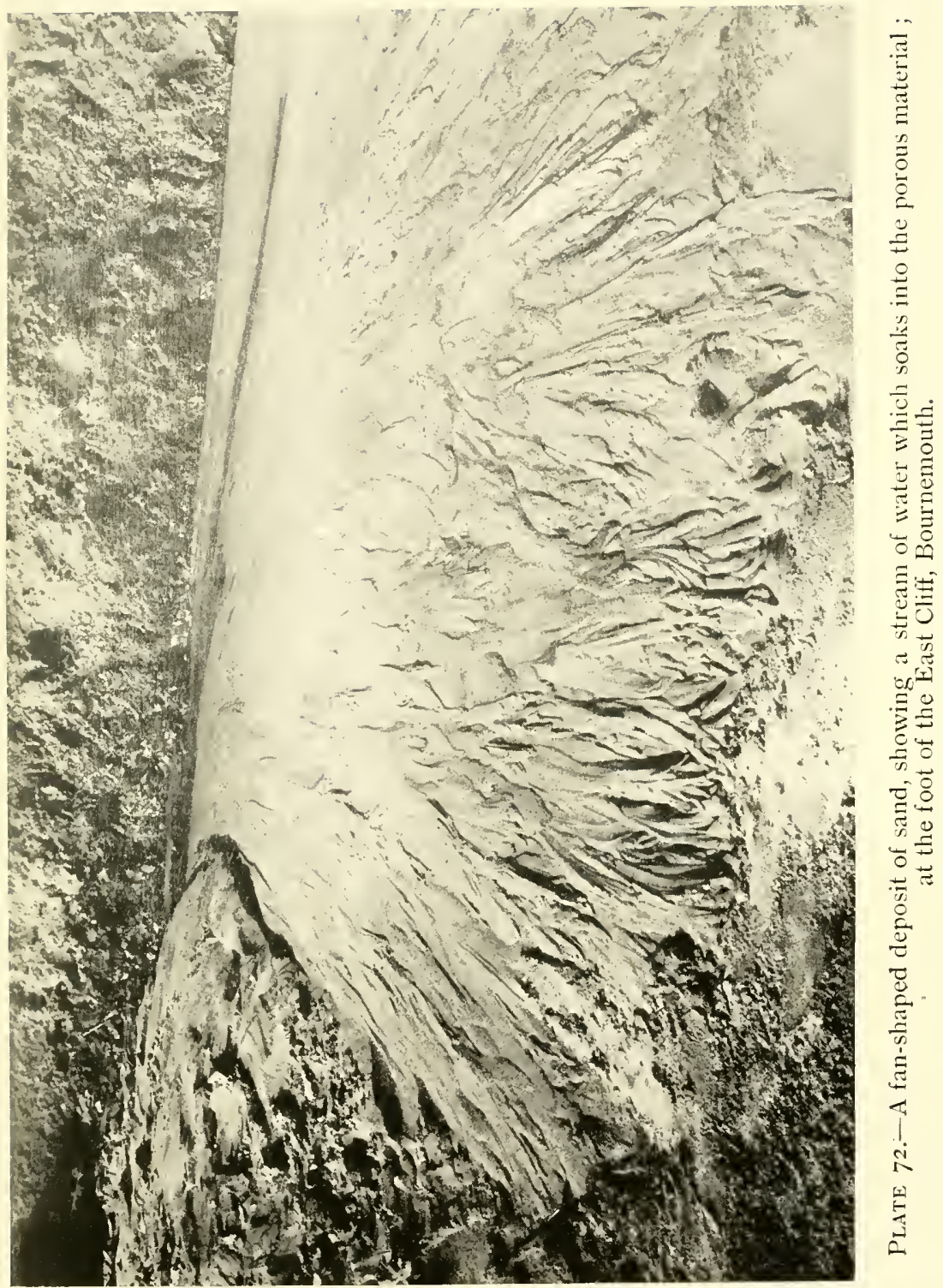






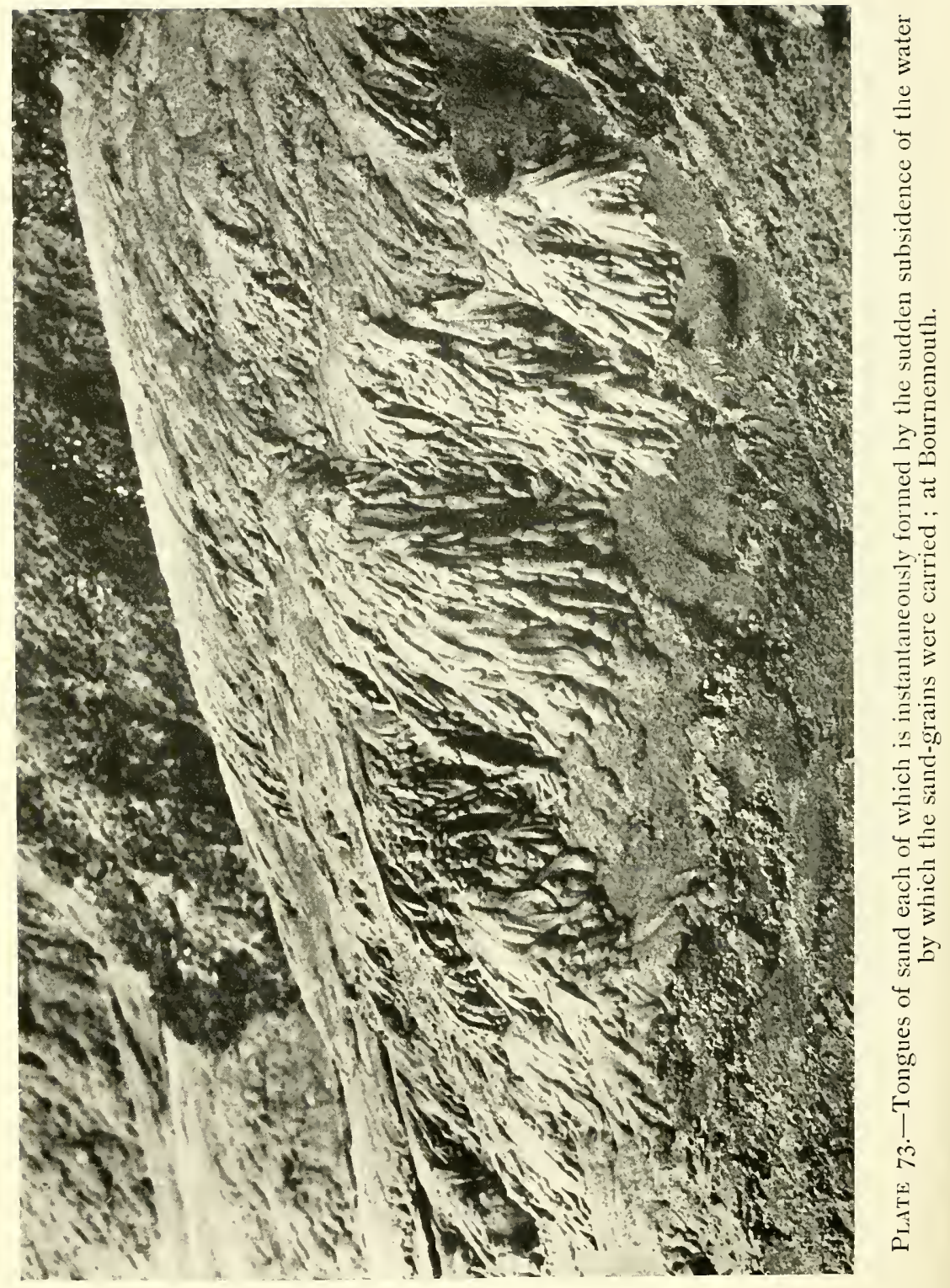


negative compared-The former shows the white clouds, the latter the blue sky-It is the latter which has the form of ripple-mark in sand-The clouds correspond, not to ripple-mark but to the eddies of water which make the ripple-mark.

On the Transverse and Longitudinal Ridges formed in the Flow of Watery Sand, and on the 'Smallest Delta.

THE great variety in the position, shape, and superficial inequalities of submerged sandbanks is due to the circumstance that sand can be carried in suspension, but that it does not follow the line of flow of the water. Wherever the current is checked or deflected the sand tends to collect in a heap.

In their lower course sandy streams often dry up owing to the escape of water by percolation. On the large scale and with gentle slopes this process forms deltas. On the small scale, with streamlets on steep slopes, the deltaic deposits have curious ridges which are somewhat analogous to the transverse ripples and longitudinal ridges formed on the beds of sandy streams. The ridges of these deltillae, or miniature deltas, are due in the first stage to the quick subsidence of sand in water, but in the final stage to the rapid subsidence of water through sand. These forms are produced very imperfectly or not at all in mud- 


\section{WAVES OF SAND AND SNOW}

flows, the separation of mud and water being too slow.

My observations of the ridges formed in miniature deltas were made on the Bournemouth cliffs between Canford Cliffs, on the west, and Southbourne, on the east. At the western end I noticed chiefly the deposits, of which a photograph is reproduced (Fig. 74), where during rains a temporary stream had carried a large load of sand over a steep and porous slope. The stream had apparently been subject to rapid fluctuations of speed. Whenever the speed slackened sand deposited at the end, raising the bed and lowering the gradient ; and presently the water subsided through this sand, leaving it in a weald or ridge. Each succeeding effort of the failing stream seemed to have ended in a repetition of the process, but at a position higher up, the final result being a long tongue of sand transversely barred by wealds. I have not had an opportunity of watching the process actually at work in these tongues of sand quickly produced during heavy rain, but the longitudinal sand-ridges, prettily arranged like the fronds of seaweed, I have often seen in actual formation. They are not found on the western part of the Bournemouth cliffs, but begin east of the Bournemouth pier and extend beyond the Boscombe pier. They occur where 


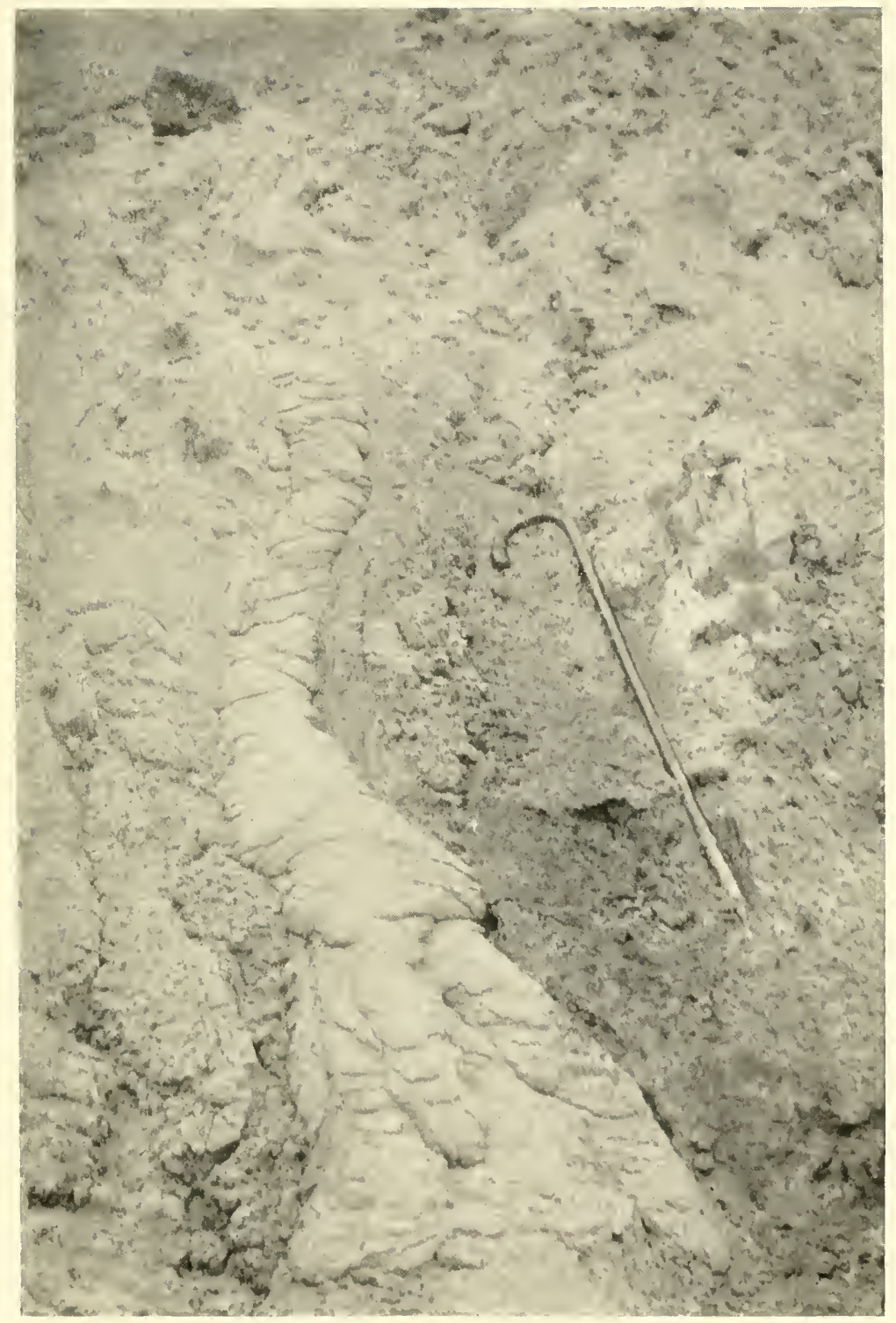

Plate 74-Deposit of cliff-sand, containing an admixture of fine particles, left after subsidence of water, showing transverse ridges; at Bournemouth. 




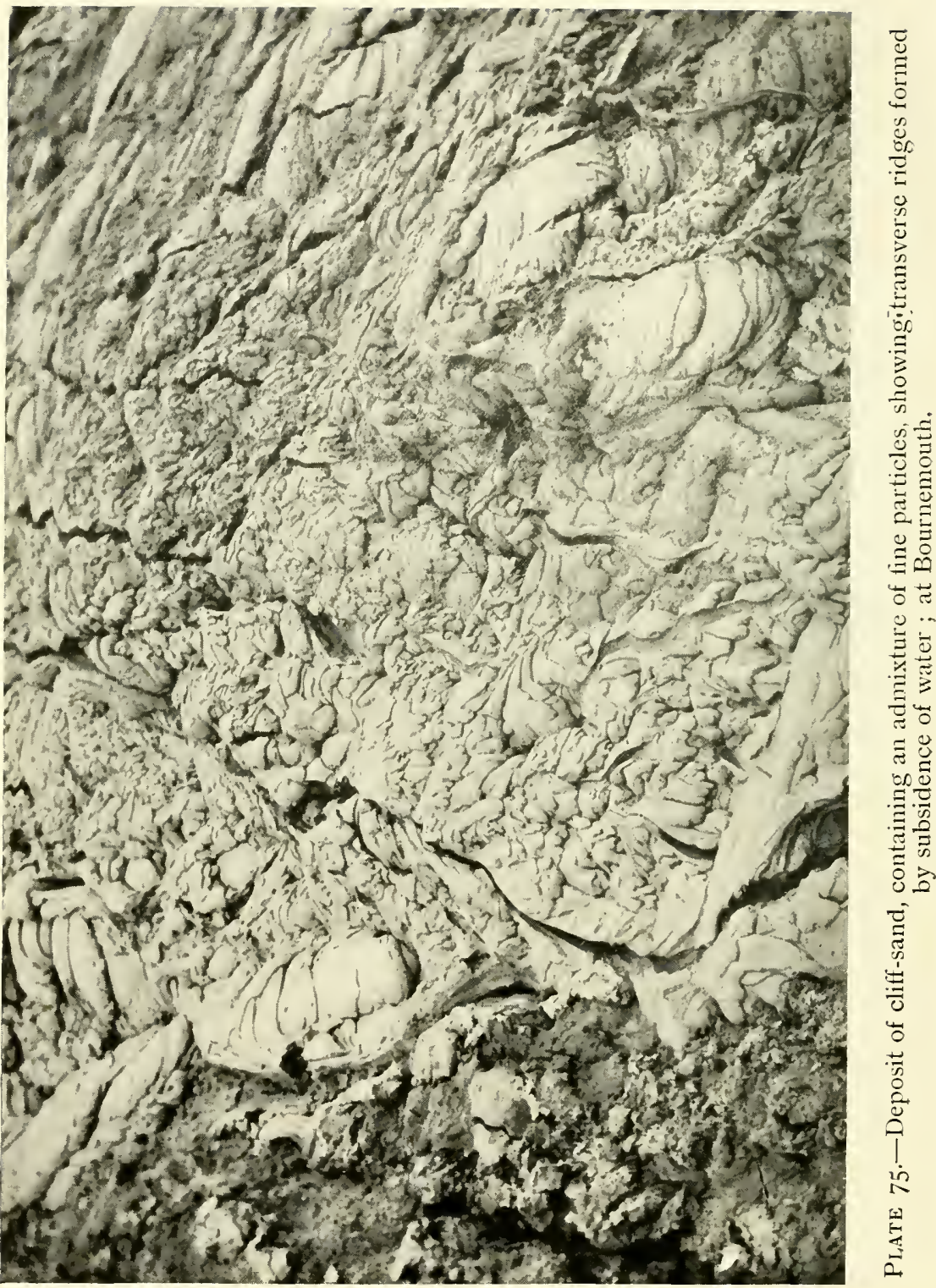


rain-water, percolating through the sandy cliffs, reaches a layer of clay, or rather hardened mud, which here lies above the level of the beach. The streamlet becomes reduced to a thread-like trickle, having only the thickness of a finger, but it continues to flow for days. When it emerges at a moderate gradient it deposits an alluvial fan, but when it overflows the bed of clay and descends very steeply it deposits its burden of sand in a different manner. The stream is subject to fluctuations both of velocity and direction. Diminution of speed is immediately followed by the deposition of a little tongue of sand at the extremity of the stream, and the thread of water is instantly deflected, darting out in another direction, where another tongue of sand is quickly formed. The process goes on very quickly, the thread of water darting this way and that like a living thing, the tongues of sand being built up with such quickness that in quite a short space of time a very pretty frond-like structure is produced. The whole process, indeed, goes on so rapidly that it would make a good cinematograph, even if the instrument were worked, and the picture reproduced, so as to show the real rate of operation.

The size and shape of the tongues of sand are of interest and significance. The surface of the 


\section{WAVES OF SAND AND SNOW}

tongue of sand is strongly curved, and its tip is often distinctly drop-like. The diameter of the tongue is commonly $\frac{1}{4}$ inch, which I find is about the width of the larger drops in which rain collects on the under side of the sash of a window. The size and form' of the thread-like stream of water is, in fact, due to capillarity, and the size and cross-section of the little tongues of sand which it deposits are therefore determined by the same force. The breadth of the smallest delta is therefore the diameter of a full-sized drop of water.

\section{On the Composition of Quicksand.}

A quicksand is one which readily swallows any heavy body placed upon it. Dr. J. C. Owens has shown experimentally how this condition can be brought about by allowing water to flow upwards through the sand.i Since, he says, a grain of siliceous sand of $\frac{1}{50}$ in. diameter settles through water at the rate of little more than $0^{\circ} 2$ foot per second, a very slight velocity of current is capable of lifting the grains out of contact and keeping. them separated by layers of water, so that they will not bear weight. In Nature, Dr. Owens says, such quicksands are due to springs finding an outlet I "The Transport and Settlement of Sand in Water, etc.," Section 9, British Association, Birmingham, I9I3. 


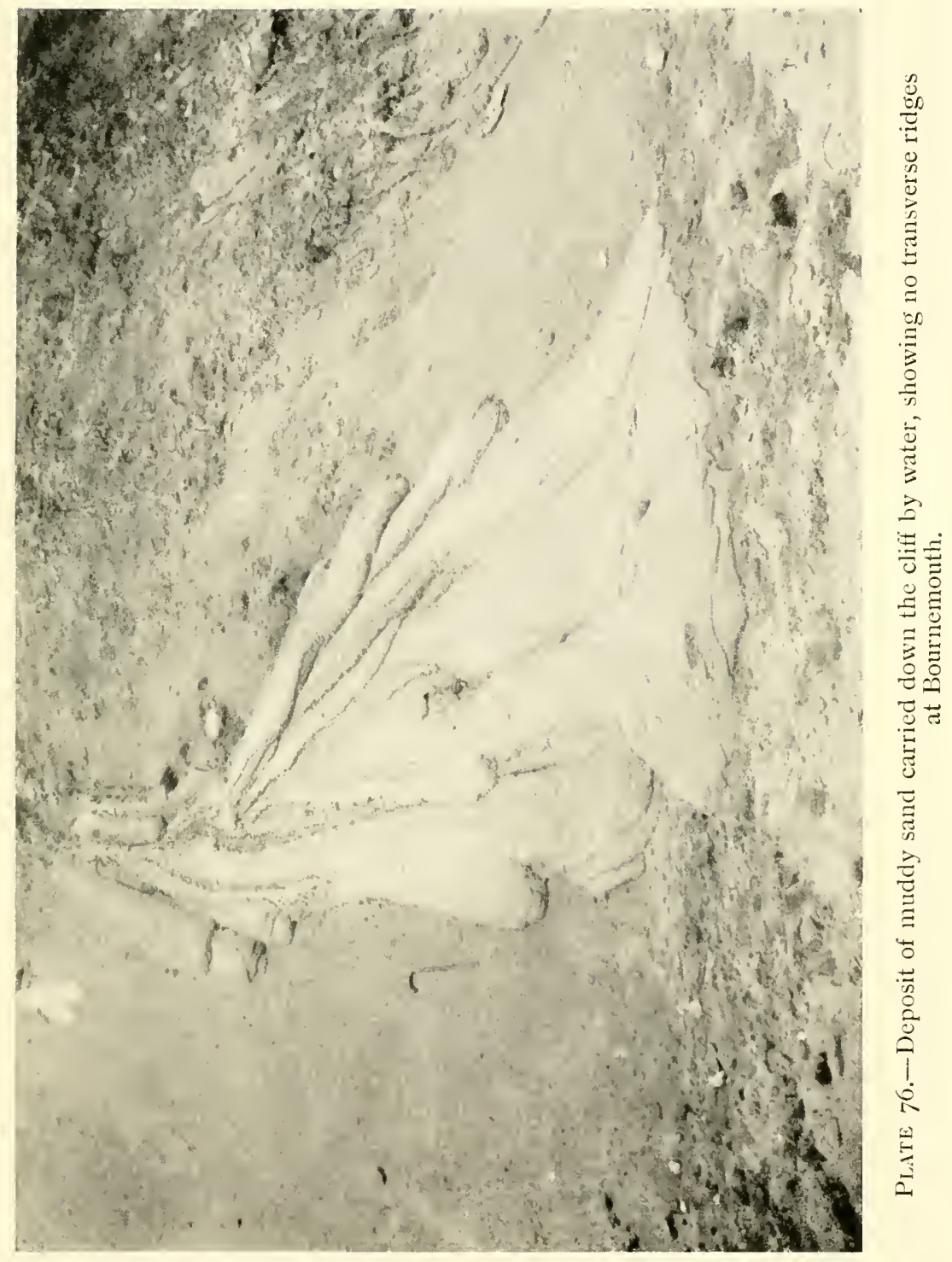





\section{THE COMPOSITION OF QUICKSAND 355}

underneath a bed of sand. Mr. C. Carus-Wilson has shown that there are also quicksands in which there is no upward or other current. They are produced by the inclusion of gas in wet sand. Such quicksands are found in Morecambe Bay where cockles and other organisms are present in numbers sufficient to produce during decomposition large quantities of gas.

In a lecture upon some properties of sand delivered at the Royal Institution Mr. C. E. S. Phillips illustrated the effect of included gas in quickening sand. $\mathrm{He}$ had two beakers containing sand, to one of which water only had been added, to the other a little carbonate and hydrochloric acid also. When the point of the finger was pressed upon the surface of the sand which contained water but no gas it penetrated only a short distance, after which the material offered solid resistance. When the point of the finger was pressed upon the surface of the wet sand in the other beaker (in which carbonic acid had been generated, some of which was still enclosed in the wet sand) there was no stiffening of the material, and the finger could be pressed down without increase of resistance.

There are three kinds of fluid-viz., gaseous, liquid, and granular-and such a statical quicksand 


\section{WAVES OF SAND AND SNOW}

is an emulsion of all three. I think it is probable that the inclusion of ordinary air often makes wet sands unable to bear a load.

I made the following observations upon the air imprisoned in wet sand at the foot of the East Bournemouth cliffs when I was examining miniature deltas and mud-flows. In one place somewhat muddy sand had flowed, with production of wealds or transverse ribs, and had come to rest. The surface was dry, but quaked under foot. I found an empty beer-bottle lying on the beach, and, holding it by the neck, I used the bottom as a plunger, inserting it in the sand and pushing it up and down without withdrawing it. Numerous large bubbles of air came up, and after a time the bottle was gripped and held pretty tightly by the sand. Near by was an alluvial fan, or deltalike deposit, where the sand was purer, containing much less admixture of fine, earthy particles. It had flowed with less formation of broad wealds and more of the longitudinal ridges already described, which are due to the rapid separation of sand from water. In this deposit I inserted the plunger and worked it up and down as before. Some bubbles of air came up, but they were few in number and small in size. I should add that in both cases the working of the plunger produced 


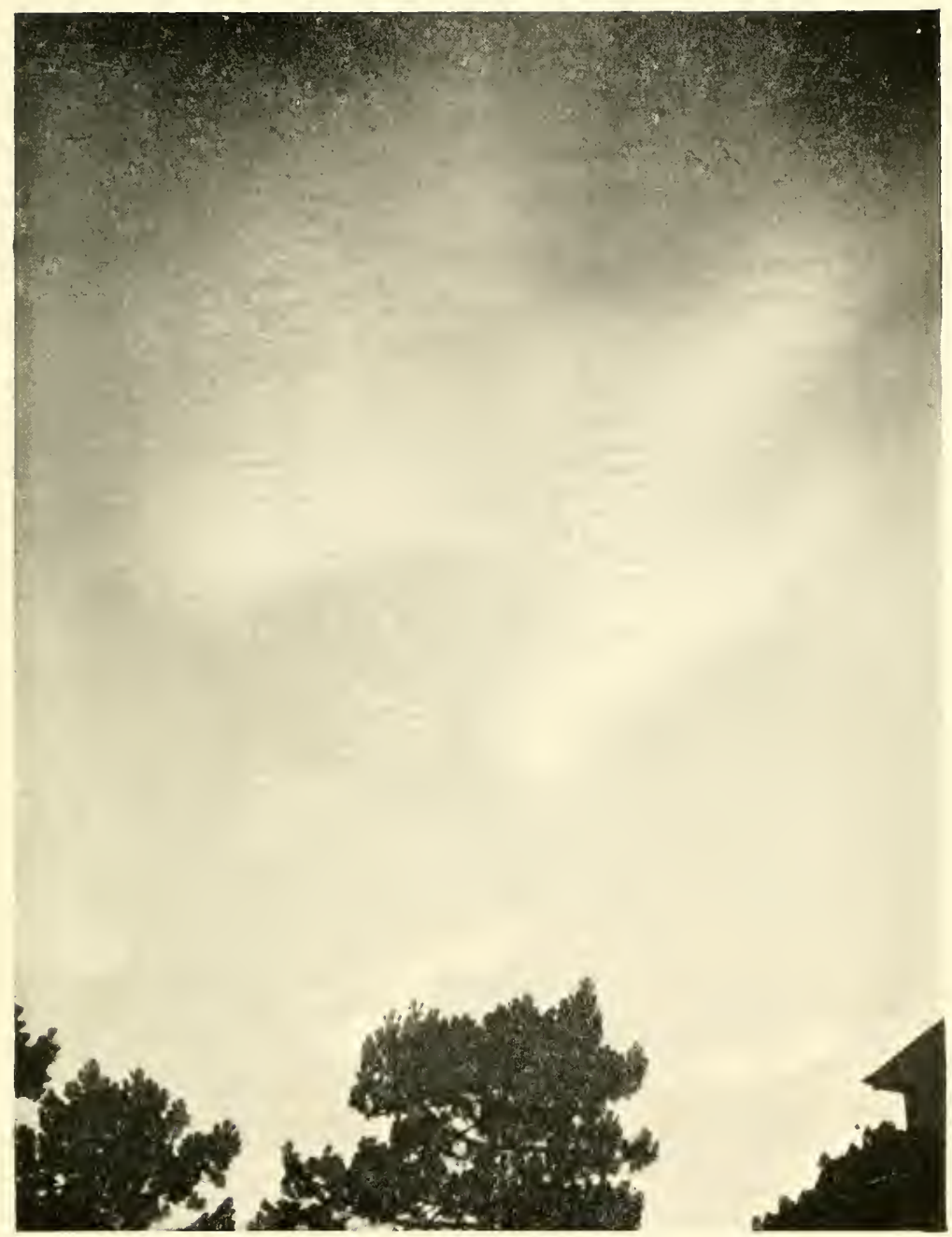

PLATE 77.- Rippled cirrus cloud, seen from Branksome Chine, near Bournemouth. 

some separation of sand from water, the upper parts becoming more watery.

Near by I found a mass of wet mud which had flowed down the lower slopes of the cliff as far as the beach, where it had come to rest with a sloping surface. I inserted the plunger and worked it up and down as before, but no air-bubbles came off and there was no separation of the water from the earthy matter.

When sand dries, air enters its pores which, if the sand be pure, readily escapes when it is again wetted, but an admixture of fine earthy particles prevents or retards the escape of air. The tenacious character of the sands of Morecambe Bay (where the neighbouring rocks are of limestone) doubtless causes the retention of the gases evolved by decomposition of the cockles. It may also cause an imprisonment of air during the rapid rise of the tide, thus co-operating with the upwelling of the water to deprive the sands of the power to bear a load. I have already described a case in which the flood-tide entrapped the air in a sandbank, and in all such cases the sands would become unstable.

\section{On the Rippled Clouds called "Mackerel Sky."}

Ruskin wrote of "mackerel " clouds that "the vapour. . . falls into ripples like sand." An 
explanation of the mode of formation of these clouds has been given by Lord Kelvin, von Helmholtz, and Sir George H. Darwin in almost identical terms. The last named includes a short treatment of the subject in the paper on "Ripplemark" to which reference has already been made, and the subject has frequently been treated since in a theoretical way. The explanation is that when a "temperature inversion" occurs in the atmosphere-i.e., when a layer of warmer air lies upon a bed of colder air-then, if there be relative movement, the surfaces become waved or rippled. Sir George Darwin writes, in the paper already cited :"The layer of transition between two currents of fluid is dynamically unstable, but if a series of vortices be interpolated, so as to form frictionrollers, as it were, it probably becomes stable. . . . If one of the currents of air be colder than the other, a precipitation of vapour will be caused in the vortices and their shapes will be rendered evident by clouds. . . . If one of the currents veers, the axes of the vortices are shifted. The existing clouds will be furrowed obliquely and the vortical stratum will be cut into diamond-shaped spaces determined by the intersection of the old and new vortex axes. This would explain the patchwork arrangement commonly observed in mackerel sky." 


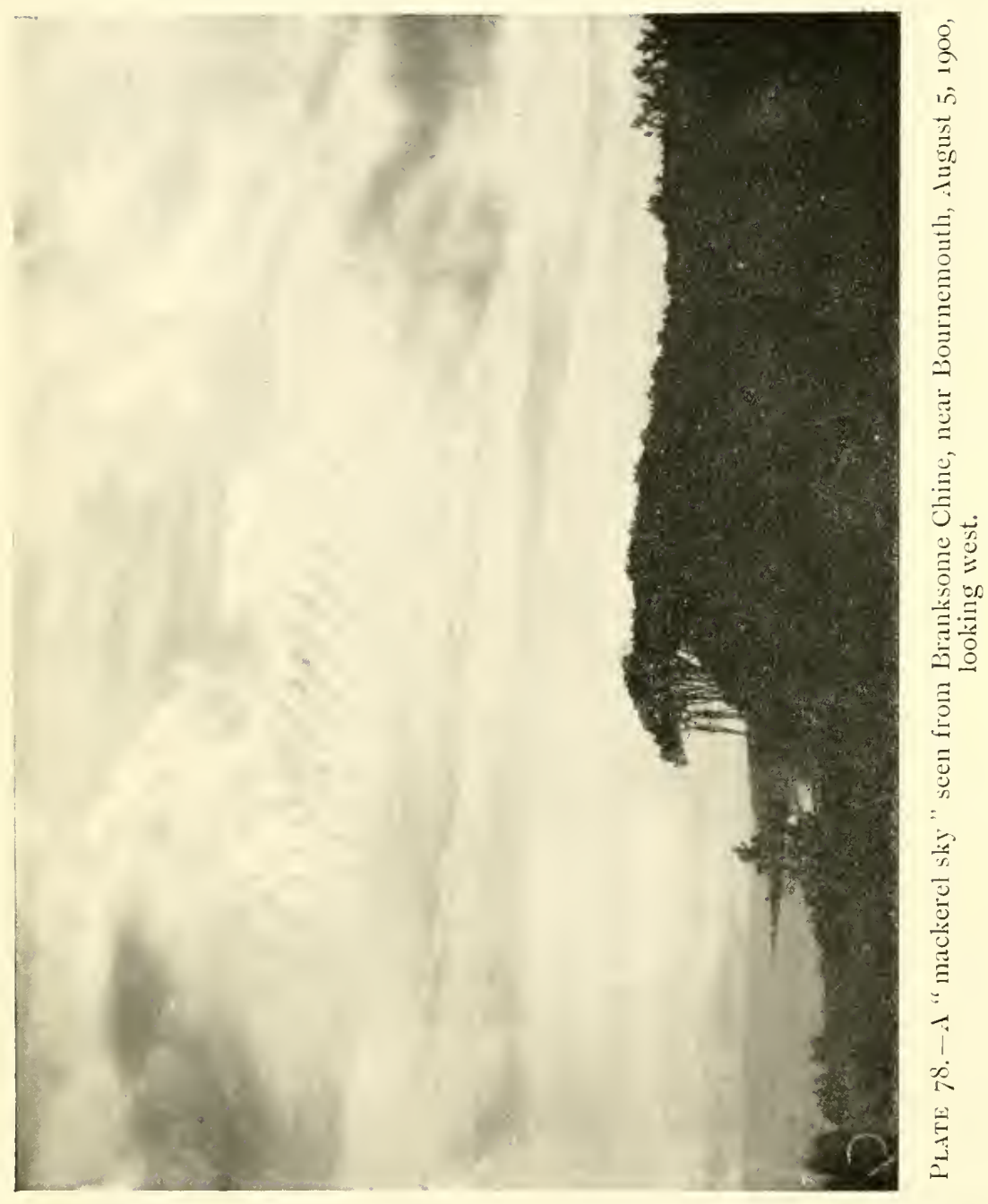



I have often watched mackerel clouds, which is best done with the aid of dark glasses. It is usually the thin white clouds of the upper air which are rippled, but in stormy weather dark, lowlying clouds sometimes go into parallel bars transverse to the wind. In the mackerel clouds formed at great altitudes a distance of one or two degrees of arc from bar to bar is a common size for the smaller ripples. This, with a distance of 30,000 feet, means a wave-length of from 250 to 500 feet. In stormy weather wave-clouds of much greater wave-length are often formed in which the scale is so large that a few of them cross the whole sky, so that they do not produce the familiar "mackerel-skin" appearance. The bars of the ordinary mackerel clouds are generally unsymmetrical in profile, as is shown by their being denser in appearance on one side than the other. This shows that, like the eddies of air or water on the lee of sand-waves, they have a thick and a thin end. Usually they drift with the thick end upstream, but occasionally I have seen them going with the thick end foremost. Sometimes they are produced by the furrowing of a continuous layer of cloud, but I have also seen them forming, bar by bar, in clear blue sky, and on looking one wave-length ahead of the last-formed member of 


\section{WAVES OF SAND AND SNOW}

the group I have been able to see the beginning: of the formation of a new member of the series. The perfect bar-like form, with straight edges, does not impart the impression of a swirling motion, but I have often seen them begin as separate circular or oval whirls of cloud, each like a puff of smoke, the whirls in each transverse row growing in size so that they come closer together until the transverse row of whirls becomes a continuous bar.

The best photographs which I have taken of these clouds were obtained on August .5, I 900 , at Branksome Chine, near Bournemouth. The barometer stood at 29.7 inches. At 8 a.m. the sky was clouded and the air exceptionally clear, indicating that rain was near at hand. The rain began at 9 a.m. and continued until 3.30 p.m. At 4.30 some blue sky was visible, some low, drifting clouds, and higher cirrus cloud. I noticed the latter beginning to fall into ripples, so I went indoors and got my cameras. On coming out I found that the ripples were already finely formed, low down in the west. Later on the rippled clouds spread up to the zenith, and by 6.30 p.m. they were low down in the east, the sky overhead and to the west being now all clear blue. Thus the area of rippled cloud moved east before the west 


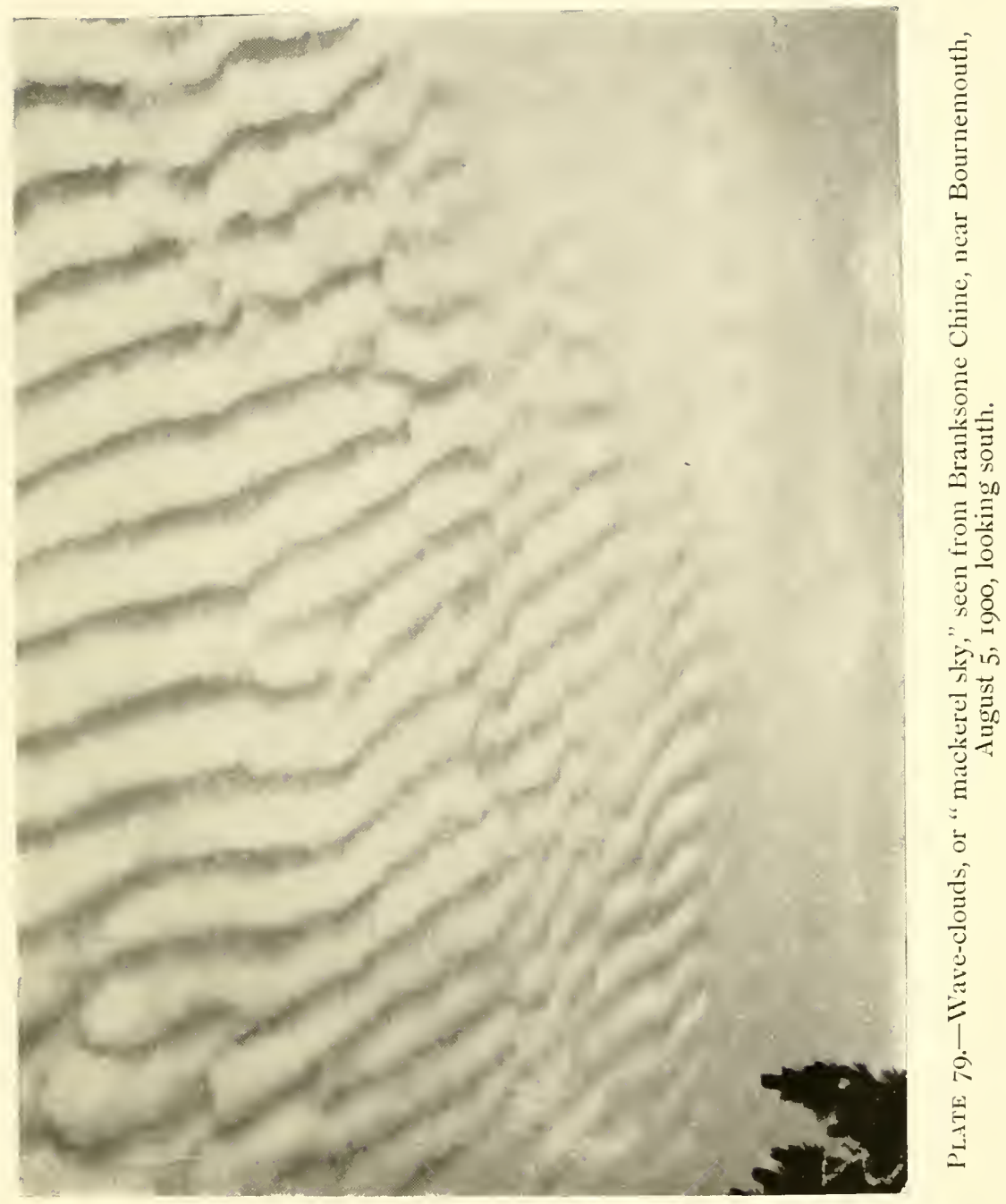





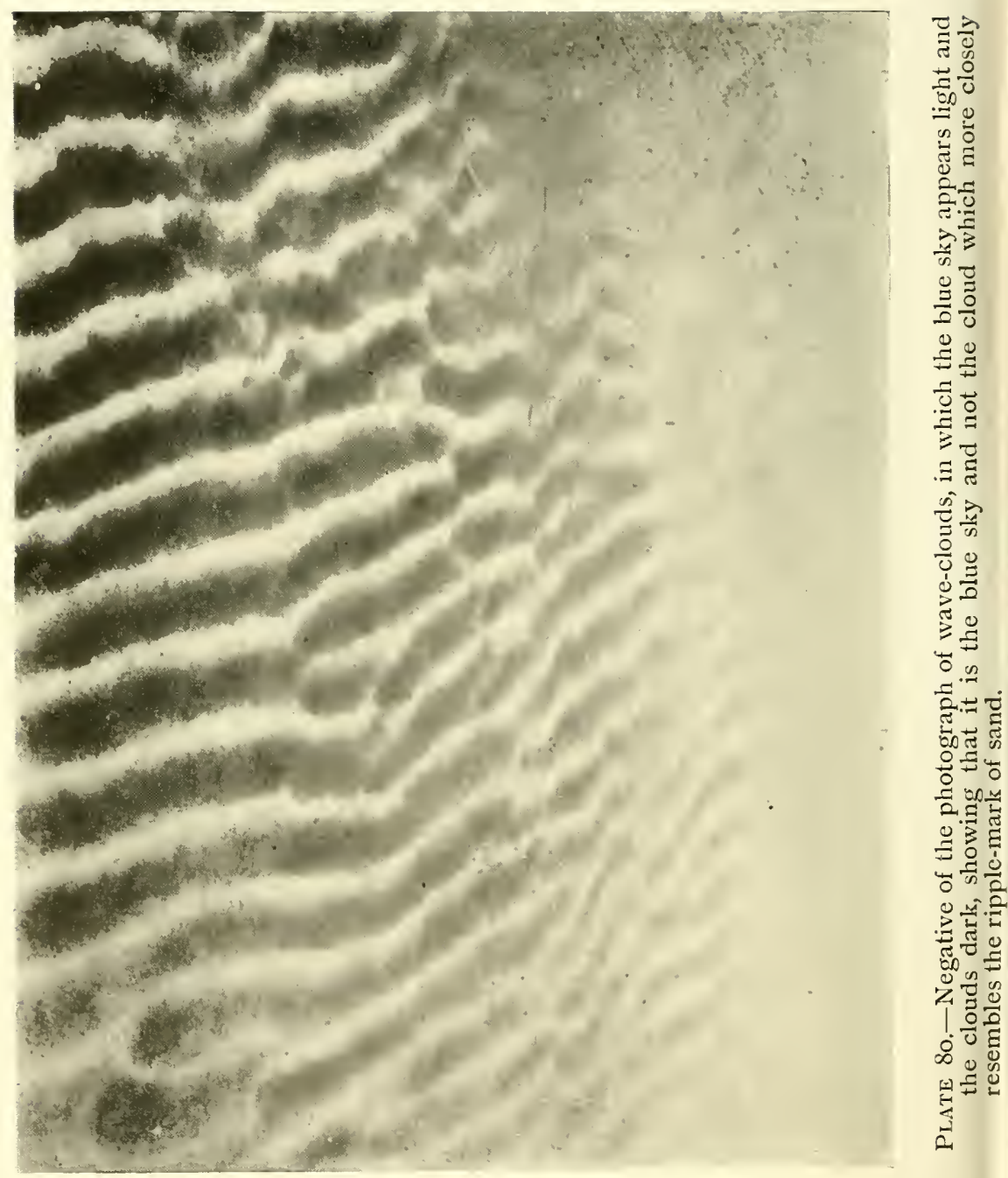
wind. Most of the time the individual transverse bars of cloud travelled fairly fast with the wind. In Plates LXXIX. and LXXX. I have had a photograph, which was taken looking south at 5 . I 5 p.m., reproduced twice, once in the ordinary way as a positive print, once as a negative. The former shows the clouds as they actually appeared. They were drifting rapidly, and this perhaps accounts for the fact that they are symmetrical. The shadow of each roll of cloud is thrown on the next cloud to the left. In the negative the clouds appear dark, and the eye, following as it is compelled to do the high lights, sees a different pattern. This is the pattern of the blue sky, which by this device stands revealed in its true form. The blue sky is thus seen to be standing up in sharp-crested ridges, which fit in between, and keep apart, the whirling air, filled with particles of mist which constitute the clouds. Thus the blue sky, not the cloud, is the true aerial ripple-mark, the clouds corresponding to the eddies of air or water. But in order that the true aerial ripple-mark should be manifest, it is necessary to adopt my device of reversing the light and dark parts. The junctions of the ridges are particularly deserving of notice as showing the completeness of the similarity between the ripple-marks of sky and sand. 

APPENDIX 



\section{APPENDIX}

CATALOGUE OF ORIGINAL PAPERS BY THE AUTHOR ON THE SURFACE WAVES OF THE ATMOSPHERE, HYDROSPHERE, AND LITHOSPHERE

I. On the Formation of Sand-Dunes. Geographical fournal, March, 1897 .

A paper read before the Royal Geographical Society, January 19, 1897, being an extension of a paper read to Section E, British Association, Liverpool, I896.

2. On Sea-Beaches and Sandbanks. Geographical Fournal, May and June, 1898 .

A paper read before the R.G.S., March I6, 1898 .

3. On Kumatology, the Study of the Waves and WaveStructures of THE Atmosphere, Hydrosphere, AND Lithosphere, Geographical Fournal, June, I899.

The abstract of a paper read before the R.G.S.. March 27, I899.

4. On the Application of the Study of Waves to GeoGRAPHY. Report of the VIIth International Geographical Congress, held at Berlin, 1899 .

A paper read at Berlin, 1899. 
5. On Desert Sand-Dunes Bordering the Nile Delta. Geographical Fournal, January, 1900.

A paper read before the R.G.S., November 27, I899.

6. On the Formation of Wave Surfaces in Sand. Scottish Geographical Magazine for January, I90I.

Contains positive and negative photographs of "mackerel sky," showing the pattern of the blue sky as the true aerial ripple-mark.

7. On Sand-Waves in Tidal Currents. Geographical Fournal, August, I90I.

A paper read before the R.G.S., June Io, I90I.

8. Cinematographing the Severn Bore. Geographical Fournal, January, I902.

A short paper read before the R.G.S., November 25, IgOI.

9. On Snow-Waves and Snow-Drifts in Canada, with Notes on the Snow-mushrooms of the SElkirk Mountains. Geographical Fournal, August, 1902.

A paper read in part before the R.G.S., May 12, 1902, and in part on June Io, I9or.

io. On the Dimensions of Deep-Sea Waves, and their Relation to Meteorological and Geographical Conditions. Geographical Fournal, May, I904.

iI. Progressive and Stationary Waves in Rivers, Engineering, I906.

These articles are included in Part III. of the book on "Waves of the Sea" (vide post). 
I2. Progressive Waves in Rivers. Geographical Fournal, January, 1907.

13. On Surface Waves Produced by Sledges. Proceedings of the Dorset Ficld Club, 1907.

The substance of this paper was communicated to Section G, Mechanical Science, of the British Association, Belfast meeting, I902.

I4. The Jamaica EarthQuake (1907). Geographical Fournal, March, 1908.

A paper read before the R.G.S., December 9, 1907, giving an account of the author's experiences at Kingston during the earthquake, and of a subsequent visit to the island, with a map showing the distribution of damage done by the earthquake, and the probable positions of the areas from which the shocks came. The character of the surface waves which overthrew buildings is described.

15. On the Observation of Desert Sand-Dunes, Geographical Fournal, April, 1908.

A short paper of suggestions to travellers in desert regions. It contains also the author's theory of the mode of formation of the longitudinal dunes of the Great Indian Desert.

16. The Panama Canal in igio. Fournal of the Royal Society of Arts, December 9, I910.

A paper read to the Royal Society of Arts, December 7, I9Io, containing an account of the author's examination of the landslides accompanied by upheaval in the Culebra Cut. 
I7. On the Cause of the Jamaica Earthouake of January I4, 1907. Geographical Fournal, September, 1912.

Shows how the distribution of the damage can be explained on the supposition that the observed redistribution of load by the rivers which rise near Hardware Gap, and the neighbouring "gaps," caused subsidence and elevation in the regions burdened and lightened respectively.

18. Ocean Waves, Sea-Beaches, and Sandbanks. Fournal of the Royal Society of Arts, November I and 8, 1912.

Two Cantor lectures, of which the first contains a formula, based upon observations at sea, for the relation between the velocity of the wind and the velocity, length, height, and steepness of the waves which it finally produces.

19. The Panama Canal and the Philosophy of Landslides. Edinburgh Review, January, 1913.

Contains a history of the landslides accompanied by upheaval which have occurred in the Culebra Cut.

20. On the Panama Canal and the Formation of Gravitation Waves in the Culebra Cut. Geographical Fournal, March, I9I3.

A short paper on the same subject as the last, but containing figures showing cross-sections of the Cut.

21. On a Simple Method of Determining the Period of Waves at Sea.

A paper read before Section A, British Association, Birmingham Meeting, 19I3.

The above papers contain the first full account of new matter on surface waves published by the author, with the following principal exceptions, viz., that the 


\section{APPENDIX}

book on "Waves of the Sea and other Water Waves," published by T. Fisher Unwin, I9IO, contains in Part II. the first account of the author's explanation of the predominant action of waves and tides to drive shingle and sand farther in the direction of their advance than of their recession ; and "The Travels of Ellen Cornish," published by W. T. Ham Smith, I9I3, contains in the chapter on "The Falls and Rapids of Niagara" original matter concerning the relation between wave motion and whirling motion in rivers.

22. ON Landslides accompanied by Upheaval in the Culebra Cut of the Panama Canal.

A paper read before Section G, British Association, Birmingham Meeting, $\mathrm{I}_{\mathrm{I}} \mathrm{I} 3$, and printed in The Engineer, October I7, I9I3. 



\section{INDEX}

Aeolian sand-ripples-

Always present on the waves, 75

Experimental reproduction of, 88

Measurements of, $8 \mathrm{I}$

Rate of advance, 82

Sorting of grains during rippling, 83

Aeolian sand-waves-

Angles of weather and lee slopes, 35

Height and length of, 37, 38

Mode of origin, $54,5^{8}$

Peaks and saddles on the ridges, $5^{8}$

Rate of advance, 54

Ayrton, Mrs. H. on ripple-mark, 258 note

Blunt, W. S., 49

Barchan, 5o, 52, 53

Barmouth, sub-aqueous sand-waves at, 292

Bournemouth, observations in neighbourhood of, $79,262,266$, 346,364

"Cahots," or undulations produced by sledges, 227 et seq.

Experiments with model sledge, $236 \mathrm{ct}$ seq.

Carus-Wilson, C., 355

Cattle, treading of, produces tranverse furrows, 253 
Clouds-

"Banner-clouds," 199

Rippled, or " mackerel sky," 359 et seq.

Coniston, Lancs, use of sledges at, 232

Current-mark, 262 et seq.

Travelling up-stream, 278

Darwin, Sir G. H.-

On ripple-mark, $39,25^{8}$

On rippled-clouds, 360

Delta, the smallest, 340

Dovey, river, sand-waves in, 3 Io

Drifting materials, rates of subsidence of, 183

Eddies, 39, 46, I47, I57, I72, I76, I79, I87, I95, 203, 360, 369

Eddy-curve-

In relation to forms of fish, 157

Of ships and torpedoes, ${ }_{5} 8,163$

Estuaries, D-shaped, 310

Findhorn, sub-aqueous sand-waves at, 296

Floyer, E. A., 73

Foam, pattern on water-waves, 179

Fuljes, 49, 52, $33^{2}$

Glacier House, B.C., snow-mushrooms at, 212

Goodwin Sands, sands-waves on, 326

Grange, Lancs, sand-ripples at, 282

Helwan, aeolian sand-waves at, 3I, 4I, 42

Hyde Park, snow-ripples observed in, 96

Ichthyomorphism, of snow-drifts, I57

Ismailia, sand-dunes near, 73 
Leaves, drifting of, 192

Medano, $5^{\circ}$

Montreal, snow-waves near, Ior

Montrose, sub-aqueous sand-waves at, 296

Morecambe Bay, sands of, 355, 359

Mundesley, sub-aqueous sand-waves at, 326

Oar, eddying disturbance caused by, $\mathbf{1} 76$

Owens, Dr. J. C., I84, 277, 290, $35^{2}$

Phillips, C. E. S., 355

Quicksand, on the composition of, 355

Reynolds, Osborne, 26r, 289

Ripple-mark, 257 et seq.

Roads, transverse inequalities in, 249

Sand-banks, to leeward of promontories, 199

Sand-dunes-

Dew upon, 69

Effect of moist ground on formation of, 70

Illusion of great height, 66

Longitudinal, of the Great Indian Desert, ${ }_{13} 8$

On route to El Arish, 6I

With crest reversed, 65

Sand-grains-

Effect of electrification of, 73

Interstices between, 280

Rate of subsidence, $4 \mathrm{I}$

Sizes of, 32, 74

Two modes of motion of, 54

Sand-reefs in the Mississippi, $33^{2}$ 
The Bresbam Press

UNWIN BROTHERS, LIMITED

WOKING AND LONDON 



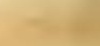


\& 